UNIVERSIDADE DE SÃO PAULO

FACULDADE DE MEDICINA DE RIBEIRÃO PRETO

PROGRAMA DE PÓS-GRADUAÇÃO EM SAÚDE MENTAL

ANTONIO PAULO ANGÉLICO

\title{
Transtorno de ansiedade social e habilidades sociais: estudo psicométrico e empírico
}




\section{Transtorno de ansiedade social e habilidades sociais: estudo psicométrico e empírico}

Tese apresentada à Faculdade de Medicina de Ribeirão Preto da Universidade de São Paulo como parte dos requisitos para a obtenção do título de Doutor em Ciências Médicas.

Área de Concentração: Saúde Mental

Orientadora: Prof ${ }^{a}$. Dr ${ }^{\mathrm{a}}$. Sonia Regina Loureiro 
AUTORIZO A REPRODUÇÃO E DIVULGAÇÃO TOTAL OU PARCIAL DESTE TRABALHO, POR QUALQUER MEIO CONVENCIONAL OU ELETRÔNICO, PARA FINS DE ESTUDO E PESQUISA, DESDE QUE CITADA A FONTE.

\section{FICHA CATALOGRÁFICA}

Angélico, Antonio Paulo

Transtorno de ansiedade social e habilidades sociais: estudo psicométrico e empírico. Ribeirão Preto, 2009.

215 p. : il.; $30 \mathrm{~cm}$

Tese de Doutorado, apresentada à Faculdade de Medicina de Ribeirão Preto/USP. Área de concentração: Saúde Mental.

Orientadora: Loureiro, Sonia Regina.

1. Transtorno de ansiedade social. 2. Habilidades sociais. 3. Falar em público. 4. Validade. 5. Escalas. 
FOLHA DE APROVAÇÃO

Antonio Paulo Angélico

Transtomo de ansiedade social e habilidades sociais: estudo psicométrico e empírico

Tese apresentada à Faculdade de Medicina de Ribeirão Preto da Universidade de São Paulo para obtenção do título de Doutor.

Área de Concentração: Saúde Mental

Aprovado em: $22 / 05 / 2009$.

Banca Examinadora

Prof. Dr. Somia Regina haurer Instituiçâo: FMRP USP Assinatura: Hilloweino

Prof. Dr. Frederico Guicherme Graft Instituiçầo: FMRPUSP Assinatura:

Prof. Dr. JOSé ALEXANBME Insititicicio: $f M R P$ - USP Assinatura:

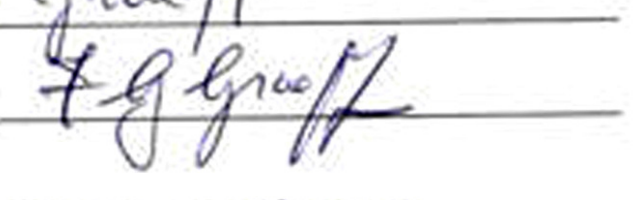

Prof. Dr. ELIAUE MARY DE OLIVEIRA FALCONE Instituição: UERJ Assinatura: Cliane Lafoon.

Prof. Dr. ZILDA APAREA $\triangle A$ Instituição:

UFSCAR

Assinatura:

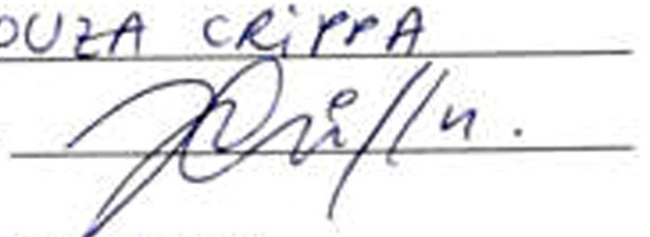




\section{DEDICATÓRIA}

A minha irmã Maria Luzia Angélico Jordan (in memoriam), pela sua presença, companhia e dedicação em muitos momentos de minha vida, seu apreço por mim, e pelo seu exemplo de força e coragem. 


\section{AGRADECIMENTOS}

À Prof ${ }^{\mathrm{a}}$. Dr ${ }^{\mathrm{a}}$. Sonia Regina Loureiro, pelo seu incentivo, apoio, companheirismo e colaboração, como orientadora, durante toda a trajetória do meu Doutoramento, sempre investindo seu profissionalismo e competência para tornar este trabalho melhor.

À Coordenação de Aperfeiçoamento de Pessoal de Nível Superior (CAPES), pela bolsa concedida para o desenvolvimento desta pesquisa.

Às Professoras: Dr ${ }^{\mathrm{a}}$. Zilda Aparecida Pereira Del Prette (UFSCar) e Dr ${ }^{\mathrm{a}}$. Alessandra Turini Bolsoni-Silva (UNESP/Bauru) que participaram da Banca para o Exame de Qualificação, cujas contribuições e sugestões foram muito valiosas para o enriquecimento deste trabalho.

Ao Prof. Dr. Sandro Caramaschi (UNESP/Bauru), pela sua incondicional atenção, prontidão e importantes sugestões e revisões no conteúdo das categorias do meu Estudo Empírico, tanto em nossas conversas por telefone quanto por e-mail.

Ao Prof. Dr. José Alexandre de Souza Crippa (FMRP-USP), pela sua colaboração, como coautor, na produção dos nossos artigos científicos.

A Geraldo Cássio dos Reis, estatístico do Departamento de Neurociências e Ciências do Comportamento, pela sua assessoria estatística.

A Flavia de Lima Osório, pela parceria em relação à coleta de dados e coleguismo ao longo do desenvolvimento do projeto maior, do qual este estudo faz parte.

Às bibliotecárias, Maria Cristina Manduca Ferreira, Márcia Regina da Silva, Angela Maria Lucato Aguilar da Biblioteca Central de Ribeirão Preto (BCRP) e Elena Luzia Palloni Gonçalves da Biblioteca da Escola de Engenharia de São Carlos pela atenção, prontidão e simpatia no atendimento. Em especial, a Tânia Aparecida Bonani Isique, do Programa de Comutação Bibliográfica da BCRP, pela eficiência do seu trabalho que contribui muito positivamente para a qualidade do meu trabalho de Doutorado.

A minha amiga, Prof ${ }^{a}$. Tatiana Maria Nege, Mestre em Lingüística e Língua Portuguesa, pelo seu trabalho de revisão de texto da minha Tese e pela sua atenção e disposição em sempre esclarecer minhas dúvidas gramaticais. 
Ao Luiz Carlos Dotta, chefe da Seção Técnica de Informática do Instituto de Ciências Matemáticas e de Computação, Gláucia Elena de Moura Dotta, técnica em informática, e Rogério Toshiaki Kondo, analista de sistemas, do Centro de Informática de São Carlos, todos da USP de São Carlos, pela atenção e profissionalismo.

Aos demais professores e funcionários do Programa de Pós-Graduação em Saúde Mental da Faculdade de Medicina de Ribeirão Preto da Universidade de São Paulo, pela atenção, colaboração e amizade.

Aos meus amigos Kátia Regina Soares da Silva Burato, Fabio Alas Martins e Ronaldo de Oliveira Salles, pelos gestos de apoio e companheirismo.

A todos que, direta ou indiretamente, participaram da realização deste trabalho, meus mais sinceros agradecimentos. 
"O universo não é apenas mais excêntrico do que imaginamos, mas mais excêntrico do que podemos imaginar."

J.B.S. Haldane

"Não pergunte que doença a pessoa tem, mas antes que pessoa a doença tem."

(atribuído a) William Osler 


\section{RESUMO}

ANGÉLICO, A. P. Transtorno de ansiedade social e habilidades sociais: estudo psicométrico e empírico. 2009. 215 f. Tese (Doutorado) - Faculdade de Medicina de Ribeirão Preto, Universidade de São Paulo, Ribeirão Preto, São Paulo, 2009.

O Transtorno de Ansiedade Social (TAS) tem sido considerado um grave problema de saúde mental pela sua alta prevalência em pessoas jovens e pelas incapacidades decorrentes no desempenho e interações sociais. É fundamental que se disponha de instrumentos validados e abrangentes que avaliem tanto os recursos e déficits comportamentais quanto os prejuízos sociais e funcionais destas pessoas. Objetivou-se, neste trabalho, verificar as associações entre as manifestações comportamentais e clínicas do TAS por meio de dois estudos, um psicométrico e outro empírico, visando: (a) aferir as propriedades psicométricas do Inventário de Habilidades Sociais (IHS-Del-Prette), enquanto medida do repertório comportamental de habilidades sociais, em relação à avaliação das manifestações clínicas próprias do TAS, medidas pelo Inventário da Fobia Social (SPIN); e (b) comparar e caracterizar o repertório de habilidades sociais apresentado por universitários brasileiros portadores de TAS e não portadores frente a uma situação experimental estruturada, o Teste de Simulação de Falar em Público (TSFP). Do estudo psicométrico, participaram 1006 universitários, na faixa etária entre 17 e 35 anos, de ambos os gêneros, provindos de duas instituições de ensino superior. Posteriormente, 86 participantes foram randomicamente selecionados desta amostra inicial e agrupados como casos e não-casos de TAS a partir de avaliação clínica sistemática por meio da Entrevista Clínica Estruturada para o DSM-IV. Do delineamento empírico, participaram 26 universitários, sendo 13 com diagnóstico de TAS e 13 não portadores de transtornos psiquiátricos. Quanto aos resultados, o IHS apresentou boa consistência interna para o escore total, reforçando a sua validade de construto. Observou-se boa validade concorrente entre o IHS e o SPIN, com um coeficiente altamente significativo de correlação negativa entre eles, indicando que quanto mais elaborado for o repertório de habilidades sociais de um indivíduo, menor é a sua probabilidade de satisfazer os critérios de rastreamento de indicadores para o TAS. O IHS demonstrou distinguir significativamente indivíduos com e sem TAS, atestando sua validade discriminativa e preditiva para esse diagnóstico, evidenciando-se assim a sua validade clínica e a possibilidade do seu uso em estudos empíricos que testem a eficácia terapêutica de programas de intervenção. No TSFP, os grupos caso e não-caso de TAS não demonstraram diferenças significativas, em termos de freqüência, para a maioria dos marcadores comportamentais de ansiedade avaliados. Um número maior de sujeitos do grupo não-caso foi avaliado como apresentando um nível de habilidades sociais apropriadas para falar em público, que variou de moderado a alto, em comparação ao grupo caso. Ao longo do TSFP, a freqüência de emissão dos marcadores comportamentais de ansiedade pelos sujeitos de ambos os grupos manteve-se estável. Os grupos diferiram significativamente na maioria dos itens indicativos da habilidade de falar em público do IHS e quanto ao escore geral desta habilidade. A análise dos resultados do estudo empírico aponta para a necessidade de novos estudos com amostras clínicas de indivíduos com TAS dos subtipos generalizado e circunscrito, e não-clínica, com maior número de sujeitos, previamente avaliados quanto ao medo de falar em público, e também para a possibilidade de uso do TSFP em programas de Treinamento em Habilidades Sociais.

Palavras-chave: Transtorno de ansiedade social, habilidades sociais, falar em público, validade, escalas. 


\begin{abstract}
ANGÉLICO, A. P. Social anxiety disorder and social skills: a psychometric and empirical study. 2009. 215 p. Thesis (Doctoral) - Medicine Faculty of Ribeirão Preto, University of São Paulo, Ribeirão Preto, 2008.
\end{abstract}

Social Anxiety Disorder (SAD) has been considered a serious mental health problem for its high prevalence in young people and for the resulting disabilities in the performance and social interactions. It stands out, thus, as being fundamental to have comprehensive and validated instruments which evaluate both the resources and the social and functional impairments of these people. In this work, we aimed at verifying the associations between the behavioral and clinical manifestations of SAD by means of two studies, a psychometric study and an empirical one, in order to: (a) check the psychometric properties of the Social Skills Inventory (HIS-Del-Prette), as a measure of the social skills behavioral repertoire in relation to the evaluation of the typical clinical manifestations of SAD, measured by the Social Phobia Inventory (SPIN); (b) compare and characterize the social skills repertoire shown by Brazilian undergraduates with and without SAD in a structured experimental situation, the Simulated Public Speaking Test (SPST). A total of 1006 undergraduates of both genders participated in the psychometric study, with ages between 17 and 35, from two universities. Subsequently, 86 participants were randomly selected from this initial sample and grouped as SAD case and non-case from the systematic clinical evaluation. In the empirical outline, 26 undergraduates participated, 13 with a SAD diagnosis and 13 without the disorder. According to the results, IHS showed good internal consistency for the total score, reinforcing its construct validity. Good concurrent validity was demonstrated between IHS and SPIN, with a highly significant negative correlation coefficient between them, indicating that the more elaborate the social skills repertoire of an individual is, the smaller the probability that he or she will meet the screening criteria for the indicators of SAD. IHS proved to significantly distinguish individuals with and without $\mathrm{SAD}$, attesting thus, discriminative and predictive validity for this diagnosis, showing its clinical validity for the diagnosis of this disorder and yet the possibility of using it in empirical studies testing the therapeutical efficacy in programs of intervention. In the SPST, the case and non-case groups of SAD did not show significant differences in terms of frequency for most of the social anxiety markers, except in relation to facial movements of discomfort, and the class of non-verbal markers, in which the non-case group presented higher values. A higher number of individuals from this group were evaluated as showing a level of appropriate social skills for speaking in public which varied from moderate to high, in comparison with the other group. Throughout SPST, the frequency of emission of anxiety behavioral markers by the participants of both groups was stable. The groups differed significantly in most items of IHS indicative of abilities to speak in public, as well as in the general score of this ability. The analysis of the results of the empirical study points to the necessity of new studies with clinical samples of individuals with SAD of the generalized and circumscribed subtypes and non-clinical, with a larger number of participants, previously evaluated as to the fear of speaking in public, and also to the possibility of using SPST in Social Skills Training.

Key-words: Social anxiety disorder, social skills, public speaking, validity, scales. 


\section{LISTA DE TABELAS}

Tabela 1 - Número total de sujeitos excluídos conforme os critérios adotados

Tabela 2 - Critérios assumidos para considerar que os instrumentos foram preenchidos incorretamente

Tabela 3 - Palavras-chave utilizadas na busca sistemática de artigos empíricos abordando a temática "avaliação comportamental da ansiedade de falar em público" na literatura indexada

Tabela 4 - Características sociodemográficas da amostra incluída no estudo

Tabela 5 - Distribuição dos itens do IHS em função do escore médio, desvio-padrão e porcentagem dos escores de 0 a 4, em uma amostra da população geral $(\mathrm{N}=1006)$

Tabela 6 - Classificação do repertório de habilidades sociais apresentado pelas amostras feminina e masculina em função dos seus escores totais no IHS transformados em percentis

Tabela 7 - Classificação do repertório de habilidades sociais dos sujeitos pertencentes às amostras feminina $(\mathrm{N}=592)$ e masculina $(\mathrm{N}=414)$

Tabela 8 - Escores médios de cada item do IHS com seus respectivos desviospadrões e Testes t para os grupos caso $(\mathrm{N}=214)$ e não-caso de TAS $(\mathrm{N}=$ 792)

Tabela 9 - Distribuição dos itens do IHS em função do escore médio, desvio-padrão e porcentagem de pontuação nos escores de 0 a 4 para os grupos caso $(\mathrm{N}$ =214) e não-caso de TAS $(\mathrm{N}=792)$

Tabela 10 - Distribuição dos itens do IHS em função da diferença entre os escores médios, média dos desvios-padrões e tamanho do efeito em uma amostra de casos $(\mathrm{N}=214)$ e não-casos de TAS $(\mathrm{N}=792)$

Tabela 11 - Valores mínimo e máximo da correlação de cada item com a escala total e Alfas de Cronbach obtidos para o IHS e cada um dos seus fatores em uma amostra da população geral $(\mathrm{N}=1006)$ e para as amostras de casos $(\mathrm{N}=214)$ e não-casos de TAS $(\mathrm{N}=792)$

Tabela 12 - Validade concorrente: Correlações entre os itens individuais do IHS com o escore total e itens individuais do SPIN em uma amostra da população geral $(\mathrm{N}=1006)$

Tabela 13 - Coeficientes de Correlação entre o IHS total e seus cinco fatores isolados com as subescalas do SPIN em uma amostra da população geral $(\mathrm{N}=$ 1006) 
Tabela 14 - Valores relativos à sensibilidade, especificidade, valor preditivo positivo, valor preditivo negativo e taxa de classificação incorreta para diferentes pontos de corte do IHS em uma amostra de casos $(\mathrm{N}=45)$ e não-casos de TAS $(\mathrm{N}=41)$

Tabela 15 - Escores médios de cada item do IHS com seus respectivos desviospadrões e Testes t para os grupos caso $(\mathrm{N}=45)$ e não-caso de TAS $(\mathrm{N}=$ 41)

Tabela 16 - Distribuição dos itens do IHS em função do escore médio, desvio-padrão e porcentagem de freqüência nos escores de 0 a 4 para os grupos caso ( $\mathrm{N}$ $=45)$ e não-caso de TAS $(\mathrm{N}=41)$

Tabela 17 - Distribuição dos itens do Inventário de Habilidades Sociais em função da diferença entre os escores médios, média dos desvios-padrões e tamanho do efeito em uma amostra de casos $(\mathrm{N}=45)$ e não-casos de TAS $(\mathrm{N}=41)$.

Tabela 18 - Classificação do repertório de habilidades sociais dos sujeitos pertencentes aos grupos caso $(\mathrm{N}=45)$ e não-caso de TAS $(\mathrm{N}=41)$, conforme o gênero

Tabela 19 - Análise Fatorial: Autovalores iniciais e porcentagem de variância (relativa e acumulada) dos componentes principais do IHS, obtidos em uma amostra de 1006 sujeitos da população geral

Tabela 20 - Análise Fatorial: Autovalores e porcentagem de variância (relativa e acumulada) dos componentes principais extraídos

Tabela 21 - Comunalidades referentes a uma solução rotacionada com 8 fatores

Tabela 22 - Análise fatorial: Matriz dos componentes rotacionada

Tabela 23 - Comparação dos escores médios obtidos no IHS em função das variáveis estudadas (gênero e grupos), e da interação entre elas na amostra total de sujeitos $(\mathrm{N}=1006)$

Tabela 24 - Comparação dos escores médios obtidos no IHS entre as variáveis grupo (caso versus não-caso) e gênero (feminino versus masculino) em função da condição analisada na amostra total de sujeitos $(\mathrm{N}=1006)$

Tabela 25 - Comparação dos escores médios obtidos nos fatores do IHS entre os gêneros na amostra total de sujeitos $(\mathrm{N}=1006)$

Tabela 26 - Comparação dos escores médios obtidos nos fatores do IHS entre os grupos caso e não-caso de TAS na amostra total de sujeitos $(\mathrm{N}=1006)$

Tabela 27 - Caracterização sociodemográfica dos sujeitos participantes do Teste de Simulação de Falar em Público $(\mathrm{N}=26)$ nos grupos caso e não-caso de TAS 
Tabela 28 - Resultados do Teste de Normalidade de Shapiro-Wilk realizado para os marcadores comportamentais (categorias) e suas respectivas classes, avaliação geral do desempenho, latência da resposta e duração total do discurso $(\mathrm{N}=26)$

Tabela 29 - Comparação dos grupos caso $(\mathrm{N}=13)$ e não-caso de TAS $(\mathrm{N}=13)$ em relação aos marcadores comportamentais de ansiedade e suas respectivas classes, avaliação geral do desempenho, duração total do discurso e latência da resposta

Tabela 30 - Frequiência mínima e máxima, média e desvio-padrão de ocorrência para cada categoria avaliada dentro dos grupos caso e não-caso de TAS

Tabela 31 - Comparação do efeito do tempo sobre os marcadores comportamentais de ansiedade e suas respectivas classes e de sua interação com os grupos caso $(\mathrm{N}=13)$ e não-caso de TAS $(\mathrm{N}=13)$

Tabela 32 - Correlações significativas encontradas a partir das associações entre todas as categorias de análise, entre essas categorias e as classes mais amplas, e entre as próprias classes na amostra total $(\mathrm{N}=26)$

Tabela 33 - Comparação dos grupos caso $(\mathrm{N}=13)$ e não-caso de TAS $(\mathrm{N}=12)$ em relação aos itens do IHS indicativos da habilidade de falar em público e ao escore geral desta habilidade

Tabela 34 - Correlações significativas encontradas entre as categorias de análise e os itens referentes à habilidade de falar em público, e entre essas categorias e o escore geral obtido para esta habilidade na amostra do estudo $(\mathrm{N}=25) \ldots .142$

Tabela 35 - Médias e desvios-padrões das amostras masculina e feminina que responderam ao IHS em comparação com as medidas dos grupos normativos deste instrumento

Tabela 36 - Comparação das médias fatoriais obtidas pela amostra feminina (C1) e seu correspondente grupo normativo (C3)

Tabela 37 - Comparação das médias fatoriais obtidas pela amostra masculina (C2) e seu correspondente grupo normativo (C4) 


\section{LISTA DE FIGURAS}

Figura 1. Curva de distribuição normal do conjunto de dados referentes ao IHS

Figura 2. Diagrama de dispersão da correlação entre os escores do IHS e SPIN 105

Figura 3. Área sob a curva ROC do escore total do IHS para uma amostra de casos e não-casos de TAS $(\mathrm{N}=86)$

Figura 4. Diagrama de declividade da análise fatorial realizada com os dados do IHS ...

Figura 5. Classificação do repertório de habilidades sociais de falar em público demonstrado pelos sujeitos dos grupos caso $(\mathrm{N}=13)$ e não-caso de TAS ( $N$ $=13)$ 


\section{SUMÁRIO}

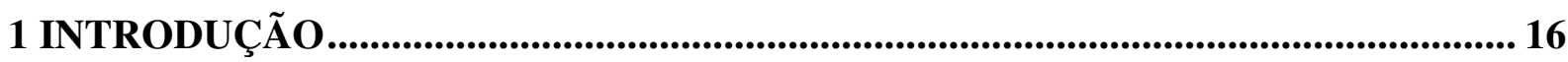

1.1 Estudos experimentais clássicos em ansiedade e o modelo de imprevisibilidade ............. 16

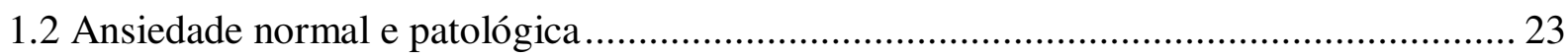

1.3 Transtorno de Ansiedade Social: Aspectos diagnósticos e epidemiológicos ................... 25

1.4 Distinção qualitativa entre os subtipos do Transtorno de Ansiedade Social.................... 31

1.5 Transtorno de Ansiedade Social: Aspectos cognitivos e comportamentais ..................... 40

1.6 Habilidades Sociais: Principais conceitos, tipos de déficits e suas causas....................... 44

1.7 Transtorno de Ansiedade Social e Habilidades Sociais ............................................. 51

1.8 O Transtorno de Ansiedade Social e o medo de falar em público.................................... 53

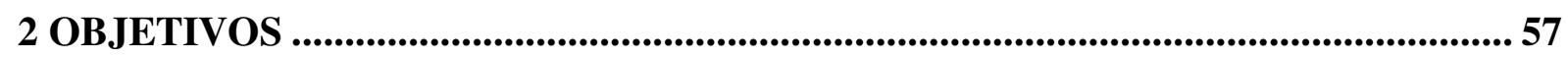

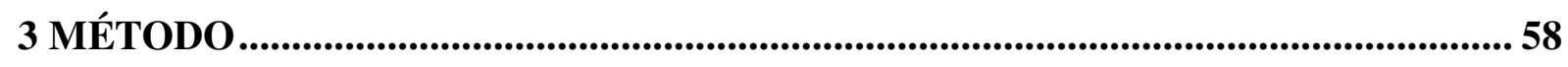

3.1 Caracterização da população estudada .................................................................. 58

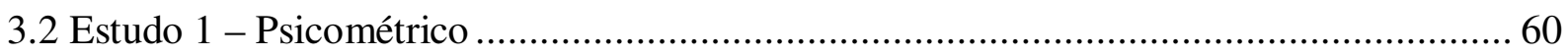

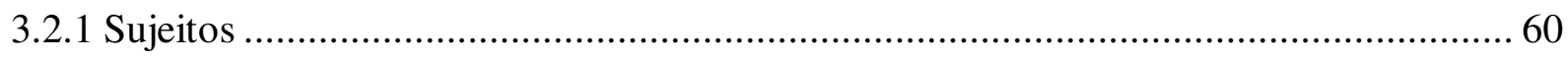

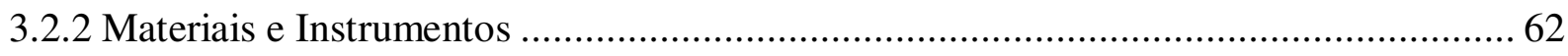

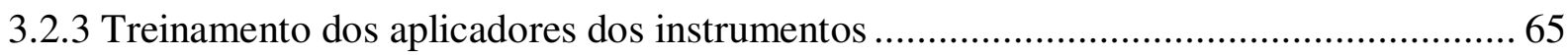

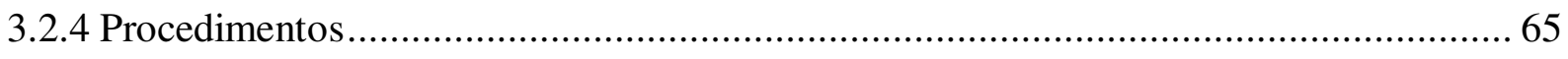

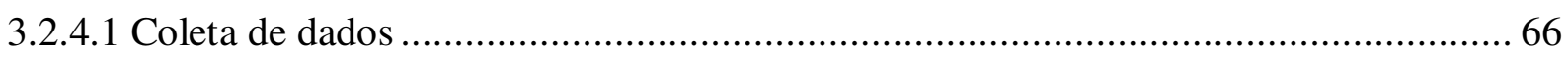

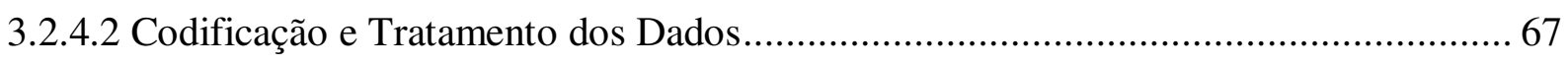

3.3 Estudo 2 - Empírico (Teste de Simulação de Falar em Público - TSFP) ........................ 73

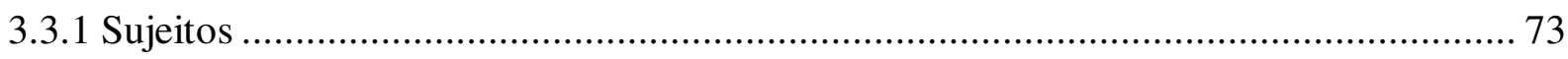

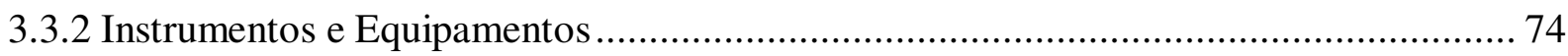

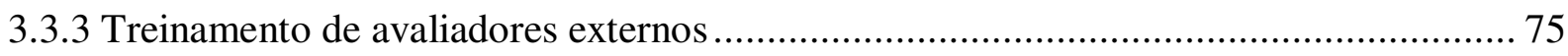

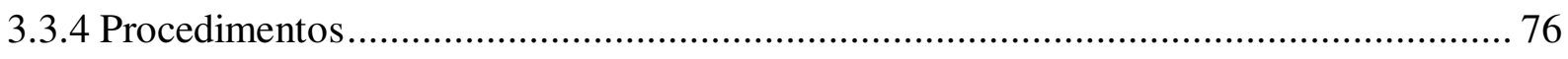

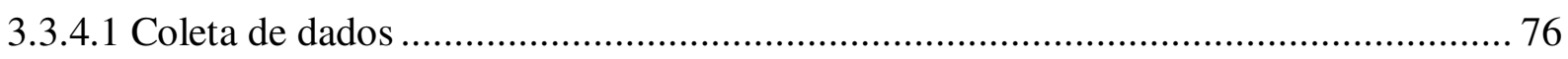

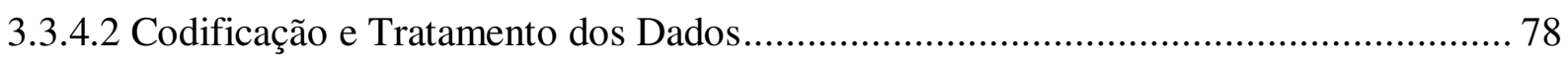

3.3.4.2.1 Proposição do Protocolo de Registro para a Análise das Filmagens Realizadas ...... 78

3.3.4.2.2 Procedimento de categorização e análise das sessões experimentais do TSFP ........ 84

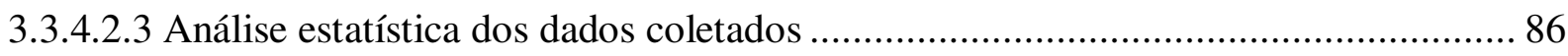

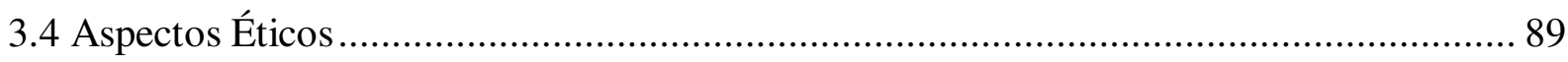




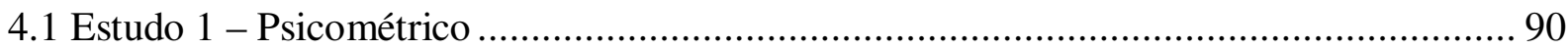

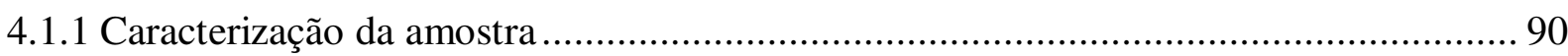

4.1.2 Indicadores psicométricos do IHS-Del-Prette ..................................................... 93

4.1.2.1 Distribuição dos dados referentes ao IHS-Del-Prette................................................ 93

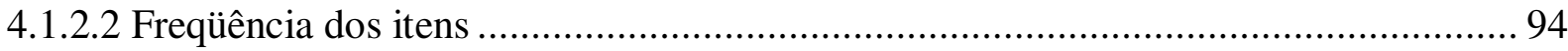

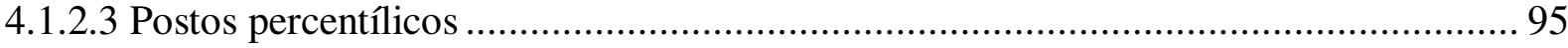

4.1.2.4 Classificação do repertório de habilidades sociais da amostra estudada.................... 97

4.1.2.5 Diferenciação entre as habilidades sociais dos grupos caso e não-caso de TAS ......... 98

4.1.2.6 Consistência interna do IHS-Del-Prette ............................................................... 103

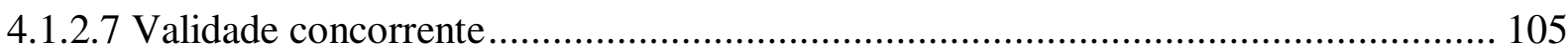

4.1.2.8 Validade discriminativa e preditiva do IHS-Del-Prette........................................ 109

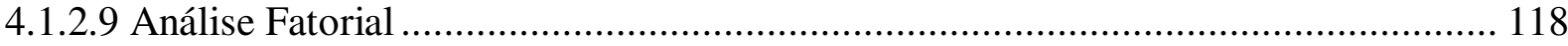

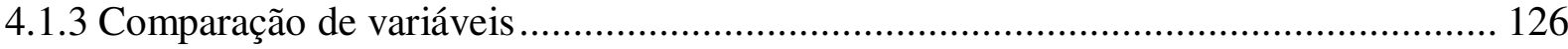

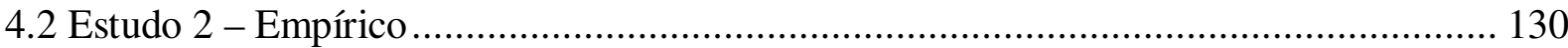

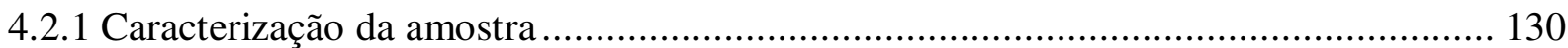

4.2.2 Comparação dos grupos caso e não-caso de TAS em relação aos marcadores comportamentais de ansiedade, latência da resposta e tempo total de fala ................. 131

4.2.3 Comparação dos grupos em relação ao início e final do TSFP ................................... 135

4.2.4 Correlação entre as categorias de análise propostas ............................................... 136

4.2.5 Avaliação do repertório de habilidades sociais de falar em público dos grupos .......... 139

4.2.6 Habilidades sociais de falar em público e marcadores comportamentais de ansiedade 141

5 DISCUSSÃO

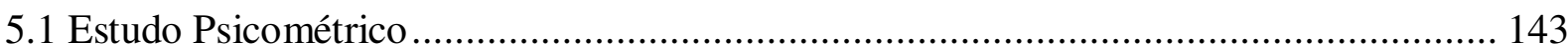

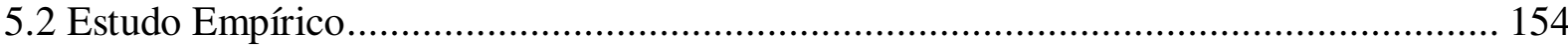

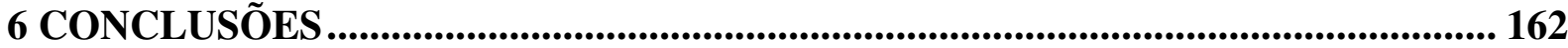

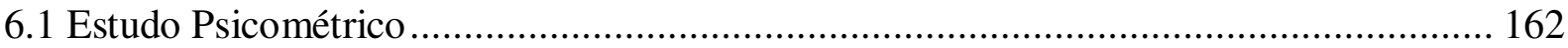

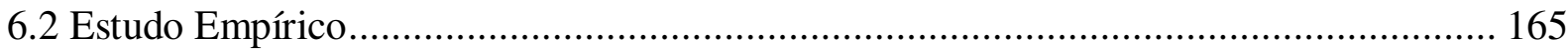

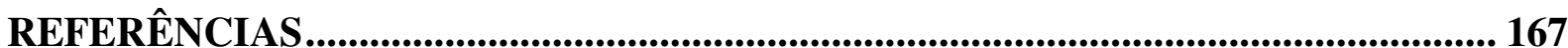

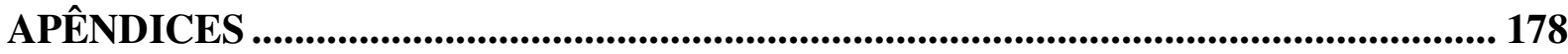

APÊNDICE A - Protocolo de Registro das Filmagens Realizadas .................................. 179 
APÊNDICE B - Curso básico sobre observação e técnicas de registro

APÊNDICE C - Síntese do conteúdo de cada item do Inventário de Habilidades Sociais ... 185

APÊNDICE D - Comparação das amostras masculina e feminina deste estudo com os grupos normativos do Inventário de Habilidades Sociais

ANEXOS 189

ANEXO A - Inventário de Fobia Social (SPIN). 190

ANEXO B - Termo de Consentimento Livre e Esclarecido (TCLE) - Delineamento 1 191

ANEXO C - Questionário de Identificação 193

ANEXO D - Protocolo de Coleta de Dados 194

ANEXO E - Protocolo Pós-Coleta de Dados. 195

ANEXO F - Protocolo de Aplicação Coletiva 196

ANEXO G - Termo de Consentimento Livre e Esclarecido - Parte 1 - Delineamento 2 .. 197

ANEXO H - Termo de Consentimento Livre e Esclarecido - Parte 2 - Delineamento 2. 199

ANEXO I - Aprovação pelo Comitê de Ética (Projeto maior) 201

ANEXO J - Aprovação da pesquisa pelo Comitê de Ética. 202

ANEXO K - Artigo publicado 203 


\section{INTRODUÇÃO}

A realização deste trabalho de pesquisa se focou em dois temas centrais: o transtorno de ansiedade social e as habilidades sociais. Considerando que esse transtorno constitui uma das categorias diagnósticas, entre outras, incluídas no transtorno de ansiedade, e as habilidades sociais um campo teórico-prático e de pesquisa muito amplo, procurou-se oferecer um contexto mais geral no qual esses temas se inserem. Quanto ao primeiro tema, em particular, buscou-se, inicialmente, contemplar os estudos experimentais clássicos que embasam o modelo de imprevisibilidade para a ansiedade, dando suporte para a sua definição científica. Deste modo, esta seção foi subdividida em tópicos que se articulam entre si para fornecer os elementos conceituais e práticos necessários para a compreensão dos temas centrais deste trabalho.

\subsection{Estudos experimentais clássicos em ansiedade e o modelo de imprevisibilidade}

A experiência de medo e a emoção relacionada de ansiedade são universais e familiares para todos. Embora medo e ansiedade sejam termos de uso bastante comum na linguagem coloquial, são ao mesmo tempo construtos hipotéticos amplamente empregados na teoria psicológica e psiquiátrica. De acordo com Seligman (1977), os mesmos nunca podem ser observados diretamente, mas inferidos a partir da observação do comportamento, da fisiologia e de relatos subjetivos. Alterações na resposta galvânica da pele, retração e tremores, úlceras, alterações de ritmo cardíaco, e muitas outras variáveis dependentes são tomadas como medida dos estados de medo e ansiedade. Sucintamente, este autor denomina medo "ao estado agudo que sucede quando um sinal prediz um evento ameaçador" e ansiedade "ao medo crônico que ocorre quando um evento ameaçador é remoto, mas imprevisível” (p. 104). 
Em termos experimentais, Estes e Skinner (1941) empregaram pela primeira vez a resposta emocional condicionada como um índice comportamental de ansiedade. Em seu procedimento, primeiro ensinaram ratos a pressionar uma barra com frequiência alta e constante para obter alimento. Um estímulo sonoro foi então pareado com choque elétrico durante as sessões de pressão à barra. Nesta combinação, o estimulo sonoro teve uma duração de cinco minutos e terminava com a apresentação do choque. Os ratos aprenderam a temer o som por meio de condicionamento pavloviano, e o demonstraram por meio da redução marcante na taxa de respostas de pressão à barra para obter alimento.

Neste experimento, a modificação do comportamento correlacionado com a antecipação de um estímulo aversivo não pôde ser atribuída a um reforçamento negativo da resposta de pressão à barra uma vez que o choque foi sempre dado independentemente do comportamento do rato em relação à barra. Nesse estudo, antecipação foi definida como uma reação a um estímulo presente $\left(S_{1}\right)$ que surge do fato que $S_{1}$ foi no passado seguido por um outro estímulo $\left(S_{2}\right)$, sendo que a reação não é necessariamente aquela que foi originalmente produzida por $\mathrm{S}_{2}$, considerando as diferentes topografias que um comportamento pode assumir. Desse modo, o decréscimo observado na taxa de respostas de pressão à barra, denominado mais tarde de resposta emocional condicionada ao som, tornou-se o índice de medo mais fidedigno e mais amplamente usado.

Assim, com propriedade, Estes e Skinner (1941) afirmam que ansiedade tem pelos menos duas características definidoras, a saber: (a) ela é um estado emocional bastante semelhante ao medo; e (b) o estímulo perturbador que é o principal responsável não precede ou acompanha o estado, mas é "antecipado" no futuro. Cabe assinalar que "estado emocional" é tratado simplesmente como uma reação ou dos efetores autonômicos ou da musculatura esquelética de um organismo. Em suma, esses autores concebem a ansiedade como um estado 
emocional que surge em resposta a algum estímulo presente que no passado foi seguido por um estímulo perturbador ou aversivo.

Posteriormente, um considerável número de estudos foi realizado com a resposta emocional condicionada produzida por choque previsível e imprevisível em sujeitos infrahumanos (AZRIN, 1956; BRIMER; KAMIN, 1963; BYRUM; JACKSON, 1971; DAVIS; MCINTIRE, 1969; IMADA; SOGA, 1971; SELIGMAN, 1968; SELIGMAN; MEYER, 1970; WEISS; STRONGMAN, 1969), dos quais apenas dois serão apresentados a seguir acompanhados de outros com foco na resposta galvânica da pele em sujeitos humanos.

No estudo de Seligman (1968), dois grupos de ratos privados de alimento aprenderam, inicialmente, a pressionar uma barra em alta freqüência para obtê-lo, um grupo em esquema previsível e o outro em esquema imprevisível. O grupo previsível foi então submetido a 45 sessões diárias, durante as quais um estímulo condicionado (EC) de um minuto de duração terminava em choque elétrico de um segundo ao longo de quatro ciclos. O EC podia ser uma luz ou um som. Entre os ciclos, os ratos receberam em média nove dias de re-treino sem a apresentação de choque ou EC para a recuperação da linha-de-base dos grupos. Apenas metade dos ratos do grupo previsível participou do ciclo 4, considerando que os demais de ambos os grupos tinham sido sacrificados para o exame de úlceras estomacais.

O grupo imprevisível foi exposto aos mesmos sinais (estímulos condicionados) e choques intercalados durante as sessões, porém de forma que a probabilidade de choque era sempre a mesma na presença ou na ausência do sinal. Considerando que não havia nenhum EC prevendo choque, este grupo também não tinha nenhum sinal de segurança. Quando o choque é confiavelmente previsto por um EC, a ausência deste estímulo prevê que segurança ocorrerá, ou seja, não haverá choque. O alimento continuava acessível por meio da pressão à barra. As apresentações do EC e choque eram independentes da pressão à barra dos sujeitos e do reforçamento por alimento. Durante os ciclos 2 e 3, os dois grupos receberam 10 dias de 
choque previsível em cada ciclo, ou seja, o procedimento para ambos os grupos foi idêntico ao procedimento empregado para o grupo previsível no ciclo 1 , que durou 15 dias. O procedimento do ciclo 4, que também durou 10 dias, foi idêntico ao dos ciclos anteriores.

No início, ocorreu uma queda na linha-de-base de ambos os grupos tanto na presença como na ausência do sinal. Em geral, à medida que aprenderam a discriminar o fato de que recebiam choque apenas durante o sinal e não na sua ausência, os ratos do grupo previsível passaram a suprimir as respostas apenas durante o sinal, pressionando a barra para obter alimento em sua ausência. Assim, mostravam medo durante o EC, porém nenhum medo em sua ausência. Os ratos do grupo imprevisível pararam de pressionar a barra, tanto na presença como na ausência do EC. Durante o ciclo 2, a experiência anterior deste grupo com EC e choque intercalado randomicamente retardou a aquisição de uma resposta emocional condicionada quando um novo estímulo condicionado sinalizava o choque. No ciclo 3 , o grupo imprevisível ainda apresentou uma perda considerável de sua linha-de-base e mostrou apenas uma recuperação parcial de resposta. Ao contrário do grupo previsível, acuados em um canto ao longo das sessões, os ratos revelaram medo crônico ou ansiedade e contraíram úlceras estomacais graves.

Seligman e Meyer (1970) submeteram cinco grupos de ratos a sessões diárias de choque previsível e imprevisível por setenta dias consecutivos. Estes grupos foram assim designados: choque-alto previsível (high-shock predictable - HP), choque-baixo previsível (low-shock predictable - LP), choque-alto imprevisível (high-shock unpredictable - HU), choque-baixo imprevisível (low-shock unpredictable - LU), e choque-alto imprevisível 3 (high-shock unpredictable - HU-3). Este último grupo recebia precisamente três choques por dia, ao passo que os demais recebiam de um a cinco choques previsíveis ou imprevisíveis, totalizando uma média de três por dia. O EC foi uma luz branca com uma duração de um minuto e o choque durava um segundo. 
Durante as últimas trinta sessões, o grupo HU-3 mostrou alguma recuperação, executando $61,6 \%$ das respostas de pressão à barra após o terceiro choque, durante os 25,0\% finais da sessão. O grupo HU não apresentou recuperação: 25,1\% de suas poucas respostas de pressão á barra foram emitidas durante os $25 \%$ da sessão após o terceiro choque. Esses dados sugerem que os ratos do grupo HU-3 foram capazes de usar a ocorrência do terceiro choque como um sinal de segurança para, então, voltarem a pressionar a barra. Uma recuperação completa ocorreu para os grupos LU e LP, sendo que o último emitiu mais resposta de pressão à barra que o primeiro. O grupo HP que teve um EC sinalizando choque (e a ausência do EC sinalizando nenhum choque) parou de pressionar a barra durante a apresentação deste estímulo, mas pressionou vigorosamente em sua ausência.

Em um experimento, Price e Geer (1972) apresentaram uma série de fotografias de cadáveres a estudantes universitários do gênero masculino $(\mathrm{N}=40)$, distribuídos em dois grupos, um previsível e outro imprevisível. Para o grupo previsível, um som de oito segundos de duração (EC) precedia cada fotografia, de forma que na ausência de som, nenhuma fotografia de cadáver aparecia e os sujeitos podiam ficar descontraídos. Os sujeitos eram expostos a um total de 15 fotografias de cadáveres e cada apresentação que funcionou como um estímulo incondicionado (EI) durava cinco segundos. Para o grupo imprevisível, não havia o som e, assim, tanto os cadáveres como a segurança eram imprevisíveis.

Durante os intervalos entre as tentativas, o grupo imprevisível exibiu significativamente mais flutuações espontâneas de resistência da pele quando comparado ao grupo previsível, indicando que o primeiro grupo exibiu excitação emocional maior do que o segundo. O grupo imprevisível também demonstrou respostas galvânicas da pele específicas com amplitude significativamente maior durante os primeiros quatro segundos (primeiro intervalo) após o início da apresentação de cada EI. Porém, não houve diferenças significativas entre os grupos durante os quatro segundos seguintes (segundo intervalo). 
Deste modo, a mensuração da resposta emocional condicionada e da resposta galvânica da pele sugere que o medo é crônico durante eventos traumáticos imprevisíveis porque não existe um sinal garantido de segurança.

Geer, Davison e Gatchel (1970) realizaram um estudo com uma amostra de estudantes universitários do gênero masculino $(\mathrm{N}=40)$, no qual uma parte dos sujeitos acreditava erroneamente estar controlando o choque. Na primeira parte do experimento, todos os sujeitos pressionavam um interruptor assim que sentiam um choque de seis segundos de duração que, por sua vez, era precedido por um estímulo-aviso de dez segundos. Na segunda parte, metade dos sujeitos (grupo controle percebido) foi informada de que poderia reduzir a duração dos choques pela metade se reagisse com rapidez suficiente, enquanto que a outra metade (grupo controle não-percebido) foi somente informada de que os choques seriam mais curtos. $\mathrm{Na}$ verdade, todos os sujeitos receberam choques de três segundos de duração, independentemente da velocidade do tempo de reação dos sujeitos. Em ambas as partes do experimento, houve um total de 10 tentativas com choques, com um intervalo de 30 segundos entre elas. Os eletrodos de condutância da pele eram fixados na palma e punho da mão nãodominante dos sujeitos, e o eletrodo de choque colocado sobre o tornozelo do mesmo lado.

O grupo controle percebido reduziu significativamente seu tempo de reação na segunda parte do experimento quando comparado ao aumento demonstrado pelo outro grupo. Além disso, os resultados indicaram que a condutância da pele diminuiu mais rapidamente para os sujeitos que acreditavam ter controle sobre a duração dos choques do que para os sujeitos que acreditavam o contrário, sugerindo que os choques estavam tornando-se menos estressantes para aqueles. O número de flutuações espontâneas de condutância da pele também foi menor para o grupo controle percebido. Estas flutuações foram empregadas como um índice do nível geral de excitação autonômica. Tais flutuações foram definidas como "uma diminuição mensurável na resistência da pele acima de 200 ohms que ocorresse em um 
momento diferente daquele em que os estímulos foram apresentados e que não estivesse associada a movimentos ou outros sinais de atividade do sujeito" (p. 735). Esse dado indica que, apesar da previsibilidade do choque ter sido exatamente idêntica para ambos os grupos, o grupo controle percebido manifestou menor reatividade ou excitação autonômica à estimulação aversiva comparado ao grupo controle não-percebido, sugerindo assim que o grupo que acreditava ter controle aparentou menos ansiedade. Para Seligman (1977), mesmo em face dos dados sobre percepção de controle, também se pode argumentar que a redução de ansiedade se deve à crença na previsibilidade mais acurada que o controle potencial pode proporcionar.

De modo análogo, pode-se supor que, frente a uma situação ansiogênica qualquer, um indivíduo que tenha a crença de que é capaz de enfrentá-la ou de que possui as habilidades necessárias para lidar com ela, demonstrará menos ansiedade, comparado a outro indivíduo sem essa crença. Assim, a crença no controle, mesmo que potencial, da situação pode propiciar algum alívio de ansiedade para as pessoas. No entanto, vale a pena destacar que tanto a aquisição quanto a manutenção desse tipo de crença perpassa pelo crivo das contingências de aprendizagem que uma pessoa foi exposta ao longo de sua vida.

Tendo em vista os estudos relatados acima, Seligman (1977) chegou ao modelo experimental de imprevisibilidade que é assim enunciado: um EI é imprevisível por meio de um EC se a probabilidade do EI na presença do EC for igual à probabilidade do EI na ausência do EC. Assumindo tal modelo para explicar a ansiedade, conclui-se que quando eventos aversivos ou traumáticos são imprevisíveis, a segurança também se torna imprevisível, ou seja, nada garante que esses eventos não ocorrerão. E, na ausência de um sinal de segurança, os organismos permanecem em ansiedade ou medo crônico.

Em termos gerais, a ansiedade pode ser definida como um estado emocional orientado para o futuro, no qual o indivíduo antecipa a possibilidade de ameaça e experimenta um 
sentimento de incontrolabilidade focado sobre um evento negativo iminente (adaptada de FIRST; TASMAN, 2006). De certo modo, essa definição guarda semelhança com a de Estes e Skinner (1941), principalmente no que diz respeito ao fato de que o estímulo perturbador ou aversivo que é o principal responsável não precede ou acompanha o estado emocional, mas é "antecipado" no futuro.

\subsection{Ansiedade normal e patológica}

Pode-se falar de uma ansiedade normal toda vez que é claramente vantajoso responder com ela em certas situações ameaçadoras, o que contrasta com uma ansiedade anormal ou patológica. A ansiedade pode ser considerada normal para o bebê ameaçado com o afastamento dos pais ou com a perda do amor, para as crianças no primeiro dia de escola, para os adolescentes no primeiro namoro, para o jovem no seu primeiro dia de trabalho, para os adultos que vislumbram a velhice e a morte, e para pessoas em qualquer idade que enfrentam uma doença grave. A ansiedade é um acompanhamento normal do crescimento, das mudanças, de experiências novas e inéditas, do encontro da identidade profissional e outras situações integradoras do desenvolvimento humano. Em contrapartida, a ansiedade patológica é uma resposta inadequada e disfuncional a determinado estímulo, considerando-se sua intensidade e duração (KAPLAN; SADOCK; GREBB, 1997). Quando a ansiedade é muito intensa, ela interfere no funcionamento social, gerando prejuízos na vida profissional, acadêmica e social das pessoas. Às vezes, as respostas de ansiedade podem ocorrer na ausência de qualquer ameaça real ou podem estar fora de proporção em relação ao perigo existente.

A sensação de ansiedade se caracteriza por um sentimento difuso, desagradável e vago de apreensão, freqüentemente, acompanhado por sintomas autonômicos como: cefaléia, hiperidrose, taquicardia, diarréia, palpitações, tremores, aperto no peito, formigamento nas 
extremidades, dificuldade de ereção, leve desconforto abdominal, freqüência alta e urgência urinária. Um indivíduo ansioso também pode sentir inquietação, expressa por incapacidade para permanecer sentado ou imóvel por muito tempo. Todos esses sintomas constituem os efeitos motores e viscerais da ansiedade. No entanto, a constelação particular de sintomas presentes tende a variar entre as pessoas. Os efeitos da ansiedade sobre o pensamento, a percepção e o aprendizado também não podem ser ignorados. A ansiedade tende a produzir confusão e distorções perceptivas, não apenas em termos de tempo e espaço, mas com relação aos significados atribuídos às pessoas e aos eventos. Essas distorções podem interferir no aprendizado, baixando a concentração, reduzindo a memória e prejudicando a capacidade de relacionar uma coisa com outra. Os indivíduos ansiosos são capazes de selecionar certos objetos em seu ambiente e ignorar outros na tentativa de provarem que estão certos ao considerarem a situação amedrontadora e ao responderem de acordo com esta percepção (KAPLAN; SADOCK; GREBB, 1997).

De acordo com os referidos autores, a psiquiatria tem buscado delimitar os vários transtornos de ansiedade com base em critérios clínicos de validade e confiabilidade reconhecidas. O Manual Diagnóstico e Estatístico dos Transtornos Mentais (DSM-IV - APA, 1994) relaciona os seguintes transtornos de ansiedade: transtorno de pânico com e sem agorafobia; agorafobia sem história de transtorno de pânico; fobias específicas; fobia social (ou transtorno de ansiedade social); transtorno obsessivo-compulsivo; transtorno de estresse pós-traumático; transtorno de estresse agudo; transtorno de ansiedade generalizada; transtorno de ansiedade devido a uma condição médica geral; transtorno de ansiedade induzido por substância; e transtorno de ansiedade sem outra especificação, incluindo transtorno misto de ansiedade-depressão. 
Dentre os vários transtornos de ansiedade, o interesse deste estudo reside no Transtorno de Ansiedade Social (TAS) ou fobia social ${ }^{1}$. O uso da terminologia "transtorno de ansiedade social" é predominante na literatura atual (GARCÍA et al., 1999), visto que pode incluir outras características inseridas em traços de personalidade ou atributos temperamentais, como a timidez (ALCALDE; LÓPEZ, 1999).

\subsection{Transtorno de Ansiedade Social: Aspectos diagnósticos e epidemiológicos}

Conforme os critérios diagnósticos do DSM-IV (APA, 1994), os indivíduos com TAS manifestam um medo excessivo, persistente e irracional de serem vistos comportando-se de um modo humilhante ou embaraçoso - pela demonstração de ansiedade ou de desempenho inadequado - e de conseqüente desaprovação ou rejeição por parte dos outros. Apontam que este transtorno pode estar associado a ataques de pânico. A exposição ao estímulo fóbico ou sua antecipação resulta, quase que invariavelmente, em um ataque de pânico em um indivíduo propenso a eles.

Por esses critérios, fica subentendido que há dois subtipos de TAS: o generalizado (medo da maioria das situações de interação social e de desempenho) e o circunscrito, específico ou não-generalizado (medo de uma situação pública de desempenho e de algumas situações de interação social), cuja caracterização pode ser útil na predição do curso, prognóstico e na resposta ao tratamento. No entanto, o subtipo específico do TAS não está reconhecido como um subtipo no DSM-IV (1994), mas tem sido freqüentemente reconhecido na literatura tanto de pesquisa quanto clínica (BEIDEL; TURNER, 1999; HEIMBERG et al., 1993).

\footnotetext{
${ }^{1}$ Os termos "transtorno de ansiedade social" e "fobia social" ou "indivíduos com transtorno de ansiedade social" e "fóbicos sociais" serão usados aqui indistintamente.
} 
As situações de desempenho (ou circunstâncias de desempenho) mais temidas são falar em público, comer, beber, escrever e tocar um instrumento na frente dos outros, usar banheiro público e entrar em uma sala onde já se encontram pessoas sentadas. Falar em público, entretanto, é o medo social mais prevalente (FURMARK, 2000). As situações interacionais abrangem conversar ao telefone, falar com pessoas estranhas, participar de festas e reuniões sociais, interagir com o sexo oposto, conversações face-a-face com estranhos e autoridades e devolver mercadoria em uma loja (HAZEN; STEIN ${ }^{2}, 1995$ apud FALCONE; FIGUEIRA, 2001; FURMARK, 2000).

De acordo com citações feitas por Falcone e Figueira (2001), os fóbicos sociais, em contato com situações ansiogênicas, costumam apresentar manifestações físicas como rubor, sudorese, palpitação, tremor das mãos ou da fala e/ou urgência em evacuar, embora alguns relatem apenas embaraço e medo.

Estes autores expõem que a evitação fóbica pode ser classificada como sutil (por exemplo, desviar os olhos, evitar iniciar uma conversação, etc.) ou extrema (evitar todos os contatos interpessoais fora do ambiente familiar). Isto pode limitar as possibilidades de sucesso profissional pela escolha de um trabalho menos qualificado, ou manter um relacionamento infeliz para não enfrentar a ansiedade de encontrar novas pessoas. Portanto, este padrão de comportamento evitativo de situações sociais, característico do TAS, favorece limitações na vida profissional, acadêmica, social ou sexual da pessoa portadora de tal transtorno.

Segundo o DSM-IV, para firmar o diagnóstico de tal transtorno é necessário ainda excluir que tais manifestações sejam resultado de evitação social originada de complicações relativas a outra condição médica geral ou de outro transtorno mental.

\footnotetext{
${ }^{2}$ HAZEN, A. L.; STEIN, M. B. Clinical phenomenology and comorbidity. In: STEIN, M.B. Social phobia: clinical and research perspectives. Washington DC: American Psychiatric Press, 1995.
} 
O TAS precisa ser diferenciado do medo apropriado e da timidez normal e o DSM-IV auxilia nessa diferenciação, exigindo que os seus sintomas comprometam a capacidade de funcionar apropriada ou funcionalmente. Conforme First e Tasman (2006), fatores similares deveriam ser considerados ao decidir em que ponto a timidez normal alcança uma intensidade que justificaria um diagnóstico de TAS. Um indivíduo que é bastante calado em grupos ou quando encontra pessoas desconhecidas, mas não evita essas situações e não se sente, particularmente, aflito por sua timidez, provavelmente, não receberia um diagnóstico de TAS. Em contrapartida, um indivíduo que, freqüentemente, recusa convites para socializar-se por causa de ansiedade, abandona um trabalho devido à ansiedade por ter que falar com os clientes, ou sente-se aflito por conta de sua ansiedade social, provavelmente, receberia um diagnóstico de TAS.

Para Stopa e Clark (1993), pessoas que são tímidas podem entrar em uma situação social com o mesmo tipo e frequiência de cognições que um fóbico social, mas notam que outras pessoas respondem demonstrando interesse e decidem que nesta situação, pelo menos, elas não estão sendo chatas e, então, termina a sequiência de pensamentos negativos. Fóbicos sociais, por outro lado, podem falhar em fazer esta verificação e, então, mantêm a sequiência de pensamentos negativos. Assim, esses autores hipotetizam que uma das principais diferenças entre fobia social e timidez poderia residir no fato da pessoa monitorar a situação social a fim de verificar a validade de suas afirmações auto-avaliativas negativas.

O DSM-IV também reconhece a diferenciação a ser considerada entre o TAS, transtorno do pânico, agorafobia e o transtorno da personalidade evitativa. Um indivíduo agorafóbico, freqüientemente, sente-se confortado pela presença de outra pessoa na situação ansiogênica, enquanto o indivíduo com TAS torna-se mais ansioso pela presença de outras pessoas. A falta de ar, tonturas, sensação de sufocamento e medo de morrer são comuns no transtorno do pânico e na agorafobia, ao passo que os sintomas associados ao TAS, 
geralmente, envolvem rubor facial, contrações musculares e ansiedade acerca do escrutínio por outros (KAPLAN; SADOCK; GREBB, 1997).

Indivíduos com transtorno do pânico experimentam ataques de pânico inesperados e ansiedade elevada fora da situação fóbica, enquanto que aqueles com TAS, tipicamente, não. O transtorno do pânico com agorafobia pode facilmente ser diagnosticado erroneamente como TAS. Por exemplo, um indivíduo pode evitar um grande número de situações, incluindo centros comerciais, supermercados, andar em ruas movimentadas, e várias situações sociais, incluindo festas, encontros e falar em público. Sem mais informações, este problema do indivíduo pareceria satisfazer os critérios para o TAS, transtorno do pânico com agorafobia, ou ambos os diagnósticos. Contudo, muitos indivíduos com transtorno do pânico evitam uma variedade de situações sociais por causa de ansiedade por ter outros observando seus sintomas. Além disso, indivíduos com TAS podem evitar situações que são comumente evitadas por indivíduos com agorafobia pelo medo de verem alguém que eles conhecem ou de serem observados por pessoas desconhecidas. Para fazer o diagnóstico neste caso, é necessário avaliar as razões para a evitação. Quatro variáveis deveriam ser consideradas para fazer o diagnóstico diferencial: (1) tipo e número de ataques de pânico, (2) foco de apreensão, (3) número de situações evitadas, e (4) nível de ansiedade intercorrente (FIRST; TASMAN, 2006).

A diferenciação entre o TAS e o transtorno da personalidade evitativa pode ser difícil, exigindo avaliação extensa por meio de entrevistas e de cuidadosa anamnese psiquiátrica (KAPLAN; SADOCK; GREBB, 1997). Como apontado por Falcone (1998), as pessoas com transtorno da personalidade evitativa manifestam menos desejo de interagir com os outros do que os fóbicos sociais. Indivíduos com transtorno de personalidade evitativa tendem a manifestar mais sensibilidade interpessoal e apresentam habilidades sociais mais pobres do que indivíduos com TAS sem transtorno de personalidade evitativa (FIRST; TASMAN, 
2006). Barlow (1988) pressupõe a existência de um continuum de gravidade envolvendo o TAS circunscrito, generalizado e o transtorno da personalidade evitativa.

Segundo Kaplan, Sadock e Grebb (1997), duas considerações diagnósticas diferenciais e adicionais para o TAS são o transtorno depressivo maior e transtorno da personalidade esquizóide. Em indivíduos com transtorno da personalidade esquizóide é a falta de interesse por se socializar e não o medo de se socializar que leva ao comportamento de esquiva social. Posto que a esquiva de situações sociais pode, freqüentemente, ser um sintoma da depressão, uma avaliação clínica sistemática tende a fornecer uma ampla constelação de sintomas depressivos para caracterizar essa diferenciação. Por outro lado, de acordo com Falcone (1998), os indivíduos com TAS que se encontram mais impedidos de obterem reforço social, devido aos seus medos, podem também desenvolver um quadro depressivo como comorbidade. Além disso, como apontam First e Tasman (2006), indivíduos com depressão, transtorno da personalidade esquizóide ou um transtorno invasivo do desenvolvimento podem evitar situações sociais devido a uma falta de interesse em passar o tempo com os outros. Para ser considerado TAS, um indivíduo deve evitar essas situações, particularmente, devido à ansiedade por poder ser avaliado negativamente.

Ademais, o TAS não deveria ser diagnosticado se o medo está completamente relacionado a outro transtorno. Por exemplo, se um indivíduo com transtorno obsessivocompulsivo evita situações sociais somente por causa do embaraço de ter outras pessoas observando seu comportamento excessivo de lavar as mãos, um diagnóstico de TAS não deveria ser dado (FIRST; TASMAN, 2006).

Com relação aos aspectos epidemiológicos, a prevalência do TAS, em seis meses, é de cerca de 2 a 3 por 100 pessoas. Em estudos epidemiológicos, as mulheres são afetadas com maior freqüência do que os homens, ocorrendo o inverso em amostras clínicas. A idade de pico de início para o TAS situa-se na adolescência, embora o seu aparecimento possa ser 
observado aos 5 ou até aos 35 anos (KAPLAN; SADOCK; GREBB, 1997). Entretanto, observa-se disparidade entre as estimativas de prevalência, variando entre 2,6\% e 16\%, o que pode estar relacionado às mudanças nos critérios diagnósticos entre as versões do DSM-III, DSM-III-R, DSM-IV e CID-10 (LECRUBIER et al., 2000).

Em um estudo epidemiológico recente, Baptista (2007) encontrou uma prevalência elevada do TAS (11,6\%) em uma população composta por 2319 estudantes universitários brasileiros. Identificou-se que os sujeitos do gênero feminino apresentaram significativamente maior prevalência do transtorno $(12,5 \%)$ em comparação aos sujeitos do gênero masculino $(7,4 \%)$. No que diz respeito aos tipos de medos, a maioria dos sujeitos com TAS apresentou medo de falar em público $(91,6 \%)$, seguido do medo de comer em público $(28,3 \%)$ e do medo de escrever em público (16,5\%). A idade média de início do TAS foi de 11,4 anos (DP = 0,27) e o tempo médio de início do transtorno foi de 10,2 ( $\mathrm{DP}=0,30)$. Com base nestes dados, o autor relata que o TAS é um transtorno sub-reconhecido, subdiagnosticado e associado às incapacidades sociais importantes.

Conforme os dados de vários estudos, as pessoas com TAS têm avaliado sua qualidade de vida como prejudicada, mostrando insatisfação com a vida e também com sua saúde (SAFREN et al., 1996/1997; STEIN; KEAN, 2000; WITTCHEN; BELOCH, 1996; WITTCHEN et al., 2000). Esses dados apontam para a necessidade do diagnóstico precoce de tal transtorno e de modalidades de tratamento eficazes que atendem as necessidades sociais, pessoais e profissionais destas pessoas.

A patogênese do TAS pode ser compreendida com base em um modelo de interações entre fatores biológicos e genéticos, por um lado, e eventos ambientais, por outro, podendo ser considerada como um fenômeno clínico multideterminado.

Os parentes em primeiro grau dos indivíduos com TAS estão cerca de três vezes mais propensos a serem afetados por TAS do que os parentes em primeiro grau de indivíduos sem 
transtornos mentais. Ademais, alguns dados preliminares indicam que os gêmeos monozigóticos são mais freqüentemente concordantes do que os gêmeos dizigóticos (FALCONE; FIGUEIRAS, 2001; KAPLAN; SADOCK; GREBB, 1997), embora para tais estudos seja particularmente importante estudar os gêmeos criados separadamente para ajudar no controle dos fatores ambientais.

Para Falcone (1998), parece haver uma vulnerabilidade constitucional que predispõe um indivíduo a desenvolver o TAS, o que em contato com variáveis relacionadas a padrões de educação, a fatores culturais e a fatos da experiência pessoal podem favorecer o desenvolvimento deste transtorno.

Tendo em vista que o TAS é caracterizado pela presença de sintomas físicos, cognitivos e comportamentais, e visando contemplar os fatores ambientais que incidem sobre este transtorno, este estudo adotará uma abordagem cognitivo-comportamental, enquanto eixo teórico, que enfatiza a interação dos indivíduos com seu ambiente histórico e imediato para a compreensão de suas condutas, quer sejam públicas ou encobertas.

\subsection{Distinção qualitativa entre os subtipos do Transtorno de Ansiedade Social}

De forma geral, alguns aspectos da distinção qualitativa entre os subtipos do TAS serão abordados, porém sem a pretensão de esgotar o tema de forma exaustiva. Alguns pesquisadores (BARLOW, 1998; HEIMBERG et al., 1995; MCNEIL, 2001) interpretam a distinção entre o TAS generalizado e específico como quantitativa e sustentam que estes subtipos não são categoricamente distintos, mas existem sobre um continuum de gravidade, com o TAS generalizado e transtorno da personalidade evitativa representando o pólo mais severo; o TAS generalizado sem transtorno da personalidade evitativa a forma menos severa do transtorno; o TAS específico representando uma forma ainda menos severa; e indivíduos sem ansiedade social representando o pólo oposto. 
Em contrapartida, o suporte para uma distinção qualitativa seria mostrado pelas diferenças significativas encontradas nos sintomas, curso e causas entre os subtipos generalizado e específico do TAS. Considerando estas diferenças parecerem difíceis de conciliar com uma perspectiva estritamente quantitativa, Hook e Valentiner (2002) propuseram uma distinção qualitativa. Com base nestes autores, as peculiaridades dessas diferenças serão apresentadas a seguir.

Quanto às diferenças no curso, os subtipos generalizado e específico do TAS parecem ter idades distintas de início. Mannuzza et al. (1995) observaram que o início para o TAS generalizado é significativamente mais precoce (média $=10,9$ anos, DP $=5,8$ ) do que para o TAS não-generalizado (média $=16,9$ anos, $\mathrm{DP}=9,3$ ), com metade do primeiro grupo desenvolvendo o transtorno antes dos 10 anos de idade. Ainda, o TAS específico é comumente descrito como tendo um início relativamente mais repentino e o TAS generalizado com um início insidioso ou por toda a vida (DSM-IV - APA, 1994).

Com relação às diferenças na etiologia, a distinção quantitativa sugere que ambos os subtipos têm histórias de desenvolvimento semelhantes e que indivíduos com TAS específico poderiam eventualmente desenvolver o subtipo generalizado. Em contrapartida, uma interpretação qualitativa propõe que estes subtipos apresentam causas diferentes em seu desenvolvimento e uma pessoa com TAS específico pode não estar propenso a desenvolver o subtipo generalizado (HOOK; VALENTINER, 2002).

Um fator contribuinte importante para o desenvolvimento do TAS parece ser a hereditariedade. Mannuzza et al. (1995) relataram que os parentes de indivíduos com TAS generalizado tinham maior probabilidade de ter um diagnóstico de TAS do que os parentes de indivíduos com TAS não-generalizado, e que os parentes daqueles com TAS nãogeneralizado não tinham maior probabilidade de ter TAS do que controles normais. De forma semelhante, Stein et al. (1998) observaram que parentes de primeiro grau de pessoas com 
TAS generalizado tinham aproximadamente 10 vezes maior probabilidade para ter TAS $(26,4 \%, \mathrm{~N}=106)$ do que pessoas sem um diagnóstico de TAS $(2,7 \%, \mathrm{~N}=74)$. Além disso, os parentes de primeiro grau de indivíduos com TAS generalizado apresentaram maior probabilidade de ter TAS generalizado do que o subtipo não-generalizado.

As práticas parentais de cuidado à criança têm sido também examinadas como possíveis fatores contribuintes para o desenvolvimento do TAS e ansiedade social. Os pais de indivíduos com TAS têm sido tipicamente avaliados como excessivamente protetores, menos calorosos (ARRINDELL et al., 1983) e mais isolados socialmente (BRUCH, 1989) do que controles normais.

Embora pouca atenção tem sido dada às possíveis diferenças nos estilos parentais entre os subtipos de TAS, evidências preliminares sugerem que diferenças existem (HOOK; VALENTINER, 2002). Bruch e Heimberg (1994) relataram que pacientes tanto com TAS generalizado quanto não-generalizado descreveram seus pais como pessoas que davam muita importância às opiniões dos outros e fazendo uso de constrangimento como uma forma de disciplina mais freqüentemente do que os pais de controles. Indivíduos com TAS generalizado, entretanto, percebiam seus pais como menos sociáveis e privando-os do contato social com os outros em comparação às descrições daqueles com TAS não-generalizado e controles normais.

Quanto aos fatores ambientais, com base em uma entrevista semi-estruturada, Stemberger et al. (1995) observaram que o grupo com TAS específico teve um percentual significativamente maior de sujeitos $(56 \%, \mathrm{~N}=16)$ relatando experiências sociais de condicionamento traumático comparado ao grupo de controles normais $(20 \%, \mathrm{~N}=25)$; porém, não houve diferenças significativas entre o grupo com TAS generalizado $(40 \%, \mathrm{~N}=$ 52) e os demais grupos. Neste sentido, os indivíduos com TAS, freqüentemente, relatam acontecimentos em suas vidas que podem ser episódios de condicionamento clássico como, 
por exemplo, o início de sintomas depois de tornarem-se ansiosos ou envergonhados em uma situação de avaliação social.

Em contrapartida, um percentual maior de indivíduos do grupo com TAS generalizado (76\%) relatou timidez na infância do que o grupo de controles normais (52\%). Não foram encontradas diferenças significativas quando o grupo com TAS específico (56\%) foi comparado com os grupos com TAS generalizado e controles normais. De acordo com Hofmann, Heinrichs e Moscovitch (2004), é possível que timidez e inibição comportamental sejam fatores de risco para o TAS, e que mais casos crônicos de TAS demonstrem uma história de inibição comportamental e timidez na infância. Estes autores reforçam que a inibição comportamental e timidez parecem estar intimamente associadas ao subtipo generalizado de TAS, mas não ao subtipo não-generalizado.

Com relação às características de personalidade, indivíduos com TAS específico obtiveram escores significativamente mais baixos em neuroticismo ${ }^{3}$ e mais altos em extroversão comparados aos indivíduos com TAS generalizado, ou seja, mostraram-se significativamente menos neuróticos e mais extrovertidos do que aqueles com TAS generalizado (STEMBERGER et al., 1995). Resultados semelhantes foram relatados em um estudo com formas subclínicas de TAS generalizado e específico (NORTON et al., 1997). Os resultados mostraram que extroversão esteve associada negativamente com ansiedade social; neuroticismo foi o preditor mais forte de tendências para o TAS generalizado; e sensibilidade à ansiedade (ou seja, o grau em que um indivíduo está aflito por seus sintomas de ansiedade), o preditor mais forte de tendências para o TAS não-generalizado. Portanto, as diferenças entre os subtipos podem estar presentes mesmo em formas subclínicas do TAS.

\footnotetext{
${ }^{3}$ Neuroticismo: afetividade negativa ou tendência disposicional para experimentar emoções negativas (BURKE et al., 2003).
} 
Hook e Valentiner (2002) tratam de quatro categorias referentes às diferenças nos sintomas entre o TAS generalizado e específico, incluindo: o tipo de situação temida, gravidade do prejuízo, comorbidade e respostas às situações temidas.

No que diz respeito ao tipo de situação temida, estes autores também definiram o TAS generalizado e específico em termos da difusão de medos sociais, com o TAS específico associado a um número mais limitado de medos. Consideram que o TAS generalizado esteja mais associado às situações de interação e o TAS específico às situações de desempenho. No entanto, argumentam que os critérios que focam o número de situações para diagnosticar os subtipos podem obscurecer uma questão muito importante: se os medos subjacentes estão relacionados às características de desempenho ou de interação das situações sociais, considerando que muitas situações de desempenho envolvem algum tipo de interação. Assim, a distinção qualitativa sugere que o número de situações temidas não seja a base para a diferenciação dos subtipos.

Particularmente, o DSM-IV apenas instrui o clínico a especificar o TAS como generalizado se os temores incluem a maioria das situações sociais, mas não fornece informações sobre a especificação de um subtipo para aqueles indivíduos que não temem a maioria das situações sociais. Sob as suas diretrizes, a distinção entre os subtipos não está clara e pode ser interpretada de maneiras diferentes. Segundo Turner, Beidel e Townsley (1992), a maioria das situações para especificar o TAS generalizado pode significar a maioria dos tipos de situações, embora também não esteja claro que número corresponderia à maioria. Por outro lado, alguns pesquisadores têm proposto uma distinção de subtipos entre aqueles que temem as situações sociais mais comuns (por exemplo, conversações, reuniões sociais ou festas) e aqueles que apresentam dificuldade em situações menos comuns, orientadas ao desempenho (por exemplo, discursos e encontros). 
Quanto à gravidade do prejuízo, talvez uma das distinções mais aparentes entre os subtipos de TAS é que o generalizado seja mais incapacitante do que o específico (HOOK; VALENTINER, 2002). Mais especificamente, indivíduos com TAS generalizado relatam maior evitação social, medo de avaliação negativa (BROWN; HEIMBERG; JUSTER, 1995; TRAN; CHAMBLES, 1995) e ansiedade social geral (BROWN; HEIMBERG; JUSTER, 1995; TURNER; BEIDEL, TOWNSLEY, 1992), além de apresentarem habilidades sociais mais pobres (HERBERT; HOPE; BELLACK, 1992) do que indivíduos com TAS específico.

Segundo Hook e Valentiner (2002), o TAS generalizado está também associado a níveis maiores de prejuízos sociais. Comparados aos indivíduos com TAS não-generalizado, indivíduos com TAS generalizado são mais comumente solteiros (MANNUZZA et al., 1995), têm menor nível educacional e menor probabilidade de estarem empregados (FIRST; TASMAN, 2006; HEIMBERG et al., 1990). Tais resultados são consistentes com uma distinção tanto qualitativa quanto quantitativa entre os subtipos de TAS (HOOK; VALENTINER, 2002).

Em termos de comorbidade, as taxas são maiores para o TAS generalizado do que para o não-generalizado, especialmente com depressão atípica ${ }^{4}$, alcoolismo (MANNUZZA et al., 1995), transtornos de humor, outros transtornos de ansiedade (STEIN; CHAVIRA, 1998), e transtorno de personalidade evitativa (BOONE et al., 1999), sendo que, na maioria dos casos, o TAS precede o início de transtornos comórbidos (SCHNEIER et al., 1992).

No que se refere às respostas em situações sociais, de acordo com Hook e Valentiner (2002), a distinção quantitativa prediz que o subtipo generalizado do TAS estaria associado a níveis mais altos de perturbação do que o subtipo específico. A distinção qualitativa, entretanto, prediz que o TAS generalizado e específico demonstrariam perfis de respostas e

\footnotetext{
${ }^{4}$ Depressão atípica: caracterizada pela hipersensibilidade à rejeição ou à crítica (BRUNELLO et al., 2000).
} 
sintomas diferentes, com o subtipo específico demonstrando níveis mais altos do que o generalizado em pelo menos alguns índices de perturbação, como demonstrado abaixo.

Em quatro estudos que mediram reatividade fisiológica para situações temidas (BOONE et al., 1999; HEIMBERG et al., 1990; HOFMANN et al., 1995; LEVIN et al., 1993), os indivíduos com TAS específico apresentaram freqüência cardíaca mais alta em uma tarefa de falar em público, do que o subtipo generalizado. Boone et al. (1999) também examinou as respostas do TAS generalizado e específico em um role-play de interação social (conversar com um desconhecido do gênero oposto). Este tipo de situação não produziu respostas fisiológicas diferenciais, ao contrário da diferença encontrada para o role-play de falar em público. Como defendem Hook e Valentiner (2002), estes resultados são consistentes com a concepção de que o TAS específico implica em ansiedade de desempenho e sugere que reações de ansiedade aguda associadas ao TAS específico não ocorrem durante desafios de interação social.

Ao contrário do padrão de maior reatividade fisiológica para o subtipo específico do que para o generalizado, o padrão geral dos resultados de quatro estudos sugere que o TAS generalizado está associado a mais auto-relatos de ansiedade do que o TAS específico. Um estudo (TRAN; CHAMBLESS, 1995) observou que o grupo com TAS específico relatou maior ansiedade comparado ao grupo com TAS generalizado sem transtorno de personalidade evitativa somente durante o discurso, e três (HOFMANN et al., 1995; LEVIN et al., 1993; TURNER et al., 1992) encontraram que os grupos com TAS generalizado relataram maior ansiedade. No estudo de Boone et al. (1999), apenas o grupo com TAS generalizado e transtorno de personalidade evitativa relatou significativamente maior ansiedade-estado do que o grupo com TAS circunscrito durante o discurso. Com relação à tarefa de conversação, ambos os grupos de TAS generalizado (com e sem transtorno de personalidade evitativa) relataram significativamente maior ansiedade-estado do que o grupo com TAS circunscrito. 
Na análise de Hook e Valentiner (2002), como estas investigações mediram ansiedade usando sistemas de avaliação diferentes, a variabilidade dos resultados pode refletir diferenças metodológicas.

Todos os estudos acima tiveram em comum o procedimento dos sujeitos receberem a tarefa de fazer um discurso frente a uma audiência de 2 a 6 de pessoas. Em geral, além desta tarefa, quatro dos cinco estudos tiveram as seguintes variações em seus procedimentos: (a) no estudo de Tran e Chambless (1995), os sujeitos participavam de duas tarefas de role-plays, nas quais tinham que iniciar e manter conversação, uma com um assistente de pesquisa do mesmo gênero e a outra com um assistente do gênero oposto; (b) no de Hoffmann et al. (1995), o sujeito conversava com o experimentador sobre o que fez no dia anterior ao experimento, durante três minutos, antes de preparar o discurso; (c) em Turner et al. (1992), os sujeitos participavam de duas interações interpessoais não-estruturadas, uma com um assistente de pesquisa do mesmo gênero (como se este fosse um vizinho ou companheiro de quarto) e a outra com um assistente do gênero oposto (como se estivesse em um primeiro encontro romântico com ele); e (d) em Boone et al. (1999), os sujeitos tinham que participar de uma conversação com um desconhecido do gênero oposto, como se estivessem se conhecendo.

No tocante às cognições, evidências preliminares sugerem características únicas associadas ao TAS generalizado e específico (HOOK; VALENTINER, 2002). McNeil et al. (1995) examinaram as respostas de indivíduos com TAS generalizado e circunscrito usando uma versão modificada do Stroop Teste. No General Social Stimuli Stroop Test, o grupo com TAS generalizado apresentou um tempo de resposta significativamente mais longo para palavras sociais (por exemplo, festa), ou seja, maior interferência cognitiva, comparado ao grupo com TAS circunscrito. Este teste, em particular, foi designado para avaliar interferência devido à ansiedade associada a uma variedade de situações sociais. De acordo com Hook e 
Valentiner (2002), o tempo mais longo para processar certos estímulos sociais tem sido interpretado como uma tendência dos indivíduos com o subtipo generalizado de TAS para desviarem a atenção de estímulos sociais e dirigi-la mais para informações de auto-referência.

Em termos comportamentais, Hofmann et al. (1997) compararam os comportamentos de fóbicos sociais generalizados e não-generalizados durante os dois primeiros minutos na situação de falar em público. O comportamento de fixar o olhar (manter contato visual) não diferiu significativamente entre os grupos. No entanto, os fóbicos sociais generalizados relataram mais ansiedade e gastaram mais tempo pausando dos que os fóbicos sociais nãogeneralizados, ou seja, aproximadamente $15 \%$ a mais. Estes autores observaram que a produção de um discurso envolve um número de processos cognitivos altamente complexos que requer certa quantidade de atenção. $\mathrm{O}$ discurso pode ser perturbado se o sujeito realoca a atenção para outros processos cognitivos. Como os fóbicos sociais generalizados relataram mais ansiedade, sua atenção pode ter sido realocada para outros processos cognitivos adicionais, como por exemplo, prestar mais atenção à própria presença, atributos e sentimentos durante o discurso, resultando em mais pausas.

O mais central deste corpo de evidências é a diferença em tipos de situações sociais temidas (isto é, desempenho versus interação), distribuições distintas da idade de início, os perfis distintos de respostas fisiológicas em situações sociais, diferenças claras em fatores causais (isto é, genéticos versus ambientais), e os prejuízos sociais e ocupacionais. Conforme Hook e Valentiner (2002), o quadro que emerge do TAS específico é bastante consistente com aquele de fobias específicas. As respostas de indivíduos com TAS específico durante confrontação com a situação social temida são semelhantes àquelas esperadas para fóbicos específicos quando confrontam seus objetos temidos. O quadro que emerge do TAS generalizado não é consistente com aquele das fobias específicas. Embora algumas das características fenotípicas, tais como comportamento evitativo, sejam comparáveis àquelas de 
outros transtornos de ansiedade, outras características não são. O mais notável a este respeito é a falta de reações fisiológicas pronunciadas em confrontação com a situação temida.

\subsection{Transtorno de Ansiedade Social: Aspectos cognitivos e comportamentais}

Em um trabalho de revisão da literatura, Furmark (2000) faz uma distinção entre os aspectos cognitivos e comportamentais associados à fobia social. A seguir, estes aspectos serão explorados segundo a revisão empreendida por este autor, com algumas contribuições de outros autores:

\section{Aspectos cognitivos}

Geralmente, os modelos cognitivos de fobia social enfatizam que os fóbicos sociais são excessivamente preocupados com a maneira pela qual eles estão sendo percebidos e avaliados pelos outros. Na perspectiva cognitiva, a ansiedade social pode emergir de um excesso de pensamentos negativos, defeitos pessoais percebidos, padrões excessivamente elevados para seus próprios desempenhos e/ou crenças irreais acerca dos padrões que as pessoas comumente usam para avaliar os outros. Conforme argumentam Stopa e Clark (1993), os pensamentos de fóbicos sociais não são informações guiadas pelas situações sociais, mas uma função bastante semelhante a um programa automático que é ativado nas situações sociais.

Para Falcone e Figueira (2001), o aspecto central da fobia social é um forte desejo de causar impressão favorável nos outros e uma insegurança marcante sobre a própria habilidade em alcançar esse objetivo. Ao entrarem em uma situação social, os fóbicos sociais acreditam que se comportarão de um modo inepto ou inadequado e, como conseqüência, serão rebaixados, rejeitados e desacreditados.

Antes de entrarem em uma situação social problemática, os fóbicos sociais freqüentemente revêem em detalhe o que eles pensam que poderia acontecer e como eles 
poderiam lidar com as várias dificuldades que podem surgir. Estas ruminações podem sensibilizar os indivíduos de modo que eles entrem na situação com um modo de processamento autofocado pré-ativado. Assim, ao pensarem que estão correndo o risco de uma avaliação negativa, os indivíduos dirigem sua atenção para uma auto-observação detalhada, o que aumenta a ansiedade e interfere no processamento da situação e dos comportamentos da outra pessoa. Frente a situações estressantes, indivíduos socialmente ansiosos comumente relatam mais pensamentos negativos e menos positivos que sujeitos não ansiosos ou não incluídos em grupos clínicos. A autopercepção gera uma impressão negativa de si mesmo que, para eles, reflete o que os outros realmente notam e pensam sobre eles.

Os pensamentos negativos nem sempre param imediatamente após o indivíduo deixar a situação social. Ao contrário, as ruminações negativas tendem a continuar na medida em que os indivíduos fóbicos, posteriormente, revêem mentalmente em detalhes o que aconteceu. Wells e Clark ${ }^{5}$ (1997 apud FURMARK, 2000) usam o termo "processamento post-mortem" para descrever o pensamento retrospectivo sobre as situações fóbicas. O processamento postmortem pode ser relacionado a uma necessidade fortemente sentida de reparar a auto-estima e planejar estratégias mais efetivas para lidar com a situação no futuro.

Nos transtornos de ansiedade, esforços consideráveis de pesquisa têm sido dedicados para a questão dos vieses no processamento de informações com relação a indícios de ameaças relevantes, por exemplo, relacionados à atenção, a interpretação e a memória. Tais vieses têm sido relatados por indivíduos com fobia social. Por exemplo, estudos empíricos usando a avaliação por meio do Stroop Teste e tarefas de decisão léxica, geralmente apontam que os fóbicos sociais demonstram maior vigilância para informação relacionada a ameaça social comparada a informação relacionada a ameaça física ou neutra. Wells e Clark (1997 apud FURMARK, 2000) relatam que a hipervigilância para os indícios interoceptivos de

\footnotetext{
${ }^{5}$ WELLS, A.; CLARK, D. M. Social Phobia: a cognitive approach. In: DAVEY, G. C. L. Phobias: a handbook of theory, research and treatment. Chichester: Wiley, 1997. p. 3-26.
} 
ameaça levam os fóbicos sociais a se esquivarem ou afastarem a atenção de informações ameaçadoras externas nos seus ambientes sociais, argumentando que os indivíduos socialmente ansiosos são caracterizados cognitivamente pela atenção autofocada e codificação pobre em dicas ambientais.

Destacam-se também elementos que demonstram viés de interpretação por parte dos fóbicos sociais. Por exemplo, indivíduos socialmente ansiosos têm uma tendência para avaliar seu próprio desempenho muito pior do que juízes independentes. Além disso, tem-se demonstrado que os fóbicos sociais tendem a interpretar eventos ambíguos como negativos e supervalorizar a probabilidade de resultados sociais negativos. Indivíduos socialmente ansiosos também exageram a extensão na qual os observadores podem notar que eles se sentem desconfortáveis. Wells e Clark (1997 apud FURMARK, 2000) argumentam que o indivíduo socialmente fóbico tipicamente constrói uma imagem negativa de si mesmo a partir da perspectiva de um observador, como se a pessoa estivesse se vendo fora do seu corpo, olhando para si mesma.

Estudos cognitivos têm demonstrado que os fóbicos sociais mostram recuperação de "memória aumentada" relativa a informações relevantes de ameaças para eles, desconsiderando os aspectos positivos ou neutros da situação como um todo. Alguns estudos sugerem que indivíduos socialmente ansiosos tendem a lembrar mais dados negativos sobre eles próprios, como conseqüência de atenção autofocada, do que pessoas menos vigilantes socialmente (BRECK; SMITH' ${ }^{6}, 1983$; O’BANION; ARKOWITZ7, 1977 apud FURMARK, 2000).

\footnotetext{
${ }^{6}$ BRECK, B. E.; SMITH, S. H. Selective recall of self-descriptive traits by socially anxious and nonanxious females. Social Behavior and Personality, Palmerston North, v. 11, n. 2, p. 71-76, 1983.

${ }^{7}$ O'BANION, K.; ARKOWITZ, H. Social anxiety and selective memory for affective information about the self. Social Behavior and Personality, Palmerston North, v. 5, n. 2, p. 321-328, 1977.
} 


\section{Aspectos comportamentais}

De acordo com os princípios do condicionamento operante, acredita-se que as fobias sejam mantidas pelos comportamentos de fuga e esquiva. Por exemplo, quando um aracnofóbico foge de um porão depois de ver uma aranha andando na parede, o comportamento de fuga é reforçado negativamente porque ele acaba com a exposição aversiva. A esquiva futura de entrar no porão similarmente evita exposição aversiva potencial. Contudo, enquanto essas estratégias reduzem ansiedade em uma perspectiva mais limitada, o indivíduo fóbico nunca tem uma chance de aprender maneiras mais adequadas e menos desconfortáveis para lidar com o objeto fóbico. É por isso que a exposição a eventos temidos é uma marca essencial nos tratamentos comportamentais das fobias. A fuga e esquiva também são importantes na fobia social, embora seja talvez mais difícil de se evitar completamente as situações sociais ou fugir delas do que outras situações fobogênicas, especificamente nas fobias específicas e agorafobia. Sair correndo da sala de aula quando precisar falar na aula, voltar de uma festa cedo para casa ou desligar o telefone antes que a outra pessoa seja capaz de atender são alguns exemplos de comportamento de fuga na fobia social. A esquiva pode ser manifestada de formas incontáveis, como, por exemplo, quando um aluno talentoso se recusa a entrar na universidade pelo medo de falar na aula ou quando um empregado habilidoso rejeita uma promoção porque a nova posição põe maior ênfase nos contatos sociais.

Wells e Clark (1997 apud FURMARK, 2000) argumentam que a fobia social é mantida por manobras sutis de esquiva ou "comportamentos de segurança", praticados por indivíduos socialmente ansiosos quando resistem a situações fóbicas. Evitar contato visual nas conversas, usar roupas frescas para evitar suor, manter os braços rígidos para evitar tremor, ensaiar um discurso várias vezes e falar rapidamente para evitar pausas longas e dar impressão de insegurança, segurar um copo com força para não aparentar tremor são alguns 
exemplos de tais comportamentos de segurança. Estes comportamentos se destinam a reduzir o risco de fracasso social, contudo eles impedem os indivíduos de testarem a validade de suas crenças negativas e preservam a sua atenção autofocada, sendo possível faltar-lhes habilidades de enfrentamento mais efetivas para lidarem com as situações interpessoais.

Por conseguinte, a questão de habilidades sociais deve ser mencionada como um dos aspectos fundamentais da fobia social. Poder-se-ia suspeitar que os fóbicos sociais careçam de habilidades adequadas (verbais ou não-verbais) necessárias para lidar com as situações sociais de interação ou de desempenho. Contudo, conforme revisão empreendida por Furmark (2000), a pesquisa nesse tópico tem sido inconsistente, considerando que embora os fóbicos sociais pareçam ter desempenhos inadequados em alguns estudos, isso poderia refletir inibição ao contrário de falta real de habilidades. É possível que tais habilidades sociais estejam apenas inibidas durante estados de alta ansiedade em situações fóbicas, sendo desejável desenvolver ou estimular habilidades de enfrentamento no repertório destes indivíduos.

\subsection{Habilidades Sociais: Principais conceitos, tipos de déficits e suas causas}

Del Prette e Del Prette (2001) definem habilidades sociais como diferentes classes de comportamentos sociais existentes no repertório de um indivíduo para lidar de maneia adequada com as demandas das situações interpessoais. Este conceito abrange mais o aspecto descritivo dos comportamentos verbais e não-verbais apresentados pelo indivíduo diante das diferentes demandas das situações interpessoais. Demanda seria uma ocasião ou oportunidade diante da qual se espera um determinado desempenho social em relação a uma ou mais pessoas.

Poder-se-ia afirmar que as demandas seriam produtos da vida em sociedade, regulada pela cultura de subgrupos. E, sendo assim, quando algumas pessoas não conseguem adequar- 
se a elas, principalmente às mais importantes, são consideradas desadaptadas, provocando reações de vários tipos nas demais. O exemplo mais extremo, segundo os autores, seria o do fóbico social "que não consegue responder às demandas interpessoais de vários contextos, isolando-se no grupo familiar e, mesmo neste, mantendo um contato social bastante empobrecido" (p. 47). Tanto as habilidades cognitivas de percepção social e processamento de informação que definem, organizam e guiam o desempenho social, quanto as habilidades comportamentais verbais e não-verbais que implementam a direção definida pelos processos cognitivos estão agrupadas no conceito de habilidades sociais (DEL PRETTE; DEL PRETTE, 2001).

Os referidos autores apresentam uma distinção clara entre os conceitos de habilidades sociais, desempenho social e competência social. O desempenho social refere-se à emissão de um comportamento ou seqüência de comportamentos em uma situação social qualquer, incluindo tanto as condutas que favorecem como as que interferem na qualidade dos relacionamentos; e a competência social é um termo amplamente utilizado para qualificar o nível de proficiência com que as classes de comportamentos verbais e não-verbais de um indivíduo são articuladas em um desempenho bem sucedido. Neste sentido, a competência social tem um sentido avaliativo que remete aos efeitos do desempenho social apresentado por um indivíduo para garantir a consecução dos seus objetivos (DEL PRETTE; DEL PRETTE, 1999; 2001), o que depende muito das características da audiência com a qual interage. O grau de efetividade do desempenho de uma pessoa também dependerá do que ela deseja conseguir na situação particular em que se encontra. Não obstante, muitas vezes a disponibilidade de um variado repertório de habilidades sociais também não implica, necessariamente, em um desempenho socialmente competente, embora seja uma das condições para isso. 
Em acréscimo, Caballo (1999) define o comportamento socialmente habilidoso como o conjunto de condutas emitidas por um indivíduo, em um contexto interpessoal, que expressa seus sentimentos, atitudes, desejos, opiniões ou direitos, de um modo adequado à situação, respeitando essas condutas nos demais e que, geralmente, resolve os problemas imediatos da situação enquanto minimiza a probabilidade de problemas futuros. Em sua definição, este autor aproxima os conceitos de habilidades sociais e comportamento assertivo, que visa a auto-afirmação do indivíduo perante os outros, a garantia dos seus direitos e a expressão apropriada, direta e honesta dos seus pensamentos, sentimentos e crenças, não violando o direito dos demais (ANGÉLICO, 2004).

As habilidades sociais devem ser consideradas dentro de um contexto situacional e cultural que estabelecem e configuram as contingências em que são aprendidas e emitidas. $O$ contexto situacional inclui o ambiente físico onde as pessoas se comportam (sala de aula, cinema, lanchonete e assim por diante), o evento antecedente e conseqüente para determinados desempenhos sociais, e as regras explícitas e implícitas que sinalizam os comportamentos valorizados, aceitos ou proibidos em cada situação específica. O contexto cultural abrange as normas e valores que definem os padrões de comportamento valorizados ou reprovados para os diferentes tipos de situações, contextos ou interlocutores. (DEL PRETTE; DEL PRETTE, 2005). Os dois contextos se interpenetram e estão sempre presentes nas interações sociais.

Com relação às diferenças culturais, embora a falta de contato visual possa ser interpretada como indicativo de timidez ou falta de assertividade pelos americanos brancos, a evitação de contato visual é, freqüentemente, vista como um sinal de respeito entre os japoneses e americanos de origem mexicana. Ao contrário dos americanos brancos, os japoneses apresentam maior probabilidade de interpretar o sorriso como um sinal de embaraço ou desconforto. Enquanto os americanos brancos, muitas vezes, ficam incomodados 
com o silêncio em uma conversação, os indivíduos árabes e britânicos podem usar o silêncio para privacidade e outras culturas o usam para indicar concordância entre as partes ou como um sinal de respeito (FIRST; TASMAN, 2006).

Além disso, as habilidades sociais são sempre avaliadas em seu nível molecular e/ou molar. Em geral, o nível molar refere-se a habilidades globais, como expressão de sentimentos, solicitar emprego, falar em público, liderar um grupo e lidar com críticas, enquanto o nível molecular refere-se a habilidades componentes, como fazer perguntas, volume da voz, contato visual, velocidade da fala, entre outros (DEL PRETTE; DEL PRETTE, 1999).

Sem dúvida alguma, as habilidades sociais são aprendidas e as demandas para a sua aquisição e desempenho variam em função do estágio de desenvolvimento do indivíduo (ANGÉLICO, 2004). Por exemplo, uma criança de escola maternal não apresentará as mesmas habilidades sociais que uma do ensino fundamental, e as habilidades sociais que um adolescente demonstrará não serão as mesmas esperadas de um adulto ou pessoa idosa.

No entanto, considera-se que os déficits de habilidades sociais dificultam o funcionamento social e a capacidade adaptativa do indivíduo, com implicações e prejuízos diversos, especialmente para o desempenho e interações sociais. Os diferentes tipos de déficits de habilidades sociais que um indivíduo pode apresentar são: (a) déficit de aquisição, caracterizado pela não ocorrência da habilidade social diante das demandas do ambiente ou, em outras palavras, o indivíduo por razões diversas simplesmente não aprendeu uma determinada habilidade em sua história de reforçamento; (b) déficit de desempenho, caracterizado pela ocorrência de uma habilidade específica com freqüência inferior à esperada diante das demandas do ambiente; e (c) déficit de fluência, demonstrado pela ocorrência da habilidade com proficiência inferior à esperada diante das demandas sociais (ANGÉLICO; CRIPPA; LOUREIRO, 2006; GRESHAM, 2002). 
De acordo com Elliott e Gresham (1993), os déficits de habilidades sociais podem ser atribuídos a várias causas, incluindo:

- Falta de conhecimento. Neste caso, o indivíduo desconhece como comportar-se de maneira socialmente apropriada. Os déficits de conhecimento estão relacionados a três áreas de deficiência:

(1) Deficiência em reconhecer as metas apropriadas para as interações sociais. Por exemplo, um indivíduo pode ver o objetivo de um jogo apenas como oportunidade de vencer ao invés de diversão com os colegas. As metas sociais representam um aspecto importante do desempenho das habilidades sociais e, freqüentemente, quando as metas de um indivíduo não são congruentes com as metas sociais do grupo, ele é excluído ou rejeitado;

(2) Falta de conhecimento de estratégias comportamentais para alcançar metas socialmente apropriadas. Este tipo de deficiência pode, muitas vezes, resultar de uma falta de prática de habilidades componentes que permitiriam o alcance de uma meta social. Por exemplo, alguém pode desejar ter um novo amigo, mas pode carecer de habilidades de iniciar e manter conversação que lhe permitiriam criar uma amizade;

(3) Falta de conhecimento dos contextos nos quais certas estratégias comportamentais seriam apropriadas ou, em outras palavras, o indivíduo não sabe combinar as estratégias comportamentais com os contextos situacionais apropriados. O indivíduo pode perceber erroneamente ou ignorar dicas ou pistas no ambiente que sugeririam estratégias comportamentais apropriadas. Por exemplo, uma garota pode estar dominando uma conversa com um grupo de amigos e não perceber as reações sutis do grupo que sugeririam que ela permita que os outros falem. O problema dessa garota não é que ela careça de metas sociais apropriadas ou de habilidades de conversação, mas sim que ela carece de habilidades para perceber dicas sociais no ambiente que sugeririam que ela mude seu comportamento. 
- Falta de prática ou feedback. Muitas pessoas exibem desempenhos deficientes em habilidades sociais porque elas não tiveram a prática suficiente em desempenhar uma habilidade social adquirida recentemente. Os déficits de habilidades sociais resultantes de prática insuficiente estão relacionados a desempenhos comportamentais inadequados de uma habilidade social. Um componente importante da prática comportamental é fornecer feedback para os desempenhos apropriados de modo que a pessoa mude ou melhore o seu comportamento social.

- Ausência de modelos ou oportunidades. Alguns indivíduos são deficientes em certas habilidades sociais porque as oportunidades ou modelos sociais que estimulariam a aprendizagem ou desempenho de comportamentos socialmente apropriados estiveram ausentes. Por exemplo, um indivíduo pode ter aprendido participar em atividades sociais somente com pessoas conhecidas. Quando esse indivíduo entra em contato com uma situação social envolvendo pessoas desconhecidas, ele não participa. Neste caso, a causa funcional de sua falta de participação foi a ausência de modelos sociais próximos (colegas conhecidos) que ocasionariam a sua participação social entre pessoas pouco conhecidas.

- Falhas de reforçamento. Muitos indivíduos exibem freqüências baixas de habilidades sociais apropriadas porque seu comportamento produz pouco ou nenhum reforçamento do ambiente. Se certos comportamentos produzem pouco reforçamento, eles serão apresentados infreqüentemente. Para muitas crianças com habilidades sociais deficientes, as interações com pares produzem pouco ou nenhum reforçamento de seus ambientes sociais e, em alguns casos, estas interações podem produzir conseqüências aversivas (por exemplo, provocação, xingamentos, ser ignorado, entre outras). Por exemplo, um indivíduo socialmente isolado pode interagir raras vezes com os amigos porque a interação com pares foi associada a pouco reforçamento no passado. Numerosos exemplos na literatura de pesquisa operante confirmam 
o poder do reforçamento dado de maneira contingente para aumentar os comportamentos socialmente apropriados.

- Comportamentos-problema. Alguns indivíduos podem falhar em adquirir ou desempenhar certas habilidades sociais por causa da presença de comportamentos-problema. Há, potencialmente, um grande número de comportamentos-problema que podem ser classificados em: (a) externalizantes (birras, discussões com os outros e brigas); (b) internalizantes (ansiedade, depressão e baixa auto-estima); e (c) hiperatividade (distração, impulsividade e inquietação).

- Excesso de ansiedade interpessoal. As reações de ansiedade muito intensas podem comprometer o desempenho socialmente competente ou podem mesmo inibi-lo, embora os indivíduos saibam como devem se comportar e possuam, em seu repertório, as habilidades necessárias para responder às demandas do ambiente. O excesso de ansiedade interpessoal foi incluído como uma das possíveis causas dos déficits de habilidades sociais por Del Prette e Del Prette (2005).

É importante ter em mente que a deficiência em uma dada habilidade social para um indivíduo em particular pode ser devido ou a uma causa isolada ou a uma combinação de causas. Além disso, algumas dessas causas encontram-se associadas aos três tipos de déficits e outras a apenas um ou dois deles. Del Prette e Del Prette (2005) associam todas as causas, acima listadas, ao déficit de fluência; a falta de conhecimento, ausência de modelos e oportunidades, e comportamentos-problema ao déficit de aquisição. E a falta de feedback, ausência de modelos ou oportunidades, falhas de reforçamento, comportamentos-problema e ansiedade interpessoal excessiva estariam associadas ao déficit de desempenho. 


\subsection{Transtorno de Ansiedade Social e Habilidades Sociais}

O repertório de habilidades sociais vem constituindo, cada vez mais, uma medida de avaliação clínica da fobia social. Segundo Falcone (1998), o déficit em habilidades sociais parece comum entre os fóbicos sociais, principalmente na forma generalizada. Por outro lado, poderia ser argumentado que os fóbicos sociais possuem habilidades sociais em seu repertório, mas que sua exibição fica inibida durante a manifestação de ansiedade (FURMARK, 2000; HEIMBERG; DODGE; BECKER, 1987).

Formas sutis de evitação (interromper uma situação, desviar o contato ocular, entre outras) podem ser identificadas por meio de observação do comportamento do indivíduo em jogos de papéis (BUTLER, 1989).

De acordo com Falcone e Figueira (2001), a preocupação com a monitoração da própria ansiedade e do desempenho, aliada aos comportamentos de segurança (por exemplo, evitação do contato visual, evitação de auto-revelação, entre outros) podem dar uma impressão pouco amigável ou calorosa. Do mesmo modo, os fóbicos sociais tornam-se preocupados com seus pensamentos negativos, e esta preocupação interfere com a habilidade para processar dicas sociais, levando a uma deterioração objetiva no seu desempenho (STOPA; CLARK, 1993). Nessas circunstâncias, o fóbico social presta pouca ou nenhuma atenção ao interlocutor e essas deficiências na interação comprometem a relação, fazendo com que a outra pessoa distancie-se, produzindo um padrão negativo de interação, o que contribui posteriormente para a manutenção da fobia social.

Considerando, por um lado, o fato dos estudantes universitários constituírem uma classe profissional emergente que tem, pelo menos em algumas áreas, a interação social como base de sua ação profissional, quando não também o objeto e objetivo dessa atuação (DEL PRETTE; DEL PRETTE; CASTELO BRANCO, 1992a; DEL PRETTE; DEL PRETTE; CASTELO BRANCO, 1992b), e, por outro, o elevado comprometimento social e funcional 
evidenciado na qualidade de vida de indivíduos com TAS, a necessidade de avaliação do desempenho social desse grupo assume inquestionável relevância tanto social quanto educacional. Um repertório de habilidades interpessoais (aproximar-se de outras pessoas, iniciar contato e conversação, estabelecer contato visual, defender os próprios direitos, criticar, fazer pedidos, recusar pedidos abusivos, pedir mudança de comportamento, entre outras) e de desempenho de falar em público (construção da fala, pronúncia, concentração no conteúdo da fala, criar consciência do outro na interação e autoconsciência pública) pode ser considerado imprescindível para um melhor desempenho acadêmico e social de indivíduos universitários.

Embora diversos instrumentos de medida já tenham sido construídos na área de estudo das habilidades sociais, poucos foram elaborados ou validados para o contexto cultural brasileiro. Ainda que existam aspectos do repertório de habilidades sociais comuns a diversas culturas, certas especificidades aconselham a adaptação de instrumentos elaborados em outros contextos ou, mesmo, a construção de novos instrumentos a partir de características próprias da subcultura para a qual se destinam (DEL PRETTE; DEL PRETTE; BARRETO, 1998).

Uma escala para a avaliação da competência social de pacientes psiquiátricos, por meio do desempenho de papéis, foi elabora por Bandeira e Tremblay (1998), com propriedades psicométricas satisfatórias (BANDEIRA, 2002). A Escala Brasileira para a Medida de Assertividade (AYRES, 1994) e a Escala de Assertividade de Rathus, adaptada e validada para o contexto brasileiro (PASQUALI; GOUVEIA, 1990), visam avaliar especificamente a assertividade e não as habilidades sociais consideradas como um conceito mais abrangente.

Para suprir a falta de uma medida que avaliasse as habilidades sociais em geral dos indivíduos, Del Prette e Del Prette (2001) elaboraram e validaram o Inventário de Habilidades Sociais (IHS-Del-Prette) para avaliar o repertório interpessoal de estudantes universitários, 
que além de ser um instrumento de fácil aplicação, cobre um grande número de situações e comportamentos interpessoais. No entanto, nenhum estudo anterior aferiu as propriedades psicométricas deste instrumento em amostras clínicas representativas de quaisquer transtornos psiquiátricos.

Ainda que o déficit em habilidades sociais não esteja presente em muitos fóbicos sociais, é recomendável que a sua avaliação seja realizada, independentemente de manifestarem estes déficits, para efeitos tanto de caracterização do repertório desses indivíduos quanto de instrumentar programas de tratamento efetivos que atendam as suas demandas interpessoais e acadêmicas de modo mais direto e objetivo. E nesta direção, considera-se também que o desempenho de falar em público pode se constituir em uma importante medida ou estratégia de avaliação clínica do TAS, enquanto uma habilidade componente do repertório interpessoal global dos indivíduos.

\subsection{O Transtorno de Ansiedade Social e o medo de falar em público}

Vários autores têm apontado a alta prevalência do medo de falar em público nos diferentes subtipos do TAS, como também na população geral (FURMARK et al., 1999; FURMARK et al., 2000; GEER, 1965; MANNUZZA et al., 1995; OSÓRIO; CRIPPA; LOUREIRO, 2008; STEIN; WALKER; FORDE, 1996), o que tem despertado e estimulado estudos que avaliem e dimensionem esta situação específica.

Em 1982, McNair et al. desenvolveram e validaram um modelo para avaliação da ansiedade, nomeado de "Teste de Simulação de Falar em Público - TSFP”, que consiste em solicitar ao sujeito que prepare um discurso e o fale em frente a uma câmara de vídeo, que estará gravando sua performance. Guimarães, Zuardi e Graeff (1988) modificaram esse modelo original, introduzindo juntamente às medidas fisiológicas avaliadas durante o procedimento, tais como pressão arterial, batimentos cardíacos e condutância da pele, 
medidas relacionadas aos estados subjetivos experimentados. Para tal propuseram o uso do Inventário de Ansiedade Traço-Estado de Spielberger (IDATE; SPIELBERGER; GORSUCH; LUSHINE, 1970) e a Escala Analógica de Humor (VAMS - traduzida e adaptada para o português por Zuardi e Karniol, 1981). Segundo Graeff et al. (2003), este modelo modificado tem sido amplamente utilizado em estudos farmacológicos e em estudos relativos a outros transtornos de ansiedade como o pânico (HETEM et al., 1996).

Rapee e Lim (1992) realizaram um estudo visando verificar como indivíduos com e sem TAS avaliam seus desempenhos por meio de uma situação simulada de falar para uma pequena audiência e de uma bateria de instrumentos específicos de auto e hetero-avaliação do comportamento e dos estados subjetivos. Encontraram que para todos os sujeitos a autoavaliação foi discrepante e pior quando comparada à hetero-avaliação. Porém, nos indivíduos com TAS, esta discrepância foi muito mais significativa, apontando para a importância do componente cognitivo do transtorno.

Stein, Walker e Forde (1996) objetivaram avaliar a prevalência, o impacto e o funcionamento dos indivíduos com medo de falar em público, tendo como participantes indivíduos da população geral. Identificaram que $57 \%$ do total dos participantes relataram medo incluído nas classificações "significativo" até "bastante significativo". Estes participantes comparativamente aos demais, cujo medo não foi classificado como significativo, apresentaram menor nível educacional, nível econômico mais baixo e menor renda pessoal, destacando assim importantes prejuízos de ordem psicossocial associados ao temor de falar em público.

Um estudo realizado por Hofmann et al. (1997) teve por objetivo avaliar se haviam diferenças entre os indivíduos com TAS e controles e entre os subtipos do TAS quanto aos distúrbios da fala (exemplificados como pausas, repetições, sentenças incompletas, gagueira, sons incoerentes) e quanto à dificuldade em manter contato visual na situação de falar em 
público, uma vez que tais aspectos parecem ser bastante característicos do medo social. Os resultados apontaram que os indivíduos com TAS apresentam maior nível de ansiedade durante o falar em público, comparativamente aos controles. Observaram que os indivíduos com TAS apresentam falas com pausas mais longas e em maior quantidade, comparativamente aos sem TAS, apontando para a validade deste comportamento como um indicador real do medo social. O mesmo não ocorreu com o comportamento de fixar o olhar, pois não se observou diferenças quanto aos diversos grupos estudados em relação à quantidade e duração do contato visual durante a situação experimental.

Outros estudos relativos ao falar em público têm abordado aspectos relacionados ao funcionamento cerebral (TILLFORS et al., 2002) e a utilização de recursos virtuais como modelo terapêutico (PERTAUB; SLATER; BARKER, 2001; LEE et al., 2002a, LEE et al., 2002b; HARRIS; KEMMERLING; NORTH, 2002).

Alguns estudos procuraram avaliar as características psicométricas de instrumentos específicos para avaliação do falar em público. Um desses estudos foi desenvolvido por Phillips et al. (1997) que realizaram a normatização em amostra de indivíduos universitários do Personal Report of Confidence as a Speaker, um instrumento de rastreamento, composto por 30 itens avaliados como falso ou verdadeiro. A validade discriminativa deste instrumento mostrou-se adequada, revelando que os níveis de ansiedade experimentados ao falar em público são razoavelmente constantes, considerando-se o gênero, a etnia e a idade.

Constata-se que múltiplos fatores determinantes incidem sobre os prejuízos no funcionamento social e comprometimento da capacidade adaptativa dos indivíduos portadores de TAS. Neste sentido, torna-se fundamental dispor de instrumentos validados e abrangentes que avaliem tanto os recursos e déficits comportamentais quanto os prejuízos sociais e funcionais destes indivíduos, visando sistematizar procedimentos de diagnóstico mais 
precisos que possibilitem a implementação de medidas de intervenção que atendam de modo mais direto, apropriado e objetivo as suas necessidades pessoais e profissionais.

Considerando a proposição de que indivíduos com TAS apresentam algum tipo de déficit em habilidades sociais e a alta prevalência do medo de falar em público presente nos diferentes subtipos do TAS, o presente estudo propõe como questão de pesquisa a identificação das possíveis associações entre as manifestações comportamentais e clínicas deste transtorno, por meio de um enfoque psicométrico e empírico. 


\section{OBJETIVOS}

Tem-se por objetivo geral verificar as associações entre as manifestações comportamentais e clínicas do TAS, apresentadas por universitários brasileiros, detectadas por meio de instrumentos de avaliação validados e exibidas frente a uma situação experimental de simulação de falar em público. Para tal, desenvolveram-se dois delineamentos, um psicométrico e outro empírico, apresentados separadamente como dois estudos independentes, contemplando os seguintes objetivos específicos:

\section{Estudo 1-Psicométrico}

a) aferir as propriedades psicométricas do Inventário de Habilidades Sociais (IHS-Del-Prette, 2001), enquanto medida do repertório comportamental de habilidades sociais, em relação à avaliação das manifestações clínicas próprias do TAS, medidas pelo Inventário de Fobia Social (SPIN - Anexo A);

Procurar-se-á verificar se as manifestações clínicas, detectadas com a aplicação do SPIN, estão ou não associadas às manifestações comportamentais do TAS, identificadas por meio do IHS-Del-Prette em estudantes universitários.

\section{Estudo 2- Empírico}

b) comparar e caracterizar o repertório de habilidades sociais apresentado por estudantes universitários, portadores de TAS e não portadores, frente a uma situação experimental estruturada, o Teste de Simulação de Falar em Público (TSFP).

Verificar-se-á aqui se as habilidades sociais apresentadas por estudantes universitários portadores de TAS frente a uma situação experimental estruturada de falar em público diferem ou não das apresentadas por não portadores deste transtorno. 


\section{MÉTODO}

Inicialmente, será apresentada uma caracterização geral da população que deu origem às amostras dos estudos que fizeram parte deste trabalho de pesquisa e, em seguida, uma descrição de cada um dos estudos.

\subsection{Caracterização da população estudada}

Esta pesquisa é parte integrante de um estudo maior, em desenvolvimento desde 2003, que visa a avaliação sistemática dos aspectos epidemiológicos, clínicos e comportamentais do TAS, por meio de instrumentos de auto e hetero-avaliação, em uma população de estudantes universitários $(\mathrm{N}=2314)$, de ambos os gêneros, com idade entre 17 e 35 anos, independentemente do nível socioeconômico, matriculados em diversos cursos de duas instituições de ensino superior, uma pública e outra particular, descritas sucintamente a seguir (Processo - CEP n . 11570/2003-HCRP).

A Universidade de São Paulo (USP), campus de Ribeirão Preto, caracteriza-se como uma instituição universitária pública, situada no nordeste do estado de São Paulo - Brasil. Duas unidades desta instituição fizeram parte do estudo, a saber: a Faculdade de Medicina de Ribeirão Preto (FMRP-USP) e a Faculdade de Filosofia, Ciências e Letras de Ribeirão Preto (FFCLRP). No período em que ocorreu a coleta de dados, a FMRP-USP oferecia os seguintes cursos: Medicina, Fonoaudiologia, Nutrição e Metabolismo, Terapia Ocupacional, Fisioterapia e Informática Biomédica, este último curso, oferecido em conjunto com a FFCLRP, totalizando 260 vagas ao ano. A FFCLRP oferecia, na ocasião, os cursos de: Psicologia, Biologia, Química (bacharelado e licenciatura), Física Médica, Pedagogia, Ciências da Documentação e Informação e Matemática Aplicada a Negócios, que totalizam 375 vagas ao ano. 
A Universidade de Franca (UNIFRAN) é uma instituição particular, localizada na cidade de Franca, também interior do estado de São Paulo, distante aproximadamente $80 \mathrm{Km}$ de Ribeirão Preto. Na época, oferecia 11 cursos na área de Ciências Biológicas e da Saúde, oito cursos na área de Ciências Humanas e Artes, sete cursos na área de Ciências Exatas e Tecnológicas e cinco cursos na área de Ciências Jurídicas e Sociais, totalizando 1100 vagas ao ano. 


\subsection{Estudo 1 - Psicométrico}

\subsubsection{Sujeitos}

Foram contatados 1182 universitários da USP, sendo 668 alunos da FMRP e 514 da FFCLRP, e 1432 da UNIFRAN para participar do estudo, totalizando 2614 alunos. No entanto, 201 alunos não aceitaram participar (65 da FMRP, 66 da FFCLRP e 70 da UNIFRAN), alegando falta de interesse ou disponibilidade para tanto, resultando uma população de 2413 alunos. Deste total, 1173 alunos responderam ao IHS-Del-Prette, considerando que este estudo foi integrado ao projeto maior já em andamento.

Para a composição da amostra resultante, foram adotados os seguintes critérios de exclusão: (a) idade superior a 35 anos de idade, (b) identificação incompleta do participante (sem menção de nome, idade, ano de curso e/ou procedência ${ }^{8}$ ), (c) uso de neurolépticos, e (d) preenchimento incorreto dos instrumentos (SPIN e IHS-Del-Prette). O número total de sujeitos excluídos segundo estes critérios está apresentado na Tabela 1.

Tabela 1 - Número total de sujeitos excluídos conforme os critérios adotados

\begin{tabular}{lc}
\hline \multicolumn{1}{c}{ CRITÉRIOS DE EXCLUSÃO ADOTADOS } & TOTAL \\
\hline Idade (> 35 anos) & 30 \\
Identificação incompleta do participante & 06 \\
Uso de neurolépticos & 04 \\
Preenchimento incorreto dos instrumentos & 127 \\
Total Geral & 167 \\
\hline
\end{tabular}

Como pode ser observado, o número maior de exclusões concentrou-se no preenchimento incorreto dos instrumentos, seguido do critério de exclusão por idade acima de 35 anos. Constata-se assim que não houve uma distribuição homogênea de exclusões dentro dos critérios adotados para este estudo e que a amostra de sujeitos foi constituída apenas pelos

\footnotetext{
${ }^{8}$ Procedência: endereço onde residia o participante no período da coleta de dados.
} 
universitários que responderam integral e corretamente os dois instrumentos. A Tabela 2 especifica os critérios utilizados para considerar que um dos instrumentos ou ambos foram preenchidos incorretamente.

Tabela 2 - Critérios assumidos para considerar que os instrumentos foram preenchidos incorretamente

\begin{tabular}{lccc}
\hline Critérios para preenchimento incorreto dos instrumentos & SPIN & IHS & SPIN + IHS \\
\hline Não preenchimento de itens & 08 & 96 & 03 \\
Duplo preenchimento de itens & 02 & 15 & 00 \\
Não preenchimento e duplo preenchimento de itens juntos & 00 & 03 & 00 \\
Total & 10 & 114 & 03 \\
\hline
\end{tabular}

Observa-se que o maior número de exclusões de participantes por preenchimento incorreto dos instrumentos concentrou-se no IHS-Del-Prette, particularmente pelo fato dos respondentes deixarem itens sem preencher seguido por duplo preenchimento de itens (critérios adotados em comum com o estudo maior do qual este é parte). Este número alto de preenchimento incorreto do IHS pode-se justificar por ele ser um instrumento extenso em termos do número de itens que o compõem, além de ter sido o último instrumento do caderno de escalas preenchido pelos participantes.

Após a aplicação dos critérios de exclusão, foram incluídos neste estudo 1006 estudantes universitários, entre 17 e 35 anos, de ambos os gêneros, independentemente do nível socioeconômico, matriculados nos diversos cursos de graduação oferecidos no campus de Ribeirão Preto da Universidade de São Paulo e pela Universidade de Franca, que aceitaram participar do estudo, assinando o Termo de Consentimento Livre e Esclarecido (TCLE Anexo B). 


\subsubsection{Materiais e Instrumentos}

A seguir, apresentar-se-á uma breve descrição dos materiais e instrumentos de avaliação que foram empregados na avaliação dos sujeitos deste estudo.

- Questionário de Identificação: composto por 16 itens que visaram a caracterização sociodemográfica dos sujeitos (Anexo C).

- Protocolo de Coleta de Dados e Protocolo Pós-coleta de Dados: protocolos relativos ao registro das situações de avaliação e pós-avaliação, envolvendo o número de estudantes presentes em sala da aula, número dos que aceitaram participar, tempo utilizado pelo primeiro que concluiu e tempo utilizado pelo último sujeito a concluir a avaliação (Anexo D e E).

- Social Phobia Inventory (SPIN): é uma escala auto-aplicável, recentemente desenvolvida com base na Escala de Fobia Social Breve (BSPS), caracterizando-se como um instrumento breve e de fácil administração, capaz de detectar sintomas de medo, evitação e fisiológicos (CONNOR et al., 2000). O instrumento compreende três subescalas: de medo (composta pelos itens $1,3,5,10,14$ e 15), de evitação (itens 4, 6, 8, 9, 11, 12 e 16), e de sintomas fisiológicos (itens 2, 7, 13 e 17). Esta escala é composta de 17 itens, cada um sendo classificado de 0 (nunca) até 4 (extremamente), com escore total variando de 0 a 68. Suas propriedades psicométricas, no estudo original, demonstraram boa consistência interna com alfa de Cronbach de 0,87 - 0,94 para duas amostras de farmacoterapia, e confiabilidade de teste-reteste com o coeficiente de correlação variando de $0,78-0,89$. A validade convergente foi relatada com correlações significativas em comparação a BSPS, Escala de Ansiedade Social de Liebowitz (LSAS), e subescala de Fobia Social do Questionário do Medo (FQ): $r=0,66,0,55$ e 0,77, respectivamente (THARWANI; DAVIDSON, 2001). Tal instrumento foi traduzido e adaptado para o português do Brasil 
por Osório (2008), sendo denominado Inventário de Fobia Social, apresentando boas qualidades psicométricas, com consistência interna de 0,90 e confiabilidade interavaliadores com índices entre 0,86 e 0,98.

- Mini-SPIN: é uma versão abreviada do SPIN, composta por três itens ("Evito fazer coisas ou falar com certas pessoas por medo de ficar envergonhado", "Evito atividades nas quais sou o centro das atenções", "Ficar envergonhado ou parecer bobo são meus maiores temores"), avaliados em uma escala de cinco pontos. Usando um escore de corte igual ou maior que seis, a Mini-SPIN demonstrou possuir boas propriedades psicométricas: uma sensibilidade de $88,7 \%$, especificidade de $90,0 \%$, valor preditivo positivo de $52,6 \%$ e valor preditivo negativo de $98,5 \%$, e $89,9 \%$ de precisão no diagnóstico do TAS (CONNOR et al., 2001).

- Inventário de Habilidades Sociais (IHS-Del-Prette): é um instrumento de auto-relato, proposto por Del Prette e Del Prette (2001), para a avaliação das dimensões situacional e comportamental molar das habilidades sociais, contendo 38 itens, cada um deles descrevendo uma relação interpessoal e uma possível reação àquela situação. Nas instruções, solicita-se que o respondente estime a frequiência com que reage da forma sugerida em cada item, considerando o total de vezes em que se encontrou na situação descrita e anotando sua resposta em escala tipo Likert, com cinco pontos, variando de nunca ou raramente (zero a $20 \%$ das vezes) a sempre ou quase sempre (81 a $100 \%$ das vezes). A análise das propriedades psicométricas, no estudo original, junto a 527 universitários obteve os seguintes resultados: índices de discriminação positivos, variando de 3,0 a 16,7; índices de correlação positivos, com apenas dois não significativos e 10 abaixo de 0,30; consistência interna satisfatória com um alfa de Cronbach de 0,75; e estrutura fatorial com cinco fatores principais, identificados em termos comportamentais- 
situacionais, com coeficientes alfa variando de 0,74 a 0,96 , que explicam $92,75 \%$ da variância total (DEL PRETTE; DEL PRETTE; BARRETO, 1998).

O IHS-Del-Prette, no estudo original, apresentou a seguinte estrutura fatorial:

(a) Fator 1 - Enfrentamento e auto-afirmação com risco - indica a capacidade do indivíduo para lidar com situações interpessoais que demandam a afirmação e defesa de direitos e auto-estima, com risco potencial de reação indesejável por parte do interlocutor, ou seja, com possibilidade de rejeição, réplica, ou de oposição por parte deste. Cabe mencionar que o Fator 1 constitui um forte indicador de assertividade e controle de ansiedade em diversas situações contempladas pelos seus itens. É composto pelos itens $1,5,7,11,12,14,15,16,20,21$ e 29

(b) Fator 2 - Auto-afirmação na expressão de sentimento positivo - envolve as habilidades do indivíduo para lidar com demandas de expressão de afeto positivo e de afirmação da auto-estima, que não implicam em risco interpessoal ou apenas um risco mínimo de reação indesejável. Compreende os itens 3, 6, 8, 10, 28, 30 e 35;

(c) Fator 3 - Conversação e desenvoltura social - representa a capacidade da pessoa para lidar com situações sociais neutras de aproximação, em termos de afeto positivo ou negativo, com risco mínimo de reação indesejável por parte do interlocutor, demandando principalmente "traquejo social" na conversação. Abrange os itens 13, 17, $19,22,24,36$ e 37

(d) Fator 4 - Auto-exposição a desconhecidos e situações novas - inclui basicamente a abordagem a pessoas desconhecidas, com maior risco de reação indesejável do outro. Compreende os itens 9, 14, 23 e 26;

(e) Fator 5 - Autocontrole da agressividade - contempla a capacidade do indivíduo de reagir a estimulações aversivas do interlocutor, como agressão, pilhéria e descontrole 
emocional, com razoável controle da raiva e da agressividade. É composto pelos itens 18,31 e 38 .

- Entrevista Clínica Estruturada para o DSM-IV (SCID-CV - versão clínica; FIRST et al., 1997), traduzida e adaptada para o português por Del-Ben et al. (2001): caracteriza-se como um instrumento utilizado para a elaboração de diagnósticos clínicos psiquiátricos baseados no DSM-IV. É composto por módulos, em um total de dez, que podem ser aplicados de forma independente ou combinada, conforme os objetivos almejados. Neste estudo foi utilizado o Módulo de Ansiedade (Módulo F), durante uma entrevista telefônica, visando a confirmação diagnóstica do TAS nos sujeitos identificados como portadores de tal transtorno psiquiátrico (grupo caso) e nos sujeitos que constituíram o grupo de comparação (não-caso).

\subsubsection{Treinamento dos aplicadores dos instrumentos}

Dois médicos psiquiatras e uma psicóloga foram treinados por uma pesquisadora vinculada ao projeto maior para procederem à aplicação coletiva dos instrumentos. $\mathrm{O}$ treinamento constou de leitura conjunta e discussão do Protocolo de Aplicação Coletiva (Anexo F), seguidas de atividades de role-play, nas quais foram simuladas situações envolvendo perguntas e dúvidas. Além disso, foram treinados quanto ao procedimento do Protocolo de Coleta de Dados.

\subsubsection{Procedimentos}

Nesta seção, serão descritos o processo de coleta de dados e análise dos mesmos, ou seja, a forma como foram codificados e tratados estatisticamente. 


\subsubsection{Coleta de dados}

Em uma primeira instância, todos os instrumentos que faziam parte do estudo maior, do qual esta pesquisa é parte integrante, foram aplicados em situação coletiva de sala de aula, evitando-se dias de provas e sendo priorizadas as disciplinas com o maior número de alunos matriculados. Contou-se sempre com a presença de dois aplicadores de modo a garantir a pronta assistência aos sujeitos quando solicitado.

Após contato e autorização com o docente responsável pela disciplina, dirigiu-se diretamente aos alunos, informando-os sobre os objetivos do estudo e convidando-os a participar. Em seguida, os alunos receberam o TCLE (Anexo B), que foi lido pausadamente em voz alta pelo aplicador e acompanhado pelos estudantes em cópia impressa. Após o término da leitura, foi pedido para permanecerem na sala de aula apenas os que concordassem em participar do estudo. Estes assinaram o TCLE, entregando uma cópia ao aplicador e permanecendo com a outra cópia. Aqueles que não concordaram em participar do estudo, por qualquer motivo, foram dispensados da atividade. Permaneceram na sala de aula apenas os estudantes que assinaram o TCLE.

Os estudantes receberam, então, um caderno contendo os instrumentos na seguinte ordem: Questionário de Identificação, SPIN, SSPS (Self Statements During Public Speaking Scale), BAI (Inventário de Ansiedade de Beck) e IHS-Del-Prette. Solicitou-se que não abrissem o caderno até que todos o tivessem recebido. O aplicador informou que as instruções de cada instrumento estavam especificadas por escrito, que o tempo para responder era livre, e que na medida em que terminassem poderiam entregar o caderno e deixar a sala. Quando tivessem dúvida deveriam levantar a mão para que fossem atendidos individualmente pelo aplicador ou pelo auxiliar.

As sessões de aplicação variaram de no mínimo 4 a 18 minutos (média = 11 minutos) e ao máximo de 7 a 40 minutos (média = 24 minutos). Não foi anotado o tempo individual, registrando-se apenas o tempo gasto pelo primeiro e pelo último sujeito a entregar o material. 
Observou-se a ocorrência de poucas dúvidas durante a aplicação dos instrumentos. As perguntas mais freqüentes feitas aos avaliadores durante o processo de aplicação relacionaram-se, em sua maioria, à especificação da procedência, à curiosidade sobre o TAS e às dúvidas quanto a referir ou não os medicamentos que faziam uso.

Posteriormente, 100 sujeitos do projeto maior foram randomicamente selecionados a partir de seus escores na Mini-SPIN. 57 sujeitos com Mini-SPIN positiva (mínimo de seis pontos) e 43 com Mini-SPIN negativa (zero a um ponto) foram avaliados pela Entrevista Clínica Estruturada - Módulo F (SCID/DSM-IV) (Del-Ben et al., 2001), objetivando-se a confirmação diagnóstica do TAS. Deste procedimento resultou uma amostra de 86 sujeitos, agrupados como caso $(\mathrm{N}=45)$ e não-caso de TAS $(\mathrm{N}=41)$, e que contavam com os dois instrumentos, objeto deste estudo, preenchidos corretamente.

As duas amostras resultantes dos procedimentos de coleta de dados acima descritos (uma com 1006 e a outra com 86 sujeitos) foram empregadas para verificar as propriedades psicométricas do IHS-Del-Prette.

\subsubsection{Codificação e Tratamento dos Dados}

Os dados obtidos com a aplicação do IHS-Del-Prette e SPIN foram codificados manualmente e alocados em um banco de dados, criado em uma planilha eletrônica do Excel disponível no programa computacional do Windows. Para posterior análise, este banco de dados foi convertido para o pacote estatístico SPSS (Statistical Package for Social Sciences) para o Windows, versão 10. Na codificação dos dados referentes ao IHS, procedeu-se a uma inversão das pontuações dos itens $2,8,9,13,17,18,19,22,23,24,26,33,34,36$ e 37 para a obtenção dos escores, por serem compostos por fraseado negativo. Desta forma, transformouse o 0 em 4, o 1 em 3, o 3 em 1, o 4 em 0, e o 2 não teve alteração. Nestes casos, as freqüências maiores são avaliadas como indicadoras de déficits e freqüências menores como indicadoras de recursos em habilidades sociais apresentadas pelos sujeitos. 
Este delineamento empregou muitas provas paramétricas que requerem que as variáveis estudadas se ajustem à curva normal. Assim, o Teste de Kolmogorov-Smirnov foi utilizado para verificar se o conjunto de dados referente ao IHS-Del-Prette possuía distribuição normal. Este teste serve para comparar a distribuição empiricamente observada com a distribuição normal teórica, sendo, portando, uma prova de qualidade de ajuste.

A análise dos dados sociodemográficos e clínicos da amostra estudada foi realizada por meio de testes estatísticos descritivos e paramétricos. Para a comparação de grupos foram empregados os Testes t de Student e Qui-Quadrado $\left(\chi^{2}\right)$.

Os testes estatísticos descritivos e paramétricos também foram utilizados para a análise dos indicadores psicométricos do IHS-Del-Prette.

No tocante à frequiência dos itens, foram calculados os escores médios e desviospadrões para cada item do IHS-Del-Prette. Obtiveram-se também as porcentagens de pontuação ou freqüência nos escores de 0 a 4 para cada item deste instrumento.

Os postos percentílicos foram obtidos a partir da distribuição dos escores totais dos sujeitos, conforme o gênero a que pertenciam. Apresentar-se-á o valor de uma pontuação direta, expressa em escores brutos, e a sua transformação em outra pontuação de mais fácil interpretação, expressa em percentis.

A interpretação (classificação) do repertório de habilidades sociais dos sujeitos foi realizada de acordo com os percentis obtidos a partir de seus escores brutos, em conformidade com o modelo proposto por Del Prette e Del Prette (2001) no estudo de normatização do instrumento. Neste sentido, para a avaliação do repertório de habilidades sociais dos sujeitos, assumiu-se que a classificação “repertório deficitário em habilidades sociais” obtida por um indivíduo, corresponde aos valores que ficam abaixo de 25\%; a classificação "bom repertório de habilidades sociais (abaixo da mediana)”, aos valores situados abaixo de 50 até 25\%; a classificação “bom repertório de habilidades sociais (acima da mediana)”, aos valores 
abaixo de 75 e acima de 50\%; a classificação "repertório bastante elaborado de habilidades sociais", aos valores na faixa de 100 até $75 \%$; e a classificação “repertório mediano" à posição central do valor na distribuição, indicando que o indivíduo apresenta um repertório médio de habilidades sociais tal como a maioria dos respondentes do seu grupo amostral.

Visando identificar os itens do IHS-Del-Prette com maior poder discriminativo entre os sujeitos com e sem TAS $(\mathrm{N}=1006)$, avaliaram-se quais itens apresentavam diferenças maiores nos escores médios entre os grupos (caso e não-caso de TAS). Observou-se também a porcentagem de pontuação para cada item nos escores menores ou iguais a 1 .

Para determinar a consistência interna do IHS-Del-Prette, o cálculo do alfa de Cronbach foi conduzido tanto para os escores totais obtidos pelos participantes no instrumento como um todo, quanto para os escores parciais obtidos para cada fator medido por ele. Também foram obtidas correlações comparando cada item com os demais itens restantes que compõem a escala como um todo e os fatores isolados. Computaram-se ainda os coeficientes alfa de Cronbach para os grupos caso e não-caso de TAS, nos quais os sujeitos foram agrupados com base nos escores da Mini-SPIN.

No que diz respeito à validade concorrente entre os instrumentos empregados, os escores do IHS-Del-Prette foram comparados com os escores do SPIN e Mini-SPIN, utilizando-se o coeficiente de Correlação Momento-Produto de Pearson. O coeficiente de correlação entre o IHS e SPIN foi elevado ao quadrado para verificar quanta variância, em termos percentuais, as duas variáveis compartilham. Foram obtidas, ainda, correlações entre: (a) os itens individuais do IHS com o escore total e itens individuais do SPIN; e (b) o escore total do IHS e de seus respectivos fatores com as subescalas do SPIN. Para determinar se a correlação da validade concorrente entre o IHS e SPIN era significativamente maior do que a correlação da validade entre o IHS e Mini-SPIN, foi aplicada a fórmula recomendada por 
Cohen e Cohen (1975) para testar a significância da diferença entre as duas correlações encontradas dentro da mesma amostra.

Adotaram-se os seguintes critérios para classificar as correlações obtidas entre as escalas totais e subescalas em: nula $(r=0)$; muito baixa $(r<0,20)$; baixa $(r=0,20-0,39)$; moderada $(r=0,40-0,59)$; alta $(r=0,60-0,79)$; muito alta $(r=0,80-0,99)$; e perfeita $(r=$ 1) (BISQUERRA; SARRIERA; MARTÍNEZ, 2004). Estes critérios foram usados para avaliar tanto as correlações Momento-Produto de Pearson quanto as de Spearman.

Já para classificar as correlações interitens e os coeficientes alfa de Cronbach obtidos nas análises, foram empregados os seguintes critérios: boa $(r=0,20-0,30$ e $\alpha=0,70-0,80$, respectivamente); moderada $(r=0,10-0,19$ e $\alpha=0,60-0,69$, respectivamente); e fraca $(r<$ 0,10 e $\alpha<0,6$, respectivamente) (ROBINSON; SHAVER; WRIGHTSMAN, 1991).

Para o estudo da validade discriminativa do IHS-Del-Prette ou validade do instrumento para grupos conhecidos (VAN DAM-BAGGEN; KRAAIMAAT, 1999), foi obtida a curva ROC (Receiver Operating Characteristic Curve), visando examinar os pontos de corte que correspondem ao diagnóstico do TAS, distinguindo assim sujeitos com TAS daqueles sem o transtorno, tomando como padrão-ouro a Entrevista Clínica Estruturada (SCID-IV/DSM-IV). Foram determinados também os escores de corte que: (a) maximizam conjuntamente a sensibilidade, a especificidade, valor preditivo positivo, valor preditivo negativo, minimizando a taxa de classificação incorreta do IHS; (b) maximizam a sua sensibilidade sem, entretanto, reduzir a especificidade, valor preditivo positivo e valor preditivo negativo a níveis baixos; e (c) maximizam a especificidade sem reduzir a sensibilidade, valor preditivo positivo e valor preditivo negativo a níveis baixos.

Ainda visando a avaliação da validade discriminativa do IHS-Del-Prette, os escores totais do IHS para os sujeitos agrupados como casos e não-casos de TAS foram comparados por meio do Teste t. Os sujeitos agrupados como casos e não-casos foram submetidos à 
confirmação diagnóstica por meio da SCID. Esse mesmo teste foi aplicado sobre os escores médios de cada um dos itens obtidos para ambos os grupos, objetivando verificar se demonstrariam diferenças significativas nos itens isolados. Ainda com relação a esse aspecto, as normas de classificação do repertório de habilidades sociais do estudo original (DEL PRETTE; DEL PRETTE, 2001) foram utilizadas para comparar as avaliações do repertório exibido pelos dois grupos, de acordo com o gênero dos sujeitos, com o intuito de examinar as diferenças.

O tamanho do efeito $(d)$ foi calculado dividindo-se a diferença entre as médias de duas condições consideradas pela média dos seus desvios-padrões. Assim, o tamanho do efeito mede o quanto duas médias diferem em termos de desvios-padrões. Adotaram-se as recomendações de Cohen (1988) para especificar a medida do tamanho do efeito em: pequeno $(0,20 \leq d<0,50)$, médio $(0,50 \leq d<0,80)$ ou grande $(d \geq 0,80)$.

Também foram identificados os itens do IHS-Del-Prette com maior poder discriminativo entre os sujeitos dos grupos caso e não-caso de TAS $(\mathrm{N}=86)$, que receberam confirmação diagnóstica pela SCID, adotando-se o mesmo procedimento descrito acima para os grupos avaliados somente pela Mini-SPIN.

A análise fatorial (AF) do IHS-Del-Prette foi realizada pelo método de análise dos componentes principais (ACP) que analisa toda a variância dos dados, tanto a compartilhada quanto a exclusiva. A técnica de rotação ortogonal Varimax, com normalização de Kaiser, foi empregada para agrupar os itens (variáveis) com cargas altas em um único fator, permitindo assim que cada fator estivesse fortemente relacionado com alguns itens, mas fracamente relacionado com outros.

No que diz respeito à comparação de variáveis, adotaram-se análises tanto univariada (ANOVA) como multivariada (MANOVA). Testes post hoc para as diferenças significativas encontradas foram executadas, empregando-se o Teste t. Para a obtenção dos escores fatoriais, 
somaram-se os pontos obtidos pelos sujeitos nos itens de cada fator e dividiu-se pelo número total de itens que compunha cada fator.

Com exceção dos Testes de Kolmogorov-Smirnov e M de Box, adotou-se o nível de significância de $p \leq 0,05$ para todos os demais testes estatísticos aplicados. Os Testes de Kolmogorov-Smirnov e B de Box assumem um nível de significância de $p \geq 0,05$. 


\subsection{Estudo 2 - Empírico (Teste de Simulação de Falar em Público - TSFP)}

\subsubsection{Sujeitos}

Participaram neste estudo 26 alunos universitários provindos da Faculdade de Medicina de Ribeirão Preto (FMRP) e Faculdade de Filosofia, Ciências e Letras de Ribeirão Preto (FFCLRP) da Universidade de São Paulo, selecionados a partir da amostra do estudo maior, do qual este faz parte. Para a composição da amostra deste estudo, os nomes de 145 sujeitos do estudo maior foram alocados randomicamente em dois grupos, a saber:

- $\underline{\text { Caso: }}$ : composto por 64 sujeitos que obtiveram resposta positiva na escala de auto-avaliação Mini-SPIN (mínimo de seis pontos nos três itens - 6, 9, 15 -, que a compõem) e com diagnóstico clínico de TAS, avaliados por meio da SCID;

- $\underline{\text { Não-caso: }}$ constituído por 71 sujeitos que obtiveram resposta negativa na Mini-SPIN (zero a um ponto nos itens que a compõem) e sem diagnóstico clínico de TAS.

Uma tabela de números aleatórios foi utilizada para a designação dos sujeitos aos grupos. Para tal, adotaram-se os seguintes critérios de inclusão: localização dos sujeitos, disponibilidade para participar do estudo e para comparecer ao Hospital das Clínicas (HC) da FMRP da USP em dia e horário previamente agendado para a realização das atividades previstas. Foram excluídos aqueles sujeitos que apresentassem as seguintes comorbidades psiquiátricas: (a) quadros psicóticos, (b) depressão atual, (c) depressão recorrente, (d) transtorno alimentar atual, (e) abuso de substâncias atual, (f) transtorno obsessivo-compulsivo atual, (g) dependência de substâncias atual, (h) episódio hipomaníaco, e (i) transtorno do pânico.

Aplicando-se sistematicamente os critérios de exclusão, foi obtida uma amostra de 26 estudantes universitários, entre 19 e 25 anos, de ambos os gêneros, independentemente do nível socioeconômico, matriculados em diversos cursos de graduação oferecidos no campus de Ribeirão Preto da Universidade de São Paulo, e que aceitaram participar do estudo, 
assinando os Termos de Consentimento Livre e Esclarecido (TCLE - Anexo G e H). Os sujeitos deste estudo foram alocados em dois grupos, caso e não-caso, por pareamento quanto ao gênero e número de indivíduos com e sem diagnóstico de TAS.

Vale a pena ressaltar que em função da necessidade de realização das atividades de coleta de dados no Laboratório de Psicofarmacologia do HC da FMRP-USP, por uma questão de praticidade, foram excluídos os sujeitos procedentes da UNIFRAN incluídos no Estudo 1.

\subsubsection{Instrumentos e Equipamentos}

No processo de seleção e identificação dos sujeitos que constituíram os dois grupos foram utilizados instrumentos de avaliação específicos e de avaliação clínica sistemática para o diagnóstico de TAS.

Os seguintes instrumentos de avaliação e materiais foram empregados na avaliação dos sujeitos:

- Mini-SPIN - instrumento auto-aplicável já descrito no Estudo 1.

- Inventário de Habilidades Sociais (IHS-Del-Prette) - instrumento de auto-relato já descrito no Estudo 1.

- Entrevista Clínica Estruturada para o DSM-IV (SCID - versão clínica; Del-Ben et al., 2001) - já descrita anteriormente. Neste estudo foram utilizados o Módulo de Ansiedade

(Módulo F) e o Critério A de cada um dos outros módulos, durante uma entrevista telefônica, visando a confirmação diagnóstica do TAS e a identificação da presença de comorbidades. Posteriormente, o Módulo F foi aplicado novamente durante uma entrevista individual "ao vivo".

- Teste de Simulação de Falar em Público (TSFP): desenvolvido por McNair et al. (1982) e modificado por Guimarães, Zuardi e Graeff (1988), o teste consiste em solicitar ao sujeito 
que prepare um discurso e depois o apresente em frente a uma câmara de vídeo que estará gravando o seu desempenho.

Visando a consecução dos objetivos deste trabalho de pesquisa, além destes instrumentos, foram utilizados os seguintes equipamentos e recursos durante o período de coleta de dados: uma filmadora Panasonic S-VHS Reporter / Modelo AG-456, fitas de vídeo EMTEC T-120, televisão Panasonic Stereo-SAP / Modelo TC-29A10, e vídeo cassete quatro cabeças Philips VHS HQ / Modelo VR 354.

Para a análise dos dados, os seguintes equipamentos e recursos foram empregados: televisão Toshiba 21' Stereo MTS / Modelo TV2157MFS U17, DVD Player Samsung Modelo P366 / XAZ, e um Protocolo de Registro das Filmagens Realizadas (Apêndice A).

\subsubsection{Treinamento de avaliadores externos}

Dois alunos de graduação em Psicologia foram treinados pelo pesquisador para procederem à análise independente de 10 sessões de observação (38,5\% do total), visando o cálculo do índice de concordância entre eles. Cada avaliador externo analisou o conteúdo das filmagens de cinco sujeitos. O treinamento constou de: (a) um curso básico sobre observação e técnicas de registro (Apêndice B), por meio de metodologia expositiva e dialogada; (b) leitura e discussão do Protocolo de Registro das Filmagens Realizadas e das definições das categorias comportamentais do TSFP; (c) discussão quanto à padronização do procedimento de análise para algumas categorias (conteúdo negativo, descontinuidade da fala, rigidez corporal, inquietação e atitude de intenção) com o intuito de evitar desacordos em relação ao registro de sua ocorrência; (d) abordagem das questões éticas relacionadas à necessidade de preservar a imagem e identidade dos sujeitos; e (e) análise conjunta da sessão de filmagem de um sujeito, cujo nome foi aleatoriamente selecionado por meio de sorteio. Durante o 
treinamento, os índices de concordância obtidos entre o pesquisador e cada um dos avaliadores foram de 96,0 e $94,8 \%$, respectivamente.

\subsubsection{Procedimentos}

Os procedimentos empregados para a coleta e análise de dados deste estudo serão descritos a seguir.

\subsubsection{Coleta de dados}

Os sujeitos selecionados para participar deste estudo foram previamente contatados por telefone por um psiquiatra e avaliados quanto ao Critério A da SCID-IV, objetivando verificar a ausência ou presença de comorbidades. Aos sujeitos que não apresentaram comorbidades psiquiátricas consideradas pelos critérios de exclusão citados acima, foi perguntado sobre a disponibilidade de continuar participando do estudo. Aos que concordaram, solicitou-se comparecer no HC da FMRP-USP, em dia e horário previamente agendado de acordo com a disponibilidade individual, para participarem de uma entrevista individual para confirmação diagnóstica e, posteriormente, de uma situação experimental considerada um teste de ansiedade. Na ocasião da entrevista, os sujeitos preencheram o IHSDel-Prette e outros instrumentos que foram objetos de estudo das demais pesquisas vinculadas ao projeto maior, em conformidade ao TCLE assinado anteriormente (Anexo B). Os dados referentes à Mini-SPIN foram aproveitados da coleta do Estudo 1.

A aplicação do TSFP foi realizada por duas assistentes de pesquisa, a saber: uma psiquiatra, previamente treinada, e uma técnica de laboratório com ampla experiência na aplicação do procedimento. No dia agendado para o teste, explicaram-se os objetivos do teste a ser realizado. Em seguida, entregaram-se duas vias do Termo de Consentimento Livre e Esclarecido (TCLE) - Parte 1 (Anexo G) ao sujeito para que lesse e assinasse concordando com a sua participação nas etapas seguintes do estudo maior do qual este faz parte, 
devolvendo uma via à assistente de pesquisa e permanecendo com a outra. Somente prosseguiu-se com aqueles sujeitos que devidamente assinaram o TCLE.

Depois, pediu-se ao sujeito que aguardasse por um período de 30 minutos na própria sala, permanecendo deitado, procurando relaxar-se. Foram oferecidas revistas com conteúdo neutro (“Caras", "Quem”, “Contigo”) com este propósito e a assistente de pesquisa retirou-se da sala. Após o término do período, a assistente de pesquisa retornava à sala e entregava ao sujeito duas vias do TCLE - Parte 2 (Anexo H), para que lesse e assinasse concordando em continuar a participar do procedimento. Novamente, somente prosseguiu-se com aqueles sujeitos que devidamente assinarem o TCLE. Iniciou-se, então, o procedimento do TSFP, conforme proposto por Guimarães, Zuardi e Graeff (1988).

A sessão experimental foi conduzida em uma sala com atenuação sonora e temperatura controlada. O sujeito sentava-se em frente a uma câmara de vídeo e assistia a um vídeotape pré-gravado com instruções sobre a tarefa que teria que desempenhar. Recebia a seguinte instrução: "Você terá dois minutos para preparar um discurso, de quatro minutos, sobre o sistema de transporte de sua cidade, que será gravado e posteriormente analisado por um psicólogo". Foi computado o tempo de dois minutos para a elaboração do discurso e, ao término, solicitado ao sujeito que o iniciasse, com a saída da assistente de pesquisa da sala. Transcorrido os quatro minutos, solicitou-se que o sujeito permanecesse no ambiente deitado, procurando relaxar, encerrando-se a sessão experimental. As sessões foram filmadas para posterior análise do desempenho dos sujeitos. Enquanto o sujeito proferia seu discurso frente à câmara, seu desempenho era simultaneamente transmitido na tela da televisão, posicionada também a sua frente, para que pudesse acompanhar o seu desempenho e, assim, aumentar a veracidade da situação. 


\subsubsection{Codificação e Tratamento dos Dados}

\subsection{Proposição do Protocolo de Registro para a Análise das Filmagens Realizadas}

A seguir serão descritos os passos para a proposição do protocolo de registro utilizado na codificação e análise dos dados referentes às filmagens do TSFP (Apêndice A).

Em um primeiro momento, procedeu-se ao levantamento de estudos empíricos relativos à temática "avaliação dos marcadores comportamentais de ansiedade" com base em uma busca sistemática na literatura, compreendendo o período de 2000 a 2006, usando os indexadores Lilacs, Scielo, Medline e PsycINFO, por meio do cruzamento de quase todas as combinações possíveis entre as palavras-chave exibidas na Tabela 3.

Tabela 3 - Palavras-chave utilizadas na busca sistemática de artigos empíricos abordando a temática "avaliação comportamental da ansiedade de falar em público" na literatura indexada

\begin{tabular}{lll}
\hline Primeiro grupo de palavras & Segundo grupo de palavras & Terceiro grupo de palavras \\
\hline Behavioral assessment & Public-speaking & Anxiety \\
Social performance & Speech & Social phobia \\
Performance & Speech disturbances & Social anxiety \\
Social skills & Public speaking anxiety & Social anxiety disorder \\
\multicolumn{1}{c}{-} & Simulated speech & - \\
\hline
\end{tabular}

As palavras performance e social skills, da primeira coluna da Tabela 3, não foram cruzadas com anxiety, social phobia, social anxiety e social anxiety disorder, da terceira coluna, por fazerem referência a termos muito amplos que implicariam na obtenção de resultados com focos muito diferentes do pretendido pelo procedimento de busca.

As categorias propostas inicialmente foram geradas a partir do exame de três fontes de informações, a saber: (a) artigos listados no procedimento de busca que se enquadravam no enfoque da temática mencionada anteriormente (HARB et al., 2003; LESNIAK-KARPIAK; MAZZOCCO; ROSS, 2003; SAWYER; BEHNKE, 2002; ZOHAR; LIVNE; FINE, 2003); (b) material já conhecido pelo pesquisador (AGUIAR, 2006; BAKER; EDELMANN, 2002; 
FYDRICH et al., 1998; HOFMANN et al., 1997; KNAPP, 1982; NORTON; HOPE, 2001; PEASE; PEASE, 2005; WENZEL et al., 2005); e (c) criação espontânea pelo pesquisador. Na leitura dos artigos arrolados, pretendeu-se identificar categorias em geral empregadas na codificação da ansiedade associada ao falar em público ou em situações típicas de interação social. Em seguida, as categorias criadas e suas respectivas definições foram analisadas com outro pesquisador para a tomada de decisão acerca de sua pertinência e relevância para comporem o protocolo, considerando a natureza da tarefa desempenhada pelos participantes no estudo em questão. Quando necessário, as definições propostas foram reformuladas de modo a permitir maior precisão e clareza, eliminado possíveis sobreposições de categorias e padronizando as definições.

Com base nestes passos, elaborou-se uma pró-forma do protocolo de registro e procedeu-se a uma testagem piloto de dois casos visando a verificação de sua adequação para a categorização dos desempenhos observados e da necessidade de ajuste das categorias propostas. Desse processo, resultou o sistema de classificação de categorias para a análise dos dados coletados.

As categorias criadas para o protocolo de registro foram definidas e agrupadas em três classes de marcadores comportamentais, a saber: (a) marcadores verbais; (b) marcadores paralingüísticos; e (c) marcadores não-verbais que compreenderam as posturas corporais, gestos e expressões faciais apresentadas pelos sujeitos. Embora os elementos paralingüísticos do desempenho dos sujeitos possam ser considerados como uma subclasse dos marcadores não-verbais, ambos os casos foram caracterizados independentemente como classes distintas visando apenas cumprir finalidades didáticas e de praticidade no processo de análise. Cada definição proposta descreve um desempenho, verbal e/ou não-verbal, específico exibido pelos sujeitos. 
Como partes integrantes do protocolo, ainda constavam: (a) uma avaliação geral do desempenho de cada sujeito, ou seja, de sua habilidade de falar em público; e (b) o tempo de duração do discurso e de latência para responder (iniciar o discurso) apresentada por cada sujeito.

As definições das categorias de análise propostas encontram-se a seguir: 


\section{DEFINIÇÃO DAS CATEGORIAS COMPORTAMENTAIS DO TSFP}

\section{A. Marcadores verbais:}

A.1. Conteúdo negativo: ação verbal do sujeito de fazer declarações, relatos ou comentários negativos relacionados ao tema do discurso;

A.2. Repetição de conteúdo: ação verbal do sujeito de repetir alguma sentença ou assunto proferido anteriormente;

A.3. Descontinuidade da fala: ação verbal do sujeito de fazer declarações sem conexão alguma entre elas (entre uma fala e outra) ou de interromper sentenças (frases ou orações) no contínuo da tarefa, tornando-as sem sentido ou significado, refletindo assim um discurso menos contínuo e mais truncado;

A.4. Uso de jargões: ação verbal do sujeito em pronunciar expressões de uso informal e popular (exemplos: "né”, "tipo assim", "sabe”, "é tudo de bom”, e outras expressões do gênero).

\section{B. Marcadores paralingüísticos:}

B.1. Pausas: ação não-verbal do sujeito de interromper o fluxo do discurso (episódio de silêncio) durante um intervalo igual ou superior a 3 segundos (pausas silenciosas), ou emitir sons de hesitação no transcorrer do discurso, tais como: “ãnnn...", "é-é-é...", "hummm", entre outros (pausas preenchidas);

B.2. Risos inapropriados: ação não-verbal do sujeito de abrir a boca em sentido horizontal, tornando os dentes visíveis e os lados (cantos) de sua boca dirigidos para cima sem coerência com o conteúdo verbal;

B.3. Velocidade da fala inapropriada: ação não-verbal do sujeito de falar excessivamente rápido ou devagar ou com uma velocidade variante (alterna velocidade de fala apropriada e inapropriada); 
B.4. Intensidade da voz inapropriada: ação não-verbal do sujeito de falar com um volume de voz excessivamente baixo (é ligeiramente ouvido) ou alto (pode causar algum desconforto auditivo para o ouvinte) ou volume variante (alterna intensidade de voz apropriada e inapropriada).

\section{Marcadores não-verbais (posturas corporais, gestos e expressões faciais):}

C.1. Evitação da tarefa: ação não-verbal do sujeito de permanecer em silêncio (sem verbalizar qualquer palavra ou frase) durante o tempo todo, não se engajando na execução da tarefa para a qual foi instruído, ou durante um intervalo de tempo igual ou superior a 20 segundos, contando após sinal dado pela auxiliar de pesquisar para dar início ao discurso;

C.2 Rigidez corporal: ação não-verbal do sujeito de sentar-se tenso ou rígido, com mudanças mínimas nas posições corporais, com a seguinte variação: agarrar firmemente os braços da cadeira com as mãos;

C.3. Inquietação: ação não-verbal do sujeito de mudar frequiente ou abruptamente as posições corporais, tais como balançar-se ou inclinar-se (curvar-se) em direções diferentes; ou emitir movimentos pequenos e irrequietos (movimentos repetidos das extremidades superiores de maneira rápida e involuntária), incluindo: contorcer as mãos, roçar um dedo sobre o outro ou sobre o braço da poltrona, enrolar os cabelos, brincar com as roupas ou quaisquer outros objetos de uso pessoal (por exemplo, presilha de cabelo), balançar o joelho ou uma das pernas e/ou bater levemente o pé (no mínimo três movimentos de vai-e-vem);

C.4. Atitude de intenção: ação não-verbal do sujeito de sentar-se na metade anterior da cadeira ou inclinar o tronco para frente com as mãos no joelho ou agarrando a cadeira com as duas mãos; 
C.5. Desvio do olhar: ação não-verbal do sujeito de interromper o comportamento de olhar em direção à câmara ou evitar completamente esta resposta durante um intervalo igual ou superior a 10 segundos;

C.6. Movimentos faciais de desconforto: ação não-verbal do sujeito de morder os lábios ou franzir a testa;

C.7. Barreiras: ação não-verbal do sujeito de apresentar o comportamento de cruzar os membros superiores ou inferiores (braços ou pernas), mantendo-os um sobre o outro; ajustar a pulseira do relógio; bater ou esfregar as mãos, ou mesmo juntá-las ficando com os dedos entrelaçados; ou fazer quaisquer outros movimentos que deixem o braço atravessado na frente do corpo.

\section{Avaliação geral do desempenho}

Trata-se de uma avaliação (impressão geral) subjetiva do observador em relação à habilidade de falar em público exibida pelo sujeito em uma escala de 0 (extremamente inadequada) a 10 (muito adequada).

\section{E. Duração total do discurso e latência para responder:}

E.1. Latência da resposta: tempo despendido pelo sujeito em silêncio (sem verbalizar qualquer palavra ou frase) para dar início à tarefa após sinal dado pela auxiliar de pesquisa, ou seja, o tempo médio (em segundos) entre o término da resposta da auxiliar de pesquisa e o início da resposta do participante;

E.2. Tempo total de fala: duração total de tempo despendido pelo sujeito falando, permanecendo engajado na tarefa para a qual foi instruído; 


\subsection{Procedimento de categorização e análise das sessões experimentais do TSFP}

Visando preservar os dados originais e facilitar o seu processo de análise, optou-se pela conversão das filmagens do TSFP realizadas em VHS para material de vídeo digital (DVD).

O procedimento de categorização e análise das sessões experimentais seguiu os passos relatados a seguir.

Primeiramente, o conteúdo das filmagens foi observado e analisado pelo pesquisador que desconhecia o grupo de origem dos sujeitos. A partir das filmagens de cada sujeito, uma série de ações foi conduzida, a saber: (a) verificaram-se as ocorrências dos marcadores comportamentais, denominados de categorias, registrando-se as suas freqüências; (b) realizouse uma avaliação geral da sua habilidade de falar em público; e (c) computaram-se a duração total do seu discurso e de sua latência para responder. Todas estas ações foram realizadas utilizando-se o protocolo de registro.

A avaliação geral da habilidade de falar em público exibida por cada sujeito foi feita em uma escala variando de 0 (extremamente inadequada) a 10 (muito adequada). Para efeitos de classificação do desempenho, a escala proposta para a avaliação da habilidade de falar em público apresentada pelo sujeito em questão seguiu a seguinte gradação:

- $0-2,5=$ carência de habilidades sociais apropriadas;

- 2,6 - 5 = nível mínimo de habilidades sociais apropriadas;

- 5,1 - 7,5 = nível moderado de habilidades sociais apropriadas;

- 7,6 - 10 = nível alto de habilidades sociais apropriadas.

Algumas observações serão feitas em relação ao procedimento adotado para a categorização dos marcadores verbais exibidos pelos sujeitos deste estudo. O conteúdo do discurso dos sujeitos foi transcrito manualmente e depois digitado para possibilitar a análise dos marcadores verbais, principalmente da categoria descontinuidade da fala, devido à 
influência de vários fatores que atuaram no ambiente durante a coleta de dados e que, posteriormente, impossibilitariam o acompanhamento do fluxo contínuo da fala dos sujeitos. Estes fatores constituíram-se de: (a) ruído produzido pelo próprio equipamento de filmagem; (b) ruídos externos ao laboratório, onde o trabalho de coleta foi realizado, provindos geralmente da enfermaria de Psiquiatria ao lado; e (c) características vocais idiossincráticas de alguns sujeitos, como por exemplo, velocidade da voz excessivamente rápida ou intensidade de voz excessivamente baixa, que demandavam retroceder o vídeo várias vezes para a compreensão do que estava sendo dito.

Considerando as divergências quanto à ocorrência desse mesmo marcador durante o treinamento de avaliadores devido ao caráter subjetivo de sua definição, e a necessidade de padronização do procedimento de análise, procedeu-se uma apreciação tanto sintática quanto gramatical do conteúdo do discurso dos sujeitos para a avaliação desta categoria, salvo os casos de falta de concordância verbal. Neste caso, assumiu-se essa restrição com o intuito de tornar a tarefa de categorização mais objetiva e, portanto, mais passível de concordância em relação a sua ocorrência.

Para a categorização de conteúdo negativo, não foram considerados como tal os acréscimos que cumpriam a função de explicar ou corrigir uma afirmação anterior já computada como sendo de caráter negativo. Exemplos: “(...) os motoristas, na maior parte das vezes, não se encontram muito preparados pra, pra poder estar executando a tarefa porque parece que eles são bastante mal educados, eles dirigem sem a menor atenção, de forma muito agressiva, não respeitam muito as leis de trânsito"; "Essa empresa, ela facilita muito pouco a nossa vida porque ela só aceita o pagamento em dinheiro, de tal forma que não aceita cartão ou outro, outra forma de pagamento"; "Mas o trânsito não é muito bem organizado, também por causa dos motoristas que não respeitam muito bem as normas de trânsito"; "Outro defeito 
que eu vejo é que pelo menos o ônibus que eu preciso tem poucas, poucas linhas que, que fazem (...). Ou melhor, são três linhas, só que passam no mesmo horário".

Com relação à avaliação geral do desempenho dos sujeitos, procurou-se levar em consideração todos os elementos analisados até o momento antes de realizá-la, ou seja, a presença e freqüência de todos os marcadores comportamentais de ansiedade levantados, assim como a duração total do discurso e a latência para iniciá-lo, além de uma comparação de desempenho entre os sujeitos.

Procedeu-se a análise independente de 10 sessões de observação (38,5\% do total) por dois avaliadores externos, previamente treinados, visando o cálculo do índice de concordância entre eles e o pesquisador. Cada avaliador analisou o conteúdo das filmagens de cinco sujeitos, selecionadas randomicamente por meio de sorteio. Os índices gerais de concordância obtidos foram de $82,4 \%$ com o primeiro avaliador e $83,0 \%$ com o segundo avaliador.

\subsection{Análise estatística dos dados coletados}

Os dados obtidos com a análise do conteúdo das filmagens foram codificados manualmente e alocados em um banco de dados criado em uma planilha do pacote estatístico SPSS. A seguir, as análises estatísticas realizadas com esses dados serão relatadas.

Para a comparação entre os grupos, considerou-se a freqüência de ocorrência dos marcadores comportamentais e suas respectivas classes, a avaliação geral do desempenho, a duração do discurso e a latência para responder apresentada pelos sujeitos. Procedeu-se a comparação por meio do Teste de Mann-Whitney, adotando-se o nível de significância de $p \leq$ 0,05. Este teste foi realizado depois de testar a normalidade destas variáveis por meio do Teste de Shapiro-Wilk.

Visando permitir uma melhor visualização das diferenças pouco significativas encontradas entre os grupos, foi apresentada: (a) a freqüência mínima e máxima de ocorrência para cada um dos marcadores comportamentais e suas respectivas classes; (b) o tempo 
mínimo e máximo em relação à latência para responder e ao tempo total de fala; e (c) a média e o desvio-padrão de todas essas categorias e classes dentro de cada grupo.

Com o intuito de verificar o efeito do tempo sobre cada um dos marcadores comportamentais de ansiedade e suas respectivas classes ao longo do TSFP, comparando-se os grupos caso e não-caso, foi realizada uma ANOVA de medidas repetidas com um fator. Foram selecionados dois momentos para essa análise, o início (primeiro minuto) e o final do discurso (quarto minuto), sendo denominados de momento 1 (M1) e momento 2 (M2), respectivamente. No caso em que a diferença entre estes dois momentos não foi significativamente a mesma para ambos os grupos, procedeu-se a testes de Wilcoxon para os grupos separadamente, visando identificar o grupo que apresentou a diferença.

Quanto à avaliação geral do desempenho exibido pelos sujeitos no TSFP, computou-se o percentual de sujeitos, agrupados como caso e não-caso, em cada nível de classificação do repertório de habilidades sociais de falar em público.

Correlações bivariadas de Spearman foram efetuadas entre todas as categorias de análise, entre estas categorias e as classes mais amplas, e entre as classes para verificar as possíveis relações ou variações concomitantes existentes entre elas.

Em concordância com outro pesquisador, foram selecionados os itens do IHS-DelPrette que melhor se ajustassem à habilidade de falar em público, a saber: itens 9 ("Evito fazer exposições ou palestras a pessoas desconhecidas”), 11 ("Em uma sala de aula ou reunião, se o professor ou dirigente faz uma afirmação incorreta, eu expresso meu ponto de vista"), 14 ("Faço exposição (por exemplo, palestras) em sala de aula ou no trabalho, quando sou indicado(a)"), 16 ("Em um grupo de pessoas conhecidas, se não concordo com a maioria, expresso verbalmente minha discordância") e 29 ("Na escola ou no trabalho, quando não compreendo uma explicação sobre algo que estou interessado(a), faço as perguntas que julgo necessárias ao meu esclarecimento”). Estes itens tiveram em comum o 
componente de falar e/ou se expor em público, alguns deles com possibilidade de rejeição, réplica, ou de oposição por parte do(s) interlocutor(es). Nas análises conduzidas, estes itens foram também somados para se obter um escore geral referente à habilidade de falar em público.

O Teste de Mann-Whitney foi empregado para a comparação dos grupos em relação a esses itens, ao escore geral da habilidade de falar em público, e ao escore total do IHS-DelPrette, adotando-se o nível de significância de $p \leq 0,05$. Um dos sujeitos do grupo não-caso não respondeu ao IHS devido ao fato de que foi incluído apenas na amostra do TSFP, não sendo, portanto, sujeito da pesquisa desde o início.

Posteriormente, executaram-se correlações bivariadas de Spearman entre todas as categorias de análise (marcadores comportamentais e suas respectivas classes; avaliação geral do desempenho, incluindo a sua classificação; latência da resposta; e tempo total de fala) e os itens específicos do falar em público, assim como entre as categorias de análise e o escore geral da habilidade de falar em público. Devido ao caráter exploratório dessas análises e tamanho pequeno da amostra, apenas foram consideradas as correlações que demonstraram significância estatística $(p \leq 0,05)$ e sentido de conteúdo. Por exemplo, foi desconsiderada a correlação positiva encontrada entre a categoria "velocidade de fala inapropriada" e o escore geral da habilidade de falar em público ( $\rho=0,50, p=0,011)$. Embora esta correlação seja estatisticamente significativa e tenha uma magnitude considerável (moderada), não faz sentido afirmar que quanto maior a frequiência de velocidade de fala inapropriada um indivíduo demonstrar em seu discurso, maior será a sua habilidade de falar em público. 


\subsection{Aspectos Éticos}

O projeto geral foi apreciado e aprovado pelo Comitê de Ética em Pesquisa da Faculdade de Medicina de Ribeirão Preto da USP, conforme processo nº 11570/2003 (Anexo I). Este estudo foi encaminhado como uma extensão deste projeto ao mesmo Comitê de Ética em Pesquisa para apreciação, sendo aprovado de acordo com o Processo HCRP nº. 6064/2006 $($ Anexo J).

Os TCLEs específicos para os Estudos 1 e 2 foram apresentados a todos os sujeitos, sendo informados sobre o objetivo, o procedimento, riscos e benefícios do estudo que estavam sendo convidados a participar (Anexos B, G e H).

A participação foi absolutamente voluntária e somente foram aceitos aqueles sujeitos que devidamente assinaram o TCLE. Eles foram esclarecidos que a não disponibilidade em participar não acarretaria nenhum prejuízo, tendo também a liberdade de retirarem seu consentimento a qualquer momento no transcorrer da pesquisa, sem risco de qualquer prejuízo ou constrangimento. Foi garantida a segurança de não serem identificados, assim como de que todas as informações fornecidas seriam mantidas em sigilo.

Aos sujeitos que foram diagnosticados com TAS foram oferecidos os devidos esclarecimentos sobre os sinais e sintomas, prognóstico e tratamento deste transtorno. Àqueles que manifestaram interesse foi feito o encaminhamento para tratamento junto ao Ambulatório de TAS do HC-FMRP da USP. 


\section{RESULTADOS}

Para cada um dos estudos realizados, os resultados serão apresentados separadamente. No Estudo 1, os dados serão apresentados na seguinte ordem: (1) os aspectos relativos à caracterização sociodemográfica da amostra estudada; (2) os dados concernentes aos indicadores psicométricos do IHS-Del-Prette; e (3) a comparação de variáveis em função da pontuação média obtida neste mesmo instrumento.

No que diz respeito ao Estudo 2, os resultados serão descritos nessa ordem: (1) caracterização geral da amostra dos sujeitos; (2) comparação dos grupos caso e não-caso de TAS em relação aos marcadores comportamentais de ansiedade, latência da resposta e tempo total de fala; (3) comparação dos grupos em relação ao início e final do TSFP; (4) correlações significativas encontradas entre as categorias de análise propostas; (5) avaliação do repertório de habilidades sociais de falar em público desses dois grupos; e (6) habilidades sociais de falar em público e marcadores comportamentais de ansiedade.

\subsection{Estudo 1 - Psicométrico}

\subsubsection{Caracterização da amostra}

A amostra final deste estudo foi composta por 1006 sujeitos, sendo 400 da USP $(39,8 \%)$ e 606 da UNIFRAN $(60,2 \%)$, observando-se um predomínio no número de universitários provindos da UNIFRAN em relação aos da USP.

A Tabela 4 oferece uma caracterização completa dessa amostra em termos de gênero dos sujeitos, sua faixa etária, área do curso em que se encontravam matriculados, ano do curso, se faziam uso de algum tipo de medicação, e se estavam ou não inseridos no mercado de trabalho, tomando por referência a sua instituição de origem. As estatísticas exibidas referem-se à comparação das variáveis relativas às duas instituições de ensino. 
Tabela 4 - Características sociodemográficas da amostra incluída no estudo

\begin{tabular}{|c|c|c|c|c|c|}
\hline VARIÁVEL & NÍVEIS & USP & UNIFRAN & TOTAL & ESTATÍSTICA \\
\hline \multirow{2}{*}{ GÊNERO } & Feminino N $(\%)$ & $216(54,0)$ & $376(62,0)$ & $592(58,8)$ & \multirow{2}{*}{$\begin{array}{l}\chi_{(1)}^{2}=6,44 \\
p=0,011^{*}\end{array}$} \\
\hline & Masculino N (\%) & $184(46,0)$ & $230(38,0)$ & $414(41,2)$ & \\
\hline \multirow{4}{*}{ FAIXA ETÁRIA } & $17-20 \mathrm{~N}(\%)$ & $184(46,0)$ & $302(49,8)$ & $486(48,3)$ & \multirow{4}{*}{$\begin{array}{l}\chi_{(3)}^{2}=4,50 \\
p=0,212^{(\mathrm{NS})}\end{array}$} \\
\hline & $21-25 \mathrm{~N}(\%)$ & $178(44,5)$ & $235(38,8)$ & $413(41,1)$ & \\
\hline & $26-30 \mathrm{~N}(\%)$ & $30(7,5)$ & $48(7,9)$ & $78(7,7)$ & \\
\hline & $31-35 \mathrm{~N}(\%)$ & $8(2,0)$ & $21(3,5)$ & $29(2,9)$ & \\
\hline \multirow{3}{*}{ ÁREA DO CURSO } & Exatas N (\%) & $248(62,0)$ & $40(6,6)$ & $288(28,6)$ & \multirow{3}{*}{$\begin{array}{c}\chi_{(2)}^{2}=376,42 \\
p<0,001^{*}\end{array}$} \\
\hline & Humanas $\mathrm{N}(\%)$ & $51(12,8)$ & $95(15,7)$ & $146(14,5)$ & \\
\hline & Biológicas N (\%) & $101(25,2)$ & $471(77,7)$ & $572(56,9)$ & \\
\hline \multirow{4}{*}{ ANO DO CURSO } & $1^{\circ}$ Ano N (\%) & $159(39,7)$ & $194(32,0)$ & $353(35,1)$ & \multirow{4}{*}{$\begin{array}{l}\chi_{(3)}^{2}=6,92 \\
p=0,075^{(\mathrm{NS})}\end{array}$} \\
\hline & $2^{\circ}$ Ano N (\%) & $104(26,0)$ & $173(28,5)$ & $277(27,5)$ & \\
\hline & $3^{\circ}$ Ano N (\%) & $82(20,5)$ & $152(25,1)$ & $234(23,3)$ & \\
\hline & $4^{\circ}$ Ano N (\%) & $55(13,8)$ & $87(14,4)$ & $142(14,1)$ & \\
\hline \multirow{2}{*}{ USO DE MEDICAÇ̃̃̃O } & $\operatorname{Sim} N(\%)$ & $82(20,5)$ & $92(15,2)$ & $174(17,3)$ & $\chi_{(1)}^{2}=4,76$ \\
\hline & Não N (\%) & $318(79,5)$ & $514(84,8)$ & $832(82,7)$ & $p=0,029^{*}$ \\
\hline \multirow{2}{*}{$\begin{array}{l}\text { INSERÇÃO NO MERCADO } \\
\text { DE TRABALHO }\end{array}$} & $\operatorname{Sim} N(\%)$ & $32(8,0)$ & $154(25,4)$ & $186(18,5)$ & $\chi_{(1)}^{2}=48,48$ \\
\hline & Não N (\%) & $368(92,0)$ & $452(74,6)$ & $820(81,5)$ & $p<0,001^{*}$ \\
\hline
\end{tabular}

$\mathrm{N}=$ freqüência; $\%=$ porcentagem; $\chi^{2}=$ Qui-Quadrado; $p=$ probabilidade associada $;{ }^{*}=$ diferença significativa; $(\mathrm{NS})=$ diferença não significativa.

É notável o predomínio do gênero feminino na amostra total e, inclusive, quanto à instituição freqüentada. Em termos de idade, observou-se haver uma diferença significativa na proporção de sujeitos distribuídos por faixa etária tanto na USP como na UNIFRAN $\left(\chi^{2}{ }_{(3)}=\right.$ $265,40, p<0,001 ; \chi_{(3)}^{2}=378,65, p<0,001$, respectivamente), mas não entre as duas instituições. A maioria dos alunos encontrava-se na faixa de 17 a 25 anos. A idade média dos alunos ficou em torno de 21,4 anos ( $\mathrm{DP}=3,3$ ), não sendo encontrada diferença significativa entre as duas universidades $\left(t_{(1004)}=0,21, p=0,834\right)$.

Verificou-se que a proporção de alunos em cada área do conhecimento diferiu significativamente tanto dentro $\left(\chi_{(2)}^{2}=157,30, p<0,001\right.$ para USP; $\chi_{(2)}^{2}=544,82, p<$ 
0,001 para UNIFRAN) quanto entre as duas universidades. A maior parte dos alunos freqüentava os anos iniciais $\left(1^{\circ}\right.$ e $\left.2^{\circ}\right)$ dos cursos. $O$ percentual de alunos matriculados ao longo dos anos de graduação não diferiu entre as duas instituições.

Quanto ao uso de medicamentos, 17,3\% da amostra total fazia uso de algum tipo de remédio, observando-se uma tendência desta porcentagem ser maior entre os alunos da USP, com diferença significativa. As medicações mais comumente usadas eram: anticoncepcionais, complexos vitamínicos, antiinflamatórios e antialérgicos, e ainda $23 \%$ dos alunos faziam uso de psicotrópicos, sendo os mais comuns os antidepressivos e ansiolíticos, com exceção de neurolépticos, os quais foram considerados critério de exclusão do estudo.

Com relação à inserção no mercado de trabalho, a maior parte dos sujeitos das duas instituições não exercia nenhuma atividade profissional além do estudo. Verificou-se haver uma diferença significativa entre a inserção no mercado de trabalho e universidade, indicando que um número maior de alunos da instituição particular de ensino exercia uma atividade profissional comparado ao número de alunos da instituição pública no contexto da amostra universitária como um todo (15,3 e 3,2\% dos alunos, respectivamente). Constatou-se ainda existir uma relação entre inserção no mercado de trabalho e gênero dos sujeitos $\left(\chi_{(1)}^{2}=\right.$ 44,58, $p<0,001)$, tendo assim um número maior de alunos $(\mathrm{N}=117)$ exercendo uma atividade profissional em comparação com o número de alunas $(\mathrm{N}=69)$ dentro da amostra total de participantes (11,6 e 6,9\%, respectivamente).

Pode-se constatar que não foram encontradas diferenças demográficas significativas entre as amostras procedentes das duas universidades, em termos de faixa etária, idade média dos alunos, e ano do curso. As diferenças significativas ocorreram quanto a gênero, área do curso, uso de medicação e inserção no mercado de trabalho. Tais dados mostram que as amostras são comparáveis quanto a variáveis relevantes para o estudo dos indicadores de habilidades sociais. 
A partir deste ponto, tratar-se-á dos resultados obtidos em relação aos indicadores psicométricos do IHS-Del-Prette, ou em outras palavras, de suas propriedades psicométricas.

\subsubsection{Indicadores psicométricos do IHS-Del-Prette}

\subsubsection{Distribuição dos dados referentes ao IHS-Del-Prette}

Pelo resultado do Teste de Kolmogorov-Smirnov, verificou-se que o conjunto de dados referentes ao IHS-Del-Prette segue uma distribuição normal $(Z=0,865, p=0,44)$. Para uma melhor visualização dos dados, a Figura 1 ilustra graficamente este resultado.

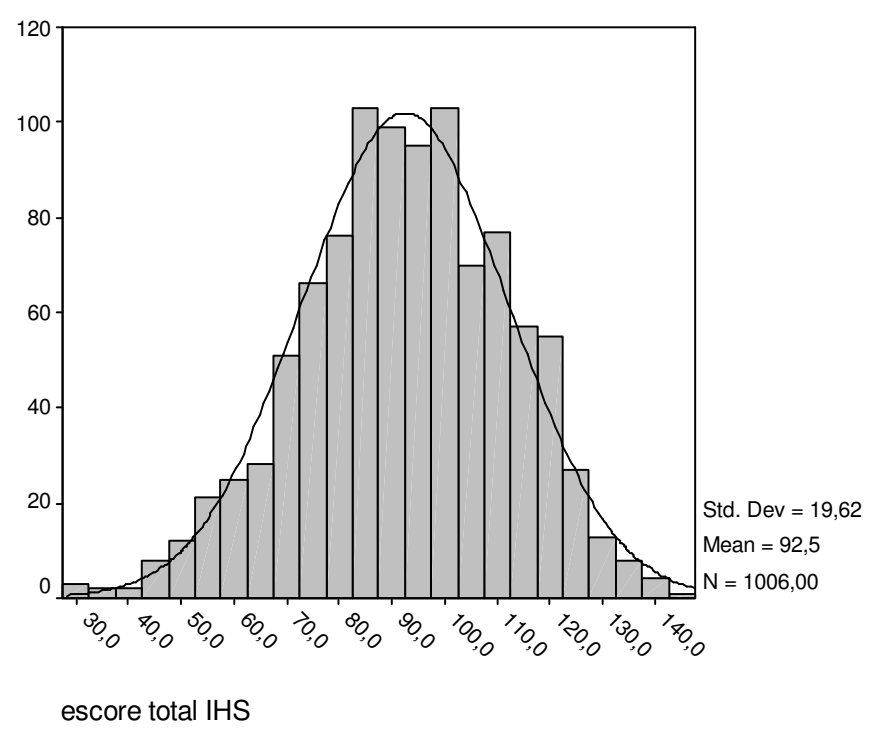

Figura 1. Curva de distribuição normal do conjunto de dados referentes ao IHS

Pode-se observar aqui que os dados referentes ao IHS-Del-Prette distribuem-se uniformemente em torno de sua média $(M=92,5)$, ou seja, o eixo que passa pela média divide a distribuição dos dados em duas partes simetricamente iguais. Cabe mencionar que, normalmente, a simetria perfeita nunca se encontra na prática, mas considera-se que entre mais ou menos 0,5 situa-se dentro das margens da distribuição simétrica (BISQUERRA; SARRIERA; MARTINEZ, 2004). 


\subsubsection{Freqüiência dos itens}

Visando avaliar individualmente a freqüência de pontuação de cada item do instrumento, foram calculados tanto os escores médios para cada item, com seus respectivos desvios-padrões, como as porcentagens de freqüências para as avaliações de cada item (escores variando de 0 a 4), conforme apresentado na Tabela 5.

Tabela 5 - Distribuição dos itens do IHS em função do escore médio, desvio-padrão e porcentagem dos escores de 0 a 4 , em uma amostra da população geral $(\mathrm{N}=$ 1006)

(continua)

\begin{tabular}{|c|c|c|c|c|c|c|c|}
\hline \multirow{2}{*}{ ITEM } & \multirow{2}{*}{ MÉDIA } & \multirow{2}{*}{$\begin{array}{l}\text { DESVIO- } \\
\text { PADRÃO }\end{array}$} & \multicolumn{5}{|c|}{ ESCORES (\%) } \\
\hline & & & $\mathbf{0}$ & 1 & 2 & 3 & 4 \\
\hline 1. Manter conversa com desconhecidos & 1,62 & 1,16 & 15,9 & 36,9 & 25,2 & 13,5 & 8,5 \\
\hline 2. Pedir mudança de conduta & 2,74 & 1,09 & 3,9 & 11,0 & 19,3 & 39,0 & 26,8 \\
\hline 3. Agradecer elogios & 3,34 & 1,01 & 2,3 & 5,5 & 9,9 & 20,1 & 62,2 \\
\hline 4. Interromper a fala do outro & 1,45 & 1,21 & 26,0 & 30,0 & 23,6 & 13,2 & 7,2 \\
\hline 5. Cobrar dívida de amigo & 1,63 & 1,37 & 26,9 & 24,6 & 20,3 & 15,1 & 13,1 \\
\hline 6. Elogiar outrem & 2,54 & 1,18 & 5,1 & 16,2 & 24,1 & 28,6 & 26,0 \\
\hline 7. Apresentar-se a outra pessoa & 1,16 & 1,23 & 39,9 & 28,3 & 14,3 & 11,4 & 6,1 \\
\hline 8. Participar de conversação & 3,04 & 1,17 & 4,9 & 8,0 & 13,0 & 26,4 & 47,7 \\
\hline 9. Falar a público desconhecido & 2,18 & 1,44 & 17,4 & 18,9 & 16,6 & 22,3 & 24,8 \\
\hline 10. Expressar sentimento positivo & 2,41 & 1,37 & 9,7 & 21,3 & 17,7 & 20,6 & 30,7 \\
\hline 11. Discordar de autoridade & 1,58 & 1,30 & 25,0 & 29,3 & 19,2 & 16,0 & 10,5 \\
\hline 12. Abordar para relação sexual & 1,28 & 1,29 & 37,9 & 23,8 & 17,9 & 13,2 & 7,2 \\
\hline 13. Reagir a elogio & 2,91 & 1,11 & 4,5 & 8,2 & 14,8 & 37,2 & 35,3 \\
\hline 14. Falar a público conhecido & 2,08 & 1,43 & 16,6 & 24,0 & 17,9 & 17,3 & 24,2 \\
\hline 15. Lidar com críticas injustas & 2,80 & 1,25 & 6,1 & 12,7 & 15,6 & 26,0 & 39,6 \\
\hline 16. Discordar do grupo & 2,51 & 1,30 & 8,1 & 18,1 & 18,4 & 25,7 & 29,7 \\
\hline 17. Encerrar conversação & 2,92 & 1,14 & 5,0 & 8,1 & 15,4 & 32,8 & 38,7 \\
\hline 18. Lidar com crítica dos pais & 3,03 & 1,09 & 3,5 & 7,7 & 14,5 & 31,2 & 43,1 \\
\hline 19. Abordar autoridade & 2,25 & 1,26 & 11,6 & 17,9 & 21,2 & 32,4 & 16,9 \\
\hline 20. Declarar sentimento amoroso & 2,16 & 1,32 & 12,5 & 23,1 & 20,7 & 23,5 & 20,2 \\
\hline 21. Devolver mercadoria defeituosa & 2,91 & 1,19 & 3,3 & 13,7 & 14,5 & 26,0 & 42,5 \\
\hline 22. Recusar pedidos abusivos & 1,82 & 1,30 & 20,4 & 23,4 & 21,2 & 24,1 & 10,9 \\
\hline 23. Fazer pergunta a desconhecido & 2,61 & 1,20 & 7,1 & 12,4 & 19,5 & 35,0 & 26,0 \\
\hline 24. Encerrar conversa ao telefone & 2,75 & 1,22 & 6,5 & 11,7 & 15,8 & 31,9 & 34,1 \\
\hline 25. Lidar com críticas justas & 2,66 & 1,15 & 4,2 & 13,7 & 22,9 & 30,0 & 29,2 \\
\hline 26. Pedir favores a desconhecidos & 2,40 & 1,39 & 12,6 & 16,4 & 18,6 & 22,8 & 29,6 \\
\hline 27. Expressar desagrado a amigos & 1,92 & 1,31 & 14,8 & 29,7 & 19,8 & 19,7 & 16,0 \\
\hline 28. Elogiar familiares & 3,25 & 1,03 & 1,9 & 6,7 & 12,4 & 22,6 & 56,4 \\
\hline 29. Fazer pergunta a conhecidos & 2,33 & 1,34 & 9,6 & 22,3 & 19,9 & 21,4 & 26,8 \\
\hline 30. Defender outrem em grupo & 2,45 & 1,10 & 4,5 & 15,7 & 28,5 & 32,5 & 18,8 \\
\hline 31. Cumprimentar desconhecidos & 2,25 & 1,26 & 8,9 & 21,7 & 25,8 & 22,5 & 21,1 \\
\hline 32. Pedir ajuda a amigos & 2,40 & 1,38 & 11,9 & 18,1 & 17,8 & 22,5 & 29,7 \\
\hline 33. Negociar uso de preservativo & 3,44 & 1,06 & 4,5 & 4,0 & 5,0 & 15,5 & 71,0 \\
\hline 34. Recusar pedido abusivo & 2,54 & 1,21 & 7,0 & 15,0 & 19,0 & 34,6 & 24,4 \\
\hline
\end{tabular}


(conclusão)

\begin{tabular}{lcccccccc}
\hline \multirow{2}{*}{ ITEM } & \multirow{2}{*}{ MÉDIA } & DESVIO- & \multicolumn{5}{c}{ ESCORES (\%) } \\
\cline { 5 - 9 } & & PADRÃO & $\mathbf{0}$ & $\mathbf{1}$ & $\mathbf{2}$ & $\mathbf{3}$ & $\mathbf{4}$ \\
\hline 35. Expressar sentimento positivo & 3,10 & 1,06 & & 2,1 & 8,2 & 15,0 & 26,8 & 47,9 \\
36. Manter conversação & 2,49 & 1,17 & & 6,3 & 15,3 & 23,2 & 33,7 & 21,5 \\
37. Pedir favores a colegas & 3,01 & 1,05 & & 3,0 & 7,1 & 15,8 & 34,4 & 39,7 \\
38. Lidar com chacotas & 2,50 & 1,22 & 7,1 & 15,6 & 22,6 & 29,6 & 25,1 \\
\hline
\end{tabular}

As pontuações médias variaram de 1,16 a 3,44. Verificou-se que as habilidades sociais que obtiveram os escores mais altos foram aquelas representadas pelos itens: $33,3,28,35,8$, 18, 37, 17, 13 e 21. Em contrapartida, as habilidades com escores mais baixos foram as representadas pelos itens: $7,12,4,11,1,5,22,27,14$ e 20 .

Os itens com diferenças muito pouco contrastantes entre as porcentagens para os escores foram os itens: 4, 5, 6, 9, 11, 13, 14, 16, 20, 22, 24, 25, 26, 27, 29, 30, 31, 32 e 38. De modo ainda mais expressivo, esses itens foram o 14, 22 e 31. Contudo, entre esses itens arrolados, alguns demonstraram uma tendência forte em termos da direção que tomaram as freqüências de ocorrência, a saber: (a) de "nunca ou raramente" a "com pouca freqüência", destacaram-se os itens 4, 5 e 11; (b) de "muito freqüentemente" a "sempre ou quase sempre", os itens $6,13,16,24,25,29$ e 38 .

Já entre os itens com diferenças mais contrastantes, essa tendência tomou a seguinte direção: (a) de “nunca ou raramente” a “com pouca freqüência”, observaram-se os itens 1, 7 e 12; (b) de "muito freqüentemente" a "sempre ou quase sempre”, os itens 2, 3, 8, 10, 15, 18, $19,21,23,28,33,34,35$ e 36 . Nesta direção, os itens mais expressivos, em termos de taxa de ocorrência para "sempre ou quase sempre”, foram o 33, 3, 28, 35 e 8.

\subsubsection{Postos percentílicos}

Considerando os grupos normativos do estudo original e a diferença significativa encontrada nos escores totais do IHS-Del-Prette comparando os sujeitos conforme o gênero 
$\left(t_{(1004)}=-3,45, p=0,001\right)$, a obtenção dos postos percentílicos foi realizada de acordo com o gênero da amostra. Deste modo, a Tabela 6 apresenta os postos percentílicos obtidos a partir dos escores totais dos sujeitos, pertencentes às amostras feminina e masculina separadamente, e a sua respectiva interpretação (classificação) em termos do conjunto de habilidades sociais avaliadas pelo instrumento, levando-se em conta a distribuição dos escores em quartis e a sua mediana.

Tabela 6 - Classificação do repertório de habilidades sociais apresentado pelas amostras feminina e masculina em função dos seus escores totais no IHS transformados em percentis

\begin{tabular}{|c|c|c|c|}
\hline \multirow{2}{*}{ INTERPRETAÇÃO } & \multirow{2}{*}{$\begin{array}{l}\text { POSIÇÃO EM } \\
\text { PERCENTIS }\end{array}$} & AMOSTRA FEMININA & AMOSTRA MASCULINA \\
\hline & & ESCORE TOTAL & ESCORE TOTAL \\
\hline \multirow{8}{*}{$\begin{array}{l}\text { Repertório bastante elaborado } \\
\text { de habilidades sociais }\end{array}$} & 100 & 144,00 & 139,00 \\
\hline & 99 & 134,00 & 134,70 \\
\hline & 97 & 125,21 & 128,00 \\
\hline & 95 & 121,00 & 126,00 \\
\hline & 90 & 116,00 & 120,00 \\
\hline & 85 & 111,00 & 116,00 \\
\hline & 80 & 108,00 & 113,00 \\
\hline & 75 & 104,00 & 110,00 \\
\hline \multirow{4}{*}{$\begin{array}{l}\text { Bom repertório de habilidades } \\
\text { sociais (acima da mediana) }\end{array}$} & 70 & 101,00 & 107,00 \\
\hline & 65 & 98,00 & 103,75 \\
\hline & 60 & 96,00 & 101,00 \\
\hline & 55 & 93,00 & 98,00 \\
\hline Repertório mediano & 50 & 91,00 & 96,00 \\
\hline \multirow{5}{*}{$\begin{array}{l}\text { Bom repertório de habilidades } \\
\text { sociais (abaixo da mediana) }\end{array}$} & 45 & 88,85 & 93,75 \\
\hline & 40 & 86,00 & 90,00 \\
\hline & 35 & 84,00 & 88,00 \\
\hline & 30 & 80,00 & 86,00 \\
\hline & 25 & 78,00 & 83,00 \\
\hline \multirow{6}{*}{$\begin{array}{l}\text { Repertório deficitário em } \\
\text { habilidades sociais }\end{array}$} & 20 & 74,00 & 80,00 \\
\hline & 15 & 70,00 & 76,00 \\
\hline & 10 & 66,00 & 69,50 \\
\hline & 5 & 57,65 & 58,00 \\
\hline & 3 & 53,00 & 51,90 \\
\hline & 1 & 46,86 & 35,75 \\
\hline Número de sujeitos: & & 592 & 414 \\
\hline Média: & & 90,71 & 95,02 \\
\hline Desvio-padrão: & & 19,15 & 20,04 \\
\hline
\end{tabular}


Verificou-se uma distribuição de escores bastante diferenciada entre as duas amostras de sujeitos. A maioria dos escores brutos relativos à amostra masculina foi superior aos escores apresentados pela amostra feminina, com exceção daqueles situados nas faixas do percentil 1,3 e 100.

Quanto aos escores que ficaram abaixo do percentil 25, a amostra masculina diferiu uma média de 0,61 pontos em relação aos escores da amostra feminina; entre os valores situados abaixo do percentil 50 até o 25 , uma média de 4,78 pontos; em termos da mediana, uma diferença de 5 pontos; entre os valores abaixo do percentil 75 e acima do percentil 50, uma média de 5,44 pontos; e entre os valores situados na faixa do percentil 100 até o 75, uma média de 2,94 pontos. A diferença de médias apresentadas pelas duas amostras foi de 4,31 pontos, diferindo uma da outra em 0,22 desvios-padrões, considerado um pequeno efeito.

\subsubsection{Classificação do repertório de habilidades sociais da amostra estudada}

Tomando por referência os dados normativos do estudo original, classificou-se o repertório de habilidades sociais da amostra deste estudo, de acordo com o gênero dos sujeitos, em função do seu escore total, como pode ser visualizado na Tabela 7.

Tabela 7 - Classificação do repertório de habilidades sociais dos sujeitos pertencentes às amostras feminina $(\mathrm{N}=592)$ e masculina $(\mathrm{N}=414)$

\begin{tabular}{|c|c|c|c|c|}
\hline \multirow{2}{*}{$\begin{array}{l}\text { CLASSIFICAÇÃO DO REPERTÓRIO DE } \\
\text { HABILIDADES SOCIAIS }\end{array}$} & \multicolumn{2}{|c|}{ AMOSTRA FEMININA } & \multicolumn{2}{|c|}{ AMOSTRA MASCULINA } \\
\hline & $\mathbf{N}$ & $\%$ & $\mathbf{N}$ & $\%$ \\
\hline $\begin{array}{l}\text { - Repertório bastante elaborado de habilidades } \\
\text { sociais }(\mathrm{P} \geq 75)\end{array}$ & 161 & 27,2 & 140 & 33,8 \\
\hline $\begin{array}{l}\text { Bom repertório de habilidades sociais } \\
\text { (acima da mediana) }(\mathrm{P}>50 \mathrm{e}<75)\end{array}$ & 115 & 19,4 & 60 & 14,5 \\
\hline - Repertório mediano $(\mathrm{P}=50)$ & 28 & 4,7 & 19 & 4,6 \\
\hline $\begin{array}{l}\text { - Bom repertório de habilidades sociais } \\
\text { (abaixo da mediana) }(\mathrm{P}=25 \mathrm{e}<50)\end{array}$ & 100 & 16,9 & 40 & 9,7 \\
\hline $\begin{array}{l}\text { - Repertório deficitário em habilidades sociais } \\
(\mathrm{P}<25)\end{array}$ & 188 & 31,8 & 155 & 37,4 \\
\hline - Total & 592 & 100 & 414 & 100 \\
\hline - Estatística & \multicolumn{2}{|c|}{$\chi_{(4)}^{2}=128,22, p<0,001^{*}$} & \multicolumn{2}{|c|}{$\chi_{(4)}^{2}=180,03, p<0,001^{*}$} \\
\hline
\end{tabular}

$\mathrm{P}=$ Percentil; $\mathrm{N}=$ Número de sujeitos dentro da amostra; $\%=$ Porcentagem; $\chi^{2}=$ Qui-Quadrado, $p=$ probabilidade associada $;{ }^{*}=$ diferença significativa. 
Verificou-se uma diferença significativa na classificação do repertório de habilidades sociais entre os sujeitos tanto da amostra feminina como da amostra masculina, sendo observado um percentual maior de sujeitos com prejuízos quanto às habilidades sociais em ambos os grupos ("repertório deficitário em habilidades sociais"), cujos escores situaram-se bem abaixo da média em relação ao seu grupo normativo. Percentuais de 46,6 e 48,3\% referentes às amostras feminina e masculina, respectivamente, encontram-se acima da média; e percentuais de 48,7 e 47,1\%, situam-se abaixo da média.

\subsubsection{Diferenciação entre as habilidades sociais dos grupos caso e não-caso de TAS}

Com base no escore total da Mini-SPIN, os sujeitos da amostra total foram divididos em dois grupos: caso (com escore igual ou superior a 6) e não-caso (com escore igual ou inferior a 5) de TAS. O grupo caso foi composto por 214 sujeitos, sendo 142 do gênero feminino $(66,4 \%)$ e 72 do gênero masculino (33,6\%). Já o grupo não-caso compreendeu 792 sujeitos, 450 do gênero feminino $(58,8 \%)$ e 342 do masculino (43,2\%). Constatou-se, assim, um percentual maior de sujeitos do gênero feminino em ambos os grupos. $O$ Teste $t$ de Student foi empregado para verificar se os dois grupos demonstrariam diferenças significativas para cada uma das habilidades avaliadas pelo IHS-Del-Prette, cujos resultados encontrados podem ser visualizados na Tabela 8.

Tabela 8 - Escores médios de cada item do IHS com seus respectivos desvios-padrões e Testes t para os grupos caso $(\mathrm{N}=214)$ e não-caso de TAS $(\mathrm{N}=792)$

\begin{tabular}{lcccl}
\hline \multicolumn{1}{c}{ Itens do IHS } & $\begin{array}{c}\text { Grupo } \\
\text { Caso }\end{array}$ & $\begin{array}{c}\text { Grupo } \\
\text { Não-caso }\end{array}$ & $\begin{array}{c}\text { Teste t } \\
\left(t_{(1004)}=\right)\end{array}$ & Probabilidade \\
\hline 1. Manter conversa com desconhecidos & $0,89(0,88)$ & $1,81(1,14)$ & $-12,66^{*}$ & $p<0,001^{* *}$ \\
2. Pedir mudança de conduta & $2,43(1,17)$ & $2,82(1,05)$ & $-4,45^{*}$ & $p<0,001^{* *}$ \\
3. Agradecer elogios & $3,07(1,22)$ & $3,42(0,94)$ & $-3,81^{*}$ & $p<0,001^{* *}$ \\
4. Interromper a fala do outro & $0,96(1,15)$ & $1,59(1,19)$ & $-7,07^{*}$ & $p<0,001^{* *}$ \\
5. Cobrar dívida de amigo & $1,17(1,24)$ & $1,75(1,37)$ & $-5,97^{*}$ & $p<0,001^{* *}$ \\
6. Elogiar outrem & $2,21(1,24)$ & $2,64(1,15)$ & $-4,76$ & $p<0,001^{* *}$ \\
7. Apresentar-se a outra pessoa & $0,51(0,84)$ & $1,33(1,27)$ & $-11,18^{*}$ & $p<0,001^{* *}$ \\
8. Participar de conversação & $2,37(1,31)$ & $3,22(1,06)$ & $-8,71^{*}$ & $p<0,001^{* *}$ \\
9. Falar a público desconhecido & $1,25(1,37)$ & $2,44(1,35)$ & $-11,38$ & $p<0,001^{* *}$
\end{tabular}


(conclusão)

\begin{tabular}{|c|c|c|c|c|}
\hline Itens do IHS & $\begin{array}{c}\text { Grupo } \\
\text { Caso }\end{array}$ & $\begin{array}{c}\text { Grupo } \\
\text { Não-caso }\end{array}$ & $\begin{array}{c}\text { Teste t } \\
\left(t_{(1004)}=\right)\end{array}$ & Probabilidade \\
\hline 10. Expressar sentimento positivo & $1,92(1,45)$ & $2,55(1,31)$ & $-6,04$ & $p<0,001^{* *}$ \\
\hline 11. Discordar de autoridade & $0,94(1,06)$ & $1,75(1,31)$ & $-9,34^{*}$ & $p<0,001^{* *}$ \\
\hline 12. Abordar para relação sexual & $0,66(0,90)$ & $1,45(1,32)$ & $-10,11^{*}$ & $p<0,001^{* * *}$ \\
\hline 13. Reagir a elogio & $2,40(1,17)$ & $3,04(1,05)$ & $-7,30^{*}$ & $p<0,001^{* * *}$ \\
\hline 14. Falar a público conhecido & $1,39(1,31)$ & $2,27(1,40)$ & $-8,65^{*}$ & $p<0,001^{* *}$ \\
\hline 15. Lidar com críticas injustas & $2,36(1,37)$ & $2,92(1,19)$ & $-5,47^{*}$ & $p<0,001^{* * *}$ \\
\hline 16. Discordar do grupo & $1,97(1,32)$ & $2,66(1,26)$ & $-7,04$ & $p<0,001^{* *}$ \\
\hline 17. Encerrar conversação & $2,16(1,28)$ & $3,13(1,01)$ & $-10,23^{*}$ & $p<0,001^{* *}$ \\
\hline 18. Lidar com crítica dos pais & $2,74(1,25)$ & $3,11(1,03)$ & $-3,90^{*}$ & $p<0,001^{* *}$ \\
\hline 19. Abordar autoridade & $1,42(1,32)$ & $2,47(1,14)$ & $-10,64^{*}$ & $p<0,001^{* *}$ \\
\hline 20. Declarar sentimento amoroso & $1,59(1,30)$ & $2,31(1,29)$ & $-7,21$ & $p<0,001^{* * *}$ \\
\hline 21. Devolver mercadoria defeituosa & $2,35(1,26)$ & $3,06(1,12)$ & $-7,42^{*}$ & $p<0,001^{* * *}$ \\
\hline 22. Recusar pedidos abusivos & $1,60(1,25)$ & $1,88(1,31)$ & $-2,75$ & $p=0,006^{* *}$ \\
\hline 23. Fazer pergunta a desconhecido & $2,00(1,25)$ & $2,77(1,13)$ & $-8,23^{*}$ & $p<0,001^{* *}$ \\
\hline 24. Encerrar conversa ao telefone & $2,20(1,31)$ & $2,90(1,15)$ & $-7,14^{*}$ & $p<0,001^{* * *}$ \\
\hline 25. Lidar com críticas justas & $2,30(1,20)$ & $2,76(1,12)$ & $-5,28$ & $p<0,001^{* *}$ \\
\hline 26. Pedir favores a desconhecidos & $1,82(1,41)$ & $2,56(1,34)$ & $-7,08$ & $p<0,001^{* * *}$ \\
\hline 27. Expressar desagrado a amigos & $1,61(1,30)$ & $2,01(1,30)$ & $-3,94$ & $p<0,001^{* *}$ \\
\hline 28. Elogiar familiares & $2,95(1,13)$ & $3,33(0,99)$ & $-4,39^{*}$ & $p<0,001^{* * *}$ \\
\hline 29. Fazer pergunta a conhecidos & $1,51(1,19)$ & $2,56(1,29)$ & $-11,15^{*}$ & $p<0,001^{* * *}$ \\
\hline 30. Defender outrem em grupo & $1,99(1,17)$ & $2,58(1,04)$ & $-7,20$ & $p<0,001^{* *}$ \\
\hline 31. Cumprimentar desconhecidos & $1,64(1,28)$ & $2,41(1,20)$ & $-8,20$ & $p<0,001^{* *}$ \\
\hline 32. Pedir ajuda a amigos & $1,88(1,28)$ & $2,54(1,38)$ & $-6,59^{*}$ & $p<0,001^{* *}$ \\
\hline 33. Negociar uso de preservativo & $3,38(1,13)$ & $3,46(1,04)$ & $-1,02$ & $p=0,307^{(\mathrm{NS})}$ \\
\hline 34. Recusar pedido abusivo & $2,27(1,24)$ & $2,61(1,19)$ & $-3,72$ & $p<0,001^{* *}$ \\
\hline 35. Expressar sentimento positivo & $2,80(1,12)$ & $3,19(1,03)$ & $-4,54^{*}$ & $p<0,001^{* *}$ \\
\hline 36. Manter conversação & $1,80(1,18)$ & $2,67(1,09)$ & $-10,22$ & $p<0,001^{* *}$ \\
\hline 37. Pedir favores a colegas & $2,43(1,11)$ & $3,16(0,98)$ & $-8,79^{*}$ & $p<0,001^{* *}$ \\
\hline 38. Lidar com chacotas & $2,12(1,25)$ & $2,61(1,19)$ & $-5,27$ & $p<0,001^{* *}$ \\
\hline Escore Total & $73,07(16,82)$ & $97,73(16,84)$ & $-19,01$ & $p<0,001^{* *}$ \\
\hline
\end{tabular}

${ }^{*}=$ condição com variâncias desiguais $;{ }^{* *}=$ diferença significativa; $(\mathrm{NS})=$ diferença não significativa.

Ambos os grupos diferiram significativamente em relação a 37 habilidades avaliadas pelo instrumento e quanto ao escore total, com a única exceção da representada pelo item 33 (negociar uso de preservativo). O grupo não-caso apresentou as maiores pontuações médias para todas as habilidades avaliadas, caracterizando um melhor repertório de habilidades sociais. O grupo caso apresentou as habilidades sociais com escores mais altos representadas pelos itens 33, 3, 28, 35 e 18. Já as habilidades sociais com escores mais altos exibidas pelo grupo não-caso foram aquelas representadas pelos itens $33,3,28,8,35,37,17,18,21,13$ e 
15. Todas as habilidades com escores mais altos apresentadas pelo grupo caso também foram compartilhadas pelo grupo não-caso.

Com relação ao poder discriminativo dos itens, o escore médio e a porcentagem de pontuação nos escores de 0 a 4 em cada item para cada grupo são apresentados na Tabela 9.

Tabela 9 - Distribuição dos itens do IHS em função do escore médio, desvio-padrão e porcentagem de pontuação nos escores de 0 a 4 para os grupos caso $(\mathrm{N}=214)$ e não-caso de TAS $(\mathrm{N}=792)$

\begin{tabular}{|c|c|c|c|c|c|c|c|c|c|c|c|c|c|c|}
\hline \multirow{3}{*}{$\begin{array}{l}\text { Item } \\
\text { IHS }\end{array}$} & \multicolumn{7}{|c|}{ GRUPO CASO } & \multicolumn{7}{|c|}{ GRUPO NÃO-CASO } \\
\hline & \multirow{2}{*}{ Média } & \multirow{2}{*}{ DP } & \multicolumn{5}{|c|}{ Escores (\%) } & \multirow{2}{*}{ Média } & \multirow{2}{*}{ DP } & \multicolumn{5}{|c|}{ Escores (\%) } \\
\hline & & & $\mathbf{0}$ & 1 & 2 & 3 & 4 & & & $\mathbf{0}$ & 1 & 2 & 3 & 4 \\
\hline 1 & 9 & 0,88 & 38,8 & 38,3 & 18,7 & 3,3 & 0,9 & & & 9,7 & 36,5 & 27,0 & 16,2 & 10,6 \\
\hline 2 & 2,43 & 1,17 & 7,5 & 15,0 & 22,9 & 36,4 & 18,2 & & 1,05 & 2,9 & 10,0 & 18,3 & 39,6 & 29,2 \\
\hline 3 & 3,07 & 1,22 & 5,1 & 10,8 & 8,0 & 23,8 & 52,3 & 3,42 & 0,94 & 1,5 & 4,0 & 10,5 & 19,1 & 64,9 \\
\hline 4 & 0,96 & 1,15 & 44,4 & 32,7 & 11,7 & 5,1 & 6,1 & 1,59 & 1,19 & 21,1 & 29,3 & 26,8 & 15,4 & 7,4 \\
\hline 5 & 1,17 & 1,24 & 41,1 & 24,3 & 16,8 & 12,2 & 5,6 & 1,75 & 1,37 & 23,1 & 24,6 & 21,2 & 15,9 & 15,2 \\
\hline 6 & 2,21 & 1,24 & 8,4 & 24,8 & 22,4 & 26,6 & 17,8 & 2,64 & 1,15 & 4,2 & 13,9 & 24,5 & 29,2 & 28,2 \\
\hline 7 & 0,51 & 0,84 & 64,0 & 26,2 & 5,6 & 2,8 & 1,4 & 1,33 & 1,27 & 33,3 & 28,9 & 16,7 & 13,8 & 7,3 \\
\hline 8 & 7 & 1,31 & 11,7 & 14,9 & 22,0 & 27,1 & 24,3 & & 1,06 & 3,0 & 6,1 & 10,6 & 26,3 & 54,0 \\
\hline 9 & 1,25 & 1,37 & 40,2 & 28,0 & 9,8 & 10,8 & 11,2 & 2,44 & 1,35 & 11,3 & 16,4 & 18,4 & 25,4 & 28,5 \\
\hline 10 & 1,92 & 1,45 & 19,2 & 28,0 & 17,3 & 12,6 & 22,9 & 2,55 & 1,31 & 7,2 & 19,4 & 17,8 & 22,7 & 32,9 \\
\hline 11 & 0,94 & 1,0 & 43,0 & 33,2 & 13,1 & 7,9 & 0 & & 1,31 & 20,1 & 28,3 & 20,8 & 18,2 & 12,6 \\
\hline 12 & 66 & 0,90 & 54,7 & 30,8 & 9,4 & 3,7 & & & 1,32 & 33,3 & 22,0 & 20,2 & 15,8 & 8,7 \\
\hline 13 & & 1,17 & 7,9 & 15,4 & 22,9 & 36,5 & & & 1,05 & & 6,3 & 12,6 & 37,4 & 40,2 \\
\hline 14 & & 1,3 & 30,8 & 29,9 & 20,6 & 7,0 & & & 1,40 & 12,8 & 22,5 & 17,1 & 20,1 & 27,5 \\
\hline 15 & 2,36 & 1,37 & 10,7 & 21,0 & 18,7 & 20,6 & 29,0 & 2,92 & 1,19 & 4,8 & 10,5 & 14,8 & 27,5 & 42,4 \\
\hline 16 & 1,97 & 1,32 & 15,4 & 25,2 & 23,4 & 19,2 & 16,8 & 2,66 & 1,26 & 6,1 & 16,2 & 17,0 & 27,5 & 33,2 \\
\hline 17 & 2,16 & 1,28 & 13,6 & 18,2 & 22,9 & 29,4 & 15,9 & 3,13 & 1,01 & 2,7 & 5,4 & 13,4 & 33,7 & 44,8 \\
\hline 18 & & 1,2 & 7,0 & 12,2 & 15,4 & 30,4 & 35 & & 1,03 & 2,5 & 6,5 & 14,3 & 31,4 & 45,3 \\
\hline 19 & & 1,3 & 31,3 & 29,0 & 15,9 & 14,0 & & & 1,14 & 6 & 14,9 & 22,6 & 37,4 & 18,8 \\
\hline 20 & & 1,3 & 26,2 & 24,8 & 22,4 & 16,8 & & & 1,29 & 8,8 & 22,6 & 0,2 & 25,4 & 23,0 \\
\hline 21 & & 1,26 & 6,1 & 26,2 & 18,2 & 25,7 & 23,8 & 3,06 & 1,12 & 2,5 & 10,4 & 13,5 & 26,1 & 47,5 \\
\hline 22 & 1,60 & 1,25 & 25,3 & 23,8 & 22,4 & 22,4 & 6,1 & 1,88 & 1,31 & 19,1 & 23,2 & 20,8 & 24,6 & 12,3 \\
\hline 23 & 2,00 & 1,25 & 15,0 & 21,5 & 23,8 & 28,5 & 11,2 & 2,77 & 1,13 & 4,9 & 10,0 & 18,3 & 36,7 & 30,1 \\
\hline 24 & & 1,3 & 12,2 & 21,0 & 21,5 & 25,2 & 20 & & 1,15 & 4,9 & 9,2 & 14,3 & 33,7 & 37,9 \\
\hline 25 & & 1,2 & 7,9 & 19,2 & 26,2 & 28,5 & 18 & 6 & 1,12 & 3,2 & 12,2 & 22,0 & 30,4 & 32,2 \\
\hline 26 & 2 & 1,41 & 22,4 & 24,8 & 17,8 & 18,2 & & & 1,34 & 10,0 & 14,1 & 18,8 & 24,0 & 33,1 \\
\hline 27 & & 1,30 & 23,8 & 29,0 & 20,1 & 16,4 & 10 & 2,01 & 1,30 & 12,4 & 29,9 & 19,7 & 20,6 & 17,4 \\
\hline 28 & & 1,13 & 2,3 & 12,6 & 14,5 & 28,5 & 42, & 3,33 & 0,99 & 1,7 & 5,2 & 11,9 & 21,0 & 60,2 \\
\hline 29 & 1,51 & 1,19 & 21,5 & 34,1 & 24,3 & 11,7 & 8 & 2,56 & 1,29 & 6,4 & 19,1 & 18,7 & 24,0 & 31,8 \\
\hline 30 & 1,99 & 1,17 & 11,2 & 25,2 & 27,1 & 26,7 & 9 & & 1,04 & 2,7 & 13,1 & 28,9 & 34,1 & 21,2 \\
\hline 31 & & 1,2 & 23,9 & 24,3 & 25,2 & 16,8 & 9 & 2,41 & 1,20 & 4,9 & 21,0 & 26,0 & 24,0 & 24,1 \\
\hline 32 & & 1,2 & 15,0 & 29,0 & 24,2 & 16,8 & 15 & 4 & 1,38 & 11,1 & 15,2 & 16,0 & 24,0 & 33,7 \\
\hline 33 & & 1,1 & 5,1 & 4,7 & 6,5 & 14,5 & 69 & & 1,04 & 4,3 & 3,9 & 4,5 & 15,8 & 71,5 \\
\hline 34 & & 1,2 & 9,3 & 22,0 & 17,8 & 34,1 & 16 & & 1,19 & 6,5 & 13,1 & 19,3 & 34,7 & 26,4 \\
\hline 35 & 2,80 & 1,12 & 2,8 & 11,2 & 24,3 & 26,6 & 35 , & 3,19 & 1,03 & 1,9 & 7,3 & 12,5 & 26,9 & 51,4 \\
\hline 36 & 1,80 & 1,18 & 14,5 & 29,0 & 27,5 & 20,1 & 8 & 2,67 & 1,09 & 4,0 & 11,6 & 22,1 & 37,4 & 24,9 \\
\hline 37 & 2,43 & 1,11 & 5,1 & 14,5 & 31,3 & 30,4 & 18, & 3,16 & 0,98 & 2,4 & 5,2 & 11,6 & 35,5 & 45,3 \\
\hline 38 & 2,12 & 1,25 & 11,2 & 22,9 & 25,2 & 24,3 & 16,4 & 2,61 & 1,19 & 6,0 & 13,6 & 21,8 & 31,1 & 27,5 \\
\hline
\end{tabular}


Ordenadamente, os itens $11,7,8,36,14,1,17,19,29$, e 9 foram aqueles que evidenciaram maior poder discriminativo para os grupos caso e não-caso de TAS, com uma diferença maior entre os escores médios registrados pelos dois grupos, variando de 0,81 a 1,19. Para o grupo caso, esses itens apresentaram os maiores percentuais de pontuação nos escores menores ou iguais a um em comparação ao grupo não-caso, a saber: 76,2, 90,2, 26,6, $68,2,43,5,60,7,77,1,31,8,60,3,55,6$ e $68,2 \%$, respectivamente. Contudo, para o grupo nãocaso, os itens 8,17 e 36 apresentaram percentuais bastante expressivos nos escores maiores ou iguais a três: $80,3,78,5$ e $62,3 \%$, respectivamente, corroborando o poder discriminativo destes itens.

Os itens 24, 21, 20, 37, 26, 23, 31 e 12 apresentaram poder discriminativo relativamente alto, com uma diferença entre os escores médios registrados pelos dois grupos variando de 0,70 a 0,79. Para o grupo caso, estes itens receberam os seguintes percentuais de pontuação nos escores menores ou iguais a um: 33,2, 32,3, 51, 19,6, 47,2, 36,5, 48,2 e 85,5\%, respectivamente. Para o grupo não-caso, os itens 21, 23, 24, 26, e 37 demonstraram percentuais bastante expressivos nos escores maiores ou iguais a três: 73,6, 66,8, 71,6, 57,1 e $80,8 \%$, respectivamente, confirmando o poder discriminativo destes itens.

Calculou-se ainda o tamanho do efeito para cada item, visando verificar o quanto os escores médios dos dois grupos nos itens diferiam em termos de desvios-padrões. Esses dados são apresentados na Tabela 10.

Tabela 10 - Distribuição dos itens do IHS em função da diferença entre os escores médios, média dos desvios-padrões e tamanho do efeito em uma amostra de casos $(\mathrm{N}=$ 214) e não-casos de TAS ( $\mathrm{N}=792)$

(continua)

\begin{tabular}{lccc}
\hline \multicolumn{1}{c}{ Item do IHS } & $\begin{array}{c}\text { Diferença entre os } \\
\text { escores médios }\end{array}$ & $\begin{array}{c}\text { Média dos } \\
\text { desvios-padrões }\end{array}$ & $\begin{array}{c}\text { Tamanho } \\
\text { do efeito }(\boldsymbol{d})\end{array}$ \\
\hline 1. Manter conversa com desconhecidos & $-0,92$ & 1,01 & 0,91 \\
2. Pedir mudança de conduta & $-0,39$ & 1,11 & 0,35 \\
3. Agradecer elogios & $-0,35$ & 1,08 & 0,32 \\
4. Interromper a fala do outro & $-0,63$ & 1,17 & 0,54 \\
5. Cobrar dívida de amigo & $-0,58$ & 1,30 & 0,45
\end{tabular}


(conclusão)

\begin{tabular}{lccc}
\hline \multicolumn{1}{c}{ Item do IHS } & $\begin{array}{c}\text { Diferença entre os } \\
\text { escores médios }\end{array}$ & $\begin{array}{c}\text { Média dos } \\
\text { desvios-padrões }\end{array}$ & $\begin{array}{c}\text { Tamanho } \\
\text { do efeito }(\boldsymbol{d})\end{array}$ \\
\hline 6. Elogiar outrem & $-0,43$ & 1,20 & 0,36 \\
7. Apresentar-se a outra pessoa & $-0,82$ & 1,06 & 0,77 \\
8. Participar de conversação & $-0,85$ & 1,18 & 0,72 \\
9. Falar a público desconhecido & $-1,19$ & 1,36 & 0,88 \\
10. Expressar sentimento positivo & $-0,63$ & 1,38 & 0,46 \\
11. Discordar de autoridade & $-0,81$ & 1,18 & 0,69 \\
12. Abordar para relação sexual & $-0,79$ & 1,11 & 0,71 \\
13. Reagir a elogio & $-0,64$ & 1,11 & 0,58 \\
14. Falar a público conhecido & $-0,88$ & 1,36 & 0,65 \\
15. Lidar com críticas injustas & $-0,56$ & 1,28 & 0,44 \\
16. Discordar do grupo & $-0,69$ & 1,29 & 0,53 \\
17. Encerrar conversação & $-0,97$ & 1,14 & 0,85 \\
18. Lidar com críticas dos pais & $-0,37$ & 1,14 & 0,32 \\
19. Abordar autoridade & $-1,05$ & 1,23 & 0,85 \\
20. Declarar sentimento amoroso & $-0,72$ & 1,30 & 0,55 \\
21. Devolver mercadoria defeituosa & $-0,71$ & 1,19 & 0,60 \\
22. Recusar pedidos abusivos & $-0,28$ & 1,28 & 0,22 \\
23. Fazer pergunta a desconhecido & $-0,77$ & 1,19 & 0,65 \\
24. Encerrar conversa ao telefone & $-0,70$ & 1,23 & 0,57 \\
25. Lidar com críticas justas & $-0,46$ & 1,16 & 0,40 \\
26. Pedir favores a desconhecidos & $-0,74$ & 1,38 & 0,54 \\
27. Expressar desagrado a amigos & $-0,40$ & 1,30 & 0,31 \\
28. Elogiar familiares & $-0,38$ & 1,06 & 0,36 \\
29. Fazer pergunta a conhecidos & $-1,05$ & 1,24 & 0,85 \\
30. Defender outrem em grupo & $-0,59$ & 1,10 & 0,54 \\
31. Cumprimentar desconhecidos & $-0,77$ & 1,24 & 0,62 \\
32. Pedir ajuda a amigos & $-0,66$ & 1,33 & 0,50 \\
33. Negociar uso de preservativo & $-0,08$ & 1,08 & 0,07 \\
34. Recusar pedido abusivo & $-0,34$ & 1,22 & 0,28 \\
35. Expressar sentimento positivo & $-0,39$ & 1,08 & 0,36 \\
36. Manter conversação & $-0,87$ & 1,14 & 0,76 \\
37. Pedir favores a colegas & $-0,73$ & 1,04 & 0,70 \\
38. Lidar com chacotas & $-0,49$ & 1,22 & 0,40 \\
\hline & & & \\
\hline
\end{tabular}

Tomando por base a classificação de Cohen (1988), cinco itens demonstraram um efeito considerado grande, a saber: item 1, 9, 17, 19 e 29. Um efeito médio foi exibido pelos itens $4,7,8,11,12,13,14,16,20,21,23,24,26,30,31,32,36$ e 37 . Os demais itens apresentaram um efeito pequeno.

Cinco dos itens que evidenciaram maior poder discriminativo $(1,9,17,19$ e 29) apresentaram um efeito grande. Os outros cinco itens (7, 8, 11, 14 e 36) exibiram um efeito 
médio. Todos os itens que demonstraram um poder discriminativo relativamente alto $(24,21$, 20, 37, 26, 23, 31 e 12) exibiram um efeito médio.

\subsubsection{Consistência interna do IHS-Del-Prette}

Na Tabela 11 estão apresentados os coeficientes alfa de Cronbach obtidos para o IHSDel-Prette como um todo e seus fatores, separadamente, e também os valores relativos à correlação de cada um dos seus itens com a escala total e seus respectivos fatores. Os coeficientes alfa de Cronbach são exibidos tanto para a amostra total de sujeitos como para os grupos caso e não-caso de TAS.

Tabela 11 - Valores mínimo e máximo da correlação de cada item com a escala total e Alfas de Cronbach obtidos para o IHS e cada um dos seus fatores em uma amostra da população geral $(\mathrm{N}=1006)$ e para as amostras de casos $(\mathrm{N}=214)$ e não-casos de TAS $(\mathrm{N}=792)$

\begin{tabular}{|c|c|c|c|c|}
\hline IHS & $\begin{array}{c}\text { Correlação Item - Escala } \\
\text { Total }(r)\end{array}$ & $\begin{array}{c}\alpha \\
\text { Amostra total }\end{array}$ & $\begin{array}{c}\alpha \\
\text { Casos }\end{array}$ & $\begin{array}{c}\alpha \\
\text { Não-casos }\end{array}$ \\
\hline $\begin{array}{l}\text { Escala total } \\
\text { (38 itens) }\end{array}$ & $0,08($ item 22$)-0,55($ item 29$)$ & 0,87 & 0,82 & 0,83 \\
\hline $\begin{array}{l}\text { Fator } \mathbf{1} \\
\text { (11 itens) }\end{array}$ & $0,39$ (item 5$)-0,57$ (item 11) & 0,81 & 0,72 & 0,78 \\
\hline $\begin{array}{l}\text { Fator } 2 \\
(7 \text { itens })\end{array}$ & $0,20($ item 8$)-0,54$ (item 28) & 0,68 & 0,67 & 0,64 \\
\hline $\begin{array}{l}\text { Fator } 3 \\
\text { (7 itens) }\end{array}$ & $0,16($ item 22$)-0,45($ item 37$)$ & 0,66 & 0,57 & 0,57 \\
\hline $\begin{array}{l}\text { Fator } 4 \\
\text { (4 itens) }\end{array}$ & 0,23 (item 26) - 0,43 (item 9) & 0,55 & 0,34 & 0,49 \\
\hline $\begin{array}{l}\text { Fator } 5 \\
\text { (3 itens) }\end{array}$ & $0,13($ item 18$)-0,25($ item 38$)$ & 0,32 & 0,21 & 0,28 \\
\hline
\end{tabular}

$r=$ Coeficiente de Correlação de Pearson; $\alpha=$ alfa de Cronbach

O IHS-Del-Prette apresentou uma consistência interna boa, com um coeficiente $\alpha$ de Cronbach de 0,87, para o escore total da amostra, o que reforça a sua validade de construto. A consistência interna do Fator 1 também foi boa; para os Fatores 2 e 3, moderada; e para os Fatores 4 e 5, fraca, com coeficientes variando de baixos a muito baixos. Assim, os coeficientes alfa encontrados foram bastante satisfatórios apenas para o instrumento como um 
todo e para o Fator 1, ou seja, superiores a 0,70 (ROBINSON; SHAVER; WRIGHTSMAN, 1991).

Os itens com as maiores e menores correlações podem ser visualizados entre parênteses, tomando-se por referência tanto a escala total quanto os fatores, independentemente. A análise da correlação de cada um dos itens com a escala total ou respectivos fatores isolados demonstrou que nem todos os itens se relacionaram fortemente com o total. Quanto à escala total, o item 22 demonstrou uma correlação fraca $(r=0,08)$ com os demais; e os itens 2, 18, 33 e 34, uma correlação moderada $(r=0,12,0,14,0,10$ e 0,15, respectivamente). Considerando o Fator 3, uma correlação moderada $(r=0,16)$ foi observada entre o item 22 e os demais; e para o Fator 5, uma correlação igualmente moderada dos itens 18 e 31 ( $r=0,13$ e 0,16 , respectivamente) com os demais.

Evidenciou-se que a consistência interna para o instrumento como um todo, ou para os fatores 1, 2 e 3, caso os itens fossem retirados da escala, não ocorreriam alterações significativas nos valores obtidos do alfa. Com relação ao Fator 4, se os itens 9 e 23 fossem retirados, o valor do alfa cairia em 0,15 e 0,08, respectivamente. Para o Fator 5, excluindo-se o item 38, o valor do alfa abaixaria em 0,25 . Isto significa que para esses dois fatores em particular, existem alguns itens discordantes do conjunto, ou seja, eles estão abaixando os valores do alfa.

A análise relativa à comparação entre os grupos caso e não-caso evidenciou que a consistência interna para a escala total e para o Fator 1 foi boa; para o Fator 2, moderada; para os Fatores 3, 4 e 5, foi fraca, sendo que os coeficientes obtidos para os Fatores 4 e 5, em particular, também variaram de baixos a muito baixos, respectivamente. Portanto, a consistência interna do IHS-Del-Prette tanto para a amostra total como para os grupos manteve-se de certo modo constante, com a única variação de moderada à fraca para o Fator 3. 


\subsubsection{Validade concorrente}

Uma validade concorrente boa foi demonstrada entre o IHS-Del-Prette e o SPIN, aplicados em 1006 sujeitos, com um coeficiente altamente significativo de correlação negativa entre estes dois instrumentos $(r=-0,68, p<0,001)$, obtido pela comparação de seus escores totais, indicando que quanto mais elaborado for o repertório de habilidades sociais de um indivíduo, menor é a probabilidade de ele satisfazer os critérios de rastreamento de indicadores diagnósticos para o TAS.

A Figura 2 ilustra esquematicamente o diagrama de dispersão obtido pela correlação inversa entre os escores totais do IHS-Del-Prette e SPIN.

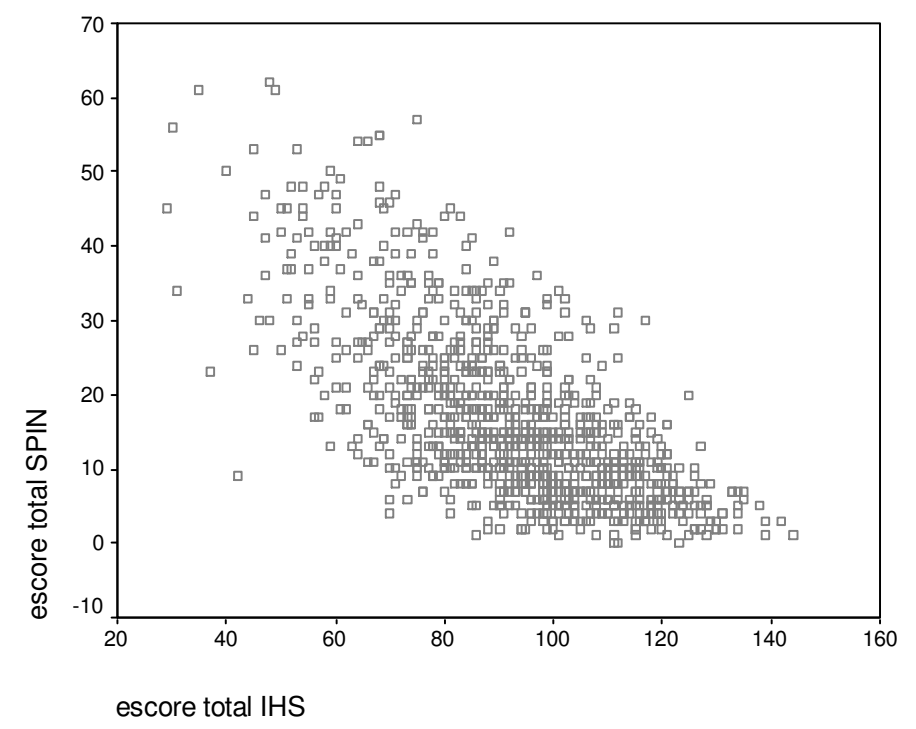

Figura 2. Diagrama de dispersão da correlação entre os escores do IHS e SPIN

Pelo exame desta figura, percebe-se que os escores totais dos instrumentos assumem uma relação negativa imperfeita na medida em que os pontos, mesmo não compondo uma linha reta, ainda assim formam um padrão visível, do canto superior esquerdo em direção ao canto inferior direito, desse relacionamento inverso. 
Por conseguinte, verificou-se que $46 \%$ correspondem à variância que o IHS-Del-Prette e SPIN compartilham. Em outras palavras, que $46 \%$ da variabilidade nos indicadores detectados com a aplicação do SPIN, como característicos do quadro de TAS, para um dado indivíduo pode ser explicado pela variabilidade no seu repertório de habilidades sociais avaliado pelo IHS. E sobram ainda 54\% que não é explicado, ou seja, a variância nos escores deve-se a outros fatores não explicados pelos instrumentos. Pode-se considerar assim que $27 \%$ da variância é exclusiva do IHS e 27\% exclusiva do SPIN.

A validade concorrente foi testada ainda entre o IHS-Del-Prette e o Mini-SPIN, com um forte relacionamento negativo obtido entre os dois $(r=-0,64, p<0,001)$, sugerindo que este instrumento em sua versão abreviada continua a produzir resultados significativos. Para confirmar este dado, o cálculo de significância da diferença entre os coeficientes de correlação demonstrou que a correlação entre o IHS e SPIN foi significativamente igual à correlação entre o IHS e Mini-SPIN $\left(t_{(2010)}=5,28, p>0,99\right)$.

Ainda no que diz respeito à determinação da validade concorrente, analisou-se a correlação dos itens individuais do IHS-Del-Prette com o escore total e os itens individuais do SPIN, conforme os dados exibidos pela Tabela 12.

Tabela 12 - Validade concorrente: Correlações entre os itens individuais do IHS com o escore total e itens individuais do SPIN em uma amostra da população geral $(\mathrm{N}=1006)$

\begin{tabular}{cclc}
\hline Itens do IHS & $\begin{array}{c}\text { Correlação com o } \\
\text { escore total do SPIN }(\boldsymbol{r})\end{array}$ & $\begin{array}{c}\text { Variação da correlação } \\
\text { com os itens do SPIN }(\boldsymbol{r})\end{array}$ & $\begin{array}{c}\text { Número total } \\
\text { de correlações }\end{array}$ \\
\hline 1 & $-0,42$ & $-0,16(1 ; 12)^{*}--0,38(4)^{*}$ & 17 \\
2 & $-0,18$ & $-0,06(16)^{* *}--0,19(6)^{*}$ & 17 \\
3 & $-0,21$ & $-0,09(2)^{* *}--0,18(3)^{*}$ & 17 \\
4 & $-0,20$ & $-0,06(7 ; 12)^{* * *}--0,21(9)^{*}$ & 17 \\
5 & $-0,22$ & $-0,09(8)^{* *}--0,20(14)^{*}$ & 17 \\
6 & $-0,17$ & $-0,07(14)^{* * *}--0,20(4)^{*}$ & 17 \\
7 & $-0,33$ & $-0,12(8)^{*}--0,29(9 ; 14)^{*}$ & 17 \\
8 & $-0,39$ & $-0,14(7)^{*}--0,33(6)^{*}$ & 17 \\
9 & $-0,44$ & $-0,10(8)^{* *}--0,62(11)^{*}$ & 17 \\
10 & $-0,24$ & $-0,09(12)^{* *}--0,22(14 ; 17)^{*}$ & 17
\end{tabular}


(conclusão)

\begin{tabular}{|c|c|c|c|}
\hline Itens do IHS & $\begin{array}{c}\text { Correlação com o } \\
\text { escore total do SPIN }(r)\end{array}$ & $\begin{array}{l}\text { Variação da correlação } \\
\text { com os itens do SPIN }(r)\end{array}$ & $\begin{array}{r}\text { Número total } \\
\text { de correlações }\end{array}$ \\
\hline 11 & $-0,34$ & $-0,09(7)^{* *}--0,35(11)^{*}$ & 17 \\
\hline 12 & $-0,29$ & $-0,11\left(7^{* *} ; 12^{*}\right)--0,28(14)^{*}$ & 17 \\
\hline 13 & $-0,34$ & $-0,16(12)^{*}--0,28(3 ; 17)^{*}$ & 17 \\
\hline 14 & $-0,33$ & $-0,08(8)^{* * *}--0,53(11)^{*}$ & 17 \\
\hline 15 & $-0,23$ & $-0,08(7)^{* *}--0,20(6 ; 14)^{*}$ & 17 \\
\hline 16 & $-0,30$ & $-0,10(7)^{* *}--0,28(14)^{*}$ & 17 \\
\hline 17 & $-0,44$ & $-0,18(7)^{*}--0,36(6)^{*}$ & 17 \\
\hline 18 & $-0,18$ & $-0,07(7)^{* * *}--0,19(5 ; 15)^{*}$ & 17 \\
\hline 19 & $-0,43$ & $-0,20(7 ; 8 ; 12)^{*}-0,37(6)^{*}$ & 17 \\
\hline 20 & $-0,30$ & $-0,09(12)^{* *}--0,27(14)^{*}$ & 17 \\
\hline 21 & $-0,34$ & $-0,11(7)^{*}--0,28(15)^{*}$ & 17 \\
\hline 22 & $-0,10$ & $-0,06(9 ; 17)^{* * *}--0,14(12)^{*}$ & 17 \\
\hline 23 & $-0,40$ & $-0,13(1)^{*}--0,39(4)^{*}$ & 17 \\
\hline 24 & $-0,30$ & $-0,14(10)^{*}--0,24(14)^{*}$ & 17 \\
\hline 25 & $-0,25$ & $-0,09(7)^{* *}--0,21(16)^{*}$ & 17 \\
\hline 26 & $-0,26$ & $-0,08(1)^{* *}--0,22(15)^{*}$ & 17 \\
\hline 27 & $-0,20$ & $-0,07(10)^{* * *}--0,18(14)^{*}$ & 17 \\
\hline 28 & $-0,22$ & $-0,08(7)^{* * *}--0,17(4 ; 9 ; 15 ; 16)^{*}$ & 17 \\
\hline 29 & $-0,43$ & $-0,16(7 ; 12)^{*}--0,43(11)^{*}$ & 17 \\
\hline 30 & $-0,27$ & $-0,08(7)^{* * *}--0,26(9 ; 11)^{*}$ & 17 \\
\hline 31 & $-0,31$ & $-0,09(7)^{* *}--0,32(4)^{*}$ & 17 \\
\hline 32 & $-0,26$ & $-0,10(11)^{* *}--0,25(3)^{*}$ & 17 \\
\hline 33 & $-0,10$ & $-0,07(2 ; 11 ; 14 ; 15)^{* * *}--0,10(1 ; 17)^{* *}$ & 17 \\
\hline 34 & $-0,20$ & $-0,08\left(2^{* *} ; 11^{* * *}\right)--0,18(12)^{*}$ & 17 \\
\hline 35 & $-0,19$ & $-0,06(1)^{* * *}--0,22(8)^{*}$ & 17 \\
\hline 36 & $-0,37$ & $-0,16(1 ; 12)^{*}--0,32(6)^{*}$ & 17 \\
\hline 37 & $-0,39$ & $-0,18(1)^{*}--0,30(15)^{*}$ & 17 \\
\hline 38 & $-0,24$ & $-0,11(7)^{* *}--0,21(5)^{*}$ & 17 \\
\hline
\end{tabular}

$r=$ Coeficiente de Correlação de Pearson; ${ }^{*}=p<0,001 ;{ }^{* *}=p<0,01 ;{ }^{* * *}=p<0,05$

Todos os itens do IHS-Del-Prette mostraram correlações significativas ao nível de $p<$ 0,001 com o escore total do SPIN, nas quais todos os coeficientes variaram de $-0,10 \mathrm{a}-0,44$, ou seja, com todas as correlações situadas na faixa de moderada a boa.

Observaram-se 17 correlações entre cada um dos itens do IHS-Del-Prette e os itens individuais do SPIN. As menores correlações encontradas foram entre os itens 2 (pedir mudança de conduta) do IHS e 16 (evitar falar com autoridades) do SPIN; 4 (interromper a 
fala do outro) do IHS com o 7 (sentir incômodo por transpirar) e o 12 (evitar situações em que posso ser criticado) do SPIN; 22 (recusar pedidos abusivos) do IHS com o 9 (evitar ser o centro das atenções) e 17 (sentir incômodo em tremer ou estremecer) do SPIN; 35 (expressar sentimento positivo) do IHS e 1 (temer autoridades) do SPIN, sendo o $r=-0,06$, dentre outras com os coeficientes abaixo de - 0,10 .

Em contrapartida, as maiores correlações foram entre os itens 9 (falar a público desconhecido), 14 (falar a público conhecido) e 29 (fazer perguntas a conhecidos) do IHSDel-Prette e o 11 (evitar dar discursos) do SPIN, sendo os coeficientes iguais a - 0,62, - 0,53, e - 0,43, respectivamente. Este item do SPIN foi, portanto, o que se correlacionou de forma melhor e mais significativa com diferentes itens do IHS. Outros itens do SPIN que também se correlacionaram significativamente foram o 4 (evitar falar com estranhos) com os itens 1 (manter conversa com desconhecidos), 23 (fazer pergunta a desconhecido) e 31 (cumprimentar desconhecidos) do IHS; o 6 (evitar falar com pessoas por medo de embaraço) com os itens 8 (participar de conversação), 17 (encerrar conversação), 19 (abordar autoridade) e 36 (manter conversação) do IHS; o 11 (evitar dar discursos) com o item 11 (discordar de autoridade) do IHS; e o 15 (temer ficar envergonhado) com o 37 (lidar com chacotas) do IHS, apresentando correlações que variaram de - 0,30 a - 0,39.

Foram analisadas as correlações entre o IHS-Del-Prette, em sua escala total e seus cinco fatores isolados, e as três subescalas do SPIN (de medo, evitação e sintomas fisiológicos), cujos dados são apresentados na Tabela 13. 
Tabela 13 - Coeficientes de Correlação entre o IHS total e seus cinco fatores isolados com as subescalas do SPIN em uma amostra da população geral $(\mathrm{N}=1006)$

\begin{tabular}{llcc}
\hline \multirow{2}{*}{ IHS } & \multicolumn{3}{c}{ CORRELAÇÃO COM AS SUBESCALAS DO SPIN $(\boldsymbol{r})$} \\
\cline { 2 - 4 } & Medo & Evitação & Sintomas fisiológicos \\
\hline Escala Total & $-0,63^{*}$ & $-0,68^{*}$ & $-0,52^{*}$ \\
Fator 1 & $-0,50^{*}$ & $-0,56^{*}$ & $-0,40^{*}$ \\
Fator 2 & $-0,38^{*}$ & $-0,42^{*}$ & $-0,32^{*}$ \\
Fator 3 & $-0,54^{*}$ & $-0,56^{*}$ & $-0,48^{*}$ \\
Fator 4 & $-0,44^{*}$ & $-0,59^{*}$ & $-0,41^{*}$ \\
Fator 5 & $-0,36^{*}$ & $-0,38^{*}$ & $-0,27^{*}$ \\
\hline
\end{tabular}

$r=$ Coeficiente de Correlação de Pearson; ${ }^{*}=p<0,001$

Detectaram-se correlações significativas para todos os aspectos analisados relativos tanto ao escore total quanto aos escores parciais dos fatores isolados do IHS-Del-Prette e as subescalas do SPIN. No geral, o escore total do IHS foi o que melhor se correlacionou com as subescalas do SPIN, destacando-se como a maior correlação evidenciada. As correlações do escore total do IHS e as subescalas de medo e evitação do SPIN foram altas; e em relação à subescala de sintomas fisiológicos, a correlação foi moderada. Os Fatores 1, 3 e 4 se correlacionaram de forma moderada com todas as subescalas do SPIN, com coeficientes variando de - 0,40 a - 0,56. Já o Fator 2 demonstrou uma correlação moderada apenas com a subescala de evitação, sendo as demais correlações baixas. O Fator 5 apresentou correlações baixas com todas as subescalas, embora significativas, cujos coeficientes variaram de $-0,27$ a $-0,38$.

\subsubsection{Validade discriminativa e preditiva do IHS-Del-Prette}

Para a avaliação da validade discriminativa do IHS-Del-Prette, utilizaram-se os dados da amostra de 86 sujeitos submetidos à confirmação diagnóstica do TAS pela Entrevista Clínica Estruturada (SCID/DSM-IV). Inicialmente, realizou-se a análise dos dados por meio da curva ROC que se encontra ilustrada na Figura 3. 


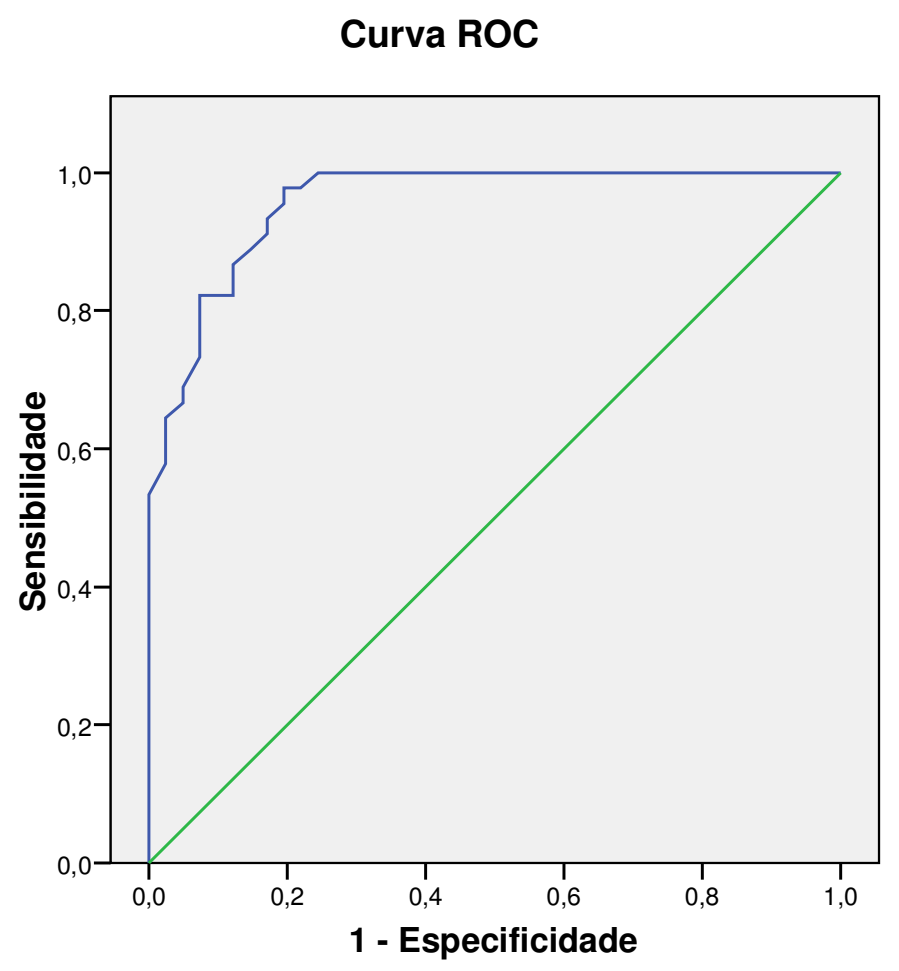

Figura 3. Área sob a curva ROC do escore total do IHS para uma amostra de casos e nãocasos de TAS $(\mathrm{N}=86)$

A área sob a curva encontrada foi de $0,96(p<0,001)$, com erro padrão de 0,02 , e intervalo de confiança de $95 \%$ entre 0,92 e 0,99 .

Calculou-se também a sensibilidade, especificidade, valor preditivo positivo, valor preditivo negativo e taxa de classificação incorreta para vários pontos (escores) de corte do IHS-Del-Prette, visando identificar aquele mais apropriado para o diagnóstico do TAS. Os dados obtidos são apresentados na Tabela 14. 
Tabela 14 - Valores relativos à sensibilidade, especificidade, valor preditivo positivo, valor preditivo negativo e taxa de classificação incorreta para diferentes pontos de corte do IHS em uma amostra de casos $(\mathrm{N}=45)$ e não-casos de TAS $(\mathrm{N}=41)$

\begin{tabular}{cccccc}
\hline Escore de corte & Sensibilidade & Especificidade & VPP & VPN & TCI \\
\hline $\mathbf{8 0}$ & 0,73 & 0,93 & 0,92 & 0,76 & 0,17 \\
$\mathbf{8 2}$ & 0,78 & 0,93 & 0,92 & 0,79 & 0,15 \\
$\mathbf{8 3}$ & 0,82 & 0,93 & 0,92 & 0,83 & 0,13 \\
$\mathbf{8 4}$ & 0,82 & 0,88 & 0,88 & 0,82 & 0,15 \\
$\mathbf{8 5}$ & 0,84 & 0,88 & 0,88 & 0,84 & 0,14 \\
$\mathbf{8 6}$ & 0,87 & 0,88 & 0,89 & 0,86 & 0,13 \\
$\mathbf{8 7}$ & 0,89 & 0,85 & 0,87 & 0,88 & 0,13 \\
$\mathbf{8 8}$ & 0,91 & 0,83 & 0,85 & 0,89 & 0,13 \\
$\mathbf{8 9}$ & 0,93 & 0,83 & 0,86 & 0,92 & 0,12 \\
$\mathbf{9 2}$ & 0,96 & 0,80 & 0,84 & 0,94 & 0,12 \\
$\mathbf{9 4}$ & 0,98 & 0,80 & 0,85 & 0,97 & 0,10 \\
$\mathbf{9 5}$ & 0,98 & 0,78 & 0,83 & 0,97 & 0,12 \\
$\mathbf{9 7}$ & 1,00 & 0,76 & 0,82 & 1,00 & 0,12 \\
$\mathbf{9 9}$ & 1,00 & 0,71 & 0,79 & 1,00 & 0,14 \\
$\mathbf{1 0 2}$ & 1,00 & 0,63 & 0,75 & 1,00 & 0,17 \\
$\mathbf{1 0 5}$ & 1,00 & 0,61 & 0,74 & 1,00 & 0,19 \\
\hline
\end{tabular}

$\mathrm{VPP}=$ valor preditivo positivo; $\mathrm{VPN}=$ valor preditivo negativo; $\mathrm{TCI}=$ taxa de classificação incorreta

Os escores de corte entre 88 e 95 foram aqueles que melhor equilibraram os valores de sensibilidade, especificidade, valor preditivo positivo e negativo, com taxa de classificação incorreta variando de 0,10 a 0,13 . Contudo, os valores entre os escores de corte 84 e 97 evidenciaram pouca variação, e taxa de classificação incorreta variando de 0,10 a 0,15 . Em geral, quanto mais alto o valor critério selecionado (escore de corte), maior foi a sua sensibilidade e valor preditivo negativo, e menor foi a especificidade e valor preditivo positivo. Para finalidades diagnósticas, o escore de corte 94 foi o que melhor distinguiu os indivíduos com e sem TAS, maximizando os valores de sua sensibilidade e especificidade e com uma taxa de classificação incorreta menor.

Para o escore de corte 102, observou-se uma diminuição em torno de $17 \%$ na especificidade e $10 \%$ no valor preditivo positivo, mantendo-se a sensibilidade e valor preditivo negativo bastante expressivos, com uma taxa de classificação incorreta de 0,17 . Já o 
escore 82 favoreceu um aumento em torno de $13 \%$ para a especificidade e $7 \%$ para o valor preditivo positivo, e uma diminuição em torno de $18 \%$ para a sensibilidade e $15 \%$ para o valor preditivo negativo, com uma taxa de classificação incorreta de 0,15 .

O IHS-Del-Prette demonstrou distinguir significativamente indivíduos com e sem TAS $\left(t_{(84)}=-11,61, p<0,001\right)$, avaliados pela SCID, atestando assim sua validade discriminativa e preditiva para esse diagnóstico. A diferença entre as médias dos dois grupos foi de 39,96, que é um grande efeito $(d=16,41)$, segundo a classificação de Cohen (1988).

Ainda com relação à validade discriminativa do IHS-Del-Prette, o grupo caso $(\mathrm{N}=45)$ teve uma média de $67,84(\mathrm{DP}=15,83)$ para os escores totais comparada com 107,80 $(\mathrm{DP}=$ 16,07) do grupo não-caso $(\mathrm{N}=41)$. Em contrapartida, o grupo caso obteve uma média de $36,58(\mathrm{DP}=11,75)$ para os escores totais do SPIN comparada com 7,80 $(\mathrm{DP}=4,29)$ do grupo não-caso.

Os escores médios de cada um dos itens do IHS-Del-Prette, com seus respectivos desvios-padrões, valores t e probabilidades associadas foram calculados para os grupos caso ( $\mathrm{N}=45)$ e não-caso $(\mathrm{N}=41)$, conforme apresentado na Tabela 15.

Tabela 15 - Escores médios de cada item do IHS com seus respectivos desvios-padrões e Testes t para os grupos caso $(\mathrm{N}=45)$ e não-caso de TAS $(\mathrm{N}=41)$

(continua)

\begin{tabular}{lcccc}
\hline \multicolumn{1}{c}{ Itens do IHS } & $\begin{array}{c}\text { Grupo } \\
\text { Caso }\end{array}$ & $\begin{array}{c}\text { Grupo } \\
\text { Não-caso }\end{array}$ & $\begin{array}{c}\text { Teste t } \\
\left(t_{(84)}=\right)\end{array}$ & Probabilidade \\
\hline 1. Manter conversa com desconhecidos & $0,78(0,93)$ & $2,32(1,19)$ & $-6,64^{*}$ & $p<0,001^{* *}$ \\
2. Pedir mudança de conduta & $2,42(1,29)$ & $2,76(0,94)$ & $-1,38^{*}$ & $p=0,171^{\text {(NS) }}$ \\
3. Agradecer elogios & $3,09(1,08)$ & $3,29(1,08)$ & $-0,87$ & $p=0,385^{\text {(NS) }}$ \\
4. Interromper a fala do outro & $0,89(1,21)$ & $1,88(1,19)$ & $-3,82$ & $p<0,001^{* *}$ \\
5. Cobrar dívida de amigo & $1,04(1,15)$ & $2,05(1,28)$ & $-3,83$ & $p<0,001^{* *}$ \\
6. Elogiar outrem & $2,31(1,29)$ & $2,95(1,02)$ & $-2,56^{*}$ & $p=0,012^{* *}$ \\
7. Apresentar-se a outra pessoa & $0,56(1,08)$ & $1,54(1,19)$ & $-4,02$ & $p<0,001^{* *}$ \\
8. Participar de conversação & $2,04(1,31)$ & $3,49(0,95)$ & $-5,87^{*}$ & $p<0,001^{* *}$ \\
9. Falar a público desconhecido & $1,11(1,25)$ & $2,98(1,06)$ & $-7,43$ & $p<0,001^{* *}$ \\
10. Expressar sentimento positivo & $1,64(1,33)$ & $2,51(1,25)$ & $-3,11$ & $p=0,003^{* *}$ \\
11. Discordar de autoridade & $0,78(1,06)$ & $2,20(1,40)$ & $-5,25^{*}$ & $p<0,001^{* *}$ \\
12. Abordar para relação sexual & $0,51(0,92)$ & $1,71(1,35)$ & $-4,76^{*}$ & $p<0,001^{* *}$ \\
13. Reagir a elogio & $2,00(1,19)$ & $3,12(1,12)$ & $-4,49$ & $p<0,001^{* *}$ \\
14. Falar a público conhecido & $1,42(1,34)$ & $2,90(1,20)$ & $-5,38$ & $p<0,001^{* *}$
\end{tabular}


(conclusão)

\begin{tabular}{|c|c|c|c|c|}
\hline Itens do IHS & $\begin{array}{c}\text { Grupo } \\
\text { Caso }\end{array}$ & $\begin{array}{c}\text { Grupo } \\
\text { Não-caso }\end{array}$ & $\begin{array}{l}\text { Teste } \mathbf{~} \\
\left(t_{(84)}=\right)\end{array}$ & Probabilidade \\
\hline 15. Lidar com críticas injustas & $2,33(1,40)$ & $3,17(1,24)$ & $-2,94^{*}$ & $p=0,004^{* *}$ \\
\hline 16. Discordar do grupo & $1,93(1,23)$ & $3,20(1,08)$ & $-5,03$ & $p<0,001^{* *}$ \\
\hline 17. Encerrar conversação & $1,91(1,10)$ & $3,27(0,90)$ & $-6,22$ & $p<0,001^{* *}$ \\
\hline 18. Lidar com crítica dos pais & $2,82(1,05)$ & $3,27(0,67)$ & $-2,37^{*}$ & $p=0,021^{* *}$ \\
\hline 19. Abordar autoridade & $1,04(1,30)$ & $2,98(1,01)$ & $-7,65$ & $p<0,001^{* *}$ \\
\hline 20. Declarar sentimento amoroso & $1,29(1,31)$ & $2,59(1,20)$ & $-4,77$ & $p<0,001^{* *}$ \\
\hline 21. Devolver mercadoria defeituosa & $2,04(1,31)$ & $3,39(0,95)$ & $-5,49^{*}$ & $p<0,001^{* *}$ \\
\hline 22. Recusar pedidos abusivos & $1,60(1,37)$ & $2,20(1,23)$ & $-2,11$ & $p=0,038^{* *}$ \\
\hline 23. Fazer pergunta a desconhecido & $1,64(1,25)$ & $3,20(0,87)$ & $-6,73^{*}$ & $p<0,001^{* *}$ \\
\hline 24. Encerrar conversa ao telefone & $2,04(1,41)$ & $3,39(0,89)$ & $-5,33^{*}$ & $p<0,001^{* *}$ \\
\hline 25. Lidar com críticas justas & $2,27(1,16)$ & $3,02(0,88)$ & $-3,44^{*}$ & $p=0,001^{* *}$ \\
\hline 26. Pedir favores a desconhecidos & $1,91(1,44)$ & $3,00(1,12)$ & $-3,93^{*}$ & $p<0,001^{* *}$ \\
\hline 27. Expressar desagrado a amigos & $1,24(1,32)$ & $2,07(1,21)$ & $-3,03$ & $p=0,003^{* *}$ \\
\hline 28. Elogiar familiares & $2,91(0,95)$ & $3,34(0,66)$ & $-2,42$ & $p=0,018^{* *}$ \\
\hline 29. Fazer pergunta a conhecidos & $1,22(1,06)$ & $2,80(1,19)$ & $-6,52$ & $p<0,001^{* *}$ \\
\hline 30. Defender outrem em grupo & $1,69(1,18)$ & $2,71(1,23)$ & $-3,91$ & $p<0,001^{* *}$ \\
\hline 31. Cumprimentar desconhecidos & $1,44(1,14)$ & $2,46(1,23)$ & $-3,99$ & $p<0,001^{* *}$ \\
\hline 32. Pedir ajuda a amigos & $1,56(1,29)$ & $2,93(1,33)$ & $-4,85$ & $p<0,001^{* *}$ \\
\hline 33. Negociar uso de preservativo & $3,53(0,92)$ & $3,63(0,77)$ & $-0,55$ & $p=0,584^{(\mathrm{NS})}$ \\
\hline 34. Recusar pedido abusivo & $2,13(1,42)$ & $3,07(1,06)$ & $-3,49^{*}$ & $p=0,001^{* *}$ \\
\hline 35. Expressar sentimento positivo & $2,38(1,28)$ & $3,17(1,02)$ & $-3,18^{*}$ & $p=0,002^{* *}$ \\
\hline 36. Manter conversação & $1,71(1,20)$ & $2,95(0,97)$ & $-5,28^{*}$ & $p<0,001^{* * *}$ \\
\hline 37. Pedir favores a colegas & $2,29(1,08)$ & $3,39(0,95)$ & $-5,01$ & $p<0,001^{* *}$ \\
\hline 38. Lidar com chacotas & $2,29(1,29)$ & $2,93(1,06)$ & $-2,52$ & $p=0,014^{* *}$ \\
\hline
\end{tabular}

${ }^{*}=$ condição com variâncias desiguais; ${ }^{* *}=$ diferença significativa; NS = diferença não significativa.

Observou-se diferença significativa entre os grupos em 35 das habilidades sociais avaliadas. Para o grupo caso, as habilidades sociais com escores mais altos foram as representadas pelos itens 33, 3, 28 e 18. Considerando o grupo não-caso, as habilidades sociais com escores mais altos foram aquelas representadas pelos itens $33,8,37,24,21,28,3$, 18 e 17. Todas as habilidades com escores mais altos apresentadas pelo grupo caso foram compartilhadas pelo grupo não-caso. Apenas em relação aos itens 2, 3 e 33, os dois grupos não diferiram, demonstrando assim uma diferença significativa para a maioria das habilidades sociais, com pontuações médias consideravelmente mais altas para o grupo não-caso em todas as habilidades. 
No que diz respeito ao poder discriminativo dos itens, o escore médio e a porcentagem de freqüência nos escores de 0 a 4 em cada item para os grupos caso e não-caso de TAS são exibidos na Tabela 16.

Tabela 16 - Distribuição dos itens do IHS em função do escore médio, desvio-padrão e porcentagem de frequiência nos escores de 0 a 4 para os grupos caso $(\mathrm{N}=45)$ e não-caso de TAS $(\mathrm{N}=41)$

\begin{tabular}{|c|c|c|c|c|c|c|c|c|c|c|c|c|c|c|}
\hline \multirow{3}{*}{$\begin{array}{c}\text { Item } \\
\text { IHS }\end{array}$} & \multicolumn{7}{|c|}{ GRUPO CASO } & \multicolumn{7}{|c|}{ GRUPO NÃO-CASO } \\
\hline & \multirow{2}{*}{ Média } & \multirow{2}{*}{ DP } & \multicolumn{5}{|c|}{ Escores (\%) } & \multirow{2}{*}{ Média } & \multirow{2}{*}{ DP } & \multicolumn{5}{|c|}{ Escores (\%) } \\
\hline & & & $\mathbf{0}$ & 1 & 2 & 3 & 4 & & & $\mathbf{0}$ & 1 & 2 & 3 & 4 \\
\hline 1 & 0,78 & 0,93 & 46,7 & 35,6 & 13,3 & 2,2 & 2,2 & 2,32 & 1,19 & 2,4 & 31,7 & 17,1 & 29,3 & 19,5 \\
\hline 2 & 2,42 & 1,29 & 11,1 & 11,1 & 26,7 & 26,7 & 24 & & 0,94 & 4,9 & 2,4 & 21,9 & 53,7 & 17,1 \\
\hline 3 & 3,09 & 1,08 & 2,2 & 8,9 & 13,3 & 28,9 & 46 & 3,29 & 1,08 & 0,0 & 12,2 & 9,8 & 14,6 & 63,4 \\
\hline 4 & 0,89 & 1,21 & 48,9 & 33,3 & 6,7 & 2,2 & 0 & & 1,19 & 9,8 & 34,1 & 26,8 & 17,1 & 12,2 \\
\hline 5 & 1,04 & 1,15 & 42,2 & 28,9 & 13,4 & 13,3 & 2, & & 1,28 & 12,2 & 24,4 & 26,8 & 19,5 & 17,1 \\
\hline 6 & 2,31 & 1,29 & 11,1 & 15,6 & 26,7 & 24,4 & 22,2 & 2,95 & 1,02 & 2,4 & 7,3 & 17,1 & 39,0 & 34,2 \\
\hline 7 & 0,56 & 1,08 & 68,9 & 20,0 & 4,4 & 0,0 & 6,7 & 1,54 & 1,19 & 22,0 & 31,6 & 22,0 & 19,5 & 4,9 \\
\hline 8 & 2,04 & 1,31 & 17,8 & 13,3 & 31,1 & 22,2 & 15 & & 0,95 & 4,9 & 0,0 & 2,4 & 26,8 & 65,9 \\
\hline 9 & 1,11 & 1,25 & 40,0 & 31,1 & 15,6 & 4,4 & 8,9 & 2,98 & 1,06 & 4,9 & 2,4 & 19,5 & 36,6 & 36,6 \\
\hline 10 & & 1,33 & 24,4 & 26,7 & 20,0 & 17,8 & 11,1 & & 1,25 & 4,9 & 21,9 & 17,1 & 29,3 & 26,8 \\
\hline 11 & & 1,06 & 55,6 & 22,2 & 13,3 & 6,7 & & & 1,40 & 12,2 & 26,8 & 4,6 & 22,0 & 24,4 \\
\hline 12 & 0,51 & 0,92 & 68,9 & 17,8 & 8,9 & 2,2 & & 1,71 & 1,35 & 24,4 & 24,4 & 17,1 & 24,4 & 9,7 \\
\hline 13 & 2,00 & 1,19 & 11,1 & 26,7 & 22,2 & 31,1 & 8 & 3, & 1,12 & 2,4 & 9,8 & 12,2 & 24,4 & 51,2 \\
\hline 14 & & 1,34 & 26,7 & 40,0 & 11,1 & 8,9 & & & 1,20 & 2,4 & 14,6 & 17,1 & 22,0 & 43,9 \\
\hline 15 & 233 & 1,40 & 11,1 & 24,4 & 11,1 & 26,7 & 26 & 317 & 1,24 & 7,3 & 7,3 & 2,5 & 26,8 & 56,1 \\
\hline 16 & & 1,23 & 15,6 & 20,0 & 31,1 & 22,2 & 11, & & 1,08 & 2,4 & 7,3 & 12,2 & 24,4 & 53,7 \\
\hline 17 & & & 11,1 & 24,4 & 33,4 & 24,4 & & & 0,90 & & 2,4 & 4 & 41,5 & 46,3 \\
\hline 18 & 2, & 1,0 & 2,2 & 11,1 & 17,8 & 40,0 & 28 , & & 0,67 & 0,0 & 0,0 & 12,2 & 48,8 & 39,0 \\
\hline 19 & 1,0 & 1,30 & 46,7 & 26,7 & 11,0 & 6,7 & & & 1,01 & 0,0 & 14,6 & 7,3 & 43,9 & 34,2 \\
\hline 20 & & 1,31 & 35,6 & 28,9 & 15,6 & 11,0 & & & 1,20 & 0,0 & 26,8 & 19,5 & 22,0 & 31,7 \\
\hline 21 & 2,04 & 1,31 & 11,1 & 31,1 & 17,8 & 22,2 & 17 & & 0,95 & 2,4 & 2,4 & 9,8 & 24,4 & 61,0 \\
\hline 22 & 1,60 & 1,37 & 31,1 & 15,6 & 26,6 & 15,6 & 11, & & 1,23 & 12,2 & 14,6 & 29,3 & 29,3 & 14,6 \\
\hline 23 & & 1,25 & 22,2 & 24,4 & 28,9 & 15,6 & & & 0,87 & 0,0 & 4,9 & 14,6 & 36,6 & 43,9 \\
\hline 24 & & & 20,0 & 15,6 & 24,4 & 20,0 & & & 0,89 & & 2,4 & 4,9 & 34,2 & 56,1 \\
\hline 25 & & 1,16 & 6,6 & 20,0 & 28,9 & 28,9 & & 3. & 0,88 & 0 & 7,3 & 14,6 & 46,4 & 31,7 \\
\hline 26 & 1 & 1,44 & 22,2 & 22,2 & 15,6 & 22,2 & & & 1,12 & 4,9 & 2,4 & 24,4 & 24,4 & 43,9 \\
\hline 27 & & 1,32 & 35,6 & 33,3 & 13,3 & 6,7 & & & 1,21 & 4,9 & 36,6 & 22,0 & 19,5 & 17,0 \\
\hline 28 & 2,91 & 0,95 & 0,0 & 8,9 & 22,2 & 37,8 & 31 , & & 0,66 & 0,0 & 0,0 & 9,8 & 46,3 & 43,9 \\
\hline 29 & & 1,06 & 28,9 & 33,4 & 28,9 & 4,4 & & & 1,19 & 0,0 & 17,1 & 29,3 & 9,8 & 43,8 \\
\hline 30 & & 1 , & 20,0 & 24,4 & 26,8 & 24,4 & & & 1,23 & 4,9 & 14,6 & 19,5 & 26,8 & 34,2 \\
\hline 31 & & 1,1 & 26,7 & 24,4 & 28,9 & 17,8 & & & 1,23 & 2, & 26,8 & 19,5 & 24,4 & 26,8 \\
\hline 32 & & 1,29 & 22,2 & 33,3 & 24,5 & 6,7 & 13 & & 1,33 & 7,3 & 12,1 & 9,8 & 22,0 & 48,8 \\
\hline 33 & 3 , & 0,92 & 2,2 & 2,2 & 8,9 & 13,4 & & & 0,77 & 0,0 & 4,9 & 2,4 & 17,1 & 75,6 \\
\hline 34 & 2,13 & 1,42 & 17,8 & 17,8 & 20,0 & 22,2 & 22 & 3,07 & 1,06 & 2,5 & 7,3 & 14,6 & 31,7 & 43,9 \\
\hline 35 & 2,38 & 1,28 & 8,8 & 15,6 & 31,1 & 17,8 & 26,7 & & 1,02 & 2,4 & 4,9 & 14,6 & 29,3 & 48,8 \\
\hline 36 & 1,71 & 1,20 & 17,8 & 28,9 & 24,4 & 22,2 & 6 & 2,95 & 0,97 & 2, & 7,3 & 12,2 & 48,8 & 29,3 \\
\hline 37 & 2,29 & 1,08 & 4,5 & 20,0 & 31,1 & 31,1 & 13 , & 5,3 & 0,95 & 0, & 7,3 & 9,8 & 19,5 & 63,4 \\
\hline 38 & 2,29 & 1,29 & 11,1 & 17,8 & 22,2 & 28,9 & 20,0 & 2,93 & 1,06 & 4,9 & 4,9 & 14,6 & 43,9 & 31,7 \\
\hline
\end{tabular}

$\mathrm{DP}=$ desvio-padrão; $\%=$ Porcentagem 
Os itens $1,8,9,11,14,19,23$ e 29 foram os oito primeiros itens com maior diferença entre as médias de pontuação nos escores $(1,54,1,45,1,87,1,42,1,48,1,94,1,56$ e 1,58, respectivamente). Para o grupo caso, esses itens apresentaram os maiores percentuais de pontuação nos escores menores ou iguais a um em comparação ao grupo não-caso, a saber: 82,3, 31,1, 71,1, 77,8, 66,7, 73,4, 46,6 e 62,3\%, respectivamente. Assim sendo, os itens 19, 9, $29,23,1,14,8$ e 11 foram, ordenadamente, os oito itens que evidenciaram maior poder discriminativo para os grupos caso e não-caso de TAS. Não obstante, para o grupo não-caso, os itens 8, 9, 19 e 23 apresentaram percentuais bastante expressivos nos escores maiores ou iguais a três: $92,7,73,2,78,1$ e $80,5 \%$, respectivamente, corroborando, deste modo, o poder discriminativo destes itens.

Os itens 20,21, 24, 17 e 32 também apresentaram poder discriminativo relativamente alto, com uma diferença entre as médias de pontuação nos escores registrados pelos dois grupos variando de 1,30 a 1,37. Estes itens receberam os seguintes percentuais de pontuação nos escores menores ou iguais a um: $64,5,42,2,35,6,35,5$ e 55,5\%, respectivamente. Para o grupo não-caso, os itens 21, 24, 17 e 32 demonstraram percentuais bastante expressivos nos escores maiores ou iguais a três: $85,4,90,3,87,8$ e 70,8\%, respectivamente, confirmando assim o poder discriminativo destes itens.

Além disso, calculou-se o tamanho do efeito para cada item, visando verificar o quanto os escores médios dos dois grupos nos itens diferiam em termos de desvios-padrões. Esses dados são apresentados na Tabela 17. 
Tabela 17 - Distribuição dos itens do Inventário de Habilidades Sociais em função da diferença entre os escores médios, média dos desvios-padrões e tamanho do efeito em uma amostra de casos $(\mathrm{N}=45)$ e não-casos de TAS $(\mathrm{N}=41)$

\begin{tabular}{|c|c|c|c|}
\hline Item do IHS & $\begin{array}{l}\text { Diferença entre } \\
\text { as médias }\end{array}$ & $\begin{array}{c}\text { Média dos } \\
\text { desvios-padrões }\end{array}$ & $\begin{array}{l}\text { Tamanho do } \\
\text { efeito }(d)\end{array}$ \\
\hline 1. Manter conversa com desconhecidos & $-1,54$ & 1,06 & 1,45 \\
\hline 2. Pedir mudança de conduta & $-0,34$ & 1,12 & 0,30 \\
\hline 3. Agradecer elogios & $-0,20$ & 1,08 & 0,19 \\
\hline 4. Interromper a fala do outro & $-0,99$ & 1,20 & 0,82 \\
\hline 5. Cobrar dívida de amigo & $-1,01$ & 1,22 & 0,83 \\
\hline 6. Elogiar outrem & $-0,64$ & 1,16 & 0,55 \\
\hline 7. Apresentar-se a outra pessoa & $-0,98$ & 1,14 & 0,86 \\
\hline 8. Participar de conversação & $-1,45$ & 1,13 & 1,28 \\
\hline 9. Falar a público desconhecido & $-1,87$ & 1,16 & 1,61 \\
\hline 10. Expressar sentimento positivo & $-0,87$ & 1,29 & 0,67 \\
\hline 11. Discordar de autoridade & $-1,42$ & 1,23 & 1,15 \\
\hline 12. Abordar para relação sexual & $-1,20$ & 1,14 & 1,05 \\
\hline 13. Reagir a elogio & $-1,12$ & 1,16 & 0,97 \\
\hline 14. Falar a público conhecido & $-1,48$ & 1,27 & 1,17 \\
\hline 15. Lidar com críticas injustas & $-0,84$ & 1,32 & 0,64 \\
\hline 16. Discordar do grupo & $-1,27$ & 1,16 & 1,09 \\
\hline 17. Encerrar conversação & $-1,36$ & 1,00 & 1,36 \\
\hline 18. Lidar com críticas dos pais & $-0,45$ & 0,86 & 0,52 \\
\hline 19. Abordar autoridade & $-1,94$ & 1,16 & 1,67 \\
\hline 20. Declarar sentimento amoroso & $-1,30$ & 1,26 & 1,03 \\
\hline 21. Devolver mercadoria defeituosa & $-1,35$ & 1,13 & 1,19 \\
\hline 22. Recusar pedidos abusivos & $-0,60$ & 1,30 & 0,46 \\
\hline 23. Fazer pergunta a desconhecido & $-1,56$ & 1,06 & 1,47 \\
\hline 24. Encerrar conversa ao telefone & $-1,35$ & 1,15 & 1,17 \\
\hline 25. Lidar com críticas justas & $-0,75$ & 1,02 & 0,74 \\
\hline 26. Pedir favores a desconhecidos & $-1,09$ & 1,28 & 0,85 \\
\hline 27. Expressar desagrado a amigos & $-0,83$ & 1,26 & 0,66 \\
\hline 28. Elogiar familiares & $-0,43$ & 0,80 & 0,54 \\
\hline 29. Fazer pergunta a conhecidos & $-1,58$ & 1,12 & 1,41 \\
\hline 30. Defender outrem em grupo & $-1,02$ & 1,20 & 0,85 \\
\hline 31. Cumprimentar desconhecidos & $-1,02$ & 1,18 & 0,86 \\
\hline 32. Pedir ajuda a amigos & $-1,37$ & 1,31 & 1,05 \\
\hline 33. Negociar uso de preservativo & $-0,10$ & 0,84 & 0,12 \\
\hline 34. Recusar pedido abusivo & $-0,94$ & 1,24 & 0,76 \\
\hline 35. Expressar sentimento positivo & $-0,79$ & 1,15 & 0,69 \\
\hline 36. Manter conversação & $-1,24$ & 1,08 & 1,15 \\
\hline 37. Pedir favores a colegas & $-1,10$ & 1,02 & 1,08 \\
\hline 38. Lidar com chacotas & $-0,64$ & 1,18 & 0,54 \\
\hline
\end{tabular}

Pela classificação de Cohen (1988), vinte e quatro itens demonstraram um efeito considerado grande, a saber: item 1, 4, 5, 7, 8, 9, 11, 12, 13, 14, 16, 17, 19, 20, 21, 23, 24, 26, 
29, 30, 31, 32, 36 e 37. Um efeito médio foi exibido pelos itens $6,10,15,18,25,27,28,34$ e

35. Os itens 2, 3, 22, 33 e 38 apresentaram um efeito pequeno.

Todos os itens que evidenciaram maior poder discriminativo $(1,8,9,11,14,19,23 \mathrm{e}$ 29) apresentaram um efeito grande. Os cinco itens que demonstraram um poder discriminativo relativamente alto $(17,20,21,24$ e 32$)$ exibiram também um efeito grande.

Tomando por base os dados normativos do estudo original, avaliou-se a presença de diferença significativa na classificação do repertório de habilidades sociais entre os sujeitos pertencentes aos grupos caso e não-caso de acordo com o gênero dos sujeitos. Os dados relativos a esta análise são exibidos na Tabela 18.

Tabela 18 - Classificação do repertório de habilidades sociais dos sujeitos pertencentes aos grupos caso $(\mathrm{N}=45)$ e não-caso de TAS $(\mathrm{N}=41)$, conforme o gênero

\begin{tabular}{|c|c|c|c|c|}
\hline \multirow{2}{*}{ CLASSIFICAÇÃO } & \multicolumn{2}{|c|}{ AMOSTRA FEMININA } & \multicolumn{2}{|c|}{ AMOSTRA MASCULINA } \\
\hline & CASO & NÃO-CASO & CASO & NÃO-CASO \\
\hline $\begin{array}{l}\text { - Repertório bastante elaborado de } \\
\text { habilidades sociais N (\%) }\end{array}$ & $0(0)$ & $14(60,9)$ & $0(0)$ & $12(66,7)$ \\
\hline $\begin{array}{l}\text { - Bom repertório de habilidades sociais } \\
\text { (acima da mediana) } \mathrm{N}(\%)\end{array}$ & $2(7,1)$ & $4(17,4)$ & $0(0)$ & $2(11,1)$ \\
\hline - Repertório mediano N (\%) & $0(0)$ & $0(0)$ & $0(0)$ & $1(5,5)$ \\
\hline $\begin{array}{l}\text { - Bom repertório de habilidades sociais } \\
\text { (abaixo da mediana) } \mathrm{N}(\%)\end{array}$ & $3(10,8)$ & $4(17,4)$ & $1(5,9)$ & $0(0)$ \\
\hline $\begin{array}{l}\text { - Repertório deficitário em habilidades } \\
\text { sociais N }(\%)\end{array}$ & $23(82,1)$ & $1(4,3)$ & $16(94,1)$ & $3(16,7)$ \\
\hline - Total $(\%)$ & $28(100)$ & $23(100)$ & $17(100)$ & $18(100)$ \\
\hline & $\chi_{(2)}^{2}=30,07$ & $\chi_{(3)}^{2}=16,82$ & $\chi_{(1)}^{2}=13,24$ & $\chi_{(3)}^{2}=17,11$ \\
\hline - Estatística & $p<0,001^{*}$ & $p=0,001^{*}$ & $p<0,001^{*}$ & $p=0,001^{*}$ \\
\hline
\end{tabular}

Foram encontradas diferenças significativas entre os sujeitos, quanto à classificação do repertório de habilidades sociais, dentro de cada um dos grupos, tanto para o gênero feminino como para o masculino. Considerando os grupos casos quer para a amostra feminina, quer para a masculina, verificou-se que maioria dos sujeitos atingiu um escore bem abaixo da 
média em relação ao seu respectivo grupo normativo, ou seja, com prejuízos quanto às habilidades sociais. Quanto ao gênero feminino, cinco sujeitos apresentaram um bom repertório de habilidades sociais, dois acima da mediana e três abaixo. Já com relação ao gênero masculino, apenas um sujeito demonstrou um bom repertório de habilidades sociais, sendo este abaixo da mediana.

A maior parte dos sujeitos pertencentes aos grupos não-casos, de ambos os gêneros, demonstrou um repertório bastante elaborado de habilidades sociais. No que diz respeito à amostra feminina, um percentual considerável de sujeitos apresentou um bom repertório de habilidades sociais, igualmente distribuído acima e abaixo da mediana, com apenas um caso apresentando um repertório deficitário em habilidades sociais. Quanto à amostra masculina, um percentual relativamente baixo apresentou uma classificação na faixa de médio a bom repertório de habilidades sociais acima da mediana. Ainda em relação a esta amostra, um percentual de $16,7 \%$ dos sujeitos foi avaliado com um repertório deficitário em habilidades sociais, sendo este percentual bem maior que o apresentado pela amostra feminina.

Tomando por referência os grupos caso e não-caso, os valores do V de Cramer foram 0,83 e 0,84 , com $p<0,001$, para as amostras feminina e masculina, respectivamente, mostrando que existe um relacionamento muito forte entre a classificação do repertório de habilidades sociais e o diagnóstico ou não de TAS. Desse modo, conclui-se que 69 e $70 \%$ da variação na classificação do repertório de habilidades sociais para o gênero feminino e masculino, respectivamente, podem ser explicados em função do diagnóstico dos sujeitos, ou seja, dos grupos a que pertencem.

\subsubsection{Análise Fatorial}

Objetivando verificar a adequação dos dados da amostra $(\mathrm{N}=1006)$ para a realização da análise fatorial, primeiramente foi obtida a medida de Kaiser-Meyer-Olkin (KMO). O 
resultado encontrado foi de 0,90 , demonstrando uma adequação ótima dos dados para a realização de tal análise.

Aplicando-se o método de análise dos componentes principais (ACP) sobre o conjunto de dados relativos ao IHS-Del-Prette, foram retidos oito fatores com base nos autovalores iguais ou acima de 1, de acordo com o critério de Kaiser, ou critério da raiz latente (ARTES, 1998), conforme pode ser observado na Tabela 19.

Tabela 19 - Análise Fatorial: Autovalores iniciais e porcentagem de variância (relativa e acumulada) dos componentes principais do IHS, obtidos em uma amostra de 1006 sujeitos da população geral

(continua)

\begin{tabular}{|c|c|c|c|}
\hline Componente Principal & Autovalores & \% de variância & $\%$ Acumulada \\
\hline 1 & 7,311 & 19,238 & 19,238 \\
\hline 2 & 2,441 & 6,423 & 25,661 \\
\hline 3 & 2,006 & 5,279 & 30,940 \\
\hline 4 & $\mathbf{1 , 5 7 7}$ & 4,150 & 35,090 \\
\hline 5 & 1,417 & 3,728 & 38,818 \\
\hline 6 & 1,216 & 3,200 & 42,018 \\
\hline 7 & 1,191 & 3,134 & 45,152 \\
\hline 8 & 1,045 & 2,750 & 47,902 \\
\hline 9 & 0,996 & 2,621 & 50,523 \\
\hline 10 & 0,957 & 2,519 & 53,042 \\
\hline 11 & 0,913 & 2,403 & 55,445 \\
\hline 12 & 0,906 & 2,385 & 57,830 \\
\hline 13 & 0,883 & 2,322 & 60,152 \\
\hline 14 & 0,852 & 2,243 & 62,395 \\
\hline 15 & 0,811 & 2,135 & 64,530 \\
\hline 16 & 0,777 & 2,044 & 66,574 \\
\hline 17 & 0,745 & 1,961 & 68,535 \\
\hline 18 & 0,729 & 1,918 & 70,453 \\
\hline 19 & 0,719 & 1,893 & 72,346 \\
\hline 20 & 0,685 & 1,802 & 74,148 \\
\hline 21 & 0,681 & 1,792 & 75,940 \\
\hline 22 & 0,665 & 1,751 & 77,691 \\
\hline 23 & 0,639 & 1,682 & 79,373 \\
\hline 24 & 0,631 & 1,661 & 81,034 \\
\hline 25 & 0,620 & 1,631 & 82,665 \\
\hline 26 & 0,606 & 1,594 & 84,259 \\
\hline 27 & 0,591 & 1,556 & 85,815 \\
\hline 28 & 0,574 & 1,510 & 87,325 \\
\hline 29 & 0,568 & 1,494 & 88,819 \\
\hline 30 & 0,550 & 1,448 & 90,267 \\
\hline
\end{tabular}


(conclusão)

\begin{tabular}{cccc}
\hline Componente Principal & Autovalores & \% de variância & \% Acumulada \\
\hline 31 & 0,534 & 1,406 & 91,673 \\
32 & 0,520 & 1,369 & 93,042 \\
33 & 0,499 & 1,314 & 94,356 \\
34 & 0,480 & 1,262 & 95,618 \\
35 & 0,465 & 1,223 & 96,841 \\
36 & 0,441 & 1,160 & 98,001 \\
37 & 0,403 & 1,061 & 99,062 \\
38 & 0,356 & 0,938 & 100,000 \\
\hline
\end{tabular}

Verificou-se que os oito fatores extraídos responderam juntos por 47,9\% da variância dos dados. Entre estes fatores, detectou-se que o Fator 1 sozinho respondeu por uma porcentagem bem maior da variância dos dados quando comparado com os demais. O Fator 8 foi o que menos respondeu pela variância dos dados. Em contrapartida, os demais fatores não retidos representaram individualmente menos que $2,7 \%$ e, quando somados, totalizaram $52,1 \%$ da variância dos dados.

Considerando apenas os fatores retidos, a Tabela 20 mostra os valores da tabela anterior corrigidos em função apenas destes fatores, evidenciando assim um ajuste desses valores por meio da soma rotacionada das cargas ao quadrado.

Tabela 20 - Análise Fatorial: Autovalores e porcentagem de variância (relativa e acumulada) dos componentes principais extraídos

\begin{tabular}{cccc}
\hline Componente Principal & Autovalores & \% de variância & \% Acumulada \\
\hline 1 & 2,895 & 7,618 & 7,618 \\
2 & 2,829 & 7,445 & 15,063 \\
3 & 2,727 & 7,176 & 22,239 \\
4 & 2,708 & 7,127 & 29,366 \\
5 & 2,134 & 5,615 & 34,981 \\
6 & 1,711 & 4,502 & 39,483 \\
7 & 1,669 & 4,391 & 43,874 \\
8 & 1,531 & 4,028 & 47,902 \\
\hline
\end{tabular}

Os oito fatores extraídos continuaram respondendo juntos por $47,9 \%$ da variância dos dados. Com essa correção aplicada sobre os valores, a porcentagem total da variância dos 
dados ficou melhor distribuída entre os fatores retidos, embora o Fator 1 permaneceu respondendo por uma porcentagem ligeiramente maior da variância dos dados.

Outra forma de obter o número de fatores extraídos em uma análise fatorial seria visualizando esses dados em um diagrama de declividade, representando o número de fatores plotado contra a quantidade de variância, conforme apresentado na Figura 4.

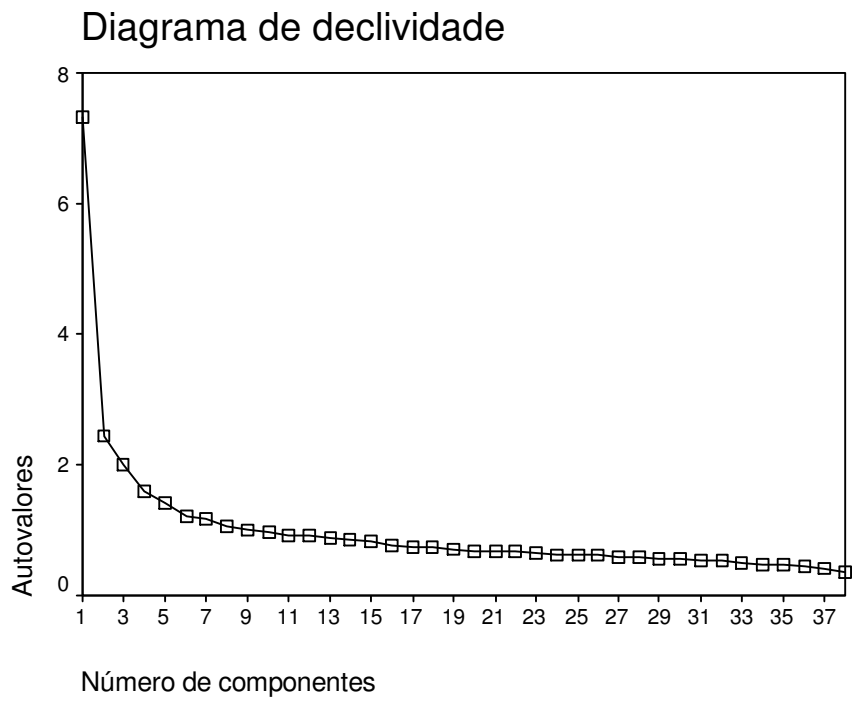

Figura 4. Diagrama de declividade da análise fatorial realizada com os dados do IHS

Neste diagrama, observa-se que os fatores decrescem até certo nível e depois formam uma linha quase horizontal. Quanto ao número de fatores a ser retido, deve-se encontrar o ponto em que o gráfico começa a ficar quase horizontal e pegar todos os valores anteriores a esse ponto, que neste caso foi oito.

Em acréscimo a essas informações, a Tabela 21 traz as comunalidades da solução com 8 fatores para os dados do IHS-Del-Prette. Comunalidades são índices atribuídos às variáveis originais (itens) que expressam, em termos percentuais, o quanto da variabilidade de cada variável é explicado pelo modelo de análise fatorial estimado (ARTES, 1998). 
Tabela 21 - Comunalidades referentes a uma solução rotacionada com 8 fatores

\begin{tabular}{cc|cc|cc}
\hline Item & Comunalidade & Item & Comunalidade & Item & Comunalidade \\
\hline 1 & 0,48 & 14 & 0,46 & 27 & 0,50 \\
2 & 0,45 & 15 & 0,54 & 28 & 0,58 \\
3 & 0,40 & 16 & 0,51 & 29 & 0,56 \\
4 & 0,40 & 17 & 0,42 & 30 & 0,49 \\
5 & 0,50 & 18 & 0,65 & 31 & 0,43 \\
6 & 0,48 & 19 & 0,49 & 32 & 0,44 \\
7 & 0,56 & 20 & 0,46 & 33 & 0,30 \\
8 & 0,45 & 21 & 0,38 & 34 & 0,46 \\
9 & 0,53 & 22 & 0,46 & 35 & 0,48 \\
10 & 0,46 & 23 & 0,42 & 36 & 0,39 \\
11 & 0,56 & 24 & 0,43 & 37 & 0,50 \\
12 & 0,56 & 25 & 0,54 & 38 & 0,51 \\
13 & 0,50 & 26 & 0,45 & & \\
\hline
\end{tabular}

Observa-se aqui um ajuste regular, o que já era de se esperar, uma vez que apenas 47,9\% da variabilidade total vem sendo explicado por essa solução. Mais especificamente, verificou-se que o item que melhor foi explicado pelos fatores foi o 18 (com 65\%) e o pior foi o $33(\operatorname{com} 30 \%)$.

A matriz da Tabela 22 mostra as correlações de cada um dos itens com os fatores, após a rotação ortogonal Varimax. Os itens com carga mínima ou maior que 0,300 foram incorporados aos fatores. No entanto, mesmo sendo adotado este critério, os itens com mais cargas em um fator específico foram agrupados juntos a ele.

Tabela 22 - Análise fatorial: Matriz dos componentes rotacionada

(continua)

\begin{tabular}{crrrrrrrr}
\hline Itens & Fator 1 & Fator 2 & Fator 3 & Fator 4 & Fator 5 & Fator 6 & Fator 7 & Fator 8 \\
\hline 12 & $\mathbf{0 , 7 0 4}$ & 0,169 & 0,140 & 0,045 & 0,090 & $-0,094$ & 0,028 & $-0,023$ \\
7 & $\mathbf{0 , 6 5 4}$ & 0,201 & 0,220 & 0,152 & $-0,030$ & $-0,075$ & 0,026 & 0,138 \\
5 & $\mathbf{0 , 6 3 7}$ & $-0,029$ & 0,069 & $-0,035$ & 0,185 & 0,215 & $-0,022$ & 0,099 \\
20 & $\mathbf{0 , 5 3 9}$ & 0,234 & 0,144 & 0,232 & 0,058 & $-0,166$ & 0,059 & $-0,056$ \\
4 & $\mathbf{0 , 4 5 0}$ & $-0,107$ & 0,031 & 0,168 & 0,182 & 0,248 & 0,094 & 0,229 \\
13 & 0,147 & $\mathbf{0 , 6 2 3}$ & $-0,015$ & 0,242 & 0,068 & 0,113 & $-0,098$ & $-0,065$ \\
37 & 0,069 & $\mathbf{0 , 5 8 3}$ & $-0,079$ & 0,106 & 0,126 & 0,143 & 0,226 & 0,220 \\
8 & $-0,055$ & $\mathbf{0 , 5 5 4}$ & 0,221 & $-0,003$ & 0,178 & $-0,027$ & 0,207 & 0,122 \\
36 & 0,137 & $\mathbf{0 , 5 4 2}$ & 0,144 & 0,071 & $-0,068$ & 0,031 & $-0,093$ & 0,199 \\
19 & 0,315 & $\mathbf{0 , 5 3 6}$ & 0,285 & 0,031 & $-0,095$ & 0,075 & 0,020 & 0,063 \\
17 & $-0,004$ & $\mathbf{0 , 4 9 7}$ & 0,246 & 0,096 & 0,129 & 0,144 & 0,191 & 0,168
\end{tabular}


(conclusão)

\begin{tabular}{crrrrrrrr}
\hline Itens & Fator 1 & Fator 2 & Fator 3 & Fator 4 & Fator 5 & Fator 6 & Fator 7 & Fator 8 \\
\hline 14 & 0,074 & 0,072 & $\mathbf{0 , 6 3 7}$ & 0,174 & 0,065 & $-0,023$ & 0,009 & 0,093 \\
29 & 0,216 & 0,180 & $\mathbf{0 , 6 2 5}$ & 0,187 & 0,165 & 0,008 & 0,173 & $-0,054$ \\
9 & 0,064 & 0,335 & $\mathbf{0 , 6 1 0}$ & $-0,139$ & $-0,046$ & 0,108 & 0,025 & 0,092 \\
11 & 0,349 & 0,035 & $\mathbf{0 , 5 9 2}$ & 0,111 & 0,234 & 0,053 & 0,121 & $-0,070$ \\
30 & 0,095 & $-0,037$ & $\mathbf{0 , 5 2 5}$ & 0,294 & 0,299 & $-0,061$ & 0,020 & 0,144 \\
28 & 0,019 & 0,037 & 0,221 & $\mathbf{0 , 7 0 9}$ & 0,124 & 0,078 & 0,093 & 0,017 \\
10 & 0,117 & 0,152 & 0,089 & $\mathbf{0 , 6 3 4}$ & $-0,062$ & 0,080 & 0,077 & $-0,046$ \\
3 & 0,109 & 0,138 & $-0,003$ & $\mathbf{0 , 5 6 9}$ & 0,016 & $-0,081$ & 0,181 & $-0,063$ \\
6 & 0,198 & $-0,110$ & 0,265 & $\mathbf{0 , 5 4 7}$ & 0,070 & $-0,029$ & 0,033 & 0,238 \\
35 & 0,007 & 0,105 & 0,010 & $\mathbf{0 , 5 3 9}$ & 0,285 & $-0,169$ & $-0,016$ & 0,268 \\
32 & 0,202 & 0,311 & $-0,152$ & $\mathbf{0 , 3 1 8}$ & 0,246 & $-0,115$ & 0,264 & 0,172 \\
15 & 0,155 & 0,075 & 0,116 & 0,116 & $\mathbf{0 , 6 8 1}$ & $-0,009$ & $-0,019$ & 0,037 \\
16 & 0,175 & 0,084 & 0,292 & 0,117 & $\mathbf{0 , 5 9 2}$ & $-0,051$ & 0,130 & 0,015 \\
2 & $-0,136$ & 0,314 & 0,084 & $-0,206$ & $\mathbf{0 , 4 5 8}$ & 0,191 & $-0,190$ & $-0,066$ \\
27 & 0,388 & $-0,052$ & 0,074 & 0,040 & $\mathbf{0 , 4 5 7}$ & 0,332 & 0,156 & $-0,037$ \\
21 & 0,334 & 0,098 & 0,154 & 0,198 & $\mathbf{0 , 3 5 6}$ & 0,063 & 0,242 & 0,035 \\
22 & 0,007 & 0,051 & 0,073 & $-0,070$ & $-0,013$ & $\mathbf{0 , 6 5 4}$ & $-0,104$ & 0,084 \\
34 & 0,049 & 0,279 & $-0,050$ & $-0,030$ & 0,069 & $\mathbf{0 , 5 9 8}$ & 0,013 & $-0,116$ \\
33 & $-0,204$ & 0,039 & 0,041 & 0,257 & $-0,093$ & $\mathbf{0 , 3 4 0}$ & 0,001 & 0,263 \\
18 & $-0,046$ & 0,175 & 0,040 & 0,131 & $-0,382$ & 0,208 & $\mathbf{0 , 6 3 6}$ & $-0,040$ \\
25 & 0,095 & 0,087 & 0,115 & 0,270 & 0,184 & $-0,026$ & $\mathbf{0 , 6 3 3}$ & $-0,046$ \\
38 & 0,070 & $-0,016$ & 0,134 & 0,026 & 0,093 & $-0,243$ & $\mathbf{0 , 5 9 9}$ & 0,250 \\
26 & 0,042 & 0,240 & 0,057 & 0,061 & $-0,062$ & 0,017 & 0,054 & $\mathbf{0 , 6 1 4}$ \\
24 & 0,130 & 0,235 & $-0,056$ & 0,012 & 0,193 & 0,372 & 0,110 & $\mathbf{0 , 4 0 7}$ \\
23 & 0,168 & 0,314 & 0,313 & $-0,069$ & 0,086 & 0,176 & 0,059 & $\mathbf{0 , 3 8 9}$ \\
1 & 0,366 & 0,213 & 0,314 & 0,164 & 0,012 & $-0,163$ & $-0,029$ & $\mathbf{0 , 3 8 5}$ \\
31 & 0,237 & 0,111 & 0,296 & 0,296 & 0,131 & $-0,256$ & 0,104 & $\mathbf{0 , 3 0 0}$ \\
\hline & & & & & & & &
\end{tabular}

O agrupamento dos itens dentro de cada um dos fatores extraídos encontra-se destacado em negrito na matriz apresentada pela Tabela 22. Procedeu-se a análise de conteúdo de cada conjunto de itens, agrupados em função de suas cargas fatoriais, procurando o que eles apresentavam em comum, para então denominar o fator resultante. Por se tratar de um material comercializado por editora especializada, não será apresentada a formulação textual original dos itens neste trabalho. Será destacada apenas a síntese do conteúdo abordado por cada item, como pode ser visualizado no Apêndice C. Apresentar-se-á, a seguir, a composição, denominação e consistência interna de cada um dos oito fatores resultantes. É interessante notar que todos os fatores foram mantidos com pelo menos três itens relacionados a ele, satisfazendo a regra prática geralmente adotada em análise fatorial. 
Os itens 12, 7, 5, 20 e 4 tiveram mais cargas no Fator 1, denominado de autoafirmação e iniciativa de expressão. No geral, este fator incluiu as habilidades sociais de auto-apresentação e auto-afirmação perante o outro. Demonstrou consistência interna moderada, com um coeficiente $\alpha$ de Cronbach de 0,69 .

O Fator 2 recebeu a designação de conversação e desenvoltura social, reunindo inicialmente os itens $13,37,8,36,19$ e 17, que denotam habilidades de iniciar, manter e encerrar conversação, e polidez social. O item 32, por ser conceitualmente pertinente ao Fator 2, foi agrupado a ele, embora tenha mostrado uma carga ligeiramente mais alta no Fator 4. Denominado de falar em público e enfrentamento com risco, o Fator 3 foi composto pelos itens 14, 29, 9, 11 e 30. De modo geral, estes itens representam habilidades de auto-exposição e enfrentamento social com risco potencial de reação indesejável do interlocutor, como rejeição, réplica ou oposição. Embora com demandas diferentes uma das outras, todas essas habilidades têm em comum o componente de falar em público. Os Fatores 2 e 3 apresentaram consistência interna boa, com coeficientes $\alpha$ de Cronbach de 0,71 e 0,72 , respectivamente. $\mathrm{O}$ coeficiente do Fator 2 não sofreu nenhuma alteração com o acréscimo do item 32.

Sendo nomeado de expressão de sentimento positivo e reconhecimento do outro, o Fator 4 agrupou inicialmente os itens 28, 10, 3, 6, 35 e 32. Como justificado acima, o item 32 foi reagrupado no Fator 2. Os itens restantes contemplam habilidades de expressar afeto ou sentimento positivo e gratificar o outro pelo seu desempenho, com risco mínimo de reação indesejável. O Fator 5 incluiu os itens 15, 16, 2, 27 e 21, sendo denominado de assertividade. Esta designação se justifica pelo fato das habilidades inclusas no fator visarem a autoafirmação do indivíduo perante os outros, a garantia dos seus direitos e a expressão apropriada, direta e honesta dos seus pensamentos, sentimentos e crenças, não violando o direito dos demais. A consistência interna demonstrada pelos Fatores 4 e 5 foi moderada, com coeficientes $\alpha$ de Cronbach de 0,68 e 0,62, respectivamente. Antes do reagrupamento do 
item 32 ao Fator 2, o coeficiente do Fator 4 era 0,69, indicando assim que não houve alteração significativa em sua consistência interna devido à redução no número de itens que o compunha.

O Fator 6 reuniu os itens 22, 34 e 33 e foi denominado de recusa de pedidos abusivos. As habilidades expressas por estes três itens tiveram em comum a reação do indivíduo em não ceder frente a pedidos abusivos. Este fator apresentou consistência interna fraca, com um coeficiente $\alpha$ de Cronbach de 0,34. As habilidades contidas neste fator também poderiam ser caracterizadas como respostas assertivas de enfrentamento, tal como as reunidas pelo Fator 5, revelando a capacidade do indivíduo se posicionar de forma adequada às demandas específicas do ambiente, entre a inibição (ou passividade) e a agressividade. Porém, a consistência interna de um novo fator composto pelos oito itens seria fraca, com um $\alpha$ de Cronbach de 0,55 , não justificando assim a junção desses dois fatores, embora ambos meçam o construto assertividade.

Os itens 18, 25 e 38 predominaram na definição do Fator 7, denominado de controle da agressividade e admissão de falhas. As habilidades representadas por estes itens se caracterizariam, principalmente, como reações do indivíduo frente a estimulações aversivas do(s) interlocutor(es) com razoável controle da raiva, desconforto e agressividade. Outra habilidade importante contemplada por este fator foi a de admitir erros ou falhas (item 25). Este fator demonstrou consistência interna fraca, com um coeficiente $\alpha$ de Cronbach de 0,47.

Por último, o Fator 8, denominado de exposição a situações novas e civilidade, foi composto pelos itens $26,24,23,1$ e 31 . Na sua maioria, estes itens representam habilidades do indivíduo em abordar ou expor-se a pessoas desconhecidas. Os componentes de "pedir favores" no item 26, "saber interromper uma conversa ao telefone" no item 24, e “cumprimentar" no item 31 referem-se à classe dos "bons modos" ou civilidade diante de 
demandas específicas do ambiente social. Sua consistência interna também foi fraca, com um coeficiente $\alpha$ de Cronbach de 0,57.

Tem-se assim a estrutura fatorial do IHS-Del-Prette obtida de acordo com os procedimentos de extração e rotação de fatores aplicados sobre as variáveis deste instrumento. Por conseguinte, procedeu-se ao agrupamento dos itens dentro de cada um dos fatores extraídos em função de suas cargas fatoriais, após rotação, e considerações conceituais na área.

\subsubsection{Comparação de variáveis}

Para a comparação das variáveis, em função dos escores médios no IHS-Del-Prette, realizou-se inicialmente uma análise univariada por meio de uma ANOVA entre sujeitos $2 \mathrm{X}$ 2. As variáveis estudadas foram: (a) gênero; e (b) grupos caso e não-caso de TAS, agrupados conforme os escores totais dos sujeitos na Mini-SPIN. Os resultados desta análise são mostrados na Tabela 23.

Tabela 23 - Comparação dos escores médios obtidos no IHS em função das variáveis estudadas (gênero e grupos), e da interação entre elas na amostra total de sujeitos $(\mathrm{N}=1006)$

\begin{tabular}{|c|c|c|}
\hline VARIÁVEIS & $F_{(1,1002)}$ & Significância \\
\hline Gênero & 0,11 & $p=0,740^{(\mathrm{NS})}$ \\
\hline Grupos & 355,41 & $p<0,001^{*}$ \\
\hline Gênero * Grupos & 7,58 & $p=0,006^{*}$ \\
\hline
\end{tabular}

$\mathrm{F}=\mathrm{F}$ de Fisher; $p=$ probabilidade associada; * = interação entre as variáveis; $(\mathrm{NS})=$ diferença não significativa; ${ }^{*}=$ diferença significativa.

No que diz respeito aos efeitos principais das variáveis independentes sobre a variável dependente, observou-se uma diferença significativa nos escores médios do IHS-Del-Prette em função dos grupos caso e não-caso de TAS. Quanto aos efeitos da interação entre as 
variáveis, também se verificou uma diferença significativa nos escores em virtude da interação gênero versus grupos.

Para a análise post hoc das diferenças significativas encontradas acima, procedeu-se ao cálculo de Testes t para os efeitos principais, conforme demonstrado na Tabela 24.

Tabela 24 - Comparação dos escores médios obtidos no IHS entre as variáveis grupo (caso versus não-caso) e gênero (feminino versus masculino) em função da condição analisada na amostra total de sujeitos $(\mathrm{N}=1006)$

\begin{tabular}{llcl}
\hline \multicolumn{1}{c}{ Condição } & \multicolumn{1}{c}{ Variáveis testadas } & Teste t $\left(t_{(1004)}=\right)$ & Significância \\
\hline \multirow{2}{*}{ Gênero feminino } & Grupos caso e não-caso & $-19,01$ & $p<0,001^{*}$ \\
Gênero masculino & Grupos caso e não-caso & $-13,50$ & $p<0,001^{*}$ \\
Grupo caso & Grupos caso e não-caso & $-13,47$ & $p<0,001^{*}$ \\
Grupo não-caso & Gênero feminino e masculino & 1,35 & $p=0,179^{(\mathrm{NS})}$ \\
\hline
\end{tabular}

$p=$ probabilidade associada $;{ }^{*}=$ diferença significativa; (NS) = diferença não significativa

A análise apontou para uma diferença significativa nos escores médios do IHS-DelPrette entre os grupos caso e não-caso de TAS, em conformidade com os resultados já apresentados na seção “4.1.2.5” referente aos indicadores psicométricos do IHS ("Diferenciação entre as habilidades sociais dos grupos caso e não-caso de TAS"). Dado que existem quatro testes de efeitos principais relativos à interação significativa entre as variáveis gênero e grupos, o critério de significância para tal análise foi ajustado para 0,0125 (0,05 / 4) como uma forma de controlar o erro do Tipo I. Observou-se que tanto para o gênero feminino quanto para o masculino, os escores médios no IHS diferiram significativamente para os grupos caso e não-caso de TAS $(\mathrm{M}=74,18$ e 95,93; $\mathrm{DP}=15,97$ e 16,99, respectivamente, para o gênero feminino; $M=70,90$ e 100,10; $\mathrm{DP}=18,31$ e 16,37 , respectivamente, para o masculino). Entretanto, não foi encontrada diferença significativa entre os gêneros para o grupo caso. Já para o grupo não-caso, verificou-se uma diferença significativa entre os gêneros. 
Em acréscimo, a ANOVA de um fator mostrou não existir diferença significativa nos escores médios do IHS-Del-Prette em função da área ou ano de curso dos sujeitos $\left(\mathrm{F}_{(2,1003)}=\right.$ $0,75, p=0,473 ; \mathrm{F}_{(2,1002)}=1,00, p=0,394$, respectivamente $)$.

Visando verificar os efeitos das variáveis gênero e grupo sobre os cinco fatores do estudo original, foi executada uma MANOVA para cada uma dessas variáveis, separadamente. As análises revelaram existir uma diferença multivariada entre os gêneros, improvável de ter ocorrido apenas por erro amostral $\left(\mathrm{F}_{(5,1000)}=45,64, p<0,001, \lambda\right.$ de Wilks = 0,81). Análises post hoc dessas diferenças são apresentadas na Tabela 25 .

Tabela 25 - Comparação dos escores médios obtidos nos fatores do IHS entre os gêneros na amostra total de sujeitos $(\mathrm{N}=1006)$

\begin{tabular}{llcl}
\hline \multicolumn{1}{c}{ Variável } & Fatores & Teste $\mathbf{t}\left(t_{(1004)}=\right)$ & Significância \\
\hline Gênero & Fator 1 & $-7,41$ & $p<0,001^{*}$ \\
(feminino versus masculino) & Fator 2 & 3,71 & $p<0,001^{*}$ \\
& Fator 3 & 0,20 & $p=0,843^{(\mathrm{NS})}$ \\
& Fator 4 & $-0,92$ & $p=0,360^{(\mathrm{NS})}$ \\
& Fator 5 & $-5,63$ & $p<0,001^{*}$ \\
\hline
\end{tabular}

$p=$ probabilidade associada $;{ }^{*}=$ diferença significativa; $(\mathrm{NS})=$ diferença não significativa.

Detectaram-se diferenças significativas para os Fatores 1 (enfrentamento $e$ autoafirmação com risco), 2 (auto-afirmação na expressão de sentimento positivo) e 5 (autocontrole da agressividade), não sendo encontradas diferenças significativas para os Fatores 3 (conversação e desenvoltura social) e 4 (auto-exposição a desconhecidos $e$ situações novas).

Considerando que o Teste $\mathrm{M}$ de Box acusou a violação da suposição de homogeneidade das matrizes de variâncias-covariâncias para a variável grupo ( $\mathrm{M}$ de Box = 39,16, $p=0,001$ ) na aplicação da MANOVA, testes $\mathrm{t}$ foram executados para comparar os 
grupos caso $(\mathrm{N}=214)$ e não-caso $(\mathrm{N}=792)$ em relação aos fatores. Os resultados obtidos encontram-se na Tabela 26.

Tabela 26 - Comparação dos escores médios obtidos nos fatores do IHS entre os grupos caso e não-caso de TAS na amostra total de sujeitos $(\mathrm{N}=1006)$

\begin{tabular}{ccc}
\hline Fatores & Teste $\mathbf{t}\left(t_{(1004)}=\right)$ & Significância \\
\hline Fator 1 & $-16,05^{*}$ & $p<0,001^{* *}$ \\
Fator 2 & $-9,61^{*}$ & $p<0,001^{* *}$ \\
Fator 3 & $-15,21^{*}$ & $p<0,001^{* *}$ \\
Fator 4 & $-14,29$ & $p<0,001^{* *}$ \\
Fator 5 & $-9,43$ & $p<0,001^{* *}$ \\
\hline
\end{tabular}

* = condição com variâncias desiguais $; *$ = diferença significativa

Observaram-se diferenças significativas entre os dois grupos em relação aos fatores, mesmo após o ajuste do critério de significância para 0,01 (0,05 / 5) como uma forma de controlar o erro do Tipo I. Deste modo, evidenciou-se que os dois grupos diferem significativamente entre si em todos os fatores que compõem o IHS-Del-Prette. 


\subsection{Estudo 2 - Empírico}

\subsubsection{Caracterização da amostra}

Aplicando-se sistematicamente os critérios de inclusão e exclusão, explicitados na seção 3.3.1 do Método, foi obtida a amostra final deste estudo composta por 26 sujeitos, sendo 13 sujeitos designados ao grupo caso e 13 sujeitos ao grupo não-caso de TAS. A Tabela 27 apresenta uma caracterização sociodemográfica dos sujeitos incluídos neste estudo de acordo com a sua designação para o grupo caso ou não-caso a partir da resposta positiva ou negativa na Mini-SPIN e confirmação do diagnóstico clínico ou não de TAS realizado por meio da SCID, respectivamente.

Tabela 27 - Caracterização sociodemográfica dos sujeitos participantes do Teste de Simulação de Falar em Público $(\mathrm{N}=26)$ nos grupos caso e não-caso de TAS

\begin{tabular}{lllll}
\hline Grupo & Sujeito & Idade & \multicolumn{1}{c}{ Gênero } & \multicolumn{1}{c}{ Área do Curso } \\
\hline & S1 & 23 anos & Feminino & Biológicas \\
S2 & 20 anos & Feminino & Biológicas \\
S3 & 20 anos & Feminino & Biológicas \\
S4 & 22 anos & Masculino & Biológicas \\
& S5 & 20 anos & Feminino & Exatas \\
& S6 & 22 anos & Feminino & Biológicas \\
S7 & 20 anos & Masculino & Exatas \\
& S8 & 23 anos & Feminino & Exatas \\
& S9 & 22 anos & Masculino & Biológicas \\
& S10 & 20 anos & Masculino & Biológicas \\
& S11 & 21 anos & Feminino & Biológicas \\
S12 & 23 anos & Masculino & Exatas \\
& S13 & 20 anos & Feminino & Exatas \\
& S14 & 22 anos & Feminino & Biológicas \\
& S15 & 19 anos & Feminino & Exatas \\
& S16 & 25 anos & Feminino & Exatas \\
& S17 & 24 anos & Masculino & Humanas \\
& S18 & 22 anos & Feminino & Biológicas \\
& S19 & 19 anos & Feminino & Biológicas \\
& S20 & 20 anos & Feminino & Biológicas \\
S21 & 21 anos & Feminino & Exatas \\
& S22 & 22 anos & Masculino & Biológicas \\
& S23 & 20 anos & Feminino & Biológicas \\
S24 & 19 anos & Masculino & Exatas \\
S25 & 24 anos & Masculino & Humanas. \\
S26 & 19 anos & Masculino & Biológicas \\
\hline NÃO-CASO & & &
\end{tabular}


Observou-se um predomínio do gênero feminino tanto na amostra total como dentro de cada grupo (61,5\% em ambos os casos) e, portanto, um percentual igual de sujeitos do mesmo gênero na composição dos dois grupos, não havendo diferença significativa entre eles em relação a esta variável $\left(\chi_{(1)}^{2}=0,00, p=1,00\right)$. A idade média dos sujeitos foi de 21,2 anos tanto para a amostra total como para os grupos caso e não-caso ( $\mathrm{DP}=1,7 ; 1,3$; e 2,1, respectivamente).

Verificou-se que entre os alunos matriculados em cursos da área de Biológicas, 53,3\% pertenciam ao grupo caso $(\mathrm{N}=8)$ e $46,7 \%$ ao grupo não-caso $(\mathrm{N}=7)$; da área de Exatas, $55,6 \%$ do grupo caso $(\mathrm{N}=5)$ e $44,4 \%$ do grupo não-caso $(\mathrm{N}=4)$; e da área de Humanas $100 \%$ do grupo não-caso $(\mathrm{N}=2)$.

\subsubsection{Comparação dos grupos caso e não-caso de TAS em relação aos marcadores comportamentais de ansiedade, latência da resposta e tempo total de fala}

Visando a tomada de decisão quanto à aplicação de testes paramétricos ou nãoparamétricos para a análise dos dados deste estudo, o Teste de Normalidade de Shapiro-Wilk foi conduzido para cada um dos marcadores comportamentais de ansiedade e suas respectivas classes, avaliação geral do desempenho, duração total do discurso e latência para iniciá-lo. Os resultados encontram-se na Tabela 28, apresentados separadamente por grupo.

Tabela 28 - Resultados do Teste de Normalidade de Shapiro-Wilk realizado para os marcadores comportamentais (categorias) e suas respectivas classes, avaliação geral do desempenho, latência da resposta e duração total do discurso $(\mathrm{N}=26)$

\begin{tabular}{|c|c|c|c|}
\hline Categorias e Classes Avaliadas & Grupo & Teste de Shapiro-Wilk & Significância \\
\hline \multirow[t]{2}{*}{ - Classe de marcadores verbais } & Caso & 0,948 & $p=0,548^{*}$ \\
\hline & Não-caso & 0,986 & $p=0,990^{*}$ \\
\hline \multirow{2}{*}{ - Classe de marcadores paralingüísticos } & Caso & 0,987 & $p=0,990^{*}$ \\
\hline & Não-caso & 0,955 & $p=0,641^{*}$ \\
\hline \multirow[t]{2}{*}{ - Classe de marcadores não-verbais } & Caso & 0,832 & $p=0,018^{* *}$ \\
\hline & Não-caso & 0,872 & $p=0,063^{*}$ \\
\hline \multirow[t]{2}{*}{ - Conteúdo negativo } & Caso & 0,945 & $p=0,498^{*}$ \\
\hline & Não-caso & 0,868 & $p=0,054^{*}$ \\
\hline
\end{tabular}


(conclusão)

\begin{tabular}{|c|c|c|c|}
\hline Categorias e Classes Avaliadas & Grupo & Teste de Shapiro-Wilk & Significância \\
\hline \multirow[t]{2}{*}{ - Repetição de conteúdo } & Caso & 0,811 & $p=0,010^{* *}$ \\
\hline & Não-caso & 0,931 & $p=0,398^{*}$ \\
\hline \multirow[t]{2}{*}{ - Descontinuidade da fala } & Caso & 0,941 & $p=0,473^{*}$ \\
\hline & Não-caso & 0,960 & $p=0,711^{*}$ \\
\hline \multirow[t]{2}{*}{ - Uso de jargões } & Caso & 0,719 & $p=0,010^{* *}$ \\
\hline & Não-caso & 0,952 & $p=0,592^{*}$ \\
\hline \multirow{2}{*}{ - Pausas } & Caso & 0,946 & $p=0,512^{*}$ \\
\hline & Não-caso & 0,869 & $p=0,058^{*}$ \\
\hline \multirow[t]{2}{*}{ - Risos inapropriados } & Caso & 0,655 & $p=0,010^{* *}$ \\
\hline & Não-caso & 0,812 & $p=0,010^{* *}$ \\
\hline \multirow[t]{2}{*}{ - Velocidade de fala inapropriada } & Caso & 0,756 & $p=0,010^{* *}$ \\
\hline & Não-caso & 0,893 & $p=0,126^{*}$ \\
\hline \multirow[t]{2}{*}{ - Intensidade de voz inapropriada } & Caso & 0,763 & $p=0,010^{* * *}$ \\
\hline & Não-caso & 0,637 & $p=0,010^{* *}$ \\
\hline \multirow[t]{2}{*}{ - Evitação da tarefa } & Caso & 0,668 & $p=0,010^{* * *}$ \\
\hline & Não-caso & 0,306 & $p=0,010^{* *}$ \\
\hline \multirow{2}{*}{ - Rigidez corporal } & Caso & 0,520 & $p=0,010^{* *}$ \\
\hline & Não-caso & 0,463 & $p=0,010^{* *}$ \\
\hline \multirow[t]{2}{*}{ - Inquietação } & Caso & 0,857 & $p=0,041^{* *}$ \\
\hline & Não-caso & 0,808 & $p=0,010^{* *}$ \\
\hline \multirow[t]{2}{*}{ - Atitude de intenção } & Caso & 0,694 & $p=0,010^{* *}$ \\
\hline & Não-caso & 0,693 & $p=0,010^{* *}$ \\
\hline \multirow[t]{2}{*}{ - Desvio do olhar } & Caso & 0,762 & $p=0,010^{* *}$ \\
\hline & Não-caso & 0,386 & $p=0,010^{* *}$ \\
\hline \multirow{2}{*}{ - Movimentos faciais de desconforto } & Caso & 0,958 & $p=0,683^{*}$ \\
\hline & Não-caso & 0,902 & $p=0,196^{*}$ \\
\hline \multirow[t]{2}{*}{ - Barreiras } & Caso & 0,844 & $p=0,027^{* *}$ \\
\hline & Não-caso & 0,871 & $p=0,060^{*}$ \\
\hline \multirow[t]{2}{*}{ - Avaliação geral do desempenho } & Caso & 0,940 & $p=0,468^{*}$ \\
\hline & Não-caso & 0,864 & $p=0,048^{* *}$ \\
\hline \multirow[t]{2}{*}{ - Latência da resposta (em segundos) } & Caso & 0,769 & $p=0,010^{* *}$ \\
\hline & Não-caso & 0,958 & $p=0,674^{*}$ \\
\hline \multirow[t]{2}{*}{ - Tempo total de fala (em segundos) } & Caso & 0,698 & $p=0,010^{* *}$ \\
\hline & Não-caso & 0,403 & $p=0,010^{* *}$ \\
\hline
\end{tabular}

$p=$ probabilidade associada $;{ }^{*}=$ com distribuição normal; ${ }^{* *}=$ sem distribuição normal

A maioria dos valores relativos às variáveis testadas não apresentou uma distribuição normal $(p<0,05)$. Neste caso, para a comparação dos grupos quanto à frequiência total de cada um dos marcadores comportamentais e suas respectivas classes, avaliação geral do desempenho, tempo total de fala e latência da resposta, procedeu-se o Teste Não-Paramétrico de Mann-Whitney, cujos resultados são apresentados na Tabela 29. 
Tabela 29 - Comparação dos grupos caso $(\mathrm{N}=13)$ e não-caso de TAS $(\mathrm{N}=13)$ em relação aos marcadores comportamentais de ansiedade e suas respectivas classes, avaliação geral do desempenho, duração total do discurso e latência da resposta

\begin{tabular}{lcc}
\hline \multicolumn{1}{c}{ Categorias e Classes Avaliadas } & U de Mann-Whitney & Probabilidade \\
\hline Classe de marcadores verbais & 56,50 & $p=0,151^{(\mathrm{NS})}$ \\
Classe de marcadores paralingüísticos & 63,50 & $p=0,281^{(\mathrm{NS})}$ \\
Classe de marcadores não-verbais & 39,50 & $p=0,021^{*}$ \\
Conteúdo negativo & 76,50 & $p=0,680^{(\mathrm{NS})}$ \\
Repetição de conteúdo & 50,50 & $p=0,073^{(\mathrm{NS})}$ \\
Descontinuidade da fala & 71,50 & $p=0,503^{(\mathrm{NS})}$ \\
Uso de jargões & 54,00 & $p=0,116^{(\mathrm{NS})}$ \\
Pausas & 51,50 & $p=0,089^{(\mathrm{NS})}$ \\
Risos inapropriados & 82,50 & $p=0,911^{(\mathrm{NS})}$ \\
Velocidade de fala inapropriada & 48,00 & $p=0,057^{(\mathrm{NS})}$ \\
Intensidade de voz inapropriada & 60,50 & $p=0,199^{(\mathrm{NS})}$ \\
Evitação da tarefa & 60,00 & $p=0,088^{(\mathrm{NS})}$ \\
Rigidez corporal & 72,00 & $p=0,385^{(\mathrm{NS})}$ \\
Inquietação & 83,50 & $p=0,959^{(\mathrm{NS})}$ \\
Atitude de intenção & 80,50 & $p=0,816^{(\mathrm{NS})}$ \\
Desvio do olhar & 59,00 & $p=0,110^{(\mathrm{NS})}$ \\
Movimentos faciais de desconforto & 29,50 & $p=0,005^{*}$ \\
Barreiras & 76,00 & $p=0,662^{(\mathrm{NS})}$ \\
Avaliação geral do desempenho & 61,00 & $p=0,226^{(\mathrm{NS})}$ \\
Latência da resposta & 79,00 & $p=0,775^{(\mathrm{NS})}$ \\
Tempo total de fala & 65,50 & $p=0,328^{(\mathrm{NS})}$ \\
\hline
\end{tabular}

$(\mathrm{NS})=$ diferença não significativa ${ }^{*}=$ diferença significativa

Observou-se que os grupos caso e não-caso demonstraram diferenças significativas apenas em relação a movimentos faciais de desconforto e à classe de marcadores não-verbais, a qual essa mesma categoria pertence. Para essa categoria e sua classe, os postos médios do grupo não-caso $(17,73$ e 16,96) foram maiores que os postos médios do grupo caso $(9,27$ e 10,04). Em termos descritivos, as médias do grupo não-caso foram 36,15 ( $\mathrm{DP}=23,85)$ para movimentos faciais de desconforto e $67,77(\mathrm{DP}=28,85)$ para a classe de marcadores nãoverbais, em comparação ao grupo caso, cujas médias foram 13,08 (DP = 8,43) e 44,92 (DP = 18,96), respectivamente. O grupo caso também não diferiu significativamente do grupo nãocaso quanto aos tipos de pausa apresentados. Para as pausas preenchidas, o U de Mann- 
Whitney foi 50,50 com um valor de probabilidade associada de 0,080, e para as pausas silenciosas 56,00, com um valor de probabilidade associada de 0,120 .

A Tabela 30 exibe a freqüência mínima e máxima de ocorrência observada para cada um dos marcadores comportamentais e suas respectivas classes; o tempo mínimo e máximo apresentado em relação à latência para responder e tempo total de fala; e a média e o desviopadrão para todas essas categorias e classes dentro de cada grupo, permitindo assim uma melhor visualização das diferenças pouco significativas encontradas entre os dois.

Tabela 30 - Frequiência mínima e máxima, média e desvio-padrão de ocorrência para cada categoria avaliada dentro dos grupos caso e não-caso de TAS

\begin{tabular}{|c|c|c|c|c|c|c|c|c|}
\hline \multirow{2}{*}{$\begin{array}{c}\text { Categorias e Classes } \\
\text { Avaliadas }\end{array}$} & \multicolumn{4}{|c|}{$\operatorname{Grupo} \operatorname{caso}(\mathbf{N}=13)$} & \multicolumn{4}{|c|}{ Grupo não-caso $(\mathbf{N}=13)$} \\
\hline & Mín. & Máx. & $\mathbf{M}$ & DP & Mín. & Máx. & $\mathbf{M}$ & DP \\
\hline Classe de marcadores verbais & 3 & 54 & 26,31 & 12,28 & 4 & 59 & 33,23 & 14,93 \\
\hline Classe de marcadores paralingüísticos & 5 & 40 & 20,54 & 9,52 & 9 & 25 & 16,69 & 5,25 \\
\hline Classe de marcadores não-verbais & 26 & 77 & 44,92 & 18,96 & 37 & 133 & 67,73 & 28,86 \\
\hline Conteúdo negativo & 1 & 25 & 10,54 & 6,40 & 2 & 19 & 11,31 & 6,76 \\
\hline Repetição de conteúdo & 0 & 3 & 1,00 & 1,15 & 0 & 4 & 1,92 & 1,32 \\
\hline Descontinuidade da fala & 2 & 15 & 8,31 & 4,07 & 0 & 16 & 8,92 & 4,50 \\
\hline Uso de jargões & 0 & 27 & 6,46 & 8,71 & 0 & 26 & 11,08 & 8,28 \\
\hline Pausas & 4 & 26 & 14,00 & 6,62 & 5 & 20 & 9,38 & 4,63 \\
\hline Risos inapropriados & 0 & 14 & 2,38 & 4,21 & 0 & 4 & 1,31 & 1,49 \\
\hline Velocidade de fala inapropriada & 0 & 7 & 1,92 & 2,56 & 0 & 15 & 4,85 & 4,63 \\
\hline Intensidade de voz inapropriada & 0 & 9 & 2,23 & 2,74 & 0 & 7 & 1,15 & 1,95 \\
\hline Evitação da tarefa & 0 & 4 & 0,92 & 1,50 & 0 & 4 & 0,31 & 1,11 \\
\hline Rigidez corporal & 0 & 8 & 7,00 & 2,27 & 5 & 8 & 7,62 & 0,96 \\
\hline Inquietação & 0 & 27 & 7,69 & 7,95 & 0 & 23 & 6,62 & 7,78 \\
\hline Atitude de intenção & 0 & 10 & 3,15 & 4,20 & 0 & 8 & 3,38 & 3,95 \\
\hline Desvio do olhar & 0 & 4 & 1,31 & 1,65 & 0 & 5 & 0,46 & 1,39 \\
\hline Movimentos faciais de desconforto & 0 & 30 & 13,08 & 8,43 & 10 & 87 & 36,15 & 23,85 \\
\hline Barreiras & 0 & 42 & 11,77 & 11,24 & 0 & 43 & 13,23 & 11,42 \\
\hline Avaliação geral do desempenho & 1,00 & 9,50 & 5,81 & 2,75 & 2,00 & 9,50 & 7,04 & 2,38 \\
\hline Latência da resposta (em seg.) & 0 & 19 & 4,69 & 5,78 & 0 & 6 & 2,54 & 1,85 \\
\hline Tempo total de fala (em seg.) & 118 & 240 & 217,08 & 33,98 & 116 & 240 & 226,85 & 33,62 \\
\hline
\end{tabular}

Em termos absolutos, o grupo caso demonstrou uma latência maior para iniciar o discurso $(\mathrm{M}=4,69$ segundos, $\mathrm{DP}=5,78)$ que variou de 0 a 19 segundos, quando comparado 
ao grupo não-caso $(\mathrm{M}=2,54$ segundos, $\mathrm{DP}=1,85)$, que apresentou latência variando de 0 a 6 segundos. Já este grupo apresentou valores superiores para a classe de marcadores nãoverbais, velocidade de fala inapropriada e movimentos faciais de desconforto em relação ao primeiro grupo.

\subsubsection{Comparação dos grupos em relação ao início e final do TSFP}

Para a comparação do efeito do tempo sobre os marcadores comportamentais de ansiedade e suas respectivas classes (verbais, paralingüísticas e não-verbais) e em relação aos grupos caso e não-caso, uma ANOVA de medidas repetidas com um fator foi realizada. Para tal análise foram selecionados o primeiro e o quarto minuto do discurso, sendo denominados de momento 1 (M1) e momento 2 (M2), respectivamente. Os resultados encontram-se na Tabela 31.

Tabela 31 - Comparação do efeito do tempo sobre os marcadores comportamentais de ansiedade e suas respectivas classes e de sua interação com os grupos caso ( $\mathrm{N}$ $=13)$ e não-caso de TAS $(\mathrm{N}=13)$

\begin{tabular}{|c|c|c|c|c|}
\hline \multirow{2}{*}{$\begin{array}{l}\text { Diferença entre M1 e M2 em relação aos } \\
\text { marcadores comportamentais e suas classes }\end{array}$} & \multicolumn{2}{|c|}{ Efeito Global } & \multicolumn{2}{|c|}{ Efeito para os grupos } \\
\hline & $\mathbf{F}_{(1,24)}$ & $p$ & $\mathbf{F}_{(\mathbf{1}, \mathbf{2 4})}$ & $p$ \\
\hline Classe de marcadores verbais & 7,22 & $0,013^{*}$ & 3,35 & $0,080^{(\mathrm{NS})}$ \\
\hline Classe de marcadores paralingüísticos & 3,66 & $0,068^{(\mathrm{NS})}$ & 0,02 & $0,892^{(\mathrm{NS})}$ \\
\hline Classe de marcadores não-verbais & 0,03 & $0,856^{(\mathrm{NS})}$ & 1,02 & $0,323^{(\mathrm{NS})}$ \\
\hline Conteúdo negativo & 0,32 & $0,576^{(\mathrm{NS})}$ & 0,10 & $0,756^{\text {(NS) }}$ \\
\hline Repetição de conteúdo & 2,77 & $0,109^{(\mathrm{NS})}$ & 1,23 & $0,278^{(\mathrm{NS})}$ \\
\hline Descontinuidade da fala & 4,58 & $0,043^{*}$ & 0,18 & $0,672^{(\mathrm{NS})}$ \\
\hline Uso de jargões & 5,02 & $0,035^{*}$ & 6,50 & $0,018^{*}$ \\
\hline Pausas & 0,56 & $0,460^{(\mathrm{NS})}$ & 0,14 & $0,711^{(\mathrm{NS})}$ \\
\hline Risos inapropriados & 1,41 & $0,247^{(\mathrm{NS})}$ & 0,72 & $0,405^{(\mathrm{NS})}$ \\
\hline Velocidade de fala inapropriada & 0,03 & $0,872^{(\mathrm{NS})}$ & 0,03 & $0,872^{(\mathrm{NS})}$ \\
\hline Intensidade de voz inapropriada & 3,66 & $0,068^{(\mathrm{NS})}$ & 0,10 & $0,753^{(\mathrm{NS})}$ \\
\hline Evitação da tarefa & 5,41 & $0,029^{*}$ & 1,35 & $0,256^{(\mathrm{NS})}$ \\
\hline Rigidez corporal & 0,00 & $1,000^{(\mathrm{NS})}$ & 2,00 & $0,170^{(\mathrm{NS})}$ \\
\hline Inquietação & 1,74 & $0,200^{(\mathrm{NS})}$ & 0,01 & $0,906^{(\mathrm{NS})}$ \\
\hline Atitude de intenção & 0,20 & $0,659^{(\mathrm{NS})}$ & 1,80 & $0,192^{(\mathrm{NS})}$ \\
\hline Desvio do olhar & 4,86 & $0,037^{*}$ & 2,73 & $0,111^{\text {(NS) }}$ \\
\hline Movimentos faciais de desconforto & 0,67 & $0,422^{(\mathrm{NS})}$ & 1,44 & $0,241^{(\mathrm{NS})}$ \\
\hline Barreiras & 2,07 & $0,163^{(\mathrm{NS})}$ & 0,45 & $0,509^{(\mathrm{NS})}$ \\
\hline
\end{tabular}

$\mathrm{M} 1=$ momento $1 ; \mathrm{M} 2=$ momento $2 ; \mathrm{F}=\mathrm{F}$ de Fisher $p=$ probabilidade associada $;{ }^{*}=$ diferença significativa; $(\mathrm{NS})=$ diferença não significativa 
Quanto ao efeito global, observaram-se diferenças significativas entre o início (M1) e o final (M2) do discurso para a classe de marcadores verbais, e para as categorias: descontinuidade da fala, uso de jargões, evitação da tarefa e desvio do olhar. Para as demais classes e categorias não foram encontradas diferenças significativas. A diferença entre estes dois momentos foi a mesma em relação a todas as classes e a maioria das categorias para ambos os grupos. Apenas em relação a uso de jargões, essa diferença não foi significativamente a mesma para os dois grupos.

Testes de Wilcoxon foram executados para comparar a diferença entre M1 e M2 para os dois grupos separadamente em relação a esta categoria. Verificou-se que essa diferença não foi significativa para o grupo caso $(z=-0,11, p=0,914)$, mas foi para o grupo não-caso $(z=$ $-2,35, p=0,019)$.

\subsubsection{Correlação entre as categorias de análise propostas}

Foram realizadas correlações bivariadas de Spearman entre todas as categorias de análise criadas, entre estas categorias e as classes mais amplas, e entre as classes, para verificar as possíveis relações ou variações concomitantes existentes entre elas. A Tabela 32 mostra apenas as correlações significativas encontradas, ou seja, com um valor de probabilidade associada menor ou igual a 0,05 .

Tabela 32 - Correlações significativas encontradas a partir das associações entre todas as categorias de análise, entre essas categorias e as classes mais amplas, e entre as próprias classes na amostra total $(\mathrm{N}=26)$

(continua)

\section{Correlações significativas}

$\rho$ de

Spearman
Probabilidade
- Conteúdo negativo x repetição de conteúdo

- Conteúdo negativo x desvio do olhar

- Conteúdo negativo $\mathrm{x}$ tempo total de fala

- Conteúdo negativo x marcadores verbais

- Repetição de conteúdo x movimentos faciais de desconforto

- Repetição de conteúdo x avaliação geral do desempenho

- Descontinuidade da fala x uso de jargões

$\begin{array}{rl}0,43 & p=0,027 \\ -0,47 & p=0,015 \\ 0,50 & p=0,009 \\ 0,60 & p=0,001 \\ 0,42 & p=0,034 \\ 0,57 & p=0,002 \\ 0,52 & p=0,006\end{array}$


(conclusão)

\section{Correlações significativas}

$\rho$ de

Spearman

\begin{tabular}{rl}
0,51 & $p=0,008$ \\
0,44 & $p=0,023$ \\
0,86 & $p=0,000$ \\
$-0,48$ & $p=0,014$ \\
0,43 & $p=0,029$ \\
0,63 & $p=0,001$ \\
0,41 & $p=0,040$ \\
0,62 & $p=0,001$ \\
0,54 & $p=0,004$ \\
$-0,42$ & $p=0,032$ \\
0,40 & $p=0,045$ \\
0,54 & $p=0,005$ \\
0,41 & $p=0,035$ \\
0,54 & $p=0,004$ \\
$-0,74$ & $p=0,000$ \\
$-0,57$ & $p=0,002$ \\
$-0,57$ & $p=0,002$ \\
$-0,52$ & $p=0,007$ \\
0,45 & $p=0,020$ \\
$-0,40$ & $p=0,042$ \\
$-0,47$ & $p=0,016$ \\
0,66 & $p=0,000$ \\
0,40 & $p=0,040$ \\
0,56 & $p=0,003$ \\
0,43 & $p=0,029$ \\
0,39 & $p=0,049$ \\
0,51 & $p=0,008$ \\
$-0,54$ & $p=0,004$ \\
\hline &
\end{tabular}

Probabilidade
- Descontinuidade da fala $\mathrm{x}$ marcadores verbais

- Uso de jargões $\mathrm{x}$ intensidade de voz inapropriada

- Uso de jargões x marcadores verbais

- Marcadores verbais $\mathrm{x}$ desvio do olhar

- Tempo total de fala $\mathrm{x}$ marcadores verbais

- Pausas x marcadores paralingüísticos

- Risos inapropriados x marcadores paralingüísticos

- Velocidade de fala inapropriada x descontinuidade da fala

- Velocidade de fala inapropriada x uso de jargões

- Velocidade de fala inapropriada x pausas

- Velocidade de fala inapropriada $\mathrm{x}$ intensidade de voz inapropriada

- Velocidade de fala inapropriada x marcadores verbais

- Intensidade de voz inapropriada x marcadores paralingüísticos

- Evitação da tarefa x desvio do olhar

- Evitação da tarefa x tempo total de fala

- Evitação da tarefa x avaliação geral do desempenho

- Rigidez corporal $x$ atitude de intenção

- Rigidez corporal $x$ barreiras

- Inquietação x marcadores não-verbais

- Desvio do olhar x tempo total de fala

- Desvio do olhar x avaliação geral do desempenho

- Movimentos faciais de desconforto x marcadores não-verbais

- Barreiras x descontinuidade da fala

- Barreiras x marcadores não-verbais

- Barreiras x atitude de intenção

- Barreiras x intensidade de voz inapropriada

- Avaliação geral do desempenho x tempo total de fala

- Latência da resposta x tempo total de fala

Observou-se que todas as correlações significativas encontradas variaram de 0,39 a 0,86, ou seja, de baixa a muito alta. Essas associações sugerem várias relações de proporcionalidade entre as categorias, como pode ser visualizado no Quadro 1. A apresentação (presença) de uma categoria, tomada como principal, esteve associada à exibição simultânea ou sucessiva (ocorrência) de outra categoria. Deste modo, a ocorrência de uma dada categoria esteve proporcionalmente relacionada à presença de outra categoria principal. 
Quadro 1. Relações de proporcionalidade apresentadas entre as categorias de análise propostas

\begin{tabular}{|c|c|}
\hline PRESENÇA & OCORRÊNCIA \\
\hline - Maior o tempo de fala: & $\begin{array}{l}\checkmark \text { menor latência para o início do discurso; } \\
\checkmark \text { menor freqüência de desvio do olhar em } \\
\text { direção à câmara, com melhor avaliação do } \\
\text { desempenho; } \\
\checkmark \text { maior frequiência de conteúdo negativo; } \\
\checkmark \text { maior freqüência de marcadores verbais de } \\
\text { ansiedade. }\end{array}$ \\
\hline - Maior velocidade da fala: & $\begin{array}{l}\checkmark \text { menor freqüência de interrupções no fluxo do } \\
\text { discurso; } \\
\checkmark \text { menor freqüência de intensidade de voz } \\
\text { inapropriada; } \\
\checkmark \text { maior freqüência de jargões. }\end{array}$ \\
\hline - Mais falas descontínuas: & $\begin{array}{l}\checkmark \text { maior freqüência de jargões, com intensidade } \\
\text { de voz inapropriada. }\end{array}$ \\
\hline - Mais conteúdo negativo: & $\begin{array}{l}\checkmark \text { maior freqüência de repetições de conteúdo; } \\
\checkmark \text { menor freqüência de desviar o olhar em } \\
\text { direção à câmara. }\end{array}$ \\
\hline - Mais repetições de conteúdo: & $\begin{array}{l}\checkmark \text { maior freqüência de movimentos faciais de } \\
\text { desconforto; } \\
\checkmark \text { melhor avaliação do desempenho. }\end{array}$ \\
\hline - Mais marcadores verbais de ansiedade: & $\begin{array}{l}\checkmark \text { menor freqüência de desvios do olhar em } \\
\text { direção à câmara. }\end{array}$ \\
\hline - Mais postura corporal tensa ou rígida: & $\begin{array}{l}\checkmark \text { menor freqüência de barreiras; } \\
\checkmark \text { menor freqüência de atitude de intenção. }\end{array}$ \\
\hline - Mais evitação da tarefa: & $\begin{array}{l}\checkmark \text { maior freqüência de desvios do olhar em } \\
\text { direção à câmara; } \\
\checkmark \text { menor o tempo total de fala; } \\
\checkmark \text { pior avaliação do desempenho. }\end{array}$ \\
\hline - Mais uso de barreiras: & $\begin{array}{l}\checkmark \text { maior freqüência de falas descontínuas; } \\
\checkmark \text { maior freqüência de intensidade de voz } \\
\text { inapropriada; } \\
\checkmark \text { maior freqüência de atitude de intenção. }\end{array}$ \\
\hline
\end{tabular}

No que diz respeito às correlações entre as categorias e as classes, observou-se que:

- As categorias descontinuidade da fala, conteúdo negativo e uso de jargões demonstraram um relacionamento positivo com a classe de marcadores verbais a que pertencem, que variou de moderado $(\rho=0,51)$ a muito alto $(\rho=0,86)$. 
- Risos inapropriados e intensidade de voz inapropriada apresentaram um relacionamento positivo moderado com a classe de marcadores paralingüísticos, onde foram incluídos, com $\rho=0,41$ para ambas as categorias. Já a categoria pausas correlacionou-se altamente com esta mesma classe $(\rho=0,63)$.

- Velocidade de fala inapropriada esteve moderadamente relacionada à classe de marcadores verbais ( $\rho=0,54)$, sugerindo que este marcador paralingüístico acompanhou a emissão dos marcadores comportamentais constituintes desta classe.

- Inquietação e barreiras estiveram moderadamente relacionadas à sua classe de marcadores não-verbais, com $\rho$ variando de 0,45 a 0,56 . A categoria movimentos faciais de desconforto correlacionou-se altamente com esta mesma classe $(\rho=0,66)$.

\subsubsection{Avaliação do repertório de habilidades sociais de falar em público dos grupos}

Para efeitos de avaliação do desempenho exibido pelos sujeitos no TSFP, a Figura 5 apresenta o percentual de sujeitos, agrupados como casos e não-casos de TAS, em cada nível de classificação do repertório de habilidades sociais de falar em público.

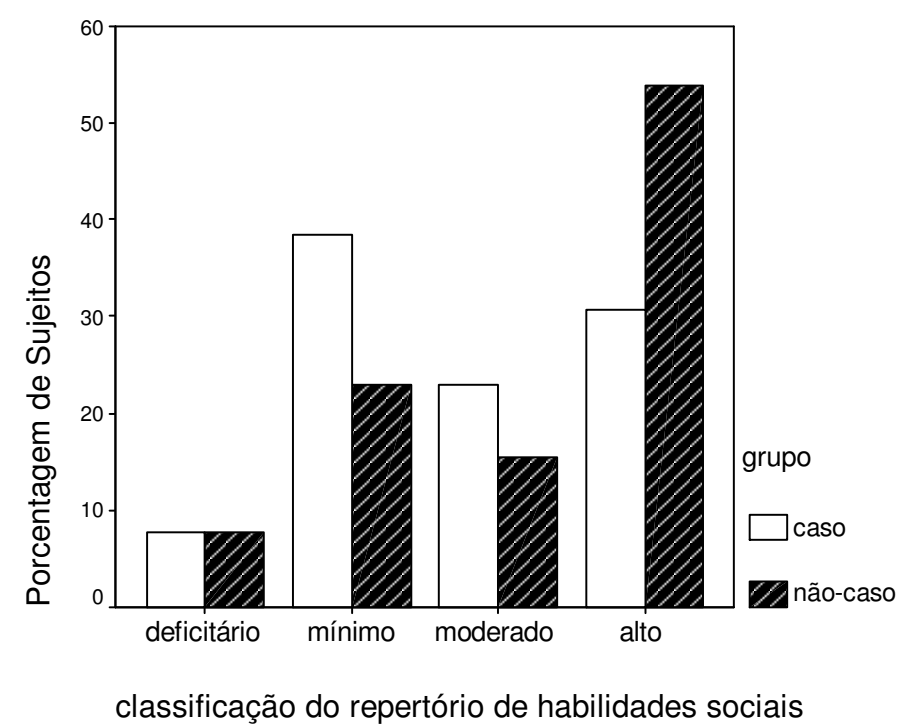

Figura 5. Classificação do repertório de habilidades sociais de falar em público demonstrado pelos sujeitos dos grupos caso $(\mathrm{N}=13)$ e não-caso de TAS $(\mathrm{N}=13)$ 
Os dois grupos apresentaram o mesmo percentual de sujeitos $(7,7 \%)$ com carência de habilidades sociais apropriadas para falar em público ( $\mathrm{N}=1$ para os dois grupos), ou seja, com um repertório deficitário. $38,4 \%$ do grupo caso $(\mathrm{N}=5)$ e $23,1 \%$ do grupo não-caso $(\mathrm{N}=$ 3) exibiram um nível mínimo de habilidades sociais apropriadas. No nível moderado, observaram-se $23,1 \%$ do grupo caso $(\mathrm{N}=3)$ e $15,4 \%$ do grupo não-caso $(\mathrm{N}=2)$. Em contrapartida, $30,8 \%$ do grupo caso $(\mathrm{N}=4)$ e $53,8 \%$ do grupo não-caso $(\mathrm{N}=7)$ demonstraram um nível alto de habilidades sociais apropriadas. No geral, 69,2\% do grupo não-caso foi avaliado como apresentando um nível de habilidades sociais variando de moderado a alto em comparação a 53,9\% do grupo caso.

Os grupos caso e não-caso de TAS foram ainda comparados em relação ao escore total do IHS-Del-Prette, aos itens específicos deste instrumento referentes à habilidade de falar em público e ao escore geral obtido para esta habilidade, cujos dados são exibidos na Tabela 33.

Tabela 33 - Comparação dos grupos caso $(\mathrm{N}=13)$ e não-caso de TAS $(\mathrm{N}=12)$ em relação aos itens do IHS indicativos da habilidade de falar em público e ao escore geral desta habilidade

\begin{tabular}{lcl}
\hline \multicolumn{1}{c}{ Habilidades de falar em público } & U de Mann-Whitney & Probabilidade \\
\hline Item 9 (falar a público desconhecido) & 13,00 & $p<0,001^{*}$ \\
Item 11 (discordar de autoridade) & 29,00 & $p=0,005^{*}$ \\
Item 14 (falar a público conhecido) & 39,50 & $p=0,031^{*}$ \\
Item 16 (discordar do grupo) & 31,50 & $p=0,008^{*}$ \\
Item 29 (fazer perguntas a conhecidos) & 56,00 & $p=0,216^{(\mathrm{NS})}$ \\
Escore geral da habilidade de falar em público & 18,00 & $p=0,001^{*}$ \\
\hline
\end{tabular}

* = diferença significativa; $(\mathrm{NS})=$ diferença não significativa

Os grupos diferiram significativamente em quatro dos cinco itens indicativos da habilidade de falar em público (item 9, 11, 14, e 16), inclusive em relação ao escore geral da habilidade de falar em público. Para esses itens e escore geral, os postos médios do grupo caso $(8,00,9,23,10,04,9,42$ e 8,38, respectivamente) foram menores que os postos médios do 
grupo não-caso (18,42, 17,08, 16,21, 16,88 e 18,00, respectivamente). Em termos descritivos, as médias do grupo caso para os mesmos itens e escore geral foram 0,92 ( $\mathrm{DP}=1,04), 0,77$ $(\mathrm{DP}=0,83), 1,92(\mathrm{DP}=1,32), 1,62(\mathrm{DP}=0,96), 7,23(\mathrm{DP}=3,11)$, respectivamente, em comparação ao grupo não-caso, cujas médias foram 3,17 (DP = 1,12), 1,92 (DP = 0,90), 3,08 $(\mathrm{DP}=1,31), 2,83(\mathrm{DP}=1,03), 13,67(\mathrm{DP}=4,21)$, respectivamente.

Quanto ao escore total do IHS-Del-Prette, foi encontrada uma diferença significativa entre os grupos $(\mathrm{U}=2,50, p<0,001)$, com o posto médio do grupo caso $(7,19)$ também sendo menor do que aquele evidenciado pelo grupo não-caso $(19,28)$. Em termos descritivos, o grupo caso obteve uma média menor de pontuação $(\mathrm{M}=70,31, \mathrm{DP}=14,82)$ comparada à média do grupo não-caso $(\mathrm{M}=107,76, \mathrm{DP}=14,22)$.

\subsubsection{Habilidades sociais de falar em público e marcadores comportamentais de ansiedade}

Todas as categorias de análise (marcadores comportamentais e suas respectivas classes; avaliação geral do desempenho, incluindo a sua classificação; latência da resposta; e tempo total de fala) foram correlacionadas com os itens específicos do falar em público e também com o escore geral da habilidade de falar em público, extraídos do IHS-Del-Prette. Como dito anteriormente, devido ao caráter exploratório dessas análises e tamanho pequeno da amostra, foram consideradas apenas as correlações que demonstraram significância estatística $(p \leq 0,05)$ e sentido de conteúdo. Esses dados são apresentados na Tabela 34. 
Tabela 34 - Correlações significativas encontradas entre as categorias de análise e os itens referentes à habilidade de falar em público, e entre essas categorias e o escore geral obtido para esta habilidade na amostra do estudo $(\mathrm{N}=25)$

\begin{tabular}{lcc}
\hline \multicolumn{1}{c}{ Correlações significativas } & $\begin{array}{c}\rho \text { de } \\
\text { Spearman }\end{array}$ & Probabilidade \\
\hline - Evitação da tarefa x item 9 (falar a público desconhecido) & $-0,43$ & $p=0,031$ \\
- Evitação da tarefa x item 14 (falar a público conhecido) & $-0,63$ & $p=0,001$ \\
- Evitação da tarefa x escore geral da HSFP & $-0,45$ & $p=0,023$ \\
- Desvio do olhar x item 14 (falar a público conhecido) & $-0,42$ & $p=0,039$ \\
- Desvio do olhar x escore geral da HSFP & $-0,49$ & $p=0,014$ \\
- Tempo total de fala x item 14 (falar a público conhecido) & 0,64 & $p=0,001$ \\
- Tempo total de fala x escore geral da HSFP & 0,45 & $p=0,025$ \\
- Avaliação geral do desempenho x item 14 (falar a público conhecido) & 0,51 & $p=0,009$ \\
- Avaliação geral do desempenho x escore geral da HSFP & 0,49 & $p=0,013$ \\
- Classificação do desempenho x item 11 (discordar de autoridade) & 0,46 & $p=0,020$ \\
- Classificação do desempenho x item 14 (falar a público conhecido) & 0,52 & $p=0,007$ \\
- Classificação do desempenho x escore geral da HSFP & 0,54 & $p=0,006$ \\
\hline
\end{tabular}

HSFP = habilidade social de falar em público

Todas as correlações com significância estatística e de conteúdo encontradas variaram de 0,42 a 0,64 , ou seja, de moderada a alta, independentemente do relacionamento entre as variáveis ser positivo ou negativo. O item 14 (falar a público conhecido) e o escore geral da habilidade de falar em público foram as variáveis que mais se correlacionaram com aquelas referentes às categorias de análise do TSFP. Estas correlações indicaram que quanto maior a habilidade de falar a um público conhecido ou a habilidade geral de falar em público de um indivíduo, ele demonstrará menos evitação de tarefa, menor freqüência de desvio de olhar, um melhor aproveitamento do tempo disponível e, conseqüentemente, será avaliado mais positivamente pela sua audiência. Menos evitação de tarefa esteve também associado a uma maior habilidade de falar a público desconhecido (item 9); e maior freqüência da habilidade de discordar de autoridade em situações sociais (item 11) associada a uma melhor avaliação do desempenho. Por exemplo, como o próprio item 11 sugere, estas situações sociais seriam ou uma sala de aula ou uma reunião. 


\section{DISCUSSÃO}

\subsection{Estudo Psicométrico}

Um ponto que merece destaque é o fato dos dados referentes ao IHS-Del-Prette seguirem uma distribuição normal, condição esta imprescindível para a aplicação de todos os testes paramétricos no Estudo 1. As amostras masculina e feminina de sujeitos que responderam o IHS neste estudo foram comparadas com aquelas que participaram da normatização do instrumento, em seu estudo original (DEL PRETTE; DEL PRETTE, 2001), para verificar se poderiam ser consideradas como procedentes da mesma população (Apêndice D). Verificou-se que as amostras de ambos os estudos, consideradas em pares, apresentam distribuição normal e, logo, os dois pares de amostras podem ser considerados como procedentes da mesma população.

A diferença significativa encontrada nos escores totais do IHS-Del-Prette comparando os sujeitos conforme o gênero pode ser explicada pelas demandas e expectativas socioculturais que influem decisivamente sobre a aquisição e o desempenho das habilidades sociais. Essas demandas e expectativas definem os papéis e as normas que darão sustentação ao desempenho social dos indivíduos, de acordo com o gênero a que pertencem. Em última análise, esse dado está coerente com estudos que situam a variável gênero como um importante moderador de diferenças e semelhanças no desempenho social entre culturas (FRAY; HECTOR, 1987). Encontra-se em concordância com vários trabalhos anteriores que também encontraram diferenças entre os gêneros na avaliação de habilidades sociais (BANDEIRA et al., 2006; DEL PRETTE et al., 2004; GROVES, 2005; TAYLOR et al., 2002; VILLA, 2002).

Quanto aos postos percentílicos apresentados, pode-se concluir que a transformação dos escores brutos em uma outra pontuação de mais fácil interpretação, expressa em percentis, 
favorece em muito a passagem da medição à avaliação do repertório de habilidades sociais demonstrado pelos sujeitos das amostras, considerando-se que os percentis mais altos correspondem aos escores totais observados também mais altos. Ainda com relação a esse ponto, constatou-se que do percentil 1 ao 25, a amostra feminina deste estudo diferiu em média de 7,14 pontos $(\mathrm{DP}=2,04)$ abaixo do escore total do grupo normativo, e a amostra masculina em 12,08 (DP = 5,85). Do percentil 30 ao 50, a amostra feminina diferiu em média de 1,83 pontos $(\mathrm{DP}=1,44)$ também abaixo, e a masculina em 2,25 $(\mathrm{DP}=1,98)$. Do percentil 55 ao 75 , a amostra feminina diferiu em 0,51 (DP = 0,50) abaixo, e a masculina em 2,57 (DP $=1,96)$ acima. Do percentil 80 ao 100, a amostra feminina diferiu em 3,13 (DP = 2,24), e a masculina em 5,54 (DP = 0,77), ambas acima do seu respectivo grupo normativo.

Na comparação da amostra feminina com o grupo normativo, os percentis 55 e 70 não apresentaram diferenças em escores totais. No caso da comparação entre a amostra masculina e o grupo normativo, não foram observadas diferenças para os percentil 50 e 55 . Evidentemente, as variações observadas nos escores totais das amostras deste estudo e do estudo original estão associadas ao tamanho das amostras e, principalmente, à singularidade do repertório de habilidades sociais de cada indivíduo.

Considerando a avaliação do repertório de habilidades sociais da amostra total de acordo com o gênero dos sujeitos, um percentual relativamente alto de sujeitos $(48,7 \%$ do gênero feminino e 47,1\% do masculino) apresentou um repertório abaixo da média, com destaque para o percentual maior referente ao repertório deficitário (31,8 e 37,4\%, respectivamente), trazendo implicações socioeducativas importantes. Este dado sugere que nem o grupo familiar e nem o sistema escolar têm favorecido ou promovido suficientemente o aprendizado de tais desempenhos aos indivíduos ao longo de suas vidas, o que traz conseqüências negativas tanto para os seus relacionamentos quanto para o seu sucesso acadêmico. Por exemplo, um aluno com um repertório deficitário dificilmente abordará um 
professor para esclarecer suas dúvidas em relação a um determinado conteúdo acadêmico ou expressará seu ponto de vista em sala de aula. Em seu dia-a-dia, este mesmo indivíduo pode ter sérias dificuldades em solicitar mudança de comportamento a outrem, recusar pedidos abusivos ou cobrar dívida de um amigo.

Quanto à consistência interna do IHS-Del-Prette, os resultados reforçam a validade de construto do instrumento em sua escala total e apóiam que os itens empiricamente derivados para o Fator 1 contribuem para o construto medido por ele (enfrentamento e auto-afirmação com risco), o que não se pode afirmar em relação aos demais fatores. Os coeficientes baixos obtidos para os demais fatores podem ser explicados pelo pequeno número de itens que os compõem e também pelos coeficientes baixos obtidos entre estes itens (BISQUERRA; SARRIERA; MARTINEZ, 2004). Com relação ao escore total, o coeficiente $\alpha$ de Cronbach deste estudo $(0,87)$ foi, comparativamente, maior que o coeficiente obtido pelo grupo normativo do instrumento ( $\alpha=0,75$ ) no estudo original.

Considerando que o IHS-Del-Prette e SPIN se focam sobre construtos diferentes, ou seja, aquele no construto de habilidades sociais e este no construto de sinais e sintomas de ansiedade social característicos do TAS, o que justificaria falar em validade concorrente entre estes dois instrumentos seria a funcionalidade de ambos no diagnóstico clínico de tal transtorno psiquiátrico. Além disso, quanto a sua normatização, o IHS utiliza uma norma intragrupo, ao passo que o SPIN uma norma referente a critério. No primeiro caso, o critério de referência dos escores é o grupo para o qual o instrumento foi construído, ou seja, o escore de um sujeito toma sentido em relação aos escores de todos os sujeitos do grupo. Já no segundo caso, o que interessa é saber se um dado sujeito atingiu ou não o escore que o põe na faixa de sujeitos identificados como psiquiátricos em frente aos normais (PASQUALI, 2003).

A validade concorrente boa demonstrada entre o IHS-Del-Prette e o SPIN evidenciou que quanto mais elaborado for o repertório de habilidades sociais de um indivíduo, menor será 
a probabilidade de ele satisfazer os critérios de rastreamento de indicadores para o TAS. Neste sentido, a hipótese inicial do estudo psicométrico foi confirmada, ou seja, as manifestações comportamentais identificadas com a aplicação do IHS estão de fato associadas às manifestações clínicas detectadas com a aplicação do SPIN. Deste modo, pode-se dizer que os resultados obtidos apontam para a relação existente entre habilidades sociais, funcionamento social e sintomas do TAS. Os 54\% da variância exclusiva do IHS e SPIN (27\% de um e 27\% do outro), que não puderam ser explicados pela variância compartilhada pelos instrumentos, devem-se a outros fatores que podem abranger os eventos ambientais tanto mais imediatos na vida de um indivíduo quanto relacionados à sua história de desenvolvimento socioemocional, ou ainda uma conjunção de ambos.

Inversamente proporcional à proposição acima, um repertório pobre de habilidades sociais facilitaria ou potencializaria o engajamento em respostas de fuga e/ou evitação de situações sociais de interação e desempenho bem características de indivíduos com TAS. Neste sentido, um repertório pobre de habilidades sociais pode ser avaliado em função dos diferentes tipos de déficits que um indivíduo pode apresentar em seu repertório de habilidades sociais, a saber: déficit de aquisição, de desempenho, e de fluência. Estes tipos de déficits foram definidos anteriormente na seção "1.6” da Introdução.

Uma observação precisa ser feita quanto à forte relação negativa também encontrada entre o IHS-Del-Prette e a Mini-SPIN, sugerindo que esta escala em sua versão abreviada continua a produzir resultados significativos. Não obstante, para efeitos de uma melhor avaliação dos indicadores diagnósticos do TAS, ainda que na condição de rastreamento, o SPIN pode fornecer uma caracterização mais completa e específica das manifestações do TAS apresentadas, visto que avalia um número maior de eventos e situações eliciadoras dos sinais e sintomas apresentados por um indivíduo. 
Serão destacados a seguir alguns comentários em relação às correlações negativas mais altas observadas entre cada um dos itens do IHS-Del-Prette e cada item do SPIN, buscando avaliar a proximidade de conteúdo avaliada pelos dois instrumentos. Coerentemente, os itens 9 ("Evito fazer exposições ou palestras a pessoas desconhecidas"), 14 ("Faço exposição [por exemplo, palestras] em sala de aula ou no trabalho, quando sou indicado"), 29 ("Na escola ou no trabalho, quando não compreendo uma explicação sobre algo em que estou interessado(a), faço as perguntas que julgo necessárias ao meu esclarecimento") e 11 (“Em uma sala de aula ou reunião, se o professor ou dirigente faz uma afirmação incorreta, eu expresso meu ponto de vista") do IHS mostraram-se altamente correlacionados, de maneira inversa, ao item 11 do SPIN ("Evito falar para uma platéia ou dar discursos [ex. apresentações em sala de aula]").

$\mathrm{O}$ item 4 do SPIN ("Evito falar com pessoas que não conheço") também se correlacionou de forma coerente com os seguintes itens do IHS-Del-Prette: 1 ("Em um grupo de pessoas desconhecidas, fico á vontade, conversando naturalmente"), 23 ("Evito fazer perguntas a desconhecidos") e 31 ("Ao entrar em um ambiente onde estão várias pessoas desconhecidas, cumprimento-as").

Isto também ocorreu entre o item 6 do SPIN ("Evito fazer coisas ou falar com certas pessoas por medo de ficar envergonhado") e os itens 8 ("Mesmo junto a conhecidos da escola ou trabalho, encontro dificuldade em participar da conversação ['enturmar']"), 17 (“Em uma conversação com amigos, tenho dificuldade em encerrar a minha participação, preferindo aguardar que os outros o façam”), 19 ("Mesmo encontrando-me próximo(a) de uma pessoa importante, a quem gostaria de conhecer, tenho dificuldade em abordá-la para iniciar conversação") e 32 ("Ao sentir que preciso de ajuda, tenho facilidade em pedi-la a alguém de meu círculo de amizades") do IHS-Del-Prette. 
O mesmo padrão foi verificado ainda entre o item 15 do SPIN ("Ficar envergonhado ou parecer bobo são meus maiores temores") e o 37 do IHS-Del-Prette ("Se preciso pedir um favor a um(a) colega, acabo desistindo de fazê-lo").

Todavia, deve-se notar aqui que a coerência dessas correlações não reside unicamente no conteúdo literal dos itens, mas também em relação às possibilidades de respostas apresentadas pela escala Likert de cada um dos instrumentos.

No tocante à validade discriminativa do IHS-Del-Prette, os resultados mostraram que os indivíduos com TAS diferiram significativamente de outros indivíduos sem TAS ou qualquer outro transtorno psiquiátrico em termos de habilidades sociais. Em acréscimo, como esperado, os indivíduos com TAS obtiveram escores mais baixos no IHS e mais altos no SPIN quando comparados com indivíduos sem este diagnóstico, corroborando assim a correlação inversa verificada entre os dois instrumentos.

A área sob a curva de 0,96 $(p<0,001)$ encontrada para os dados do IHS-Del-Prette indicou uma precisão alta deste instrumento para discriminar casos e não-casos de TAS. Deste modo, a área de 0,96 significa que um indivíduo selecionado randomicamente do grupo caso tem um valor (escore) de teste menor do que aquele obtido por um indivíduo escolhido randomicamente do grupo não-caso em 96\% das vezes. Além disso, a análise da curva ROC indicou que o escore de corte 94 foi o que melhor distinguiu os indivíduos com e sem TAS, produzindo um melhor equilíbrio entre a sensibilidade e especificidade, com uma taxa de classificação incorreta menor. No entanto, o escore de corte 97 evidenciou ser o mais adequado para propósitos de rastreamento, ou seja, com uma sensibilidade e valor preditivo negativo mais alto.

Sete dos itens $(1,8,9,11,14,19$ e 29$)$ que evidenciaram maior poder discriminativo entre os grupos caso e não-caso de TAS submetidos à confirmação diagnóstica pela SCID (N = 86) também o apresentaram para os grupos avaliados apenas por meio da Mini-SPIN $(\mathrm{N}=$ 
1006). Três dos cinco itens (20, 21 e 24) com poder discriminativo relativamente alto entre os grupos submetidos à SCID compartilharam esta propriedade com os grupos avaliados pela Mini-SPIN.

Do mesmo modo, os cinco itens $(1,9,17,19$ e 29) com um efeito grande para a amostra avaliada pela Mini-SPIN compartilharam esta propriedade com a amostra submetida à confirmação diagnóstica. Em contrapartida, os nove itens $(6,10,15,18,25,27,28,34$ e 35) que mostraram um efeito médio para a segunda amostra, não o apresentaram para a primeira, cujo tamanho do efeito foi pequeno. Além disso, os 18 itens com um efeito médio para a amostra avaliada pela Mini-SPIN exibiram um efeito grande para a amostra submetida à SCID. Esses dados sugerem que a precisão do tamanho do efeito $(d)$ para dimensionar a diferença entre dois grupos está proporcionalmente associada à eficácia do método utilizado para designar os sujeitos aos grupos.

Os itens 1 (manter conversa com desconhecidos) e 23 (fazer pergunta a desconhecido) evidenciaram maior poder discriminativo e um efeito grande para os sujeitos dos grupos caso e não-caso de TAS, submetidos à confirmação diagnóstica, e tal dado está consistente com os resultados de Stopa e Clark (1993). Os resultados obtidos por esses autores demonstraram que, em uma situação social hipotética de encontrar dois velhos amigos de uma pessoa conhecida, quando na companhia dela em um bar, os fóbicos sociais tiveram mais pensamentos auto-avaliativos negativos comparados aos controles ansiosos e não-pacientes. Neste caso, os fóbicos sociais também tiveram mais pensamentos acerca de evitação e poucos sobre planejamento (pensamentos sobre estratégias de enfrentamento e objetivos comportamentais) do que os controles. Esse foco em pensamentos negativos interfere com o comportamento adaptativo, impedindo o sujeito de formular um plano de como lidar adequadamente com o encontro e, assim, aumentando a ansiedade e estimulando mais julgamentos negativos sobre si mesmo. 
A habilidade de negociar uso de preservativo encontrada em comum para os grupos caso e não-caso, submetidos ou não à SCID, assume relevância não só social como também profilática, considerando dois fatores: (1) ambos os grupos são provindos de uma amostra pertencente a uma faixa etária jovem que estimula desde contatos meramente sociais até práticas sexuais; e (2) compartilham uma parte significativa de suas vidas dentro do contexto universitário, um ambiente favorável também para novos contatos interpessoais e práticas sexuais. Com o avanço das doenças sexualmente transmissíveis e, particularmente, com a disseminação da AIDS, essa habilidade torna-se cada vez mais requerida tanto para a consolidação de uma relação como para a garantia da saúde. Conforme apontam Del Prette e Del Prette (2001), solicitar ou exigir o uso de preservativo e recusar sexo inseguro, dentre outras medidas, constituem habilidades de enfrentamento que precisam ser desenvolvidas e exercitadas. Embora os dois grupos não tenham demonstrado diferença para a habilidade de negociar o uso de preservativo, atestaram diferenças significativas para as habilidades de abordar para relação sexual e declarar sentimento amoroso que do mesmo modo estão inseridas no contexto do relacionamento afetivo/sexual.

Do rol de habilidades sociais que os dois grupos demonstraram diferenças significativas, observou-se que essas habilidades estão relacionadas a diferentes: (a) interlocutores, como parceiro sexual (itens 12 e 20), autoridades (11 e 19), familiar (10, 15, 18 e 28), desconhecidos $(1,7,9,21,23,26,31$ e 36), conhecidos $(8,13,14,16,22,24,29$, 34, 37 e 38), amigos (5, 17, 27, 32 e 35) e indefinido (4, 6, 25 e 30); e (b) contextos, entre eles o público, como de trabalho, estudo ou consumo (itens 1, 5, 8, 9, 11, 13, 14, 16, 19, 21, 22, 23, 26, 29, 30, 31, 37 e 38), o privado, como o doméstico ou íntimo (2, 10, 12, 15, 17, 18, 20, 28, 34, 35, e 36) e indefinido (3, 4, 6, 7, 24, 25, 27 e 32). Assim sendo, esses resultados evidenciam claramente a relação entre os possíveis déficits em habilidades sociais e prejuízos 
diversos no funcionamento social que indivíduos com TAS podem experimentar em seu diaa-dia.

$\mathrm{Na}$ comparação dos grupos que foram submetidos à confirmação diagnóstica pela SCID com os grupos que não receberam essa avaliação, foram encontradas as seguintes diferenças: o grupo caso sem confirmação diagnóstica apresentou apenas a habilidade de expressar sentimento positivo (item 35) a mais no conjunto daquelas com escores mais altos em relação ao mesmo grupo com diagnóstico confirmado. O grupo não-caso que não foi avaliado pela SCID exibiu as habilidades de expressar sentimento positivo, reagir a elogio e lidar com críticas injustas (itens 35, 13 e 15, respectivamente) a mais no rol de habilidades com escores mais altos quando comparado ao mesmo grupo submetido a tal avaliação que, por sua vez, apresentou a habilidade de encerrar conversa ao telefone (item 24) a mais. Os grupos caso e não-caso com confirmação diagnóstica diferiram em relação às habilidades de pedir mudança de conduta, agradecer elogios e negociar uso de preservativo quando comparados entre si. Os grupos sem confirmação diagnóstica não apresentaram diferenças significativas entre si em relação às duas primeiras habilidades, apenas para a última. No geral, essas poucas diferenças encontradas entre os grupos submetidos ou não à confirmação diagnóstica corroboram o potencial do IHS-Del-Prette em distinguir indivíduos com e sem diagnóstico de TAS.

Como esperado na aplicação da análise fatorial sobre o conjunto de dados referentes ao IHS-Del-Prette, observou-se que alguns itens mostraram-se relacionados a outros em um modelo de oito fatores que conseguiu explicar uma parte considerável da variabilidade do conjunto original de itens $(47,9 \%)$. Por outro lado, caso todos os itens do Fator 3, 5 e $6(\mathrm{~N}=$ 13) fossem agregados em um único fator, denominado de assertividade e enfrentamento com risco, sintetizando todas habilidades assertivas em um sentido mais amplo, ter-se-ia um coeficiente de 0,72 , indicando uma consistência interna boa, o que resultaria em um modelo 
de seis fatores. Contudo, essa redução no número de fatores ganharia no quesito generalidade dos itens em detrimento à especificidade dos mesmos. De acordo com as diretrizes de Artes (1998), a análise fatorial executada, independentemente dessa redução, pode ser caracterizada como bem sucedida, considerando que foi possível determinar um número relativamente pequeno de fatores que interpretados responderam por uma porcentagem razoável de dados.

Em concordância com outro pesquisador, decidiu-se não realizar uma análise fatorial confirmatória com os dados do IHS-Del-Prette por vários motivos que poderiam enviesar os resultados obtidos em tal análise, a saber: (a) o período de tempo relativamente longo (aproximadamente cinco anos) entre a coleta de dados deste estudo e a coleta do estudo original; (b) a impossibilidade de garantia de que os procedimentos de aplicação do instrumento, principalmente em relação às instruções fornecidas aos sujeitos, foram idênticos; (c) na coleta deste estudo, o IHS foi aplicado conjuntamente com outros instrumentos do projeto maior, diferentemente do estudo original; (d) o número extremamente maior de sujeitos que participaram deste estudo comparado ao número do estudo normativo; (e) a faixa etária maior admitida por este estudo, apresentando uma diferença significativa da idade média entre os sujeitos dos dois estudos $\left(t_{(1390)}=4,50, p<0,0001\right.$, com correção de Welch); (f) no geral, os sujeitos de ambos os estudos eram procedentes de cursos diferentes em cada área do conhecimento; e (g) a porcentagem de sujeitos em cada área do conhecimento também foi bastante contrastante, com um predomínio de alunos matriculados nos cursos da área de Biológicas $(56,9 \%)$ neste estudo, comparado ao predomínio de alunos matriculados nos cursos da área de Humanas $(47.5 \%)$ no estudo original.

O fato de não ter sido encontrada diferença significativa nos escores médios do IHSDel-Prette em função da área e ano de curso dos alunos sugere que os mesmos não fizeram, necessariamente, suas escolhas profissionais de acordo com um repertório mais ou menos elaborado de habilidades sociais. Pode-se questionar ainda que o período de permanência na 
universidade não tem favorecido consideravelmente a aprendizagem de novas habilidades ou a melhoria de desempenhos prévios. Esperar-se-ia que ao longo dos anos na universidade, os indivíduos refinassem cada vez mais seus desempenhos interpessoais na medida em que são progressivamente mais solicitados em tarefas e demandas que poderiam favorecer tanto a aquisição quanto a melhoria de muitos desempenhos sociais, ou seja, seu nível de proficiência. Como por exemplo, podem ser citadas as solicitações para apresentação de seminários em grupo na sala de aula, além das trocas e interações sociais com seu grupo de iguais no contexto universitário que, a priori, constituiriam oportunidades propícias para um aprendizado ou desenvolvimento de habilidades interpessoais.

Diferentes análises, como as realizadas pelo Teste t e ANOVA, demonstraram que os grupos caso e não-caso de TAS apresentam diferenças significativas em seu repertório de habilidades sociais, em conformidade com os resultados relatados pela literatura da área (ALDEN; MELLINGS, 2004; BAKER; EDELMANN, 2002; FYDRICH et al., 1998; STOPA; CLARK, 1993; VONCKEN; BÖGELS, 2008). Tanto para o gênero feminino quanto para o masculino, ambos os grupos atestaram diferenças significativas em habilidades sociais. Em relação aos cinco fatores do IHS-Del-Prette, os dois grupos também diferiram significativamente, evidenciando que indivíduos com TAS apresentam um déficit generalizado de habilidades sociais com implicações diversas para o seu funcionamento social, sucesso acadêmico e possível sucesso profissional. 


\subsection{Estudo Empírico}

As poucas diferenças significativas entre os grupos caso e não-caso de TAS em relação à maioria das categorias e suas respectivas classes podem ser atribuídas a dois fatores. O primeiro deles, de caráter metodológico, refere-se ao fato dos sujeitos diagnosticados com TAS para compor o grupo caso não terem sido avaliados quanto aos subtipos de manifestação do transtorno, ou seja, se generalizado ou circunscrito. Desse modo, os sujeitos com TAS que participaram deste estudo poderiam se enquadrar no tipo circunscrito ou específico, temendo apenas uma ou poucas situações públicas de desempenho, com exceção de falar em público, tais como comer, beber, tocar um instrumento na frente dos outros ou usar banheiro público.

No entanto, mesmo que esses indivíduos apresentassem o medo de falar em público pregressamente, pode-se pensar que as exigências acadêmicas de apresentação de trabalhos e seminários em sala de aula ou mesmo exposição de opiniões em grupo, tão freqüentes na vida universitária, podem ter gradualmente reduzido as reações mais severas e debilitantes de ansiedade frente a esse tipo de tarefa. A exposição dos sujeitos aos estímulos ansiogênicos dessas situações pode ter ocorrido a custos bastante altos para eles, mas ao mesmo tempo é possível que tenha contribuído para que enfrentassem de forma relativamente mais adaptativa os seus medos.

Para reforçar a relevância de uma classificação dos subtipos de TAS na realização de estudos com indivíduos diagnosticados com este transtorno, os dados de Levin et al. (1993) demonstraram padrões distintos de resposta subjetiva e fisiológica entre pacientes com TAS generalizado e circunscrito em uma situação experimental de falar em público, na qual eles discursavam perante uma audiência. Neste estudo, os pacientes do subtipo generalizado experimentaram aumentos significativos em ansiedade subjetiva enquanto falavam comparados tanto a pacientes circunscritos quanto a controles. Em auto-relato anterior ao discurso, os pacientes generalizados relataram mais medos no Personal Report of Confidence 
as a Speaker, comparados ao grupo circunscrito, sugerindo que aqueles pacientes experimentam mais ansiedade subjetiva ao falar em público do que os pacientes deste grupo. Dessa forma, os autores advogam a validade desses agrupamentos diagnósticos e a necessidade dos mesmos em estudos psicobiológicos do TAS.

Em termos de manifestações comportamentais de ansiedade, somente os pacientes generalizados deste estudo (LEVIN et al., 1993) diferiram de controles, embora os autores aleguem que pacientes generalizados e circunscritos geralmente demonstram manifestações comportamentais similares e deixem a questão em aberto para novos estudos.

Em Hofmann et al. (1997), os fóbicos sociais generalizados também relataram uma elevação maior em sua ansiedade subjetiva desde a linha-de-base até durante o discurso, quando comparados aos fóbicos não-generalizados, controles generalizados e nãogeneralizados. Neste estudo, a designação dos sujeitos aos subtipos generalizados e nãogeneralizados foi realizada com base em avaliações subjetivas de medo de situações sociais específicas (ter o primeiro encontro romântico, usar o telefone, ser apresentado à outra pessoa, encontrar pessoas de autoridade, ser ridicularizado e ser observado por outros).

A importância da classificação do TAS em subtipos também encontra respaldo na proposição da distinção qualitativa apresentada por Hook e Valentiner (2002). Estes autores defendem que os subtipos generalizado e específico do TAS são qualitativamente distintos, sugerindo que podem representar categorias diagnósticas diferentes e, conseqüentemente, requerendo abordagens de tratamento diferentes.

Em um estudo recente conduzido por Voncken e Bögels (2008), pacientes com TAS generalizado $(\mathrm{N}=48)$ foram avaliados como demonstrando uma aparência mais nervosa e comportamento social menos adequado do que os controles não-clínicos $(\mathrm{N}=27)$ durante uma tarefa de conversação, mas estas diferenças não foram significativas durante um discurso de cinco minutos em frente a uma audiência de duas pessoas. Com relação ao desempenho 
social geral (medida resultante da transformação da aparência ansiosa e comportamento social em uma nova variável), foram observados os mesmos resultados. Diferentemente deste estudo, as avaliações dos sujeitos foram feitas sobre uma escala tipo Likert (Social Behavior and Anxious Appearance rating scale) pela própria dupla de auxiliares de pesquisa, um do gênero masculino e outro do feminino, que participou em cada uma das tarefas. Entretanto, ainda que o referido estudo contasse com a homogeneidade de classificação de todos os sujeitos com TAS como sendo do subtipo generalizado, pode-se afirmar que as avaliações realizadas pelos auxiliares de pesquisa foram bastante subjetivas visto que foram feitas apenas sobre a escala citada.

Um outro fator diz respeito à possibilidade dos sujeitos com TAS apresentarem um bom processamento cognitivo para alguns estímulos externos, sendo assim capazes de discriminar que estavam se comportando frente a uma câmara e não frente a uma audiência de pessoas, mesmo sendo a situação em si ansiogênica. Desta forma, essa capacidade discriminativa pode ter feito com que a situação tivesse um menor impacto sobre os seus desempenhos. Conseqüentemente, surge uma questão básica a esse respeito que não pode ser respondida por este estudo: O desempenho exibido durante a situação experimental do TSFP corresponderia ao desempenho observado em uma situação natural de falar em público? Dado que o uso de métodos observacionais análogos é universal em avaliação comportamental, torna-se imperativo que novas pesquisas sejam conduzidas para abordar esse tipo de questão.

Este estudo empregou níveis de medida comportamental tanto molecular quanto molar do desempenho dos sujeitos. O nível molecular consistiu em avaliações altamente específicas usando a freqüência e/ou duração de comportamentos específicos, enquanto o nível molar compreendeu avaliações mais gerais, uma usando a freqüência das classes de comportamentos e outra realizada sobre uma escala. A avaliação no nível molecular dos marcadores comportamentais de ansiedade forneceu informações importantes acerca de pontos fracos 
específicos dos indivíduos avaliados que podem ser usadas tanto no planejamento de tratamentos quanto durante o curso de tratamentos voltados para reduzir déficits e promover desempenhos mais habilidosos.

Dentro desta perspectiva, o conteúdo das filmagens do TSFP poderia ser empregado como técnica de vídeofeedback acerca do desempenho dos sujeitos em programas de Treinamento em Habilidades Sociais voltado para o contexto acadêmico, visando a modelagem de desempenhos mais adequados. Além disso, esse conteúdo pode fornecer feedback corretivo importante aos sujeitos com TAS, uma vez que eles podem crer que se comportam mais pobremente do que de fato se comportam. Nesta direção, os resultados de Rapee e Hayman (1996) indicam que quando indivíduos socialmente ansiosos avaliam o próprio desempenho em um discurso por meio do registro em vídeo, eles são capazes de avaliá-lo de maneira mais consistente com a avaliação de observadores independentes. Os sujeitos que não foram expostos a esse registro, tenderam a subestimar o próprio desempenho em comparação com avaliações fornecidas por observadores.

Particularmente, embora os grupos caso e não-caso de TAS não demonstraram diferenças estatisticamente significativas entre si em relação à evitação da tarefa e aos tipos de pausas, observaram-se diferenças entre os dois grupos quanto ao número de sujeitos que exibiram tais marcadores comportamentais de ansiedade. Um número maior de sujeitos do grupo caso demonstrou evitação da tarefa em comparação ao grupo não-caso. Mais precisamente, cinco sujeitos do grupo caso permaneceram em silêncio por um período que variou de 20 a 80 segundos em relação ao tempo total disponibilizado para a tarefa, que foi 4 minutos, ao passo que apenas um sujeito do grupo não-caso ficou em silêncio por um período total de 80 segundos.

Observou-se também que nove sujeitos do grupo caso apresentaram pausas silenciosas $(\mathrm{M}=2,08, \mathrm{DP}=2,47)$, cujas freqüências de ocorrência variaram de 1 a 8 , ao lado de cinco do 
grupo não-caso $(\mathrm{M}=1,00, \mathrm{DP}=1,87)$, com freqüências variando de 1 a 6 . Esse resultado contradiz a suposição de Stopa e Clark (1993) de que muitos fóbicos sociais falam rápido demais e tentam evitar pausas silenciosas em seus discursos porque acreditam que outras pessoas pensarão que são tediosos ou ansiosos se eles pausam; e encontra-se concordante com os resultados do estudo de Hofmann et al. (1997). Neste estudo, em particular, os sujeitos tinham que preparar um discurso sobre três de cinco tópicos apresentados (energia nuclear, punição física nas escolas, leis da obrigatoriedade do cinto de segurança, aborto e sistema de saúde americano). Eles podiam cobrir de um a três tópicos durante um discurso de 10 minutos, gastando quantos minutos quisessem em cada um deles, frente a uma audiência composta por duas pessoas (um homem e uma mulher). Poderiam encerrar seu discurso antes do tempo determinado se experimentassem ansiedade excessiva ou se sentissem que a fala tinha chegado a um final lógico.

Quanto às pausas preenchidas, 12 sujeitos do grupo caso apresentaram este tipo de pausa $(\mathrm{M}=11,92, \mathrm{DP}=6,65)$, com freqüências variando de 5 a 24 , ao passo que todos os sujeitos do grupo não-caso o apresentaram $(\mathrm{M}=8,38, \mathrm{DP}=4,57)$, com freqüências variando de 4 a 20. Desse modo, o grupo caso teve um número maior de sujeitos que apresentaram pausas silenciosas durante o discurso quando comparado ao grupo não-caso.

A freqüência consideravelmente alta de falas descontínuas no discurso dos sujeitos de ambos os grupos sugere que a ansiedade, por meio dos seus efeitos sobre o processamento cognitivo de informações, prejudica o encadeamento das sentenças, ou seja, a qualidade da relação entre sentenças sucessivas ao longo do discurso.

As poucas diferenças encontradas entre o início e o final do discurso para os dois grupos em relação a cada uma das categorias e suas classes evidenciam que o tempo de exposição ao TSFP não conseguiu promover, de maneira satisfatória, uma redução ou inibição das reações comportamentais de ansiedade demonstradas pelos sujeitos. Em outras palavras, 
que a frequiência de emissão dos marcadores comportamentais de ansiedade pelos sujeitos de ambos os grupos manteve-se estável ao longo do TSFP.

Por outro lado, embora seja assumido que os elementos avaliados do repertório comportamental dos sujeitos no TSFP sejam em geral representativos do seu comportamento, pode-se questionar se isto realmente representa o seu repertório comportamental. Tal questão aponta para a necessidade de novos estudos respaldados por uma validade ecológica (grau em que as condições de um estudo são verdadeiras ou aplicáveis para a vida real) e com possibilidade de generalização dos resultados.

Possivelmente, a observação naturalística permitiria ao observador avaliar o desempenho de falar em público dos sujeitos dentro de contextos situacionais normais e com reforçadores e conseqüências ocorrendo naturalmente. Todavia, a reatividade dos sujeitos para a presença do observador pode diminuir a validade da observação, mas conduzir observações sem o consentimento dos sujeitos e outros significantes violaria os limites éticos da pesquisa com seres humanos. Dadas essas dificuldades associadas aos métodos de observação naturalística, uma alternativa para a extensão deste estudo, em uma perspectiva que contemple tanto a validade ecológica quanto a possibilidade de generalização dos resultados, consistiria em ajustar o delineamento do teste para uma versão que contasse com uma audiência constituída de duas ou três pessoas, no mínimo, para assistir o discurso.

A seguir, serão tecidas algumas considerações acerca de algumas correlações significativas encontradas. A relação indicando que quanto mais repetições de conteúdo o sujeito apresentasse ao longo do discurso, melhor avaliado seria o seu desempenho ( $\rho=$ 0,57, $p=0,002$ ) ganha consistência considerando o forte relacionamento negativo entre evitação da tarefa e avaliação geral do desempenho $(\rho=0,86, p=0,002)$. Mais especificamente, isto significa que o desempenho do sujeito foi melhor avaliado mesmo quando ele repetia, ao longo do discurso, sentenças ou assuntos proferidos anteriormente do 
que quando ficou em silêncio por um período considerável de tempo, sem verbalizar coisa alguma.

Coerentemente, as categorias descontinuidade da fala, conteúdo negativo e uso de jargões demonstraram um relacionamento positivo com a sua própria classe de marcadores verbais. Do mesmo modo, risos inapropriados, intensidade de voz inapropriada e pausas correlacionaram-se positivamente com a sua respectiva classe de marcadores paralingüísticos. E também inquietação, barreiras e movimentos faciais de desconforto estiveram relacionados à sua classe de marcadores não-verbais. As demais categorias não apresentaram um relacionamento significativo com as suas respectivas classes.

Considerou-se a categoria movimentos faciais de desconforto como uma medida pouco válida do desempenho dos sujeitos à medida que a sua definição contemplou toda e qualquer forma de franzir a testa e morder os lábios, tornando-a imprecisa. Por exemplo, franzir a testa, erguendo as sobrancelhas, acompanha muito do que é expresso verbalmente. Além disso, nem sempre foi possível identificar claramente, pela morfologia do gesto, se morder os lábios tinha a função de mordida mesmo ou de umedecer os lábios. Portanto, ou essa categoria precisaria ser revista para garantir uma melhor definição ou a análise do conteúdo das filmagens deveria contar com equipamentos que possibilitassem uma visualização mais clara e precisa daquilo que estava sendo observado.

Com relação aos itens indicativos da habilidade social de falar em público, selecionados a partir do IHS-Del-Prette, a maioria (item 9, 11, 14 e 16) evidenciou significativamente distinguir os sujeitos do grupo caso daqueles do grupo não-caso de TAS, com exceção apenas do item 29. Esses mesmos itens também atestaram maior poder discriminativo para os grupos caso e não-caso de TAS, cujos sujeitos foram sistematicamente avaliados pela SCID. Além disso, o escore geral da habilidade de falar em público, obtido pela somatória dos itens, mostrou coerentemente discriminar ambos os grupos. 
Possivelmente, o contraste encontrado entre a capacidade discriminativa desses itens e os marcadores comportamentais de ansiedade seja atribuído ou explicado pelos diferentes tipos de déficits avaliados em cada situação específica. No primeiro caso, os itens do IHSDel-Prette avaliam, assumidamente, os déficits de desempenho existentes no repertório de um indivíduo e, no segundo, pode-se dizer que os marcadores comportamentais de ansiedade avaliaram os déficits de fluência dos sujeitos. Sendo assim, ambos os instrumentos, o IHS e o TSFP, avaliam dimensões distintas do repertório comportamental de um indivíduo. 


\section{CONCLUSÕES}

O perfil amostral dos Estudos 1 e 2 caracterizou-se exclusivamente por estudantes universitários do Estado de São Paulo e, embora com uma faixa etária bem ampla, este fato impossibilita a generalização dos resultados obtidos para outras amostras com diferentes níveis educacionais e advindas de outras regiões culturalmente distintas.

Por outro lado, considera-se que uma avaliação clínica ampla seja imprescindível na decisão de qual abordagem de tratamento será a mais apropriada para um dado indivíduo com TAS. Uma avaliação completa incluiria uma entrevista estruturada ou semi-estruturada, medidas de auto-relato e avaliação comportamental. Cada uma destas medidas forneceria diferentes tipos de informação que podem ser relevantes para decisões posteriores quanto ao tratamento. Nesta direção, este estudo contou com a aplicação da SCID, SPIN, IHS-Del-Prette e TSFP que, conforme o contexto (se acadêmico ou não), poderiam conjuntamente constituir medidas diretas, objetivas e confiáveis para uma avaliação completa e específica no diagnóstico do TAS e, conseqüentemente, para o planejamento de medidas de intervenção mais apropriadas às necessidades dos indivíduos portadores de tal transtorno. Algumas conclusões e considerações finais dos resultados obtidos em cada um dos estudos serão apresentadas a seguir, separadamente.

\subsection{Estudo Psicométrico}

Neste estudo, foram confirmadas as boas propriedades psicométricas do IHS-DelPrette como uma medida para identificar indivíduos com diagnóstico de TAS, demonstrando uma diferença significativa entre indivíduos com e sem este transtorno, sistematicamente avaliados por meio de uma entrevista clínica "padrão-ouro" (SCID/DSM-IV). 
Os resultados apontam que o IHS-Del-Prette pode ser um instrumento apropriado para detectar as dificuldades ou déficits interpessoais que indivíduos com TAS apresentam, constituindo uma ferramenta útil para uma melhor caracterização do seu quadro diagnóstico, ou mais especificamente para a avaliação dos seus déficits de desempenho em habilidades sociais. Evidencia-se assim tanto a sua validade clínica no diagnóstico deste transtorno, quanto a possibilidade de uso do instrumento em estudos empíricos que testem a eficácia terapêutica de programas de intervenção.

Em particular, o IHS-Del-Prette pode ser empregado como um forte aliado do SPIN, que avalia o espectro completo dos sintomas em termos de medo, evitação e componentes fisiológicos, para a obtenção de uma avaliação mais completa e específica dos indicadores diagnósticos apresentados pelos indivíduos com fobia social.

Estudos adicionais serão necessários para abordar aspectos não contemplados e limitações do estudo em questão. São estes:

(1) A avaliação da validade discriminativa e preditiva do IHS-Del-Prette ganharia uma maior consistência e respaldo se realizada com uma amostra mais ampla de sujeitos diagnosticados como casos e não-casos de TAS, deixando esta questão em aberto para futuros estudos;

(2) Faltou uma maior abrangência do estudo para determinar se a escala discriminaria participantes socialmente fóbicos daqueles com outros transtornos de ansiedade e/ou com outros quadros diagnósticos, como a depressão;

(3) A confiabilidade teste-reteste também não foi avaliada, embora já existam estudos dos próprios autores do instrumento com este objetivo (BANDEIRA et al., 2000; DEL PRETTE; DEL PRETTE; BARRETO, 1998);

(4) O IHS-Del-Prette foi validado, neste estudo, como uma escala para selecionar participantes socialmente fóbicos, mas ainda não está claro se esta escala é capaz de 
distinguir participantes com TAS do subtipo generalizado daqueles do subtipo circunscrito ou específico;

(5) Verificou-se a necessidade de avaliar a sensibilidade do IHS-Del-Prette à redução de déficits interpessoais e sintomas apresentados pelos indivíduos diagnosticados com esse transtorno ao longo do tempo, principalmente após a aplicação de intervenções farmacológicas e/ou programas de tratamento, como por exemplo, o Treinamento em Habilidades Sociais. Neste caso, em particular, estar-se-ia testando a validade do instrumento para detectar as possíveis mudanças produzidas por tais abordagens de intervenção. No entanto, poder-se-ia testar também a validade do tratamento (ou terapêutica) avaliada pelo instrumento por meio da SCID, visando verificar, assim, a sua validade de dupla face nesse quesito;

(6) Constatou-se a necessidade de investigações com delineamento longitudinal visando uma verificação mais acurada de possíveis associações entre habilidades sociais e ano de curso, realizadas com os mesmos sujeitos. Poder-se-á assim verificar se níveis de habilidades sociais funcionam de fato como preditores de desempenho acadêmico e permanência na universidade. 


\subsection{Estudo Empírico}

Apesar de todas as limitações deste estudo, o TSFP mostrou-se um procedimento bastante útil para avaliar os sinais ou marcadores comportamentais de ansiedade à medida que simula uma das situações sociais temidas mais prevalente nos diferentes subtipos do TAS, como também na população geral. Desse modo, a situação experimental do TSFP demonstrou que a ansiedade experimentada pelos indivíduos em situações de falar em público é manifestada comportalmente e pode ser confiavelmente avaliada. Além disso, o TSFP por ser uma tarefa de avaliação padronizada facilita comparações acerca do desempenho de indivíduos ou grupos definidos.

No geral, os resultados deste estudo apontam para a possibilidade do TSFP ser usado em programas de Treinamento em Habilidades Sociais no contexto educacional para a avaliação tanto dos recursos quanto dos déficits comportamentais de habilidades sociais de falar em público, visando promover um melhor desempenho de estudantes universitários nas atividades acadêmicas de apresentação de trabalhos e seminários. Esse refinamento no repertório comportamental dos alunos refletiria, futuramente, em uma melhor qualificação profissional dos mesmos para enfrentar o mercado de trabalho.

Um limite deste estudo foi não ter sido tomada uma medida dos sintomas de ansiedade ao longo do procedimento do TSFP e associá-la tanto aos marcadores comportamentais de ansiedade propostos quanto às habilidades sociais de falar em público extraídas do IHS-DelPrette, visando explorar as possíveis relações entre os relatos subjetivos e as manifestações comportamentais de ansiedade e ainda entre estes relatos e a habilidade de falar em público dos sujeitos.

A análise dos resultados deste estudo aponta para a necessidade de novos estudos com amostras clínicas de indivíduos com TAS dos subtipos generalizado e circunscrito, e nãoclínica mais amplas, com avaliação prévia dos sujeitos quanto ao medo de falar em público, 
dando assim respaldo para comparações mais consistentes entre os grupos, e que contemplem uma validade ecológica e uma possibilidade de generalização dos resultados. 


\section{REFERÊNCIAS*}

AGUIAR, A. A. R. Construção e avaliação de um programa multimodal de habilidades comunicativas junto a adultos com deficiência mental. 2006. $201 \mathrm{f}$. Tese (Doutorado) Universidade Federal de São Carlos, São Paulo, 2006.

ALCALDE, M. C. B.; LÓPEZ, V. J. M. C. Trastorno por ansiedad social de inicio en la infancia y la adolescencia. In: GARCÍA, J. B.; GARCÍA-PORTILLA, M. P. G.; MARTÍNEZ, P. A. S.; GARCÍA, M. B. (Eds.). Abordaje actual del trastorno por ansiedad social. Barcelona: Masson, 1999. p. 35-62.

ALDEN, L. E.; MELLINGS, T. M. B. Generalized social phobia and social judgments: the salience of self- and partner-information. Journal of Anxiety Disorders. New York, v. 18, p. 143-157, 2004.

AMERICAN PSYCHIATRIC ASSOCIATION. Diagnostic and statistical manual of mental disorders. $4^{\text {th }}$ ed. Washington, 1994.

ANGÉLICO, A. P. Estudo descritivo do repertório de habilidades sociais de adolescentes com síndrome de Down. 2004. 126 f. Dissertação (Mestrado) - Universidade Federal de São Carlos, São Carlos, São Paulo, 2004.

ANGÉLICO, A. P.; CRIPPA, J. A. S.; LOUREIRO, S. R. Fobia social e habilidades sociais: uma revisão da literatura. Interação em Psicologia, Curitiba, v. 10, n. 1, p. 113-125, Jan./Jun. 2006.

ARRINDELL, W. A.; EMMELKAMP, P. M. G.; MONSMA, A.; BRILMAN, E. The role of perceived parental rearing practices in the etiology of phobic disorders: a controlled study. British Journal of Psychiatry, London, v. 143, 183-187, Aug. 1983.

ARTES, R. Aspectos estatísticos da análise fatorial de escalas de avaliação. Revista de Psiquiatria Clínica, São Paulo, v. 25, n. 5, p. 223-228, 1998. Edição Especial.

AYRES, L. S. M. Uma escala brasileira para a medida da assertividade. $1994.75 \mathrm{f}$. Dissertação (Mestrado), Universidade Gama Filho, Rio de Janeiro, 1994.

AZRIN, N. H. Some effects of two intermittent schedules of immediate and non-immediate punishment. Journal of Psychology, Washington, v. 42, p. 3-21, 1956.

\footnotetext{
* De acordo com:

ASSOCIAÇÃO BRASILEIRA DE NORMAS TÉCNICAS. NBR 6023: informação e documentação: referências: elaboração. Rio de Janeiro. 2002
} 
BAKER, S. R.; EDELMANN, R. J. Is social phobia related to lack of social skills? Duration of skill-related behaviours and ratings of behavioural adequacy. British Journal of Clinical Psychology, London, v. 41, p. 243-257, Sept. 2002.

BANDEIRA, M. Escala de avaliação da competência social de pacientes psiquiátricos através de desempenho de papéis - EACS. Avaliação Psicológica, Porto Alegre, v. 1, n. 2, p. 159171, Nov. 2002.

BANDEIRA, M.; COSTA, M. N.; DEL PRETTE, Z. A. P.; DEL PRETTE, A.; GERKCARNEIRO, E. Qualidades psicométricas do Inventário de Habilidades Sociais (IHS): estudo sobre a estabilidade temporal e a validade concomitante. Estudos de Psicologia, Natal, v. 5, n. 2, p. 401-419, Jul./Dez. 2000.

BANDEIRA, M.; ROCHA, S. S.; FREITAS, L. C.; DEL PRETTE, Z. A. P.; DEL PRETTE, A. Habilidades sociais e variáveis sociodemográficas em estudantes do ensino fundamental. Psicologia em Estudo, Maringá, v. 11, n. 3, p. 541-549, Set./Dez. 2006.

BANDEIRA, M.; TREMBLAY, L. Competência social de psicóticos: um estudo de validação social. Jornal Brasileiro de Psiquiatria, Rio de Janeiro, v. 47, n. 4, 185-192, 1998.

BAPTISTA, C. A. Estudo da prevalência do transtorno de ansiedade social em estudantes universitários. 2007. 111f. Dissertação (Mestrado) - Faculdade de Medicina de Ribeirão Preto, Universidade de São Paulo, Ribeirão Preto, São Paulo, 2007.

BARLOW, D. Anxiety and its disorders: the nature and treatment of anxiety and panic. New York: Guilford.

BEIDEL, D. C.; TURNER, S. M. Shy children, phobic adults: nature and treatment of social phobia. Washington, DC: American Psychological Association, 1999.

BISQUERRA, R.; SARRIERA, J. C.; MARTÍNEZ, F. Introdução à estatística: enfoque informático com o pacote estatístico SPSS. Porto Alegre: Artmed, 2004.

BOONE, M. L.; MCNEIL, D. W.; MASIA, C. L.; TURK, C. L.; CARTER, L. E.; RIES, B. J.; LEWIN, M. R. Multimodal comparisons of social phobia subtypes and avoidant personality disorder. Journal of Anxiety Disorders, Oxford, v. 13, n. 3, p. 271-292, May 1999.

BRIMER, C. J.; KAMIN, L. J. Disinhibition, habituation, sensitization and the conditioned emotional response. Journal of Comparative and Physiological Psychology, Washington, v. 56, n. 3, p. 508-516, Jun. 1963.

BROWN, E. J.; HEIMBERG, R. G.; JUSTER, H. R. Social phobia subtype and avoidant personality disorder: Effect on severity of social phobia, impairment, and outcome of cognitive-behavioral treatment. Behavior Therapy, New York, v. 26, n. 3, p. 467-486, Summer 1995. 
BRUCH, M. A. Familial and developmental antecedents of social phobia: issues and findings. Clinical Psychology Review, Oxford, v. 9, n. 1, p. 37-47, 1989.

BRUCH, M. A.; HEIMBERG, R. G. Differences in perceptions of parental and personal characteristics between generalized and nongeneralized social phobics. Journal of Anxiety Disorders, Oxford, v. 8, n. 2, p. 155-168, Apr./Jun. 1994.

BRUNELLO, N.; DEN BOER, J. A.; JUDD, L. L.; KASPER, S.; KELSEY, J. E.; LADER, M.; LECRUBIER, Y.; LEPINE, J. P.; LYDIARD, R. B.; MENDLEWICZ, J.; MONTGOMERY, S. A.; RACAGNI, G.; STEIN, M. B.; WITTCHEN, H. -U. Social phobia: diagnosis and epidemiology, neurobiology and pharmacology, comorbidity and treatment. Journal of Affective Disorders, Amsterdam, v. 60, n. 1, p. 61-74, Oct. 2000.

BURKE, H. M.; ZAUTRA, A. J.; DAVIS, M. C.; SCHULTZ, A. S.; REICH, J. W. Arthritis and Musculoskeletal Conditions. In: NEZU, A. M.; NEZU, C. M.; GELLER, P. A. (Eds.). Health Psychology. New Jersey: John Wiley \& Sons, Inc., 2003. Chap. 8, p. 169-190. (Handbook of Psychology, Vol. 9).

BUTLER, G. Issues in the application of cognitive and behavioral strategies to the treatment of social phobia. Clinical Psychology Review, Amsterdam, v. 9, n. 1, p. 91-106, 1989.

BYRUM, R. P.; JACKSON, D. E. Response availability and second-order conditioned suppression. Psychonomic Science, Austin, 1971, v. 23, n. 1B, p. 106-108.

CABALLO, V. E. O treinamento em habilidades sociais. In: Manual de técnicas de terapia e modificação do comportamento. Tradução de Marta Donila Claudino. São Paulo: Editora Santos, 1999. p. 361-398.

COHEN, J. Statistical Power for Behavioral Sciences. $2^{\text {nd }}$ ed. New York: Academic Press, 1988.

COHEN, J.; COHEN, P. Applied multiple regression/correlation analysis for the behavioral sciences. Hillsdale: Lawrence Erlbaum. 1975.

CONNOR, K. M.; DAVIDSON, J. R. T.; CHURCHILL, L. E.; SHERWOOD, A.; FOA, E.; WEISLER, R. H. Psychometric properties of the social phobia inventory (SPIN): a new selfrating scale. British Journal of Psychiatry, London, v. 176, p. 379-386, Apr. 2000.

CONNOR, K. M.; KOBAK, K. A.; CHURCHILL, L. E.; KATZELNICK, D.; DAVIDSON, J. R. T. Mini-SPIN: a brief screening assessment for generalized social anxiety disorder. Depression and Anxiety, New York, v. 14, n. 2, p. 137-140. 2001.

DAVIS, H.; MCINTIRE, R. W. Conditioned suppression under positive, negative, and no contingency between conditioned and unconditioned stimuli. Journal of the Experimental Analysis of Behavior, Bloomington, v. 12, n. 4, p. 633-640, Jul. 1969. 
DEL-BEN, C. M.; VILELA, J. A. A.; CRIPPA, J. A. S.; HALLAK, J. E. C.; LABATE, C. M.; ZUARDI, A. W. Confiabilidade da entrevista clínica estruturada para o DSM-IV - versão clínica traduzida para o português. Revista Brasileira de Psiquiatria, São Paulo, v. 23, n. 3, p. 156-159, Set. 2001.

DEL PRETTE, A.; DEL PRETTE, Z. A. P. Psicologia das relações interpessoais: vivências para o trabalho em grupo. Rio de Janeiro: Vozes, 2001.

DEL PRETTE, A.; DEL PRETTE, Z. A. P.; CASTELO BRANCO, U. V. Competência social na formação do psicólogo. Paidéia: Cadernos de Psicologia e Educação, Ribeirão Preto, n. 2, p. 40-50, Fev., 1992a.

DEL PRETTE, Z. A. P.; DEL PRETTE, A. Psicologia das habilidades sociais: terapia e educação. Petrópolis: Vozes, 1999.

DEL PRETTE, Z. A. P.; DEL PRETTE, A. Inventário de habilidades sociais (IHS-DelPrette): manual de aplicação, apuração e interpretação. São Paulo: Casa do Psicólogo, 2001.

DEL PRETTE, Z. A. P.; DEL PRETTE, A. Psicologia das habilidades sociais na infância: teoria e prática. Petrópolis: Vozes, 2005.

DEL PRETTE, Z. A. P.; DEL PRETTE, A.; BARRETO, M. C. M. Análise de um inventário de habilidades sociais (IHS) em uma amostra de universitários. Psicologia: teoria e pesquisa, Brasília, v. 14, n. 3, p. 219-228, 1998.

DEL PRETTE, Z. A. P.; DEL PRETTE, A.; BARRETO, M. C. M.; BANDEIRA, M.; RIOSSALDAÑA, M. R.; ULIAN, A. L. A. O.; GERK-CARNEIRO, E.; FALCONE, E. M. O.; VILLA, M. B. Habilidades sociais de estudantes de psicologia: um estudo multicêntrico. Psicologia: reflexão e crítica, Porto Alegre, v. 17, n. 3, p. 341-350, 2004.

DEL PRETTE, Z. A. P.; DEL PRETTE, A.; CASTElO BRANCO, U. V. Competência social: um levantamento de situações críticas de interação para estudantes de Psicologia. In: CONGRESSO NACIONAL DE PSICOLOGIA ESCOLAR, 1., 1992, Valinhos. Anais do I Congresso Nacional de Psicologia Escolar. Campinas: Abrapee/Atomo, 1992b. p. 384-387.

ELLIOTT, S. N.; GRESHAM, F. M. Social skills interventions for children. Behavior Modification, Newbury Park, v. 17, n. 3, p. 287-313, Jul. 1993.

ESTES, W. K.; SKINNER, B. F. Some quantitative properties of anxiety. Journal of Experimental Psychology: General, Washington, v. 29, n. 5, p. 390-400, Nov. 1941.

FALCONE, E. M. O. Fobia social. In: RANGÉ, B. Psicoterapia comportamental e cognitiva de transtornos psiquiátricos. Campinas: Psy, 1998. p. 133-149. 
FALCONE, E.; FIGUEIRA, I. Transtorno de ansiedade social. In: RANGÉ, B. Psicoterapias cognitivo-comportamentais: um diálogo com a psiquiatria. Porto Alegre: Artmed, 2001. p. 183-207.

FIRST, M. B.; SPITZER, R. L.; GIBBON, M.; WILLIAMS, J. B. W. Structured clinical interview for DSM-IV Axis I disorders - clinician version (SCID-CV). Washington: American Psychiatric Press, 1997.

FIRST, M. B.; TASMAN, A. Anxiety Disorders: social and specific phobias. In:

Clinical Guide to the Diagnosis and Treatment of Mental Disorders. Chichester: John Wiley \& Sons, Ltd., 2006. p. 301-315.

FRAY, J. S.; HECTOR, M. A. The assertive-aggressive distinction and the cross-cultural perspective. International Journal for the Advancement of Counselling, Berlin, v. 10, p. 103-110, Jun. 1987.

FURMARK, T. Social Phobia. From epidemiology to brain function. 2000. 72 p. PhD (Thesis) - Uppsala University, Uppsala, 2000.

FURMARK, T.; TILLFORS, M.; EVERZ, P. -O.; MARTEINSDOTTIR, I.; GEFVERT, O.; FREDRIKSON, M. Social phobia in the general population: prevalence and sociodemographic profile. Social Psychiatry and Psychiatric Epidemiology, Berlin, v. 34, n. 8, p. 416-424, Sept. 1999.

FURMARK, T.; TILLFORS, M.; STATTIN, H.; EKSELIUS, L.; FREDRIKSON, M. Social phobia subtypes in the general population revealed by cluster analysis. Psychological Medicine, London, v. 30, n. 6, p. 1335-1344, Nov. 2000.

FYDRICH, T.; CHAMBLESS, D. L.; PERRY, K. J.; BUERGENER, F.; BEAZLEY, M. B. Behavioral assessment of social performance: a rating system for social phobia. Behaviour Research and Therapy, Oxford, v. 36, n. 10, p. 995-1010, Oct. 1998.

GARCÍA, M. B.; FERNÁNDEZ, M. T. B.; GARCÍA-PORTILLA, M. P. G.; GARCÍA, J. B. Evolución histórica del concepto de ansiedad social. In: GARCÍA, J. B.; GARCÍAPORTILlA, M. P. G.; MARTÍNEZ, P. A. S.; GARCÍA, M. B. (Eds.). Abordaje actual del trastorno por ansiedad social. Barcelona: Masson, 1999. p. 1-2.

GEER, J. H.; DAVISON, G. C.; GATCHEL, R. I. Reduction of stress in humans through nonveridical perceived control of aversive stimulation. Journal of Personality and Social Psychology, Washington, v. 16 n. 4, p. 731-738, Dec. 1970.

GEER, J. H. The development of a scale to measure fear. Behaviour Research and Therapy, Oxford, v. 3, p. 45-53, Aug. 1965. 
GRAEFF, F. G.; PARENTE, A.; DEL-BEN, C. M.; GUIMARÃES, F. S. Pharmacology of human experimental anxiety. Brazilian Journal of Medical and Biological Research, Ribeirão Preto, v. 36, n. 4, p. 421-432, Apr. 2003.

GRESHAM, F. M. Social skills assessment and instruction for students with emotional and behavioral disorders. In: LANE, K. L.; GRESHAM, F. M.; O’SHAUGHNESSY, E. Children with or at risk for emotional and behavioral disorders. Boston: Allyn \& Bacon, 2002. p. 177-194.

GROVES, K. S. Gender differences in social and emotional skills and charismatic leadership. Journal of Leadership \& Organizational Studies, Thousand Oaks, v. 11, n. 3, p. 30-46, 2005.

GUIMARÃES, F. S.; ZUARDI, A. W.; GRAEFF, F. G. Effect of chlorimipramine and maprotiline on experimental anxiety in humans. Journal of Psychopharmacology, Thousand Oaks, v. 1, n. 3, p. 184-192, 1988.

HARB, G. C.; ENG, W.; ZAIDER, T.; HEIMBERG, R. G. Behavioral assessment of publicspeaking anxiety using a modified version of the Social Performance Rating Scale. Behaviour Research and Therapy, Oxford, v. 41, n. 11, p. 1373-1380, Nov. 2003.

HARRIS, S. P.; KEMMERLING, R. L.; NORTH, M. M. Brief virtual reality therapy for public speaking anxiety. Cyberpsychology \& Behavior, Larchmont, v. 5, n. 6, p. 543-550, Dec. 2002.

HEIMBERG, R. G.; DODGE, C. S.; BECKER, R. E. Social phobia. In: MICHELSON, L.; ASCHER, M. L. Anxiety and stress disorders. New York: Guilford. 1987.

HEIMBERG, R. G.; HOLT, C. S.; SCHNEIER, F. R.; SPITZER, R. L.; LIEBOWITZ, M. R. The issue of subtypes in the diagnosis of social phobia. Journal of Anxiety Disorders, Oxford, v. 7, n. 3, p. 249-269, Sept. 1993.

HEIMBERG, R. G.; HOPE, D. A.; DODGE, C. S.; BECKER, R. E. DSM-III-R subtypes of social phobia: comparison of generalized social phobics and public speaking phobics. Journal of Nervous and Mental Disease, Hagerstown, v. 178, n. 3, p. 172-179, Mar. 1990.

HEIMBERG, R. G.; LIEBOWITZ, M. R.; HOPE, D. A.; SCHNEIER, F. R. Social phobia: diagnosis, assessment, and treatment. New York: Guilford Press, 1995.

HERBERT, J. D.; HOPE, D. A.; BELLACK, A. S. Validity of the distinction between generalized social phobia and avoidant personality disorder. Journal of Abnormal Psychology, Washington, v. 101, n. 2, p. 332-339, May 1992. 
HETEM, L. A. B.; DE SOUZA, C. J.; GUIMARÃES, F. S.; ZUARDI, A. W.; GRAEFF, F. G. Effect of d-fenfluramine on human experimental anxiety. Psychopharmacology, Berlin, v. 127, n. 3, p. 276-282, Oct. 1996.

HOFMANN, S. G.; GERLACH, A. L.; WENDER, A.; ROTH, W. T. Speech disturbances and gaze behavior during public speaking in subtypes of social phobia. Journal of Anxiety Disorders, New York, v. 11, n. 6, p. 573-585, Nov./Dec. 1997.

HOFMANN, S. G.; HEINRICHS, N.; MOSCOVITCH, D. A. The nature and expression of social phobia: toward a new classification. Clinical Psychology Review, Oxford, v. 24, n. 7, p. 769-797, Nov. 2004.

HOFMANN, S. G.; NEWMAN, M. G.; EHLERS, A.; ROTH, W. T. Psychophysiological differences between subgroups of social phobia. Journal of Abnormal Psychology, Washington, v. 104, n. 1, p. 224-231, Feb. 1995.

HOOK, J. N.; VALENTINER, D. P. Are Specific and Generalized Social Phobias Qualitatively Distinct? Clinical Psychology: Science and Practice, Malden, v. 9, n. 4, Winter 2002.

IMADA, H.; SOGA, M. The CER and BEL as a function of the predictability and escapability of an electric shock. Japanese Psychological Research, Richmond, v. 13, n. 3, p. 116-123, 1971.

KAPLAN, H. I.; SADOCK, B. J.; GREBB, J. A. Transtornos de ansiedade. In: Compêndio de Psiquiatria: ciências do comportamento e psiquiatria clínica. 7. ed. Tradução de Dayse Batista. Porto Alegre: Artes Médicas, 1997. p. 545-567.

KNAPP, M. La comunicación no verbal. Buenos Aires: Paidós, 1982.

LECRUBIER, Y.; WITTCHEN, H. U.; FARAVELLI, C.; BOBES, J.; PATEL, A.; KNAPP, M. A European perspective on social anxiety disorder. European Psychiatry, Paris, v. 15, n. 1, p. 5-16, Feb. 2000.

LEE, J. M.; KIM, H.; OH, M. J.; KU, J. H.; JANG, D. P.; KIM, I. Y.; KIM, S. I. Development of a virtual speaking simulator using image based rendering. Studies in Health Technology and Informatics, Amsterdam, v. 85, p. 258-260, 2002a.

LEE, J. M.; KU., J. H.; JANG, D. P.; KIM, D. H.; CHOI, Y. H.; KIM, I. Y.; KIM, S. I. Virtual reality system for treatment of the fear of public speaking using image based rendering and moving pictures. Cyberpsychology \& Behavior, Larchmont, v. 5, n. 3, p. 191195, Jun. 2002b. 
LESNIAK-KARPIAK, K.; MAZZOCCO, M. M. M.; ROSS, J. L. Behavioral assessment of social anxiety in females with Turner or Fragile X Syndrome. Journal of Autism and Developmental Disorders, New York, v. 33, n. 1, p. 55-67, Feb. 2003.

LEVIN, A. P.; SAOUD, J. B.; STRAUMAN, T.; GORMAN, J. M.; FYER, A. J.; CRAWFORD, R.; LIEBOWITZ, M. R. Responses of "generalized" and "discrete" social phobics during public speaking. Journal of Anxiety Disorders, New York, vol. 7, n. 3, p. 207-221, July/Sept. 1993.

MANNUZZA, S.; SCHNEIER, F. R.; CHAPMAN, T. F.; LIEBOWITZ, M. R.; KLEIN D. F.; FYER, A. J. Generalized social phobia: reliability and validity. Archives of General Psychiatry, Chicago, v. 52, n. 3, p. 230-237, Mar. 1995.

MCNAIR, D. M.; FRANKENTHALER, L. M.; CZERLINSKY, T.; WHITE, T. W.; SASSON, S.; FISHER, S. Simulated public speaking as a model of clinical anxiety. Psychopharmacology, Berlin, v. 77, n. 1, p. 7-10, May 1982.

MCNEIL, D. W. Terminology and evolution of construct in social anxiety and social phobia. In: HOFMANN, S. G.; DIBARTOLO, P. M. (Eds.). From social anxiety to social phobia: multiple perspectives. Needham Heights, MA: Allyn \& Bacon, 2001. p. 8-19.

MCNEIL, D. W.; RIES, B. R.; TAYLOR, L. J.; BOONE, M. L.; CARTER, L. E.; TURK, C. L.; LEWIN, M. R. Comparison of social phobia subtypes using stroop tests. Journal of Anxiety Disorders, Oxford, v. 9, n. 1, p. 47-57, Jan./Feb. 1995.

NORTON, G. R.; COX, B. J.; HEWITT, P .L.; McLeod, L. Personality factors associated with generalized and nongeneralized social anxiety. Personality and Individual Differences, Oxford, v. 22, n. 5, p. 655-660, May 1997.

NORTON, P. J.; HOPE, D. A. Analogue observational methods in the assessment of social functioning in adults. Psychological Assessment, Norwood, v. 13, n. 1, p. 59-72, Mar. 2001.

OSÓRIO, F. L. Transtorno de ansiedade social: validação de instrumentos de avaliação. 2008. 313 f. Tese (Doutorado) - Faculdade de Medicina de Ribeirão Preto, Universidade de São Paulo, Ribeirão Preto, São Paulo, 2008.

OSÓRIO, F. L.; CRIPPA, J. A.; LOUREIRO, S. R. Experimental models for the evaluation of speech and public speaking anxiety: a critical review of the designs adopted. Journal of Speech-Language Pathology and Applied Behavior Analysis, Philadelphia, n. 2.4-3.1, p. 97-121, Mar. 2008. Special issue.

PASQUALI, L. Psicometria: teoria dos testes na psicologia e na educação. 2. ed. Rio de Janeiro: Vozes, 2003. 
PASQUALI, L.; GOUVEIA, V. V. Escala de assertividade de Rathus - RAS: adaptação brasileira. Psicologia: Teoria e Pesquisa, Brasília, v. 6, n. 3, p. 233-249, Set./Dez. 1990.

PEASE, A.; PEASE, B. Desvendando os segredos da linguagem corporal. 3. ed. Tradução Pedro Jorgensen Junior; Rio de Janeiro: Sextante, 2005.

PERTAUB, D. P.; SLATER, M.; BARKER, C. An experiment on fear of public speaking in virtual reality. Studies in Health Technology and Informatics, Amsterdam, v. 81, p. 372378, 2001.

PHILLIPS, G. C.; JONES, G. E.; RIEGER, E. R.; SNELL, J. B. Normative data for the personal report of confidence as a speaker. Journal of Anxiety Disorders, New York, v. 11, n. 2, p. 215-220, Mar./Apr. 1997.

PRICE, K. P.; GEER, J. H. Predictable and unpredictable aversive events: evidence for the safety signal hypothesis. Psychonomic Science, Austin, v. 26, n. 4, p. 215-216, 1972.

RAPEE, R. M.; HAYMAN, K. The effects of video feedback on the self-evaluation of performance in socially anxious subjects. Behaviour Research and Therapy, Oxford, v. 34, n. 4, p. 315-322, Apr. 1996.

RAPEE, R. M.; LIM, L. Discrepancy between self and observer ratings of performance in social phobics. Journal of Abnormal Psychology, Boston, v. 101, n. 4, p. 728-731, Nov. 1992.

ROBINSON, J.; SHAVER, P. R.; WRIGHTSMAN, L. S. Measures of personality and social psychological attitudes. Academic Press, Inc., 1991.

SAFREN, S. A.; HEIMBERG, R. G.; BROWN, E. J.; HOLLE, C. Quality of life in social phobia. Depression and Anxiety, New York, v. 4, n. 3, p. 126-133, 1996/1997.

SAWYER, C. R.; BEHNKE, R. R. Behavioral inhibition and the communication of public speaking state anxiety. Western Journal of Communication, Salt Lake City, v. 66, n. 4, p. 412-422, Fall 2002.

SCHNEIER, F. R.; JOHNSON, J.; HORNIG, C. D.; LIEBOWITZ, M. R.; WEISSMAN, M. M. Social phobia: comorbidity and morbidity in an epidemiologic sample. Archives of General Psychiatry, Chicago, v. 49, n. 4, p. 282-288, Apr. 1992.

SELIGMAN, M. E. P. Ansiedade e Imprevisibilidade. In: Desamparo: sobre depressão, desenvolvimento e morte. Tradução Maria Teresa de Araújo Silva, São Paulo: HUCITEC, 1977, p. 100-122. 
SELIGMAN, M. E. P. Chronic fear produced by unpredictable electric shock. Journal of Comparative and Physiological Psychology, Baltimore, v. 66, n. 2, p. 402-411, Oct. 1968.

SELIGMAN, M. E. P.; MEYER, B. Chronic fear and ulcers in rats as a function of the unpredictability of safety. Journal of Comparative and Physiological Psychology, Baltimore, v. 73, n. 2, p. 202-207, Nov. 1970.

SPIELBERGER, C. D.; GORSUCH, R. L.; LUSHINE, R. E. Manual for the state-trait anxiety inventory. Palo Alto: Consulting Psychologists, 1970.

STEIN, M. B.; CHARTIER, M. J.; HAZEN, A. L.; KOZAK, M. V.; TANCER, M. E.; LANDER, S.; FURER, P.; CHUBATY, D.; WALKER, J. R. A direct-interview family study of generalized social phobia. American Journal of Psychiatry, Arlington, v. 155, n. 1, p. 9097, Jan. 1998.

STEIN, M. B.; CHAVIRA, D. A. Subtypes of social phobia and comorbidity with depression and other anxiety disorders. Journal of Affective Disorders, Amsterdam, v. 50, Supplement 1, p. 1-39, Sept. 1998.

STEIN, M. B.; KEAN, Y. M. Disability and quality of life in social phobia: epidemiologic findings. American Journal Psychiatry, Washington, v. 157, n. 10, p. 1606-1613, Oct. 2000.

STEIN, M. B.; WALKER, J. R.; FORDE, D. R. Public-Speaking fears in a community sample: prevalence, impact on functioning and diagnostic classification. Archives of General Psychiatry, Chicago, v. 53, n. 2, p. 169-174, Feb. 1996.

STEMBERGER, R.; TURNER, S. M.; BEIDEL, D. C.; CALHOUN, K. S. Social phobia: an analysis of possible developmental factors. Journal of Abnormal Psychology, Washington, v. 104, n. 3, p. 526-531, Aug. 1995.

STOPA, L.; CLARK, D. M. Cognitive processes in social phobia. Behaviour Research and Therapy, Oxford, v. 31, n. 3, p. 255-267, Mar. 1993.

TAYLOR, C. A.; LIANG, B.; TRACY, A. J.; WILLIAMS, L. M.; SEIGLE, P. Gender differences in middle school adjustment, physical fighting, and social skills: evaluation of a social competency program. The Journal of Primary Prevention, Dordrecht, v. 23, n. 2, p. 259-272, Dec. 2002.

THARWANI, H. M.; DAVIDSON, J. R. T. Symptomatic and functional assessment of social anxiety disorder in adults. Psychiatric Clinics of North America, Philadelphia, v. 24, n. 4, p. 643-659, 2001.

TILLFORS, M.; FURMARK, T.; MARTEINSDOTTIR, I.; FREDRIKSON, M. Cerebral blood flow during anticipation of public speaking in social phobia: a PET study. Biological Psychiatry, Amsterdam, New York, v. 52, n. 11, p. 1113-1119, Dec. 2002. 
TRAN, G. Q.; CHAMBLESS, D. L. Psychopathology of social phobia: effects of subtype and of avoidant personality disorder. Journal of Anxiety Disorders, Oxford, v. 9, n. 6, p. 489501, Nov./Dec. 1995.

TURNER, S. M.; BEIDEL, D. C.; TOWNSLEY, R. M. Social phobia: a comparison of specific and generalized subtypes and avoidant personality disorder. Journal of Abnormal Psychology, Washington, v. 101, n. 2, p. 326-331, May 1992.

VAN DAM-BAGGEN, R.; KRAAIMAAT, F. Assessing social anxiety: the inventory of interpersonal situations (IIS). European Journal of Psychological Assessment, Norwood, v. 15, n. 1, p. 25-38, 1999.

VILLA, M. B. Habilidades sociais conjugais em casais de diferentes filiações religiosas. 2002. 98 f. Dissertação (Mestrado) - Faculdade de Filosofia, Ciências e Letras de Ribeirão Preto, Universidade de São Paulo, Ribeirão Preto, São Paulo, 2002.

VONCKEN, M. J.; BÖGELS, S. M. Social performance deficits in social anxiety disorder: reality during conversation and biased perception during speech. Journal of Anxiety Disorders, Oxford, v. 22, n. 8, p. 1384-1392, Dec. 2008.

WEISS, K. M.; STRONGMAN, K. T. Shock-induced response bursts and suppression. Psychonomic Science, Austin, v. 15, n.5, p. 238-240, 1969.

WENZEL, A.; GRAFF-DOLEZAL, J.; MACHO, M.; BRENDLE, J. R. Communication and social skills in socially anxious and nonanxious individuals in the context of romantic relationships. Behaviour Research and Therapy, Oxford, v. 43, p. 505-519, Apr. 2005.

WITTCHEN, H. U.; BELOCH, E. The impact of social phobia on quality of life. International Clinical Psychopathology, Munich, v. 11, p. 15-23, June 1996. Suppl. 32.

WITTCHEN, H. U.; FUETSCH, M.; SONNTAG, H.; MÜLLER, N.; LIEBOWITZ, M. Disability and quality of life in pure and comorbid social phobia. Findings from a controlled study. European Psychiatry, Paris, v. 15, n. 1, p. 46-58, Feb. 2000.

ZOHAR, D.; LIVNE, Y.; FINE, J. The effect of anxiety on linguistic parameters of public speech: a verbal impairment model. Anxiety, Stress and Coping, London, v. 16, n. 3, p. 293306, Sept. 2003.

ZUARDI, A. W.; KARNIOL, I. G. Estudo transcultural de uma escala de auto-avaliação para estados subjetivos. Jornal Brasileiro de Psiquiatria, Rio de Janeiro, v. 31, n. 5, p. 403-406, 1981. 


\section{APÊNDICES}


APÊNDICE A - Protocolo de Registro das Filmagens Realizadas

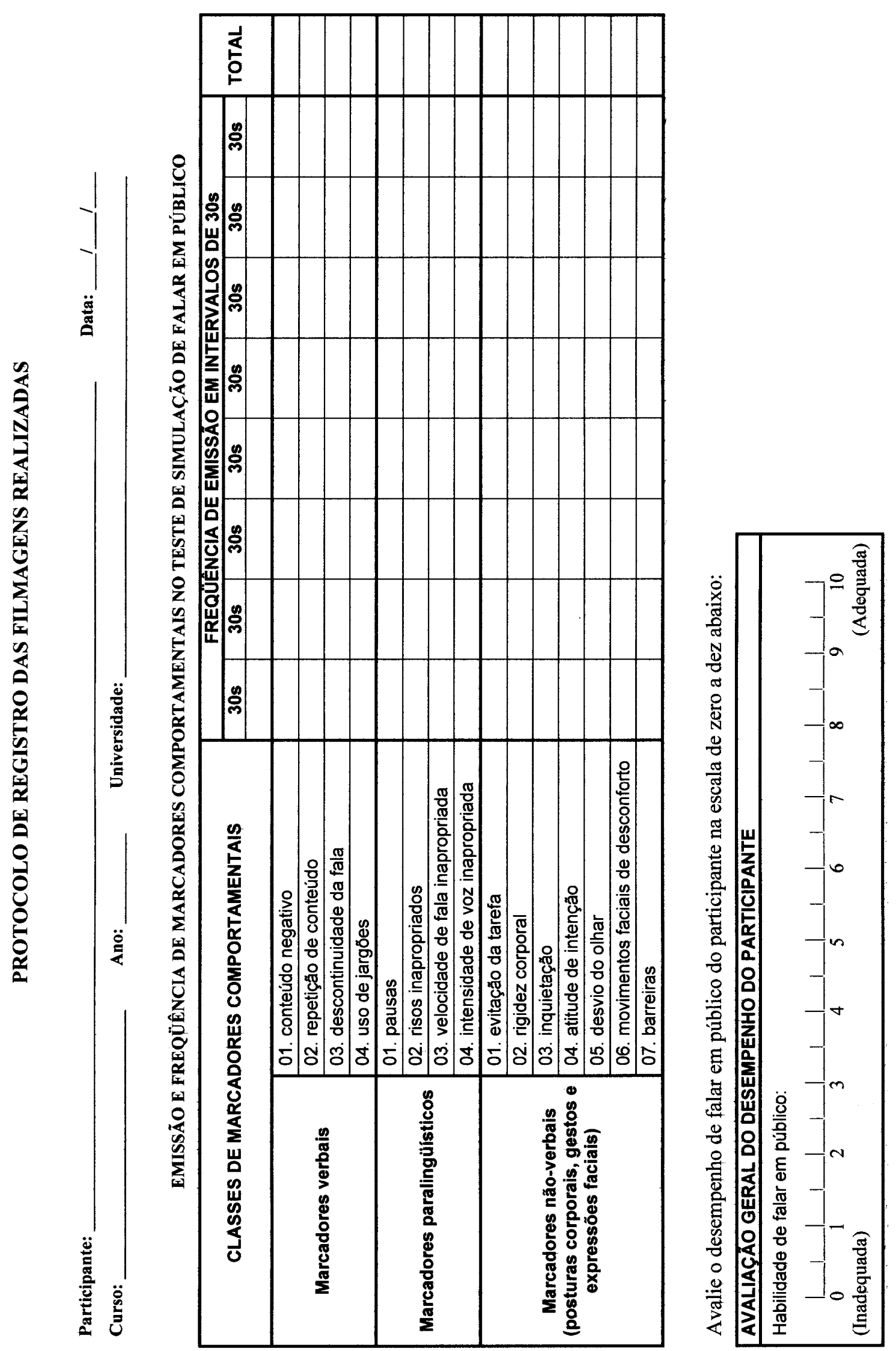




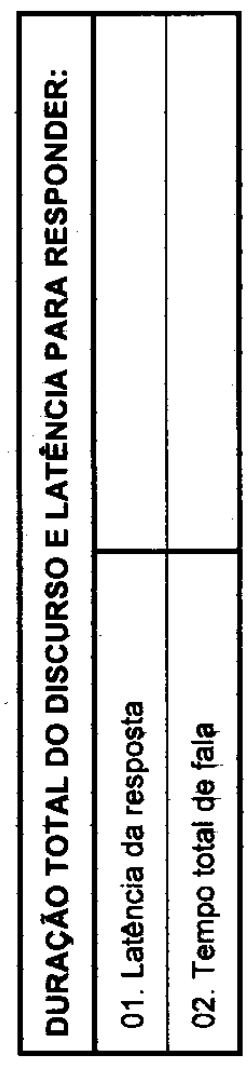


APÊNDICE B - Curso básico sobre observação e técnicas de registro

\section{CURSO BÁSICO DE OBSERVAÇÃO E TREINAMENTO DE OBSERVADORES}

\section{O uso da observação em diferentes contextos}

A observação constitui o instrumento mais satisfatório na coleta de dados atendendo aos mais diferentes propósitos e interesses.

A observação serve, assim, para coletar dados acerca tanto do comportamento quanto da situação ambiental.

É utilizada pelo psicólogo nas diferentes situações de aplicação da Psicologia, tais como: clínica, escolar e organizacional.

Na clínica, o psicólogo recorre à observação ao investigar, por exemplo, a queixa apresentada pelo cliente, isto é, para identificar o que vem a ser "agressividade", "nervosismo", "dificuldades na aprendizagem", "timidez", "ciúmes", etc. Neste caso, trata-se de definir operacionalmente a queixa trazida pelo cliente;

$\checkmark$ Os psicólogos escolares utilizam a observação para identificar dificuldades de socialização, deficiências na aprendizagem, assim como deficiências no ensino ministrado ou mesmo no currículo da escola;

$\checkmark$ O psicólogo organizacional emprega a observação para identificar as necessidades de treinamento, a dinâmica dos grupos de trabalho, para fazer a análise de cargos, etc.

De modo geral, os dados coletados por observação são usados para diagnosticar a situação-problema, para escolher as técnicas e procedimentos a serem empregados em uma intervenção e para avaliar a eficácia dessas técnicas e procedimentos.

\section{Observação científica}

A observação científica tem que ser sistemática e objetiva. $E$ o relato dessa observação precisa ser objetivo, claro e preciso!

Um relato objetivo evita:

a) utilizar termos que designem estados subjetivos;

b) interpretar as intenções dos sujeitos;

c) interpretar as finalidades da ação.

Em um relato claro e preciso, o observador evita o uso de:

a) termos amplos: termos cujo significado inclui uma série de ações. Por exemplo: "brincar" pode significar "jogar bola", "jogar peteca", "nadar", "pular corda", "pular amarelinha", etc. O observador deve especificar os comportamentos apresentados pelo 
sujeito: "o menino anda ou corre em direção à bola, pega a bola, joga-a no chão, chutaa com o pé direito".

b) termos indefinidos ou vagos: termos que não identificam o objeto ou identificam parcialmente os atributos do objeto. Exemplo: "bola pequena", "por algum tempo", "criança". Um relato mais apropriado seria "um menino de aproximadamente 4 anos jogou futebol com os colegas durante mais ou menos 30 minutos".

c) termos ou expressões ambíguas: um termo pode ser referente tanto ao sujeito da frase quanto a seu complemento. Exemplos: (1) "P. amarra o sapato. Encosta na parede". P. encostou-se ou encostou o sapato na parede?; (2) "M. quebrou as cadeiras". Ele quebrou móveis que servem de assento, ou fraturou os ossos iliacos?

\section{A importância das definições comportamentais na prática científica}

$\mathrm{Na}$ prática cientifica, os pesquisadores devem ser capazes de comunicar aquilo que observam, ou seja, de definir os comportamentos que estão medindo. $O$ estabelecimento prévio de definições comportamentais é extremamente útil porque facilita o trabalho do observador e, por eliminar as contradições existentes nas noções que cada um tem sobre os mesmos comportamentos, permite haver maior concordância entre os observadores quanto à ocorrência dos comportamentos sob observação.

\section{Técnicas de mensuração}

As descobertas de Pavlov e Skinner e os princípios de comportamentos resultantes de seus trabalhos dependeram da observação acurada e da mensuração precisa do comportamento.

Três métodos são geralmente usados para medir e registrar o comportamento, a saber: registro automático, mensuração direta de permanentes produtos e registro de observação.

1) Registro automático: é aquele no qual a resposta do organismo aciona um dispositivo elétrico ou mecânico que, por sua vez, registra automaticamente cada resposta. Exemplo: pombos bicam uma chave ou ratos pressionam uma barra ativando um micro-interruptor que aciona um calculador cada vez que a resposta é exibida.

Vantagens: (a) a precisão oferecida pela automatização; (b) a baixa freqüência de controle do experimentador; e (c) a fácil tradução para termos numéricos do resultado. 
2) Mensuração direta de produtos permanentes: os comportamentos de organismos têm como resultado produtos permanentes, que são palpáveis e podem ser observados e contados. Exemplo: quando um aluno escreve respostas a problemas de matemática.

Vantagens: (a) registros precisos; (b) são de modo geral traduzíveis em termos numéricos; e (c) produtos que são resultado final de comportamentos acadêmicos importantes.

3) Registro de observação: o observador vê um comportamento e o registra na forma como ocorre. Existem diversos tipos:

a) registro contínuo: o observador tenta escrever tudo o que está ocorrendo. Tem como vantagem a possibilidade de ser incluidas muitas classes de comportamento. Geralmente, toma muito tempo do observador;

b) registro de evento: é uma contagem da freqüência de eventos na medida em que estes ocorrem. Trata-se de um registro cumulativo de eventos distintos de certa classe.

c) registro de duração: é registrada a duração de determinado comportamento durante um dado período de observação. Usado quando é importante saber quanto tempo dura um comportamento.

d) registro de intervalo: registra-se a ocorrência do comportamento durante intervalos ou períodos de tempo iguais. Exige atenção ininterrupta do observador.

e) amostragem de tempo: é semelhante ao registro de intervalo, exceto quanto à não exigência de uma observação contínua. $O$ comportamento-alvo é registrado apenas ao fim de cada intervalo.

\section{Protocolo de observação}

$E$ a folha onde o observador registra os dados coletados. Um protocolo contém uma série de itens que abrangem as informaçōes relevantes para a análise dos comportamentos. Uma das habilidades requeridas do observador é a de preencher corretamente esses itens, o que implica em demonstrar seriedade e rigor com a tarefa de análise que empreenderá.

\section{Fidedignidade das observações}

A qualidade da definição científica do comportamento pode ser determinada por meio de uma medida de fidedignidade da observação. A fidedignidade é o grau ou índice de concordância de observadores independentes acerca daquilo que observaram do mesmo sujeito durante a mesma sessão de observação. 
Um estudo científico válido inclui sempre: (a) uma definição científica; (b) os procedimentos de observação usados para registrar o comportamento; (c) uma descrição de como a fidedignidade de mensuração foi obtida; e (d) o grau de concordância entre registros de observação independentes.

Portanto, o índice de concordância serve para:

(a) medir a confiabilidade dos registros de observadores independentes;

(b) fornecer indícios acerca das categorias que oferecem maior dificuldade para observação e talvez devam ser redefinidas;

(c) sugerir quando encerrar o treino dos observadores.

O ideal seria a obtenção de índices iguais ou superiores a $70 \%$ em todas as sessōes de observação.

\section{Bibliografia Consultada:}

DANNA, M. F.; MATOS, M. A. Ensinando observação: uma introdução. São Paulo: EDICON. 1986.

FAGUNDES, A. J. F. M. Descrição, definição e registro de comportamentos. São Paulo: EDICON. 1981.

HALL, R. V. Manipulação de comportamento: modificação de comportamento. Tradução Waldir Bettoi. São Paulo: EPU. 1973. 
APÊNDICE C - Síntese do conteúdo de cada item do Inventário de Habilidades Sociais

\section{ITENS DO INVENTÁRIO DE HABILIDADES SOCIAIS (IHS-DEL-PRETTE)}

1. Conversar à vontade em um grupo de pessoas desconhecidas

2. Pedir mudança de comportamento aos familiares

3. Agradecer ao ser elogiado por alguém

4. Solicitar ao outro que espere eu concluir a minha fala quando sou interrompido

5. Cobrar dívida de um amigo

6. Elogiar outra pessoa quando julgo que merece

7. Apresentar-se a uma pessoa que desejo conhecer

8. Participar de conversação junto a pessoas conhecidas

9. Falar em público para pessoas desconhecidas

10. Expressar sentimentos de carinho a familiares

11. Manifestar opinião quando uma autoridade faz uma afirmação incorreta

12. Abordar uma pessoa para relação sexual

13. Reagir adequadamente a um elogio no trabalho ou na escola

14. Falar em público em sala de aula ou no trabalho

15. Expressar aborrecimento frente a uma crítica injusta feita por um familiar

16. Discordar de um grupo de pessoas conhecidas

17. Encerrar conversação com amigos

18. Lidar adequadamente com a crítica de um familiar

19. Abordar uma autoridade que gostaria de conhecer

20. Declarar sentimento amoroso para uma pessoa que venho saindo

21. Devolver uma mercadoria defeituosa à loja

22. Recusar o pedido de colocar o nome de um colega em um trabalho do qual não participou

23. Fazer pergunta a pessoas desconhecidas

24. Saber interromper conversa ao telefone

25. Saber lidar com críticas justas, admitindo os meus erros

26. Pedir donativos ou favores a desconhecidos em campanhas de solidariedade

27. Expressar desagrado a um amigo que abusa de minha boa vontade

28. Elogiar um familiar por conseguir algo pelo qual se empenhou muito

29. Fazer perguntas sobre algo que não compreendi na escola ou no trabalho

30. Defender alguém que foi injustiçado em um grupo

31. Cumprimentar pessoas desconhecidas

32. Pedir ajuda a amigos

33. Negociar o uso de preservativo com o(a) parceiro(a)

34. Recusar pedidos abusivos no trabalho ou na escola

35. Expressar o sentimento de que estou bem (feliz) aos amigos

36. Manter conversação com pessoa desconhecida

37. Pedir favores a colegas

38. Saber lidar com as gozações de colegas 
APÊNDICE D - Comparação das amostras masculina e feminina deste estudo com os grupos normativos do Inventário de Habilidades Sociais

As amostras feminina e masculina que responderam o IHS-Del-Prette neste estudo (condição 1 e 2, respectivamente) foram comparadas com os grupos normativos do próprio instrumento (condição 3 e 4), verificando-se que as diferenças entre os desvios-padrões das amostras comparadas são extremamente significativas, como pode ser visto na Tabela 35, refletindo que as variâncias entre elas são desiguais.

Tabela 35 - Médias e desvios-padrões das amostras masculina e feminina que responderam ao IHS em comparação com as medidas dos grupos normativos deste instrumento

\begin{tabular}{lrrrr}
\hline Parâmetro & $\begin{array}{r}\text { Amostra } \\
\text { Feminina }\end{array}$ & $\begin{array}{r}\text { Grupo } \\
\text { Normativo 1 }\end{array}$ & $\begin{array}{r}\text { Amostra } \\
\text { Masculina }\end{array}$ & $\begin{array}{r}\text { Grupo } \\
\text { Normativo 2 }\end{array}$ \\
\hline Média & 90,714 & 92,406 & 95,024 & 96,436 \\
Desvio-padrão & 19,145 & 15,489 & 20,043 & 13,605 \\
$\mathrm{~N}$ & 592 & 266 & 414 & 204 \\
\hline
\end{tabular}

$\mathrm{N}=$ número de participantes nas amostras

Uma vez que o Teste $\mathrm{t}$ assume para análise que as amostras tenham desvios-padrões iguais, empregou-se o Teste t com correção de Welch como alternativa para contornar esse problema. A diferença de médias entre as condições 1 e 3 foram de 1,692, e entre as condições 2 e 4 de 1,412, com um pequeno efeito em ambos os casos $(d=0,098$ e 0,084 , respectivamente). Esta medida do efeito mede o quanto duas médias diferem uma da outra, em termos de desvios-padrões, sendo tomada como a magnitude da diferença entre duas condições; e quando existe uma diferença pequena entre os grupos, os valores coincidem substancialmente. Por conseguinte, se existe pouca diferença entre eles, as distribuições têm grande sobreposição e, deste modo, conclui-se que existe uma área grande sobreposta entre os dois pares de condições consideradas aqui. Por último, o Teste t com correção de Welch para os dois pares de condições $\left(t_{(622)}=1,37, p=0,171 ; t_{(556)}=1,03, p=0,303\right)$ revelou não existir 
diferenças significativas entre eles, ou seja, que ambos os pares apresentam distribuição normal e, consequientemente, os dois pares de amostras podem ser considerados como procedentes da mesma população.

As Tabela 36 e Tabela 37 demonstram as análises de diferenças entre as médias dos escores fatoriais calculadas para as amostras feminina e masculina deste estudo (condição 1 e 2, respectivamente) e os seus grupos normativos (condição 3 e 4) do IHS-Del-Prette. Para efeitos de comparação, o valor de cada item $(0,1,2,3$ ou 4) do IHS, deste estudo, foi convertido em um escore fatorial específico, conforme os valores apresentados pelos autores no Manual de aplicação, apuração e interpretação do instrumento (DEL PRETTE; DEL PRETTE, 2001). Em seguida, procedeu-se a comparação para o conjunto de escores convertidos que compõe cada fator.

Tabela 36 - Comparação das médias fatoriais obtidas pela amostra feminina (C1) e seu correspondente grupo normativo (C3)

\begin{tabular}{|c|c|c|c|c|c|c|c|c|c|c|}
\hline \multirow{2}{*}{ Estatística } & \multicolumn{2}{|c|}{ Fator 1} & \multicolumn{2}{|c|}{ Fator 2} & \multicolumn{2}{|c|}{ Fator 3} & \multicolumn{2}{|c|}{ Fator 4} & \multicolumn{2}{|c|}{ Fator 5} \\
\hline & $\mathrm{C} 1$ & $\mathrm{C3}$ & $\mathrm{C} 1$ & $\mathrm{C3}$ & $\mathrm{C} 1$ & $\mathrm{C3}$ & $\mathrm{C1}$ & $\mathrm{C3}$ & $\mathrm{C} 1$ & $\mathrm{C3}$ \\
\hline Média & 8,024 & 3,296 & 8,729 & 1,782 & 7,208 & 1,356 & 3,281 & 1,288 & 2,632 & 0,777 \\
\hline DP & 3,333 & 0,202 & 1,949 & 0,109 & 1,842 & 0,083 & 1,299 & 0,079 & 0,804 & 0,048 \\
\hline Teste $\mathrm{t}$ & \multicolumn{2}{|c|}{$t_{(600)}=34,37^{*}$} & \multicolumn{2}{|c|}{$t_{(599)}=86,42^{*}$} & \multicolumn{2}{|c|}{$t_{(596)}=77,12^{*}$} & \multicolumn{2}{|c|}{$t_{(600)}=37,18^{*}$} & \multicolumn{2}{|c|}{$t_{(602)}=55,92 *$} \\
\hline Prob. & \multicolumn{2}{|c|}{$p<0,0001$} & \multicolumn{2}{|c|}{$p<0,0001$} & \multicolumn{2}{|c|}{$p<0,0001$} & \multicolumn{2}{|c|}{$p<0,0001$} & \multicolumn{2}{|c|}{$p<0,0001$} \\
\hline
\end{tabular}

$\mathrm{C} 1$ = condição $1 ; \mathrm{C} 3=$ condição $3 ; \mathrm{DP}=$ desvio-padrão; $*$ = Teste $\mathrm{t}$ com correção de Welch ; Prob. = probabilidade associada

O Teste $\mathrm{t}$ com correção de Welch foi utilizado para todos os pares de comparação, visto que foram encontradas diferenças bastante significativas entre os desvios-padrões dos grupos que serviram para a comparação. Analisando-se os valores t e as probabilidades associadas exibidas, fica claro que existem diferenças significativas entre as médias obtidas por fatores entre a amostra feminina participante deste estudo e o grupo normativo para o mesmo gênero (condição 1 e 3 , respectivamente). 
Tabela 37 - Comparação das médias fatoriais obtidas pela amostra masculina (C2) e seu correspondente grupo normativo (C4)

\begin{tabular}{|c|c|c|c|c|c|c|c|c|c|c|}
\hline \multirow{2}{*}{ Estatística } & \multicolumn{2}{|c|}{ Fator 1} & \multicolumn{2}{|c|}{ Fator 2} & \multicolumn{2}{|c|}{ Fator 3} & \multicolumn{2}{|c|}{ Fator 4} & \multicolumn{2}{|c|}{ Fator 5} \\
\hline & $\mathrm{C} 2$ & $\mathrm{C4}$ & $\mathrm{C} 2$ & $\mathrm{C} 4$ & $\mathrm{C} 2$ & $\mathrm{C4}$ & $\mathrm{C} 2$ & $\mathrm{C} 4$ & $\mathrm{C} 2$ & $\mathrm{C} 4$ \\
\hline Média & 9,783 & 10,436 & 8,210 & 8,564 & 7,170 & 6,671 & 3,362 & 3,275 & 2,917 & 0,245 \\
\hline DP & 3,469 & 2,740 & 2,020 & 1,786 & 1,946 & 1,415 & 1,307 & 1,222 & 0,776 & 0,702 \\
\hline Teste $\mathrm{t}$ & \multicolumn{2}{|c|}{$t_{(497)}=2,54$} & \multicolumn{2}{|c|}{$t_{(451)}=2,22$} & \multicolumn{2}{|c|}{$t_{(531)}=3,62$} & \multicolumn{2}{|c|}{$t_{(616)}=0,79$} & \multicolumn{2}{|c|}{$t_{(616)}=41,51$} \\
\hline Prob. & \multicolumn{2}{|c|}{$p=0,0113^{*}$} & \multicolumn{2}{|c|}{$p=0,0271^{*}$} & \multicolumn{2}{|c|}{$p=0,0003^{*}$} & \multicolumn{2}{|c|}{$p=0,4270$} & \multicolumn{2}{|c|}{$p<0,0001$} \\
\hline
\end{tabular}

O Teste $\mathrm{t}$ com correção de Welch foi utilizado para os pares de comparação dos Fatores 1, 2 e 3. Para os Fatores 4 e 5 não foram encontradas diferenças significativas entre os desvios-padrões dos grupos de comparação, atestando assim que ambos apresentaram homogeneidade de variâncias. Verificou-se que existem diferenças significativas entre os valores fatoriais de cada amostra (condição 2 e 4), com exceção dos valores obtidos para o Fator 4.

De tudo o que foi exposto até aqui, pode-se concluir que:

(a) tomando por referência as médias dos escores totais obtidos pelos respondentes, não existem diferenças significativas entre as amostras masculina e feminina deste estudo e os seus correspondentes grupos normativos, ou seja, as amostras consideradas em pares podem ser consideradas como procedentes da mesma população;

(b) com relação às análises de diferenças entre as médias obtidas por fatores, os pares de amostras revelaram diferenças significativas, exceto para a amostra masculina e o seu respectivo grupo normativo em relação ao Fator 4. 
ANEXOS 
ANEXO A - Inventário de Fobia Social (SPIN)

\section{INVENTÁRIO DE FOBIA SOCIAL (SPIN)}

Por favor, indique quanto os seguintes problemas incomodaram você durante a última semana. Marque somente um item para cada problema, e verifique se respondeu a todos os itens.

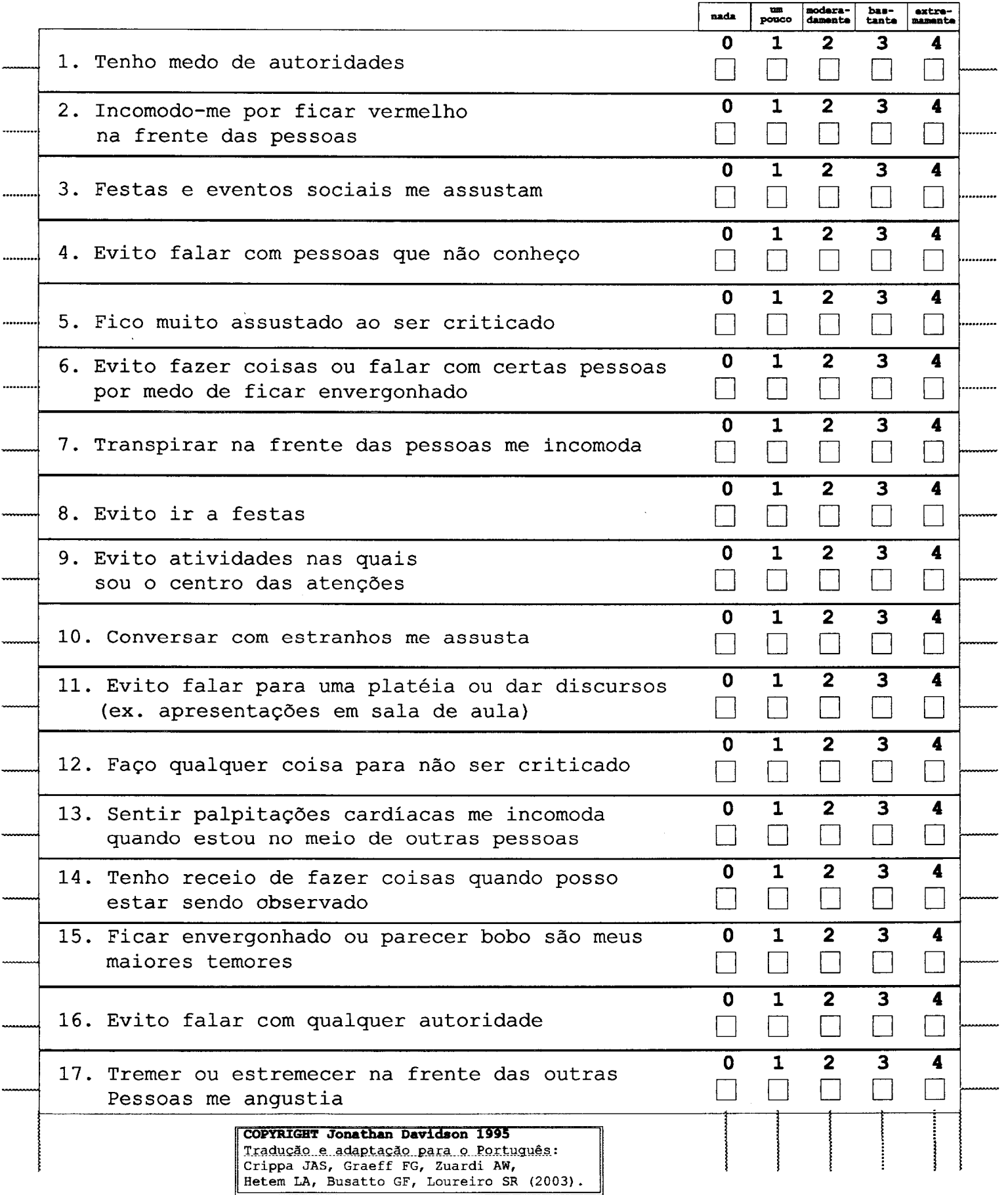




\section{ANEXO B - Termo de Consentimento Livre e Esclarecido (TCLE) - Delineamento 1}

\section{- Termo de Consentimento Livre e Esclarecido* -}

A Ansiedade Social ou Fobia Social é um transtorno de ansiedade que se caracteriza por sentir-se incomodado em situações sociais nas quais se está muito próximo de outras pessoas. As pessoas que experimentam este transtorno muitas vezes tendem a evitar as situações sociais, o que pode dificultar os relacionamentos e a carreira profissional. Para conhecer e melhor identificar este transtorno, estamos solicitando sua participação em responder alguns instrumentos dos tipos escala e questionário que têm por objetivo identificar pessoas jovens que possam estar tendo esta dificuldade. Com isto, conheceremos se estes instrumentos são adequados para identificar a Ansiedade Social.

A Ansiedade Social é considerada hoje um transtorno que pode ser tratado com bons resultados. Caso você aceite participar, estará nos ajudando a melhorar a possibilidade de identificar este transtorno em pessoas adultas, beneficiando no futuro outras pessoas, que precocemente poderão ser diagnosticadas e tratadas. Vale a pena salientar que só o resultado positivo nos instrumentos não é por si só indicador da Ansiedade Social, pois estes instrumentos têm uma margem de erro, e isto é parte do que queremos conhecer nesta pesquisa. Por isto, pretendemos quando da identificação de Ansiedade Social nos instrumentos, verificar pessoalmente com as pessoas como é para elas estarem em situações sociais e de interação com outras pessoas.

Num primeiro momento, sua participação consistirá em responder por escrito, em sala de aula, a cinco instrumentos diferentes, incluindo questionário e escala, nos quais você estará avaliando seu comportamento em situações sociais e alguns sintomas físicos. Para tanto você gastará em torno de 40 minutos. Num segundo momento, será feito contato telefônico com alguns participantes identificados e não-identificados como portadores de Ansiedade Social, aos quais serão feitas algumas questões visando confirmar se os instrumentos iniciais realmente são bons para identificar a Ansiedade Social. Esta entrevista telefônica durará aproximadamente 10 minutos. Em um terceiro momento, apenas participarão do estudo aqueles participantes que forem identificados pelos instrumentos e pela entrevista telefônica como possíveis portadores de Ansiedade Social. Se este for o seu caso, você será convidado por carta, telefone ou e-mail, a participar de uma entrevista que durará cerca de uma hora, em local e data a serem combinados de acordo com sua disponibilidade. Esta entrevista também terá por objetivo avaliar o seu comportamento em situações sociais.

A sua participação não significa nenhum ônus ou risco para você ou para a sua saúde. Caso no decorrer das atividades desista de participar, poderá entregar os questionários sem ou antes de terminar de respondê-los, e ainda, caso seja chamado para participar no segundo momento, poderá manter ou retirar a sua participação sem qualquer constrangimento.

\footnotetext{
* Modelo utilizado em comum por todos os estudos integrantes do projeto maior de pesquisa.
} 
Se por acaso você for identificado como portador deste transtorno, serão colocadas à sua disposição informações sobre o mesmo (sinais, sintomas, curso, prognóstico, tratamento) e encaminhamento para tratamento medicamentoso e/ou psicoterápico em serviço específico do Hospital das Clínicas da Faculdade de Medicina de Ribeirão Preto.

Sem qualquer identificação dos participantes, nos comprometemos com a divulgação científica das informações colhidas e assumimos a responsabilidade por qualquer ônus que a participação no estudo possa acarretar.

Qualquer dúvida que você tenha poderá entrar em contato conosco.

Pesquisador

Orientadora

$\mathrm{Eu}$,

RG tendo lido as informações acima, voluntariamente concordo em participar do referido projeto de pesquisa, estando ciente dos meus direitos e da possibilidade de desistência sem quaisquer ônus ou prejuízo.

Assinatura 
ANEXO C - Questionário de Identificação

\section{QUESTIONÁRIO DE IDENTIFICAÇÃO}

Número:0003002324945

Nome:

Data de Nascimento: $\square[/, \square, \square$ Idade $\square \square$ anos

Sexo: $\begin{aligned} & \square \text { Feminino } \\ & \square \text { Masculino }\end{aligned}$

Procedência:

Atividade Profissional:

Universidade:

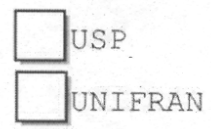

Curso:

Ano: Nível: $\begin{aligned} & \square \text { Graduação } \\ & \square \text { Pós-graduação }\end{aligned}$

Endereço:

Cidade:

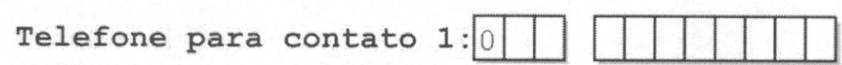

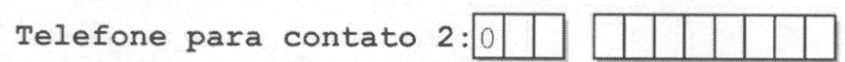

E-mail:

Faz uso contínuo de alguma medicação ?

$\square$ Não $\square$ Sim especificar:

Nome :

Período de uso:

Dosagem:

Nome :

Período de uso:

Dosagem:

Nome :

Período de uso:

Dosagem:

Nome :

Período de uso:

Dosagem: 
ANEXO D - Protocolo de Coleta de Dados

REGISTRO - COLETA DE DADOS

Projeto de pesquisa: Transtorno de Ansiedade Social: Validação de instrumentos de auto e heteroavaliação

Data: $. . . \ldots \ldots . . . . . . . . \ldots \ldots . . . . . . \ldots \ldots \ldots . .$.

Curso:

Turma:

Disciplina:

Aplicador:

\begin{tabular}{|c|c|c|}
\hline \multicolumn{2}{|l|}{$N^{0}$ de alunos presentes em sala aula } & \\
\hline \multirow{2}{*}{$N^{\circ}$ de alunos (após explicação geral e ...) } & - antes TCLE & \\
\hline & - após TCLE & \\
\hline
\end{tabular}

\begin{tabular}{|l|l|l|}
\hline & Horas & Minutos \\
\hline Hora de início & & \\
\hline $1^{\circ}$ aluno a entregar & & \\
\hline Último aluno a entregar & & \\
\hline
\end{tabular}

\begin{tabular}{|l|l|l|}
\hline Perguntas realizadas & Instrumento & Item \\
\hline & & \\
\hline & & \\
\hline & & \\
\hline & & \\
\hline & & \\
\hline & & \\
\hline & & \\
\hline
\end{tabular}

Intercorrências: ( ) Não ( ) Sim-Quais? 
ANEXO E - Protocolo Pós-Coleta de Dados

\section{REGISTRO - PÓS-COLETA DE DADOS}

Projeto de pesquisa: Transtorno de Ansiedade Social: Validação de instrumentos de auto e hetero-avaliação

Data: ................................ Curso:

Turma:

Disciplina:

Aplicador:

\section{$\mathbf{N}^{\circ}$ de questionários aplicados}

\section{$\mathbf{N}^{\circ}$ de sujeitos incluídos completos}

(TCLE, Identificação, Instrumentos)

\begin{tabular}{|c|l|l|}
\hline \multirow{4}{*}{$\begin{array}{c}\text { No sujeitos duvidosos } \\
\text { (falta informação) }\end{array}$} & - TCLE (exclusão) & \\
\cline { 2 - 3 } & - Identificação & \\
\cline { 2 - 3 } & - Instrumentos & \\
\hline
\end{tabular}

IDENTIFICAÇÃO - Providências ( ) não ( ) sim

\begin{tabular}{|l|l|l|l|}
\hline $\mathrm{N}^{\circ}$ sujeito & qual & colaborador & desfecho \\
\hline & & & \\
\hline & & & \\
\hline & & & \\
\hline
\end{tabular}

\begin{tabular}{|l|c|c|c|c|}
\hline \multicolumn{6}{|l|}{ INSTRUMENTOS - Providências ( ) não ( ) sim } \\
\hline $\mathrm{N}^{\mathrm{o}}$ sujeito & Instr/o & qual & colaborador & desfecho \\
\hline & & & & \\
\hline & & & & \\
\hline & & & & \\
\hline & & & & \\
\hline
\end{tabular}


ANEXO F - Protocolo de Aplicação Coletiva

\section{PROJETO DE PESQUISA: TRANSTORNO DE ANSIEDADE SOCIAL: VALIDAÇÃO DE INSTRUMENTOS DE AUTO E HETEROAVALIAÇÃO}

\section{- Instruções para a Aplicação Coletiva -}

1) anotar o no de alunos presentes na sala;

2) explicação geral e sucinta sobre a atividade: "Estamos solicitando a participação dos alunos da FMRP-USP numa pesquisa sobre Fobia Social / Transtorno de Ansiedade Social, que vem sendo realizada por psiquiatras e psicólogos do HC-FMRP-USP, a qual já fora aceita e aprovada pela Faculdade e pelo Comitê de Ética. Gostaríamos agora de contar com a sua colaboração voluntária";

3) solicitar que os alunos que tenham interesse em participar, permaneçam na sala para que seja lido o Termo de Consentimento Livre e Esclarecido (TCLE) com explicações mais detalhadas sobre o projeto, e que os que não concordarem com a participação, que retirem-se da sala;

$\Rightarrow$ após saída dos que não participarão:

4) entregar para cada participante 2 vias do TCLE;

5) iniciar a leitura em voz alta, solicitando que os mesmos acompanhem;

6) após o término da leitura, solicitar que assinem o TCLE. Recolher uma das vias. A outra ficará com o participante (isto é muito importante);

Apenas deverão permanecer na sala os participantes que devidamente assinarem o TCLE!

Os participantes que após a leitura do TCLE resolverem por qualquer motivo não participar, deverão devolver as 2 vias do TCLE e retirarem-se da sala.

7) não esquecer de preencher o quadro com o $n^{\circ}$ de participantes antes e depois do TCLE na folha de registro;

8) só então será entregue um caderno para cada participante, solicitando que só abram e iniciem

o preenchimento após todos receberem;

9) falar que as instruções gerais para o preenchimento constam por escrito na $1^{\text {a }}$ folha do caderno;

10) anotar hora de início;

11) anotar hora de entrega do $1 \%$ participante;

12) a medida que os participantes forem entregando os cadernos, verificar:

a) todos os dados do questionário de identificação foram preenchidos?

b) todos os instrumentos foram preenchidos corretamente?

c) há dúvidas quanto ao preenchimento de algum item (por exemplo, 2 caselas assinaladas, rasuras não inteligíveis...) ?

13) anotar hora de entrega do último participante;

14) anotar na folha de registro eventuais dúvidas e intercorrências. 
ANEXO G - Termo de Consentimento Livre e Esclarecido - Parte 1 - Delineamento 2

\section{- Termo de Consentimento Livre e Esclarecido - Parte $1^{*}$ -}

A Ansiedade Social ou Fobia Social é um transtorno de ansiedade que se caracteriza por sentir-se incomodado em situações sociais nas quais se está muito próximo de outras pessoas, tendo que interagir com as mesmas ou realizar algo sendo observado por elas. A Ansiedade Social é considerada hoje um transtorno que pode ser tratado com bons resultados.

Estamos interessados neste estudo em verificar como pessoas com ansiedade social se comportam em um teste de ansiedade em comparação ao comportamento das pessoas que não apresentam este transtorno. Esta parte do estudo é composta de duas partes. Nesta primeira parte, a sua participação consistirá em preencher escalas para nos dizer como você está se sentindo naquele momento. Estas escalas são bastante simples, mas nós faremos um treinamento antes de iniciarmos os procedimentos. Também mediremos sua pressão arterial e seu pulso. Geralmente, quando as pessoas ficam nervosas, as mãos ficam suadas. Por isso vamos verificar o suor da sua pele, através de um aparelho específico. No final desta primeira parte, nós lhe explicaremos a segunda metade do estudo e você nos dirá se deseja continuar participando ou não.

A sua participação neste estudo contribuirá para que possamos ampliar a nossa compreensão a respeito das alterações que ocorrem nas reações normais de ansiedade e também nos quadros de ansiedade patológica / anormal. Com estas informações poderemos ajudar pessoas portadoras de transtornos ansiosos, melhorando a forma de tratamento destas pessoas.

A sua participação não significa nenhum ônus ou risco para você ou para a sua saúde. Caso no decorrer das atividades desista de participar, poderemos interrompê-las, sem qualquer constrangimento.

Sem qualquer identificação dos participantes, nos comprometemos com a divulgação científica das informações colhidas e assumimos a responsabilidade por qualquer ônus que a participação no estudo possa acarretar.

Qualquer dúvida que você tenha poderá entrar em contato conosco.

Pesquisador Orientadora

\footnotetext{
* Modelo utilizado em comum por todos os estudos integrantes do projeto maior de pesquisa.
} 
$\mathrm{Eu}$,

$\mathrm{RG}$

tendo lido as informações acima,

voluntariamente concordo em participar do referido projeto de pesquisa, estando ciente dos meus direitos e da possibilidade de desistência sem quaisquer ônus ou prejuízo.

Assinatura 
ANEXO H - Termo de Consentimento Livre e Esclarecido - Parte 2 - Delineamento 2

\section{- Termo de Consentimento Livre e Esclarecido - Parte 2* -}

Como nós havíamos lhe dito anteriormente, estamos interessados em verificar como pessoas com ansiedade social se comportam em um teste que mede ansiedade, e se este comportamento difere do das pessoas que não apresentam este transtorno.

A sua participação nesta parte do estudo consistirá em participar de uma situação simulada de falar em público sobre os meios de transporte de sua cidade. Você terá dois minutos para preparar o discurso, e então fará a apresentação do mesmo, o qual terá uma duração de 4 minutos. Este discurso será gravado em vídeotape. Para tanto precisamos de sua autorização para a gravação. Durante e após a realização do discurso, você deverá também responder a alguns questionários a respeito de como está se sentindo naquele momento, e nós mediremos sua pressão arterial, seu pulso e o suor da sua pele, como fizemos na primeira parte do estudo. Esta atividade durará em torno de uma hora e dez minutos.

A sua participação neste estudo contribuirá para que possamos ampliar a nossa compreensão a respeito das alterações que ocorrem nas reações normais de ansiedade e também nos quadros de ansiedade patológica / anormal. Com estas informações poderemos ajudar pessoas portadoras de transtornos ansiosos, melhorando a forma de tratamento dessas pessoas.

A sua participação não significa nenhum ônus ou risco para você ou para a sua saúde. Caso no decorrer das atividades desista de participar, poderemos interrompê-las, sem qualquer constrangimento.

\footnotetext{
Modelo utilizado em comum por todos os estudos integrantes do projeto maior de pesquisa.
} 
Sem qualquer identificação dos participantes, nos comprometemos com a divulgação científica das informações colhidas e assumimos a responsabilidade por qualquer ônus que a participação no estudo possa acarretar.

Qualquer dúvida que você tenha poderá entrar em contato conosco.

Pesquisador

Orientadora

$\mathrm{Eu}$

RG

tendo lido as informações acima,

voluntariamente concordo em participar do referido projeto de pesquisa, estando ciente dos meus direitos e da possibilidade de desistência sem quaisquer ônus ou prejuízo.

Assinatura 
ANEXO I - Aprovação pelo Comitê de Ética (Projeto maior)

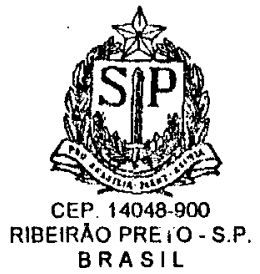

HOSPITAL DAS CLÍNICAS DA FACULDADE DE MEDICINA DE RIBEIRÃO PRETO DA UNIVERSIDADE DE SÃO PAULO

CAMPUS UNIVERSITARIO - MONTE ALEGRE FONE: 602-1000 - FAX (016) 633-1144

Ribeirão Preto, 15 de dezembro de 2003

Oficio $n^{\circ} 3708 / 2003$

$\mathrm{CEP} / \mathrm{SPC}$

Prezada Senhora:

O trabalho intitulado "TRANSTORNO $D \mathbb{E}$ ANSIEDADE SOCIAL: VALIDAÇĀO DE INSTRUMENTOS DE AUTO I hetero-avaliação", fui analisado pelo Comitê de Ética em Pesquisa, em sua $171^{\text {a }}$ Rcunião Ordinária realizada em 15/12/2003, e enquadrado na categoria: APROVADO, de acordo com o Processo HCRP $n^{0} 11570 / 2003$.

Aproveito a oportunidade para apresentar a Vossa Senhoria protestos de estima e consideffação.

PROF. DR: SERGLO PEREIRA DA CUNHA

Coordgnador do Comitê de Ética

em Pesqujsado hCFMRP UST eda FMRP-USP

Ilustrissima Senhora

FLÁVIA DE LIMA OSÓRIO

PROF ${ }^{\mathrm{a}} \mathrm{DR}^{\mathrm{a}}$ SONIA REGINA LOUREIRO (Orientadora)

Depto. de Neurologia, Psiquiatria e Psicologia Médica

Em mãos 
ANEXO J - Aprovação da pesquisa pelo Comitê de Ética

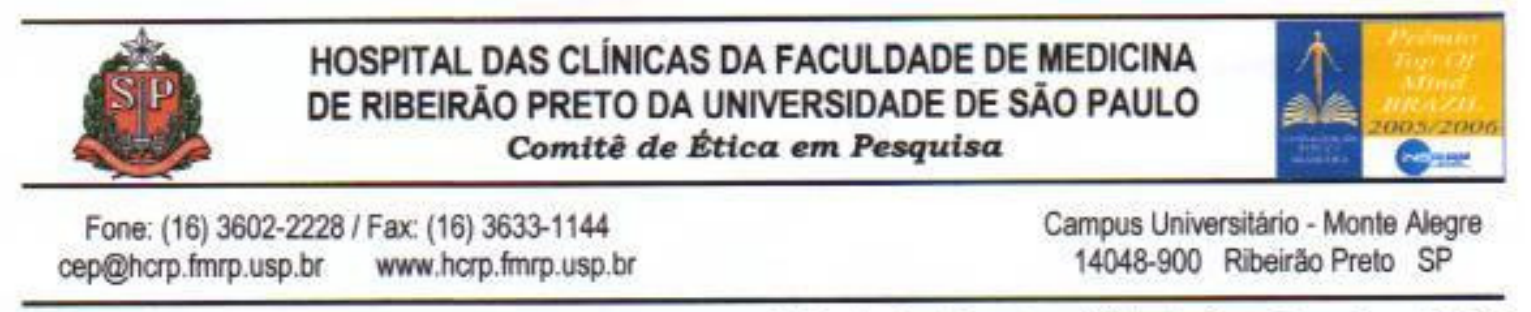

Ribeirão Preto, 07 de junho de 2006

Oficio $n^{\circ} 1558 / 2006$

CEP/SPC

Prezado Senhor:

O trabalho intitulado "TRANSTORNO DE ANSIEDADE SOCIAL E HABILIDADES SOCIAIS", foi analisado pelo Comitê de Ética em Pesquisa, em sua 226 Reunião Ordinária realizada em 05/06/2006, e enquadrado na categoria: APROVADO, bem como o Termo de Consentimento Livre e Esclarecido, de acordo com o Processo HCRP n 6064/2006.

Aproveito a oportunidade para apresentar a Vossa Senhoria protestos de estima e consideração.

PROF. DR. SERRIO PEREIRA DA CUNHA Coordenador do Comitê de Ética em Pesquisa do HCRP e da FMRP-USP

Ilustríssimo Senhor

ANTONIO PAULO ANGÉLICO

PROF $^{a}$ DR $^{a}$ SONIA REGINA LOUREIRO (Orientadora)

Depto. de Neurologia, Psiquiatria e Psicologia Médica - FMRP-USP

Em mãos 
ANEXO K - Artigo publicado

Interação em Psicologia, 2006, 10(1), p. 113-125

\title{
Fobia social e habilidades sociais: uma revisão da literatura
}

\author{
Antonio Paulo Angélico \\ Universidade Federal de São Carlos \\ José Alexandre de Souza Crippa \\ Sonia Regina Loureiro \\ Faculdade de Medicina de Ribeirão Preto da Universidade de São Paulo
}

\begin{abstract}
RESUMO
Objetivou-se identificar nos indexadores Medline, PsycINFO, Lilacs e Scielo, no período de 2000 a 2005, estudos empíricos que abordem a fobia social e suas associações às habilidades sociais, visando a análise crítica das metodologias empregadas nesses estudos. Identificou-se 16 artigos, agrupados para análise em duas categorias: Modalidades Terapêuticas - Aplicação e Comparação de Intervenções Clínicas $(\mathrm{N}=6)$, e Caracterização do Repertório de Habilidades Sociais $(\mathrm{N}=10)$. Os estudos que compararam abordagens terapêuticas constataram a maior eficiência do treinamento em habilidades sociais (THS) para o desenvolvimento de repertório social mais competente, em comparação com a terapia cognitivo-comportamental. Os estudos de caracterização de perfis (10), relataram que os pacientes com fobia social apresentaram habilidades sociais mais deficitárias, apontando para o benefício potencial da participação em programas de THS. A análise crítica dos delineamentos apontou para a necessidade de novos estudos com amostras clínicas e não-clínicas, com alocação randômica dos participantes, com diagnóstico preciso e proposição de tarefas de interação contextualizadas, de modo a respaldar a generalização quanto à associação das habilidades sociais e fobia social, e evidenciar a funcionalidade e o processo pelo qual a ansiedade interfere no desempenho social.
\end{abstract}

Palavras-chave: fobia social; ansiedade social; habilidades sociais.

\section{ABSTRACT \\ Social phobia and social skills: a literature review}

This study aimed to identify in the indexers Medline, PsycINFO, Lilacs and Scielo, in the period between 2000 and 2005, empirical studies that investigated social phobia in relation to social skills, followed by a critical analysis of the methodologies used by the studies listed. Sixteen papers were identified and grouped in two categories: Therapeutic Modalities - Application and Comparison of Clinical Interventions $(N=6)$ and Characterization of the Social Skills Repertoire $(N=10)$. The studies that compared therapeutic approaches evidenced the higher efficiency of the Social Skills Training (SST), for the development of more competent social repertoire, compared to cognitive-behavioral therapy. The studies of profile characterization (10) reported that the patients with social phobia presented a social skills deficit, suggesting the potential benefit of participation in social skills training programs. The critical analysis of the researches design pointed to the need of new studies with clinical and non-clinical samples, with random allocation of participants, precise diagnosis, and proposition of contextualized interaction tasks, in order to support the generalization of findings related to the association between the social skills and social phobia, and to demonstrate the functionality and process by which anxiety interferes with social performance.

Keywords: social phobia; social anxiety; social skills.

As habilidades sociais em geral são consideradas essenciais para os processos de ajustamento social dos indivíduos, portadores ou não de transtornos psiquiátricos (Angélico, 2004; Argyle, 1967/1994; Bandeira,
2003; Halford \& Hayes, 1995; Morrison \& Bellack, 1987; Turner, Beidel \& Townsley, 1992; Zigler \& Phillips, 1962). 
As habilidades sociais podem ser definidas como "diferentes classes de comportamentos sociais no repertório do indivíduo para lidar de maneira adequada com as demandas das situações interpessoais" (Del Prette \& Del Prette, 2001, p. 31). Tal conceito abrange o aspecto descritivo dos comportamentos verbais e não verbais apresentados pelo indivíduo diante das diferentes demandas das situações interpessoais. Uma demanda é entendida aqui como a ocasião diante da qual se espera um determinado desempenho social em relação a uma ou mais pessoas. No entanto, uma distinção entre esse conceito e o de desempenho social precisa ser feita. Desempenho social refere-se à emissão de um comportamento ou seqüência de comportamentos em uma situação social qualquer. Já o desempenho socialmente competente é aquele que, segundo Del Prette e Del Prette (2001), expressa uma leitura apropriada do ambiente social, que decodifica corretamente os desempenhos esperados, valorizados e efetivos para o indivíduo em sua relação com os demais, contribuindo na maximização de ganhos e na minimização de perdas para si e para aqueles com quem interage.

Considera-se que os déficits de habilidades sociais dificultam o funcionamento social do indivíduo e a sua capacidade adaptativa. Especificamente, questiona-se o envolvimento das habilidades sociais nos quadros clínicos de fobia social.

A fobia social tem sido considerada um grave problema de saúde mental pela sua alta prevalência e pelas incapacidades decorrentes no desempenho e nas interações sociais. Conforme os critérios diagnósticos do DSM-IV (American Psychiatric Association APA, 1994), os indivíduos com fobia social manifestam um medo excessivo, persistente e irracional de serem vistos comportando-se de um modo humilhante ou embaraçoso - pela demonstração de ansiedade ou de desempenho inadequado - e de conseqüente desaprovação ou rejeição por parte dos outros.

Conforme revisão empreendida por Furmark (2000), a investigação sobre fobia social e habilidades sociais tem sido inconsistente, considerando que embora os fóbicos sociais pareçam ter desempenhos inadequados como apontado em alguns estudos, isso poderia refletir inibição durante estados de alta ansiedade ao contrário de falta real de habilidades. Neste sentido, seria possível e desejável desenvolver ou estimular habilidades de enfrentamento no repertório destes indivíduos.
Ao se avaliar os tipos de déficits que um indivíduo pode apresentar em seu repertório de habilidades sociais, pode-se destacar: a) déficit de aquisição (caracterizado pela não-ocorrência da habilidade social diante das demandas do ambiente); b) déficit de desempenho (caracterizado pela ocorrência de uma habilidade específica com freqüência inferior à esperada diante das demandas do ambiente); e c) déficit de fluência (demonstrado pela ocorrência da habilidade com proficiência inferior à esperada diante das demandas sociais).

Considerando o papel da ansiedade na inibição do desempenho socialmente competente e a inconsistência de dados quanto à associação entre fobia social e habilidades sociais, buscou-se identificar na literatura indexada, no período de 2000 a 2005, artigos empíricos que abordem tal temática, visando a análise crítica das metodologias de pesquisa empregadas nesses estudos.

\section{PROCEDIMENTO}

Procedeu-se à identificação dos estudos empíricos relativos à temática "Fobia Social e Habilidades Sociais" com base em uma busca sistemática na literatura, usando os indexadores eletrônicos Medline, PsycINFO, Lilacs e Scielo, por meio do cruzamento das palavras-chave: social phobia, social anxiety, social skills e social skills training.

Incluíram-se estudos com participantes de ambos os sexos, adultos, procedentes de amostras clínicas, universitárias e da comunidade. Adotaram-se como critérios de exclusão estudos relativos a: (a) outras faixas etárias (crianças, adolescentes e idosos); (b) outros diagnósticos (outros transtornos e síndromes); (c) outras abordagens aplicadas à temática, como estudos farmacológicos ou exclusivamente psicométricos; (d) relatos de programas sobre modalidades de intervenções; (e) questões de pesquisa abordando a associação de ansiedade social e/ou habilidades sociais a desfiguração da face, problemas endócrinos, lesões cerebrais, implante coclear, enurese e adversidades sociais; e (f) associação de ansiedade social e/ou habilidades sociais às variáveis como auto-imagem, locus de controle, comportamentos internalizantes/externalizantes, stress e mecanismos de defesa.

Com base no procedimento de busca e aplicação dos critérios de inclusão e exclusão, foi identificado e analisado um conjunto de 16 artigos. 


\section{RESULTADOS}

Para a análise, os 16 artigos incluídos foram agrupados em duas categorias distintas: Caracterização do Repertório de Habilidades Sociais $(\mathrm{N}=10)$, e Modalidades Terapêuticas - Aplicação e Comparação de Intervenções Clínicas $(\mathrm{N}=6)$.

\section{Caracterização do repertório de habilidades sociais}

Quanto aos métodos de pesquisa empregados nos estudos incluídos nesta categoria, observou-se uma predominância de estudos de corte transversal (Alden \& Mellings, 2004; Baker \& Edelmann, 2002; Bögels,
Rijsemus \& De Jong, 2002; Christensen, Stein \& Means-Christensen, 2003; Horley, Williams, Gonsalvez \& Gordon, 2003; Sheffer, Penn \& Cassisi, 2001; Stopa \& Clark, 2000; Thompson \& Rapee, 2002; Wenzel, Graff-Dolezal, Macho \& Brendle, 2005) e apenas um estudo longitudinal (Strahan, 2003).

Estes estudos tiveram em comum as descrições de perfis de habilidades sociais apresentadas por indivíduos com fobia social generalizada ou com níveis altos de ansiedade social em medidas de auto-relato. Uma caracterização de aspectos específicos acerca dos delineamentos adotados nos estudos de descrição de perfis é apresentada na Tabela 1 .

Tabela 1: Caracterização dos delineamentos adotados nos estudos de descrição de perfis

\begin{tabular}{|c|c|c|c|c|c|c|c|c|c|c|}
\hline \multirow{2}{*}{ DELINEAMENTOS } & \multicolumn{10}{|c|}{ ESTUDOS } \\
\hline & 1 & 2 & 3 & 4 & 5 & 6 & 7 & 8 & 9 & 10 \\
\hline $\mathrm{N}^{\circ}$ de participantes: - com fobia social generalizada & 18 & $\cdot$ & - & $\cdot$ & - & 25 & - & 15 & 20 & - \\
\hline - com outros transtornos de ansiedade & 18 & - & - & - & $\cdot$ & - & - & - & 20 & - \\
\hline - ansiosos socialmente & - & 36 & 26 & - & 13 & - & 62 & - & - & 55 \\
\hline - não-clínicos & 18 & 36 & 24 & 29 & 14 & 26 & 62 & 15 & 20 & 198 \\
\hline Indicadores de HS: - desempenho social & + & + & + & + & + & $\cdot$ & $\cdot$ & - & $\cdot$ & $\cdot$ \\
\hline - percepçōes interpessoais & - & $\cdot$ & - & - & $\cdot$ & + & + & + & + & - \\
\hline - desempenho acadêmico & - & $\cdot$ & $\cdot$ & - & $\cdot$ & - & - & - & $\cdot$ & + \\
\hline - habilidades de comunicação & - & $\cdot$ & $\cdot$ & $\cdot$ & + & - & - & - & $\cdot$ & - \\
\hline - competencia social & + & $\cdot$ & - & + & + & $\cdot$ & $\cdot$ & - & $\cdot$ & + \\
\hline Contexto de coleta: a) tarefas de interação social & + & + & + & + & + & + & + & - & $\cdot$ & - \\
\hline - uso de dicas verbais pelo aux. pesq. & + & - & + & + & $\cdot$ & + & - & $\cdot$ & $\cdot$ & $\cdot$ \\
\hline - duração da interação social (em min.) & 9 & 5 & 10 & 6 & 30 & 5 & 15 & $\cdot$ & $\cdot$ & $\cdot$ \\
\hline b) apresentação de fotos com faces & - & - & - & $\cdot$ & - & - & - & + & $\cdot$ & $\cdot$ \\
\hline c) preenchimento de question. e escalas & + & + & + & + & + & + & + & + & + & + \\
\hline d) emprego de medidas fisiológicas & - & + & $\cdot$ & + & $\cdot$ & - & $\cdot$ & - & $\cdot$ & $\cdot$ \\
\hline Interlocutor na interaçăo social: - auxiliar de pesquisa & + & + & + & + & $\cdot$ & + & - & - & $\cdot$ & + \\
\hline - parceiro afetivo & $\cdot$ & - & - & - & + & - & $\cdot$ & $\cdot$ & $\cdot$ & - \\
\hline - outro participante & - & - & - & - & - & - & + & - & - & - \\
\hline
\end{tabular}

1: Baker e Edelmann (2002); 2: Bögels e cols. (2002); 3: Thompson e Rapee (2002); 4: Sheffer e cols. (2001); 5: Wenzel e cols. (2005); 6: Alden e Mellings (2004); 7: Christensen e cols (2003); 8: Horley e cols. (2003); 9: Stopa e Clark (2000); 10: Strahan (2003).

HS: habilidades sociais; aux. pesq.: auxiliar de pesquisa; question.: questionários; (+) presente no estudo; (-) ausente no estudo.

As amostras dos estudos variaram de 27 a 253 participantes (mediana - 52), sendo constituídas por pacientes com diagnóstico de fobia social generalizada ou outros transtornos de ansiedade, indivíduos ansiosos socialmente e não-clínicos, de ambos os sexos, com idades variando entre 18 a 64 anos. A origem dos participantes foi predominantemente do ambiente universitário, seguido do ambiente clínico e da comunidade. Três estudos apresentaram critérios de exclusão para a composição da amostra, tendo em comum entre eles a condição dos pacientes satisfazerem os critérios diagnósticos para transtornos psicóticos, transtorno mental orgânico e adição a substâncias
(Alden \& Mellings, 2004; Baker \& Edelmann, 2002; Horley e cols., 2003).

Os objetivos dos estudos analisados focalizaram o papel da ansiedade sobre diversos indicadores de habilidades sociais. Tais estudos sugeriram que níveis altos de ansiedade social afetam negativamente: (a) o desempenho social, definido como desempenho comportamental molecular e molar exibido durante a interação social; (b) o desempenho acadêmico, avaliado pela taxa de abandono e aproveitamento acadêmico; (c) as habilidades de comunicação, definidas pelo conteúdo verbal e função da fala exibidos na interação com o parceiro afetivo; (d) as percepções interpessoais, 
definidas como julgamentos sociais, autopercepções, meta-percepções e percepção do outro, interpretação de eventos sociais e processamento de expressões faciais; e (e) a competência social, definida como o nível de proficiência com que as classes de comportamentos verbais e não verbais de um indivíduo são articuladas em um desempenho social bem sucedido.

Entre os diversos instrumentos e medidas empregados nos estudos, o Beck Depression Inventory (BDI) foi o mais utilizado (Alden \& Mellings, 2004; Baker \& Edelmann, 2002; Christensen e cols., 2003; Horley e cols., 2003; Thompson \& Rapee, 2002), seguido do Fear Negative Evaluation Scale (FNE) (Horley e cols., 2003; Thompson \& Rapee, 2002; Stopa \& Clark, 2000; Wenzel e cols., 2005).

Predominantemente, os dados de sete estudos foram coletados em situação experimental de interação social (conversação) com um auxiliar de pesquisa, com o parceiro de relacionamento afetivo ou com outros participantes (indivíduos ansiosos socialmente e não-ansiosos socialmente). Todos os auxiliares de pesquisa foram previamente treinados para as tarefas de interação social. Apenas no estudo de Thompson e Rapee (2002), os auxiliares de pesquisa foram vistos como outros participantes, ao passo que nos demais foram identificados como tal. As interações dos participantes com o seu interlocutor variaram de 5 a 30 minutos, sendo que a maioria dos estudos adotou uma duração inferior a 10 minutos.

Os auxiliares de pesquisa de quatro estudos foram instruídos para iniciar a conversa ou dar dicas verbais para a sua continuidade toda vez que ocorresse um período de silêncio.

As medidas empregadas nos procedimentos destes estudos foram: (a) subjetivas; (b) objetivas; e (c) fisiológicas. As medidas objetivas se constituíram de filmagens das interações; as subjetivas de aplicação de questionários, escalas ou inventários; e as fisiológicas do exame de condutância da pele, nível de coloração da bochecha ou freqüência cardíaca. A Tabela 2 apresenta os momentos em que tais medidas foram tomadas no decorrer das sessões experimentais.

Tabela 2: Registro das medidas realizadas durante as sessōes experimentais dos estudos

\begin{tabular}{|c|c|c|c|}
\hline \multirow{2}{*}{ Estudos } & \multicolumn{3}{|c|}{ Medidas } \\
\hline & Antes & Durante & Depois \\
\hline Bögels e cols. (2002) & $\begin{array}{l}\text { - condutância da pele; } \\
\text { - coloração da bochecha; } \\
\text { - Visual Analogue Scales (VAS). }\end{array}$ & $\begin{array}{l}\text { - condutância da pele; } \\
\text { - coloração da bochecha. }\end{array}$ & $\begin{array}{l}\text { - condutância da pele; } \\
\text { - coloração da bochecha; } \\
\text { - VAS; } \\
\text { - atribuições causais de sucesso e fracasso; } \\
\text { - Escala de avaliação de habilidades sociais. }\end{array}$ \\
\hline Sheffer e cols. (2001) & $\begin{array}{l}\text { - Subjective Units of Distress (SUDS); } \\
\text { - freqüência cardíaca. }\end{array}$ & - freqüência cardíaca. & $\begin{array}{l}\text { - SUDS; } \\
\text { - freqüência cardíaca; } \\
\text { - Escala de Impressão. }\end{array}$ \\
\hline Wenzel e cols. (2005) & $\begin{array}{l}\text { - Fear of Negative Evaluation Scale } \\
\text { (FNE); } \\
\text { - Social Avoidance and Distress Scale } \\
\text { (SAD); } \\
\text { - Dyadic Adjustment Scale (DAS); } \\
\text { - Couples's Problem Inventory (CPI). }\end{array}$ & - filmagem das interaçōes. & - \\
\hline $\begin{array}{l}\text { Baker e Edelmann } \\
\text { (2002) }\end{array}$ & - & - filmagem das interaçōes. & $\begin{array}{l}\text { - escalas de avaliação relacionadas à sen- } \\
\text { sação corporal percebida }\end{array}$ \\
\hline Alden e Mellings (2004) & - & - & $\begin{array}{l}\text { - Questionário de Julgamento Social; } \\
\text { - Focus of Attention Questionnaire (FAQ) }\end{array}$ \\
\hline $\begin{array}{l}\text { Christensen e cols. } \\
\text { (2003) }\end{array}$ & - & - & - Avaliação de traços. \\
\hline $\begin{array}{l}\text { Thompson e Rapee } \\
\text { (2002) }\end{array}$ & - & - filmagem das interaçōes. & $\begin{array}{l}\text { - niveis de ansiedade durante as situaçōes } \\
\text { estruturadas e não-estruturadas. }\end{array}$ \\
\hline
\end{tabular}


Para uma melhor compreensão dos delineamentos de pesquisa empregados, em função das especificidades dos mesmos, os procedimentos de coleta de dados serão detalhados.

Em quatro destes estudos, os participantes receberam a instrução geral para atuar como se estivessem sendo apresentados e conhecendo a outra pessoa com a qual estariam interagindo (Alden \& Mellings, 2004; Baker \& Edelmann, 2002; Christensen e cols., 2003; Thompson \& Rapee, 2002). Os participantes de outros dois estudos receberam a instrução específica para iniciar e manter conversa com os auxiliares de pesquisa (Sheffer e cols., 2001; Bögels e cols., 2002).

No procedimento de Bögels e cols. (2002), os participantes interagiram com dois auxiliares de pesquisa, um do sexo masculino e o outro do sexo feminino, e foram informados de que estes auxiliares julgariam suas habilidades de iniciar e manter conversação, e que esta seria filmada para avaliar seu comportamento. Durante a interação, os auxiliares de pesquisa deixaram visíveis três espelhos grandes, nos quais a metade dos participantes via sua imagem refletida durante a conversa, favorecendo a condição de autoconsciência.

Em Wenzel e cols. (2005), os casais foram instruídos a conversarem acerca de três assuntos: neutro (um evento do dia), negativo (problema) e positivo, com uma duração de dez minutos para cada um destes tópicos.

Após cada interação alternada com outros três indivíduos, os participantes do estudo de Christensen e cols. (2003) foram solicitados avaliar a si próprios (autopercepções), seus parceiros de interação e suas meta-percepções (como eles pensaram que foram vistos pelos parceiros), com base em uma série ampla de características de personalidade, como por exemplo, sociável, simpático, nervoso, calado, em escalas de classificação de 9 pontos, ancoradas entre 1 ("nada") e 9 ("muito").

Em Thompson e Rapee (2002), participante e auxiliar de pesquisa foram deixados pelo experimentador na sala experimental com a desculpa de que iria buscar uma fita de vídeo para gravar a interação de desempenho de papéis. Um gravador de vídeo estava visível ao participante, indicando que estava em funcionamento, embora não contivesse fita alguma. A interação resultante foi considerada como tarefa nãoestruturada. Depois que o experimentador retornou, instruiu o participante e auxiliar de pesquisa para imaginar que estavam em uma festa e tinham que conhecer um ao outro tão bem quanto possível, e informou que seriam filmados. Esta interação compreendeu a tarefa estruturada do estudo. Os dois tipos de tarefas foram objeto de comparação.

No estudo de Alden e Mellings (2004), a pesquisadora inicia a conversa e depois observa, atrás de um espelho unidirecional, a interação do participante com uma auxiliar de pesquisa, tendo como instrução que deveriam se conhecer como se tivessem acabado de ser apresentados. Depois, o participante e a auxiliar de pesquisa preencheram os questionários pós-interação.

Em Sheffer e cols. (2001), os participantes tomaram parte em duas provas de conversação em roleplays, correspondendo às condições com demandas altas e baixas para produzir uma impressão positiva de si. Cada prova foi realizada com uma auxiliar de pesquisa diferente. Na condição com demandas baixas, foi dito aos participantes que a auxiliar de pesquisa seria o foco da avaliação, que ela tinha sido instruída para dar a melhor impressão possível, e que eles deveriam avaliá-la usando a Escala de Impressão. Na condição com demandas altas, foi dito aos participantes que eles eram o foco da avaliação, que deveriam dar a melhor impressão possível à auxiliar de pesquisa, e que ela e um outro assistente de pesquisa os avaliariam usando a Escala de Impressão.

Os procedimentos de coleta de dados dos outros três estudos restantes contaram com medidas objetivas (Horley e cols., 2003), subjetivas (Stopa \& Clark, 2000), e objetivas e subjetivas (Strahan, 2003).

Em Horley e cols. (2003), a medida objetiva se constituiu do monitoramento da exploração visual de três fotos apresentando diferentes expressões faciais aos participantes, por meio de um sistema computadorizado. As faces neutra, alegre e triste foram apresentadas por $10 \mathrm{~s}$ aos participantes, com um intervalo de $15 \mathrm{~s}$ entre os estímulos. Eles foram instruídos para se fixarem no centro da tela até a foto aparecer e, então, olhar para ela de qualquer maneira.

$\mathrm{Na}$ pesquisa de Stopa e Clark (2000), foi enviado aos participantes um pacote contendo os questionários e escalas, e solicitado a eles para completá-los de forma independente.

Em Strahan (2003), os participantes universitários preencheram inventários e questionários, abrangendo avaliações de ansiedade, habilidades sociais, ajustamento social e acadêmico, e teste de realização educacional, em pequenos grupos (com 4-5 alunos por sessão) realizadas nas 4-6 primeiras semanas de aula. As informações relacionadas ao desempenho acadêmico dos alunos foram fornecidas, semestralmente, pela secretaria da universidade durante dois anos. 
Com relação à codificação e análise dos dados, os observadores de quatro estudos foram treinados para a avaliação ou dos desempenhos comportamentais dos participantes (Bögels e cols., 2002; Sheffer e cols., 2001; Thompson \& Rapee, 2002;) ou de testes e inventários preenchidos por eles (Wenzel e cols., 2005). Em Stopa e Clark (2000), um segundo avaliador independente classificou os dados dos questionários utilizados para verificar a confiabilidade da categorização do primeiro avaliador. A análise dos dados coletados pelos estudos foi realizada, predominantemente, com base em estatística inferencial.

Quanto aos resultados dos estudos incluídos nesta categoria, observou-se uma concordância entre cinco estudos indicando que indivíduos com fobia social e com níveis altos de ansiedade social apresentaram, em comparação com controles não-clínicos, um repertório de habilidades sociais inferior (Baker \& Edelmann, 2002; Horley e cols., 2003; Strahan, 2003; Wenzel e cols., 2005; Thompson \& Rapee, 2002), além de demonstrarem uma competência social inferior (Baker \& Edelmann, 2002; Strahan, 2003; Wenzel e cols., 2005)

No estudo de Horley e cols. (2003), os sujeitos com fobia social apresentaram evitação de características mais importantes da face, particularmente dos olhos, comprometimento este que pode ser atribuído à atenção mais autofocada e autopercepção negativa apresentadas pelos indivíduos com este transtorno. Os resultados de exploração visual deste estudo ofereceram confirmação empírica para a observação clínica de que indivíduos com fobia social tendem a evitar o contato visual durante interação social.

No estudo de Strahan (2003), a ansiedade social não alcançou significância como um preditor de desempenho acadêmico e permanência na universidade. Entretanto, como reconhece a autora, é possível que níveis altos de ansiedade social exerçam seus efeitos sobre a permanência e o desempenho acadêmico indiretamente, considerando que sua correlação negativa com ajustamento universitário foi moderadamente significativa, e ajustamento universitário teve um efeito claro sobre os índices de sucesso acadêmico.

Três estudos verificaram a influência da estrutura e das demandas da situação sobre a ocorrência de desempenhos sociais dos indivíduos com fobia social, ansiosos socialmente ou não-clínicos. Os resultados de Thompson e Rapee (2002) indicaram que a estrutura das situações de interação social regula diferenças entre o desempenho social de indivíduos ansiosos socialmente e de não-ansiosos, sendo que os indivíduos apresentaram um desempenho social melhor em situa- ções estruturadas comparativamente a situações nãoestruturadas. De acordo com esta conclusão, os resultados do experimento de Sheffer e cols. (2001) revelaram que as demandas altas e baixas para produzir uma impressão positiva de si, inerentes às situações sociais, constituem um fator mediador importante nas relações entre ansiedade, freqüência cardíaca e competência social em sujeitos não-clínicos. $\mathrm{Na}$ condição com demandas baixas para produzir uma impressão positiva de si, a competência social maior foi consistentemente associada com menor freqüência cardíaca e menor ansiedade auto-relatada. Na condição com demandas altas para produzir uma impressão positiva de si, competência social maior foi associada apenas com maior freqüência cardíaca.

O estudo de Stopa e Clark (2000), indicou que pacientes com fobia social tendem a interpretar situações sociais ambíguas (p. ex., "você tem visitas para uma refeição e elas saem mais cedo do que você esperava") de maneira negativa e apresentam uma tendência específica para interpretar os eventos sociais moderadamente negativos (p. ex., "você está falando com alguém durante algum tempo e ficou claro que ele não está interessado naquilo que você está dizendo") de maneira mais catastrófica, em comparação com os grupos controle.

Outros três estudos tiveram como foco cotejar a auto-avaliação dos participantes com uma avaliação externa. Dois estudos encontraram concordância quanto às autopercepções negativas de indivíduos com níveis altos de ansiedade social. Em Christensen e cols. (2003), os participantes com níveis altos de ansiedade social viram a si mesmos como menos sociáveis, menos simpáticos, mais nervosos, menos inteligentes e mais distantes na interação com outros participantes. Além disso, foram vistos como menos sociáveis, menos relaxados, mais calados, mais nervosos, mais distantes, e com uma tendência ligeiramente significativa para serem vistos como mais superficiais pelos seus parceiros de interação. Os resultados mostraram que outras pessoas são capazes de detectar algum desconforto em indivíduos ansiosos socialmente nas situações sociais, mas elas não os julgam inferiores em conseqüência disto. Este tipo de informação pode ser usado por diferentes abordagens de tratamento para contrapor algumas das crenças negativas, mantidas pelos indivíduos com fobia social, acerca de como eles são percebidos pelos outros, e as conseqüências imaginadas disto.

No estudo de Bögels e cols. (2002), os participantes com ansiedade social alta avaliaram suas habilidades sociais, apresentadas durante a conversa, como 
mais deficitárias do que aqueles com ansiedade social baixa. Entretanto, as diferenças entre as pessoas com ansiedade social alta e baixa com respeito às habilidades auto-avaliadas e avaliadas por auxiliares de pesquisa foram devido a diferenças na demonstração de sintomas de ansiedade (p. ex., movimentos irrequietos), mas não diferenças em comportamento socialmente habilidoso.

Em Alden e Mellings (2004), os participantes com fobia social generalizada foram avaliados por eles próprios e pelas auxiliares de pesquisa como menos habilidosos e sentindo ou parecendo mais ansiosos do que os participantes do grupo controle.

Analisando os resultados obtidos pelos estudos, notou-se que níveis altos de ansiedade social afetaram negativamente o desempenho social, as habilidades de comunicação, as percepções interpessoais e a competência social dos indivíduos com fobia social ou ansiosos socialmente. Os resultados do estudo que visou verificar a associação de ansiedade social e desempenho acadêmico foram inconclusivos a este respeito, representando a única restrição à confirmação da hipótese inicial.

Uma breve discussão será feita acerca destes resultados. Embora possa ser assumido que o elemento avaliado do repertório comportamental de um indivíduo com fobia social ou com níveis altos de ansiedade social, em uma situação planejada, seja em geral representativo do seu comportamento, pode-se questionar se isto realmente representa o seu repertório comportamental. Tal questão aponta para a necessidade de estudos respaldados por uma validade ecológica (grau em que as condições de um estudo são verdadeiras ou aplicáveis para a vida real) e com possibilidade de generalização dos resultados, o que não pôde ser contemplado por nenhum dos estudos incluídos nesta categoria. Além disso, as características de gênero das amostras foram muito circunscritas, sendo constituídas predominantemente por participantes do sexo feminino. Outra limitação potencial do rol de estudos analisados foi a imprecisão dos critérios de confirmação diagnóstica para as amostras de casos e comparação.

$\mathrm{Na}$ condução de vários destes estudos é quase inevitável assumir que o tamanho das amostras foi influenciado pela natureza da população estudada. Embora se assuma esta limitação, teria sido desejável contar com uma amostra maior de indivíduos com diagnóstico clinicamente confirmado de fobia social.

Constatou-se a inexistência de um teste, inventário ou escala de avaliação de habilidades sociais padronizado que confira maior validade e confiabilidade aos resultados dos estudos incluídos, visto que utilizaram instrumentos diferentes para esta finalidade.

Conclui-se que o perfil de indivíduos com fobia social generalizada ou níveis altos de ansiedade social caracteriza-se pela presença de prejuízos em suas habilidades sociais.

\section{Modalidades terapêuticas - Aplicação e comparação de intervenções clínicas}

Os estudos incluídos nesta categoria utilizaram delineamentos quase-experimentais e tiveram por objetivo avaliar, direta ou indiretamente, a eficácia do Treinamento em Habilidades Sociais (THS) enquanto abordagem terapêutica para tratamento da fobia social.

A eficácia da aplicação do THS foi testada de forma diversa nos diferentes estudos. Em três desses, a eficácia de tratamento foi comparada com a de outras modalidades terapêuticas, tais como terapia cognitivocomportamental (Van Dam-Baggen \& Kraaimaat, 2000a), terapia de suporte (Cottraux e cols., 2000) e terapia comportamental (Stravynski e cols., 2000), que foram empregadas como controles metodológicos. No estudo de Cottraux e cols. (2000), o THS constituiu um módulo componente da terapia cognitivocomportamental.

Em outro estudo, Van Dam-Baggen e Kraaimaat (2000b) investigaram a eficácia do THS em grupo para pacientes com fobia social generalizada agrupados em subtipos "reticente" e "não-reticente". Os autores definiram como "reticentes" os participantes que apresentaram freqüência baixa de comportamentos sociais, e como "não-reticentes" aqueles que registraram freqüência alta de comportamentos sociais.

Com base em um estudo de caso, Espada, Quiles e Méndez (2002) apresentaram uma intervenção multicomponente, na qual o THS constituiu um módulo de tratamento junto a outras técnicas cognitivo-comportamentais (reestruturação cognitiva, auto-instruções, exposição encoberta e ao vivo, focalização da atenção, respiração profunda e relaxamento).

E ainda em um outro estudo, Bishop (2003) testou a aplicabilidade do sistema de aprendizagem à distância para THS, via internet, para ajudar os participantes a enfrentarem melhor suas dificuldades sociais, convertendo frases e sentenças que eles julgavam confusas ou ofensivas em definições mais concisas e compreensíveis.

Nos estudos de comparação (Van Dam-Baggen \& Kraaimaat, 2000a; Cottraux e cols., 2000; Stravynski e cols., 2000), os autores formularam como hipótese a 
afirmativa da melhor eficácia do THS sobre outras abordagens terapêuticas (terapia cognitvo-comportamental, de suporte e comportamental).

Além do estudo de caso, as amostras dos estudos variaram de 13 a 60 pacientes, adultos, de ambos os sexos, com idade variando entre 18 a 57 anos, que receberam diagnóstico de fobia social, primário ou secundário, segundo os critérios do DSM-IV, com e sem comorbidades. Os participantes foram recrutados, na sua maioria, no ambiente clínico. No estudo de Stravynski e cols. (2000), a amostra procedeu predominantemente da comunidade, seguindo descrições do programa de tratamento em vários meios de comunicação. Apenas o estudo de Bishop (2003) não relatou a procedência da amostra. Quatro estudos (Van DamBaggen \& Kraaimaat, 2000a; Van Dam-Baggen \& Kraaimaat, 2000b; Cottraux e cols., 2000; Stravynski e cols., 2000) apresentaram como critérios comuns de exclusão, a presença de indicadores de transtornos psicóticos e adição a substâncias.

Ainda no que diz respeito aos critérios de inclusão de participantes, observou-se uma diversidade de condições destacadas nos diferentes estudos. Van DamBaggen e Kraaimaat (2000a) utilizaram um procedimento de emparelhamento dos participantes para as duas condições de tratamento, visando garantir duas amostras razoavelmente equivalentes. Em outro estu- do (Van Dam-Baggen \& Kraaimaat, 2000b) que incluiu pacientes internos de uma clínica psiquiátrica, a designação para a composição da amostra "reticente" e "não-reticente" teve por base os escores na Frequency Scale do Inventory of Interpersonal Situations (IIS). Nos estudos de Cottraux e cols. (2000) e Stravynski e cols. (2000), os participantes foram aleatoriamente distribuídos para os grupos de tratamento. No caso clínico apresentado por Espada e cols. (2002), o participante era um paciente identificado que buscou espontaneamente o atendimento. Bishop (2003) não fez menção alguma acerca do procedimento de seleção dos participantes para o estudo. Os pacientes identificados em três estudos (Cottraux e cols., 2000; Espada e cols., 2002; Stravynski e cols., 2000) tiveram em comum o fato de buscarem espontaneamente atendimento, e apenas em dois estudos a alocação nos grupos foi aleatória.

Cada um dos estudos empregou um conjunto de instrumentos e medidas diferentes dos demais. O Symptom Checklist-90 (SCL-90) foi o único que se repetiu em três estudos (Van Dam-Baggen \& Kraaimaat, 2000a; 2000b; Stravynski e cols., 2000).

A Tabela 3 apresenta uma caracterização detalhada dos delineamentos adotados nos estudos sobre a eficácia do THS.

Tabela 3. Caracterização dos delineamentos adotados nos estudos de eficácia

\begin{tabular}{|c|c|c|c|c|c|}
\hline \multirow[b]{2}{*}{ Delineamentos } & \multicolumn{5}{|c|}{ Estudos } \\
\hline & $\begin{array}{l}\text { v. Dam-Baggen e } \\
\text { Kraaimaat (2000a) }\end{array}$ & $\begin{array}{l}\text { v. Dam-Baggen e } \\
\text { Kraaimaat (2000b) }\end{array}$ & $\begin{array}{l}\text { Cottraux e } \\
\text { cols. (2000) }\end{array}$ & $\begin{array}{c}\text { Stravynski } \\
\text { e cols. }(2000)\end{array}$ & $\begin{array}{l}\text { Espada e } \\
\text { cols. (2002) }\end{array}$ \\
\hline Aplicação: - grupo & + & + & + & + & - \\
\hline - individual & - & - & - & - & + \\
\hline Duração das sessōes: & $90 \mathrm{~min}$ & $\mathrm{sr}$ & $120 \mathrm{~min}$ & $120 \mathrm{~min}$ & $50 \mathrm{~min}$ \\
\hline $\mathrm{N}^{0}$ de participantes: & 5 a 8 & 8 a 10 & 4 a 6 & $\mathrm{sr}$ & 1 \\
\hline Terapeuta: - único & + & + & - & + & + \\
\hline - dupla & - & - & + & - & - \\
\hline - co-terapeuta & + & - & - & + & - \\
\hline Técnicas: - ensaio comp. & + & + & + & + & + \\
\hline - modelagem & + & + & + & + & + \\
\hline - tarefas de casa & + & + & + & + & + \\
\hline - feedback & - & - & + & + & + \\
\hline - reforçamento & - & - & + & + & + \\
\hline - biblioterapia & + & + & + & - & - \\
\hline - apr. sucessiva & + & + & - & - & - \\
\hline - an. funcional & - & - & - & + & + \\
\hline - instruçōes & . & - & - & + & + \\
\hline - automonit. & + & + & - & + & + \\
\hline - modelação & - & - & - & $\cdot$ & + \\
\hline - fase educativa & - & - & - & - & + \\
\hline - estr. sol. prob. & + & + & - & - & - \\
\hline $\mathrm{N}^{0}$ de sessōes: & 20 & 20 & 6 & 14 & 4 \\
\hline Seguimento: & $3 \mathrm{~m}$ & - & 6 e $12 \mathrm{~m}$ & $6 \mathrm{e} 12 \mathrm{~m}$ & $12 \mathrm{~m}$ \\
\hline
\end{tabular}

comp.: comportamental; apr.: aproximação; an.: análise; automonit.: automonitoramento; estr. sol. prob.: estratégias de solução de problemas; m: meses; (+): presente nos estudo; (-): ausente no estudo; sr: sem referência. 
Como pode ser observado, o THS foi administrado em grupo em quatro estudos. Na intervenção multicomponente de Espada e cols. (2002) e no sistema de aprendizagem à distância de Bishop (2003), o THS foi aplicado individualmente. A predominância de aplicação do THS no formato grupal, em detrimento ao individual, pode ser justificada por apresentar as seguintes vantagens: (a) representa economia de tempo para o terapeuta; (b) oferece maior diversidade de ensaio comportamental com um número maior de pessoas; (c) possibilita generalização mais rápida dos ganhos e uma maior quantidade de feedback efetivo para os desempenhos treinados; (d) proporciona experiência com um número maior de situações-problema e mais suporte para solucioná-las; (e) possui maior disponibilidade de modelos múltiplos, além dos fornecidos pelo terapeuta; e (f) favorece aprendizagem de discriminação das possíveis conseqüências desejáveis e indesejáveis para emissão dos novos comportamentos aprendidos.

Os grupos de THS descritos foram constituídos de quatro a dez participantes e em um deles não foi mencionado o número de participantes que compuseram os grupos de tratamento. Quanto à duração das sessões, estas variaram de 90 a 120 minutos. O número total de sessões variou de seis a vinte sessões. No estudo de caso, o módulo de THS incluído no tratamento multicomponente durou quatro sessões de cinqüenta minutos.

As intervenções clínicas em Van Dam-Baggen e Kraaimaat (2000a; 2000b), Cotraux e cols. (2000) e Stravynski e cols. (2000) foram realizadas por terapeutas experientes em THS ou terapia cognitivocomportamental, contando com um co-terapeuta em duas dessas intervenções.

Tendo como base os estudos de Van Dam-Baggen e Kraaimaat (2000a; 2000b) e Espada e cols. (2002), as seguintes habilidades sociais foram incluídas no programa de THS para pacientes com fobia social generalizada: observar; ouvir; iniciar, manter e encerrar conversação; dar e receber feedback; contato visual; modulação do volume e entonação da fala; fazer e recusar pedidos; aceitar recusas; fazer queixas; cumprimentar; declarar auto-afirmações positivas; fazer e receber críticas; expressar opiniões; e defender os próprios direitos. No estudo de Espada e cols. (2002), a fase educativa compreendeu ensinar o paciente sobre os estilos de desempenho social passivo, assertivo e agressivo; sobre os componentes do desempenho social; e a definição de comportamento socialmente habilidoso. Observou-se que a assertividade esteve presente de forma explícita em quatro intervenções clínicas do THS (Cottraux e cols., 2000; Espada e cols., 2002; Van Dam-Baggen \& Kraaimaat, 2000a; 2000b).

As técnicas típicas empregadas em programas de THS e comuns a todos os estudos de intervenção clínica foram: ensaio comportamental, modelagem e atribuição de tarefas de casa. O emprego de biblioterapia foi comum a três estudos, e as técnicas de feedback e reforço positivo estiveram presentes também em três estudos. O procedimento de análise funcional foi empregado em apenas dois estudos.

A atribuição de tarefas de casa tem sido um dos recursos utilizados para verificar a generalização dos efeitos de programas de THS (Del Prette \& Del Prette, 2005). Além disso, as tarefas de casa também permitem aos participantes a discriminação de características da situação natural diante das quais o desempenho das habilidades recém-adquiridas pode gerar conseqüências desejáveis ou indesejáveis (discriminação de conseqüências), visando assim emissão de outros comportamentos alternativos. Em termos analíticoconceituais, a atribuição de tarefas de casa serve como uma ferramenta para a identificação de problemas de controle de estímulos que estejam dificultando a eficácia da intervenção sobre o funcionamento social do indivíduo em seu ambiente natural. Por conseguinte, esta eficácia encontra-se implicada na validade social das aquisições previstas pelos programas de THS.

Em todas as intervenções do THS aplicadas em contextos clínicos, foram realizadas avaliações antes e depois do tratamento. Avaliações de segmento foram aplicadas em quatro estudos, havendo uma variabilidade de período entre eles, como demonstrado pela Tabela 3.

A maioria dos estudos incluídos nesta categoria utilizou a estatística inferencial para o tratamento e análise dos dados coletados, com exceção do estudo de Espada e cols. (2002) que comparou os dados de auto-registro (freqüência do comportamento-problema e intensidade do desconforto) e os escores obtidos nas medidas empregadas, e de Bishop (2003) que comparou as médias das atitudes favoráveis dos participantes, pontuadas em uma escala de gradação, em relação ao sistema de aprendizagem à distância.

Uma desvantagem do fato da maioria dos participantes dos estudos terem sido recrutados no ambiente clínico é a possibilidade deste contexto representar os casos mais graves de fobia social, o que, em última 
análise, teria implicações para a generalização dos dados. Referendando esta limitação, observou-se que os participantes recrutados neste contexto receberam, predominantemente, o diagnóstico primário ou secundário de fobia social generalizada, com e sem comorbidades.

Com relação aos resultados obtidos, a eficácia do THS foi comprovada pela maioria dos estudos, inclusive em comparação às outras modalidades de tratamento, tais como a terapia cognitivo-comportamental e a terapia de suporte, confirmando a hipótese inicial. No estudo de Stravynski e cols. (2000), embora o THS tenha produzido melhores resultados mais rapidamente, esta tendência se nivelou com a terapia comportamental, e ambos os tratamentos resultaram em um nível igual de melhora na avaliação de segmento após doze meses. Na intervenção multicomponente de Espada e cols. (2002), o paciente apresentou melhora notável em suas relações sociais, especialmente frente às conversações e aos eventos sociais. No estudo de Bishop (2003), os participantes com fobia social generalizada indicaram se perceberem mais capazes de compreender as histórias, mas consideraram que o sistema de aprendizagem à distância não fez com que se sentissem melhores, além de demonstrarem uma atitude um pouco negativa com relação à funcionalidade do mesmo.

A validade interna do THS poderia se beneficiar muito se ele fosse contrastado com uma condição controle ("placebo") convincente, ou seja, uma condição planejada para se assemelhar a uma terapia sem sê-lo. Esta proposição ganha consistência considerando que, provavelmente, um período na lista de espera não seria o melhor controle para os efeitos de tratamento, além da falta de uma definição precisa do que constituiria a melhor condição de controle para intervenções psicossociais.

Em cinco estudos, a eficácia tanto do THS quanto das outras modalidades terapêuticas foi comprovada pelos dados de medida de auto-relato. Apenas os estudos de Stravynski e cols. (2000) e de Espada e cols. (2002) utilizaram entrevistas clínicas para avaliar a eficácia dos tratamentos oferecidos, além das medidas de auto-relato.

Entretanto, uma ressalva precisa ser feita com relação à eficácia atestada por esses estudos. Analisandose as metodologias empregadas, apenas os estudos de Cottraux e cols. (2000) e Stravynski e cols. (2000) podem ser caracterizados como estudos de eficácia, que supõem a existência de randomização para os grupos de intervenção, na composição de seus delineamentos de pesquisa. Os demais estudos (Van DamBaggen \& Kraaimaat, 2000a; 2000b; Espada e cols., 2002) se propuseram a testar eficácia quando não o fizeram, sendo melhor caracterizados como estudos de efetividade, que não requerem alocação randômica de participantes nos grupos.

Algumas considerações precisam ser feitas com relação aos resultados de três estudos realizados em contextos clínicos. No estudo de Cottraux e cols. (2000), qualquer conclusão sobre a eficácia relativa às fases de terapia cognitiva, que ocorreu primeiro, e THS seria incerta, embora a maior parte da mudança foi vista depois do módulo de THS. Supostamente, a terapia cognitiva abriu caminho para o THS, uma vez que os pacientes puderam continuar usando técnicas cognitivas durante o restante da intervenção. Neste sentido, pode-se considerar que uma ação sinérgica da terapia cognitiva mais THS pode ter influenciado os dados. Isto também pode ter estado presente no estudo de caso de Espada e cols. (2002), visto que várias técnicas cognitivas e comportamentais antecederam o módulo de THS. Mesmo não se tratando de estudos clínicos cruzados (cross-over), uma aplicação alternada entre os procedimentos em amostras diferentes seria desejável para garantir melhor controle metodológico aos delineamentos propostos, o que também não evitaria o problema dos efeitos da primeira intervenção manterem-se durante o período em que a segunda fosse dada.

Em Stravynski e cols. (2000), a terapia comportamental foi planejada para adotar a forma do THS, visando melhorar como o paciente desempenhava espontaneamente o comportamento-alvo escolhido, com a única restrição de não utilizar determinadas técnicas típicas de programas de treinamento, como a modelação, ensaio comportamental e feedback. Pela descrição oferecida pelos autores, houve uma convergência entre a terapia comportamental e o THS nos seguintes pontos: teve como base um foco interpessoal forte e visou ensinar o paciente tanto a buscar criar circunstâncias sociais novas como a se engajar em todas situações sociais de uma maneira diferente. Estas proposições em comum sugerem que a terapia comportamental proposta pelos autores se apresentou como uma interface do THS, sem a aplicação de todas as técnicas utilizadas em programas típicos de treinamento.

A funcionalidade do sistema de aprendizagem à distância proposto por Bishop (2003) apresenta algumas limitações e implicações para sua utilização em 
situações sociais reais. Em primeiro lugar, o sistema teria que ser adaptado para satisfazer as necessidades dos indivíduos com fobia social generalizada, uma vez que os mesmos não têm problemas para interpretar o significado literal do que lhes é dito em situações sociais, mas sim por interpretarem comentários de maneira negativa. Em segundo lugar, a aplicação prática deste sistema exigiria um processamento cognitivo adicional de informações dos indivíduos para participarem em uma situação social, além de fazê-los perderem contato visual com o interlocutor, o que amplificaria os seus sintomas de prejuízo social.

Devido aos resultados dos estudos atestando a sua aplicabilidade no contexto clínico, o THS pode ser um dos melhores tratamentos de escolha para pacientes psiquiátricos com diagnóstico primário ou secundário de fobia social generalizada.

Tendo em vista as descrições e os resultados dos estudos, pode-se concluir que o melhor delineamento para testar a eficácia do THS em pacientes com diagnóstico de fobia social seria aquele no qual esta modalidade terapêutica constituísse abordagem única de tratamento, sendo administrada no formato grupal, com alocação randômica dos participantes nos grupos de treinamento e de comparação, e utilizando-se de tarefas de interação contextualizadas com base em avaliação prévia dos recursos e déficits das habilidades apresentadas pelos participantes em diferentes contextos. Parece que os delineamentos de THS com melhores resultados foram os utilizados nos estudos de Van Dam-Baggen e Kraaimaat (2000a; 2000b), embora não possam ser caracterizados de forma estrita como estudos de eficácia.

No que diz respeito aos resultados de seu estudo, Stravynski e cols. (2000) reconheceram numerosas divergências entre os escores obtidos na Social Adjustment Scale (SAS) e os registros das entrevistas clínicas, levantando questões óbvias de validade. Analisando os resultados que atestaram a "eficácia" do THS entre os estudos, pode-se concluir que o alcance desta modalidade terapêutica teve como fator limitador o caráter inferencial das escalas na avaliação da aquisição de habilidades sociais e outros ganhos terapêuticos pelos pacientes, deixando questões de validade ecológica em aberto.

\section{COMENTÁRIOS FINAIS}

Examinando os 16 estudos agrupados nas duas categorias propostas, constatou-se a inexistência de um instrumento ou medida padrão para avaliação de ha- bilidades sociais que confira uma maior validade e confiabilidade aos dados coletados, levando em conta a diversidade de instrumentos utilizados com este objetivo. No conjunto de artigos analisados, observouse também a necessidade de reconhecimento de um instrumento sistematicamente estudado como "padrão-ouro" para a avaliação de habilidades sociais e/ou competência social dos indivíduos.

Verificou-se que os estudos sobre a eficácia do THS não mantiveram uma homogeneidade de procedimentos adotados quanto ao número de sessões e técnicas empregadas nas intervenções, não oferecendo, portanto, um modelo de delineamento típico que possa ser prescrito para o tratamento de fobia social.

Considera-se que o excesso de ansiedade interpessoal e as dificuldades de processamento em termos cognitivo-afetivos (vieses interpretativos, auto e metapercepções negativas, e atenção autofocada) dos indivíduos com fobia social possam estar implicados nos déficits de desempenho ou de fluência apresentados por eles, inibindo assim a exibição de um desempenho socialmente competente em suas interações sociais, caso não atestem um déficit de aquisição.

No artigo de Thompson e Rapee (2002), parece que o termo "treinamento em habilidades sociais" está sendo usado como se fosse sinônimo de instalar habilidades sociais nas pessoas. Neste ponto, aparentemente, os autores não consideram que o THS não visa somente instalar novas habilidades sociais no repertório comportamental dos indivíduos que apresentam déficits nesse repertório, mas também melhorar o desempenho social deles diante de demandas específicas das situações interpessoais, assim como promover a competência social frente a audiências distintas. Além disso, o THS também abrange a redução de ansiedade enquanto objetivo alcançável, não apenas para indivíduos fóbicos sociais, por meio de técnicas apropriadas e especificas para tal.

Os resultados do estudo de Christensen e cols. (2003) evidenciaram que as meta-percepções negativas de indivíduos ansiosos socialmente eram mais uma função de suas próprias autopercepções negativas do que as percepções negativas dos outros, encontrando consonância com a afirmação de Furmark (2000) de que a autopercepção de indivíduos com fobia social gera uma impressão negativa de si mesmo que, para eles, reflete o que os outros realmente notam e pensam sobre eles.

Estando de acordo com os argumentos de Wells e Clark (1997), os resultados dos estudos de Alden e 
Mellings (2004) mostraram que o indivíduo socialmente fóbico tipicamente constrói uma imagem negativa de si mesmo a partir da perspectiva de um observador externo.

Estudos futuros com melhor controle metodológico precisam ser realizados para uma verificação mais acurada de possíveis associações entre ansiedade social e desempenho acadêmico.

Concluiu-se que é de suma importância a caracterização prévia do repertório de habilidades sociais dos indivíduos em geral e, particularmente dos fóbicos sociais e ansiosos socialmente, para propor programas de tratamento efetivos que atendam de modo mais direto e objetivo as suas demandas interpessoais.

A análise do alcance dos resultados atestando a eficácia do THS e dos indicadores de habilidades sociais avaliados evidenciou a necessidade de novos estudos com amostras clínicas e não-clínicas, com alocação randômica dos participantes, com diagnóstico preciso e proposição de tarefas de interação contextualizadas, respaldados por uma validade ecológica que contemple a generalização dos resultados obtidos quanto à associação das habilidades sociais e fobia social, podendo assim evidenciar a funcionalidade e o processo pela qual a ansiedade interfere no desempenho social dos indivíduos.

\section{REFERENCIAS}

Alden, L. E. \& Mellings, T. M. B. (2004). Generalized social phobia and social judgments: The salience of self- and partnerinformation. Journal of Anxiety Disorders, 18, 143-157.

American Psychiatric Association. (1994). Diagnostic and statistical manual of mental disorders ( $4^{\mathrm{a}}$ ed.). Washington DC.

Angélico, A. P. (2004). Estudo descritivo do repertório de habilidades sociais de adolescentes com síndrome de Down. Dissertação de Mestrado não publicada. Programa de PósGraduação em Educação Especial: Universidade Federal de São Carlos. São Carlos, SP, 126 p.

Argyle, M. (1994). Psicologia del comportamiento interpersonal. Madrid: Alianza Universidad. (Originalmente publicado em 1967)

Baker, S. R. \& Edelmann, R. J. (2002). Is social phobia related to lack of social skills? Duration of skill-related behaviours and ratings of behavioural adequacy. British Journal of Clinical Psychology, 41(3), 243-257.

Bandeira, M. (2003). Avaliando a competência social de pacientes psiquiátricos: Questões conceituais e metodológicas. Em A. Del Prette \& Z. A. P. Del Prette (Orgs.), Habilidades sociais, desenvolvimento e aprendizagem: Questões conceituais, avaliação e intervenção (pp. 207-234). Campinas: Alínea.

Bishop, J. (2003). The internet for educating individuals with social impairments. Journal of Computer Assisted Learning, 19(4), 546-556.
Bögels, S. M., Rijsemus, W. \& De Jong, P. J. (2002). Self-focused attention and social anxiety: The effects of experimentally heightened self-awareness on fear, blushing, cognitions, and social skills. Cognitive Therapy \& Research, 26(4), 461-472.

Christensen, P. N., Stein, M. B. \& Means-Christensen, A. (2003). Social anxiety and interpersonal perception: A social relations model analysis. Behaviour Research and Therapy, 41, 13551371.

Cottraux, J., Note, I., Albuisson, E., Yao, S. N., Note, B., Mollard, E., Bonasse, F., Jalenques, I., Guérin, J. \& Coudert, A. J. (2000). Cognitive behavior therapy versus supportive therapy in social phobia: A randomized controlled trial. Psychotherapy and Psychosomatics, 69(3), 137-146.

Del Prette, A. \& Del Prette, Z. A. P. (2001). Psicologia das relações interpessoais: Vivências para o trabalho em grupo. Rio de Janeiro: Vozes.

Del Prette, A. \& Del Prette, Z. A. P. (2005). A importância das tarefas de casa como procedimento para a generalização e validação do treinamento de habilidades sociais. Em $\mathrm{H}$. Guilhardi \& N. C. de Aguirre (Orgs.), Primeiros passos em análise do comportamento e cognição (pp. 67-74). Santo André: ESETec Editores Associados.

Espada, J. P., Quiles, M. J. \& Mendez, F. X. (2002). Terapia cognitiva y exposición mixta en un caso de fobia social. Análisis y Modificación de Conducta, 28(117), 129-160.

Furmark, T. (2000). Social phobia: From epidemiology to brain function. Acta Universitatis Upsaliensis. Comprehensive Summaries of Uppsala Dissertations from the Faculty of Social Sciences 97. Uppsala. 72 p.

Halford, W. K. \& Hayes, R. L. (1995). Social skills in schizophrenia: Assessing the relationship between social skills, psychopathology and community functioning. Social Psychiatry and Psychiatric Epidemiology, 30(1), 14-19.

Horley, K., Williams, L. M., Gonsalvez, C. \& Gordon, E. (2003). Social phobics do not see eye to eye: A visual scanpath study of emotional expression processing. Journal of Anxiety Disorders, $410,1-12$.

Morrison, R. L. \& Bellack, A. S. (1987). Social functioning of schizophrenic patients: Clinical and research issues. Schizophrenia Bulletin, 13(4), 715-725.

Sheffer, C. E., Penn, D. L. \& Cassisi, J. E. (2001). The effects of impression management demands on heart rate, self-reported social anxiety, and social competence in undergraduate males. Journal of Anxiety Disorders, 15(3), 171-182.

Stopa, L. \& Clark, D. M. (2000). Social phobia and interpretation of social events. Behaviour Research and Therapy, 38, 273-283.

Strahan, E. Y. (2003). The effects of social anxiety and social skills on academic performance. Personality and Individual Differences, 34(2), 347-366.

Stravynski, A., Arbel, N., Bounader, J., Gaudette, G., Lachance, L., Borgeat, F., Fabian, J., Lamontagne, Y., Sidoun, P. \& Todorov, C. (2000). Social phobia treated as a problem in social functioning: A controlled comparison of two behavioural group approaches. Acta Psychiatrica Scandinavica, 102(3),188198.

Thompson, S. \& Rapee, R. M. (2002). The effect of situational structure on the social performance of socially anxious and non-anxious participants. Journal of Behavior Therapy and Experimental Psychiatry, 33(2), 91-102. 
Turner, S. M., Beidel, D. C. \& Townsley, R. M. (1992). Behavioral treatment of social phobia. Em S. M. Turner, K. S. Calhoum \& H. E. Adams (Orgs.), Handbook of clinical behavior therapy ( $2^{\mathrm{a}}$ ed.) (pp. 13-37). Nova Iorque: Willey.

Van Dam Baggen, R. \& Kraaimaat, F. (2000a). Group social skills training or cognitive group therapy as the clinical treatment of choice for generalized social phobia? Journal of Anxiety Disorders, 14(5), 437-51.

Van Dam Baggen, R. \& Kraaimaat, F. W. (2000b). Social skills training in two subtypes of psychiatric inpatients with generalized social phobia. Scandinavian Journal of Behaviour Therapy, 29(1), 14-21.

Wells, A. \& Clark, D. M. (1997). Social phobia: A cognitive approach. Em G. C. L. Davey (Org.), Phobias: A handbook of theory, research and treatment (pp. 3-26). Chichester: John Wiley e Sons.

Wenzel, A., Graff-Dolezal, J., Macho, M. \& Brendle, J. R. (2005). Communication and social skills in socially anxious and nonanxious individuals in the context of romantic relationships. Behaviour Research and Therapy, 43, 505-519.

Zigler, E. \& Phillips, L. (1962). Social competence and the process-reactive distinction in psychopathology. Journal of Abnormal and Social Psychology, 6, 215-223.

Recebido: 20/12/2005

Revisado: 06/06/2006 Aceito: 15/06/2006

\section{Sobre os autores:}

Antonio Paulo Angélico: Doutorando pelo Programa de Pós-Graduação em Saúde Mental da Faculdade de Medicina de Ribeirão Preto da Universidade de São Paulo (FMRP - USP) e Mestre em Educação Especial pelo Programa de Pós-Graduação em Educação Especial da Universidade Federal de São Carlos (UFSCar). Endereço para correspondência: Programa de Pós-Graduação em Saúde Mental, Rua Tenente Catão Roxo, 2650 -14048-900 - Ribeirão Preto/SP - Endereço eletrônico: angelico@rnp.fmrp.usp.br.

José Alexandre de Souza Crippa: Professor Doutor do Departamento de Neurologia, Psiquiatria e Psicologia Médica da Faculdade de Medicina de Ribeirão Preto da Universidade de São Paulo. Endereço para correspondência: Programa de Pós-Graduação em Saúde Mental, Rua Tenente Catão Roxo, 2650 - 14048-900 - Ribeirão Preto/SP - Endereço eletrônico: jcrippa@fmrp.usp.br.

Sonia Regina Loureiro: Professora Doutora do Departamento de Neurologia, Psiquiatria e Psicologia Médica da Faculdade de Medicina de Ribeirão Preto da Universidade de São Paulo. Endereço para correspondência: Programa de Pós-Graduação em Saúde Mental, Rua Tenente Catão Roxo, 2650 - 14048-900 - Ribeirão Preto/SP - Endereço eletrônico: srlourei@ fmrp.usp.br 